Valtemir de Alencar e Silva

\title{
PROPOSTA DE INTERFACE ENTRE A WBS DO PROJETO E A CONFIGURAÇÃO DO PRODUTO: UMA CONTRIBUIÇÃO PARA O ACOMPANHAMENTO DE PROJETOS
}

Dissertação apresentada à Escola de Engenharia de São Carlos, da Universidade de São Paulo, como parte dos requisitos para obtenção do título de Mestre em Engenharia de Produção.

Orientador: Prof. Dr. Daniel Capaldo Amaral

São Carlos

2006 



\section{FOLHA DE JULGAMENTO}

\section{Candidato: Bacharel VALTEMIR DE ALENCAR E SILVA}

Dissertação defendida e julgada em 19-10-2006 perante a Comissão Julgadora:

$$
12 \text {. }
$$

ArkU VANO

Prof. Dr. DANIEL CAPALDO AMARAL (Orientador)

(Escola de Engenharia de São Carlos/USP)

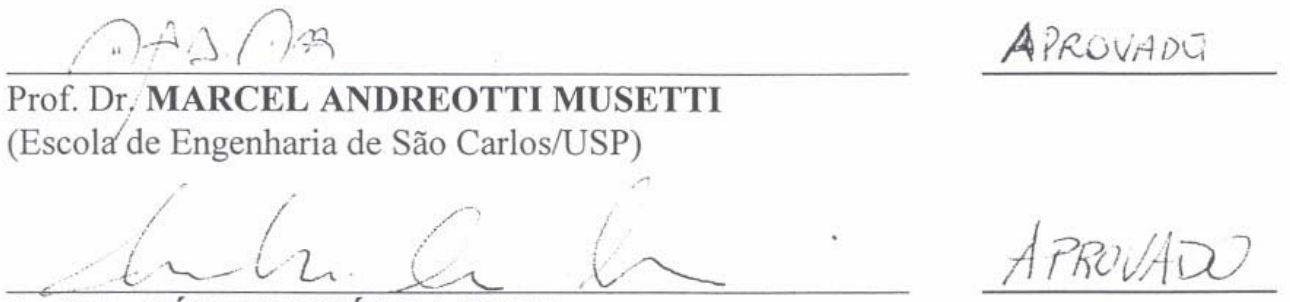

Prof. Dr. SÉRGIO LUÍS DA SILVA

(Universidade Federal de São Carlos/UFSCar)

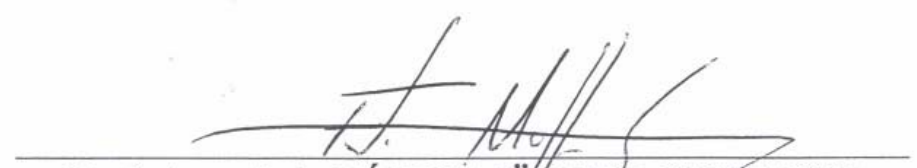

Prof. Associado FÁBIO MüLLER GUERRINI

Coordenador do Programade Pos-Graduação em em Engenharia de Produção

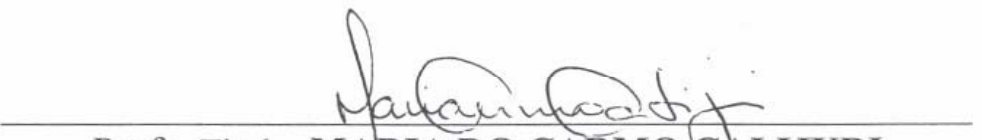

Profa. Titular MARIA DO CARMO CALIJURI

Presidente da Comissão de Pós-Graduação da EESC 

Ao meu filho Vitor, razão da minha vida.

À minha brava companheira de todas as horas e meu grande amor Graziela.

À minha família. 


\section{AGRADECIMENTOS}

Ao Prof. Daniel, pela paciência, orientação e rigor científico.

Ao Diego Muriel, da Orion-ASP, que muito me auxiliou no levantamento da revisão bibliográfica e ao Francis na obtenção das ferramentas de desenvolvimento.

À Vânia Paludetto, da Orion-ASP, pelo apoio na liberação de horários para dedicação ao mestrado e do sistema MEGA, para ser utilizado no exemplo.

Ao Ronaldo, companheiro de mestrado, e um grande amigo conquistado durante o curso e que espero ter para o resto da vida.

Ao Zé Luiz da Pós-Graduação e Cris do Numa, pelo apoio no período do trabalho.

A Deus, por nos permitir o prazer de viver. 


\section{RESUMO}

SILVA, V. A. (2006). Proposta de interface entre a WBS do projeto e a configuração do produto: uma contribuição para o acompanhamento de projetos. Dissertação (Mestrado) - Escola de Engenharia de São Carlos, Universidade de São Paulo, São Carlos, 2006.

Este trabalho investiga a integração entre a gestão de itens da WBS de projetos e os itens da configuração de produtos, visando um acompanhamento mais eficiente de projetos de desenvolvimento de produto. Trata-se de uma pesquisa-ação na qual se propôs um modelo de interface entre sistemas de gestão de projetos e sistemas de gestão de configuração e empreendeu-se uma análise de sua aplicação em uma empresa de desenvolvimento de software. A interface define um mecanismo para apurar o trabalho desenvolvido, a partir das alterações dos itens da configuração e, através do relacionamento entre estes itens e os pacotes de trabalho da WBS, exportar as informações sobre início, término e trabalho realizado para as respectivas atividades do projeto. O seu objetivo é auxiliar o acompanhamento em projetos complexos, seja com um grande número de atividades, ou aqueles realizados por consórcios de empresas. São apresentados os conceitos básicos sobre gerenciamento de projetos e gerenciamento da configuração do produto; além dos processos, atividades relacionadas e análise comparativa entre os sistemas de gerenciamento existentes. Os resultados obtidos foram: um levantamento dos principais problemas relacionados com a relação entre sistemas de gestão de projetos e de gestão de configuração, uma lista de requisitos para a integração destes sistemas, a definição e modelagem de uma interface que apóie esta integração e um exemplo prático de aplicação da interface proposta.

Palavras-chave: gerenciamento de projetos, gerenciamento da configuração, pacote de trabalho, item da configuração, apontamento de projetos. 


\section{ABSTRACT}

SILVA, V. A. (2006). Propose of an interface between project WBS and product configuration: a contribution to project tracking. - Escola de Engenharia de São Carlos, Universidade de São Paulo, São Carlos, 2006.

This work performs an investigation about the WBS and product configuration items, aiming to improve the tracking activity during the project management effort. It is an action research in witch was proposed a model to integrate project management and configuration management systems and was analyzed this model through the application in a specific software development company. The interface defines a way to identify the project work from the configuration item changes at change management application and review information about start, finish and performed work at project management ones. In challenger project's, involving to much activities or complex enterprise clusters, tracking is a complex activity because it is dependent to the capacity to measure all project results. This work presents the basic concepts about project management and configuration management, the activities related to these topics, and project management software evaluations. The results are: an study of the problems and requirements related with the WBS and configuration items integration; requirements for this kind of application; the design of an interface to support the integration of the traditional and simple project management and configuration management applications; and a practical example to the use of this interface.

Keywords: project management, configuration management, work package, configuration item, project tracking. 


\section{LISTA DE FIGURAS}

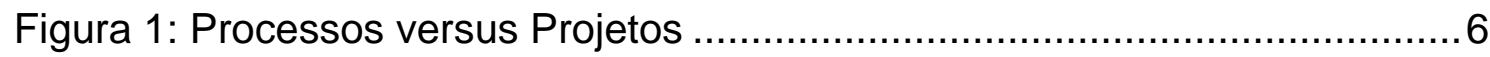

Figura 2: O Processo de Desenvolvimento de Produtos ..................................... 8

Figura 3: Mudanças devem acontecer o quanto antes na E. S. ......................11

Figura 4: Relacionamentos possíveis entre pares de atividades ..................... 13

Figura 5: Seqüência típica das fases de um projeto .....................................18

Figura 6: Principais interações entre os grupos de processos..........................24

Figura 7: Documentos do projeto e as áreas de conhecimento........................ 29

Figura 8: Fases do Ciclo de Vida para o Gerenciamento da Configuração .......33

Figura 9: Ciclo de vida do produto e atividades do gerenciamento. da

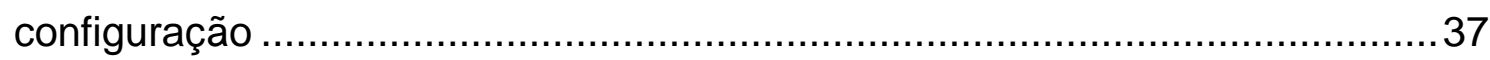

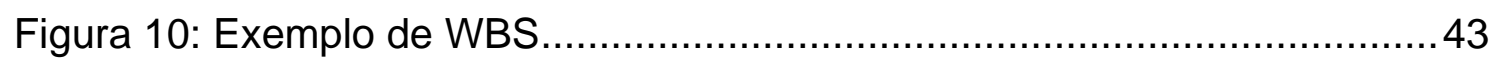

Figura 11: Exemplo de WBS estruturada por fase ......................................4

Figura 12: Exemplo de WBS organizada pelos itens do sistema de aeronave. 45

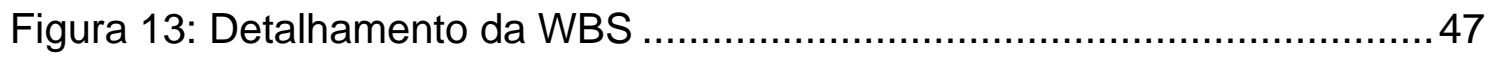

Figura 14: Exemplos de Relações de precedência entre as atividades............ 49

Figura 15: Gráfico de Gantt ...................................................................... 51

Figura 16: Comunicação entre gerenciamento da configuração do projeto e o

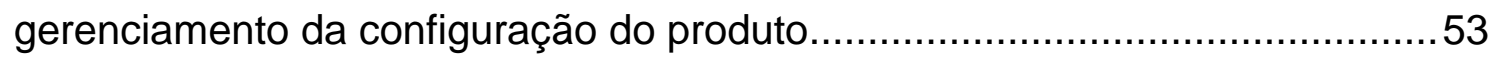

Figura 17: Exemplo de estrutura de objetos ................................................58

Figura 18: Quadrante Mágico comparativo dos Sistemas para Gerenciamento

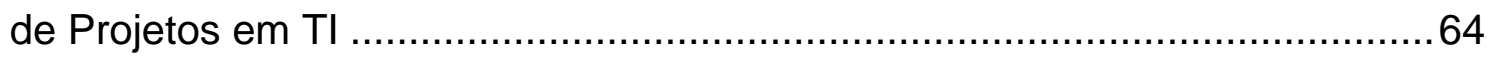

Figura 19: Sistema integrado para engenharia colaborativa na Web ................76

Figura 20: Visualização Web do tempo de duração do processo e o

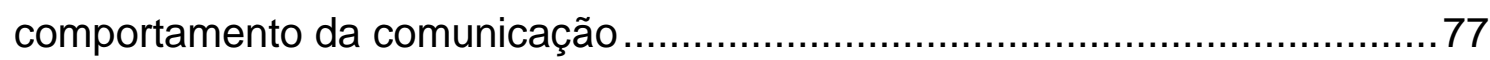

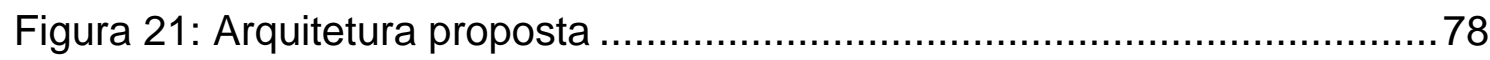

Figura 22: Gráfico de Gantt com projetos cooperados ....................................79

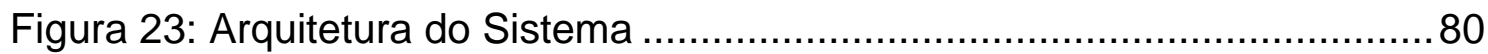

Figura 24: Visualização dos dados do Primavera no Web browser.................... 81

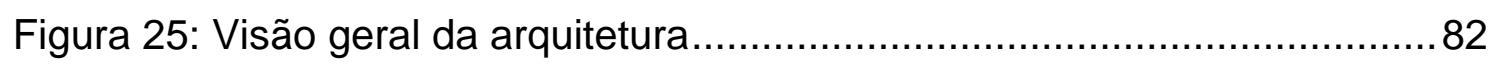

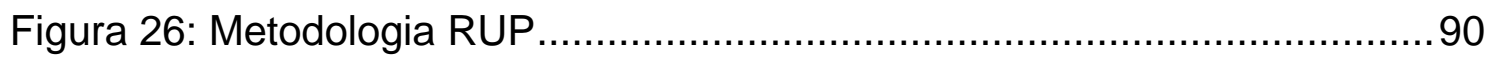

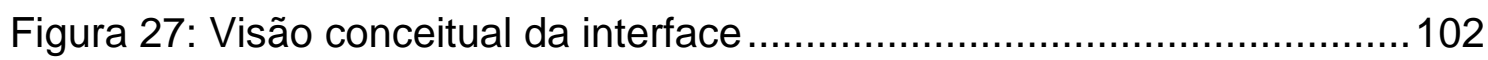

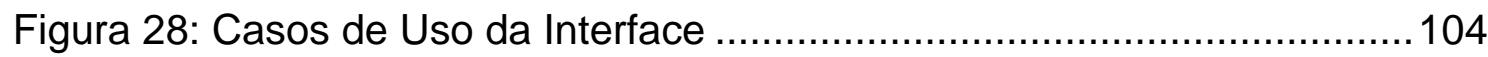


Figura 29: Casos de Uso: Integração Projeto-Produto ................................106

Figura 30: Visão geral funcional da interface ................................................114

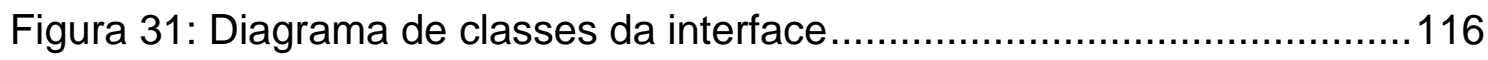

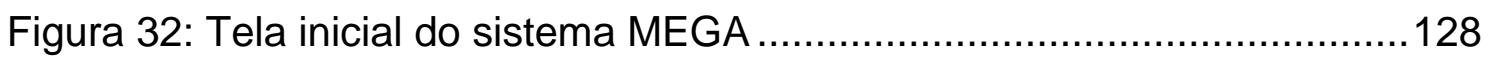

Figura 33: Configuração da estrutura do produto MEGA ..............................131

Figura 34: Visualização de arquivos no TortoiseCVS ..................................133

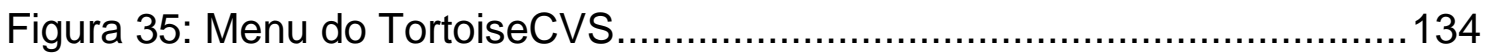

Figura 36: Gráfico de Revisões no TortoiseCVS ........................................135

Figura 37: Utilização do Microsoft Project em projeto de release ...................138

Figura 38: Criação de mapas de importação de arquivos para o Microsoft

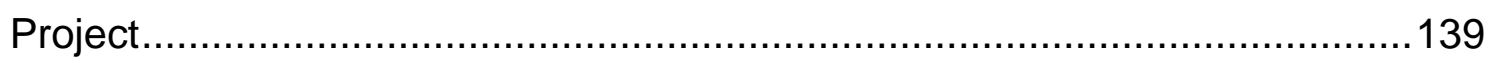

Figura 39: Sistema MEGA-Atend: Chamado Técnico ..................................140

Figura 40: Apontamento de atividades no Sistema MEGA-Atend.................. 142

Figura 41: Exportação do Cadastro de Projetos ............................................143

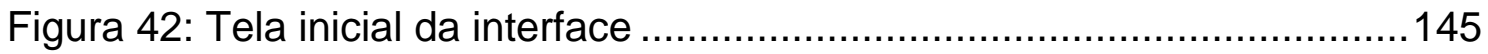

Figura 43: Visão geral da WBS de uma release do produto MEGA no Microsoft

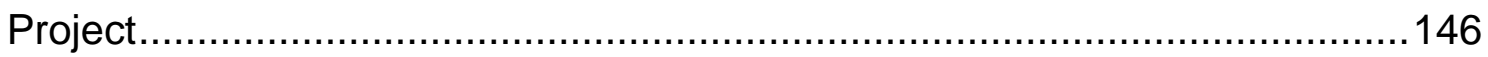

Figura 44: Pacotes de trabalho utilizados no exemplo...................................147

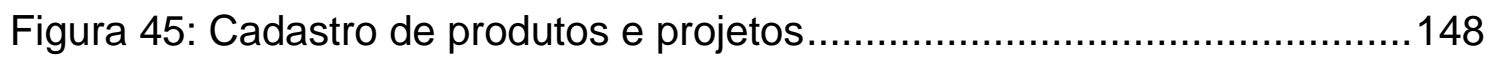

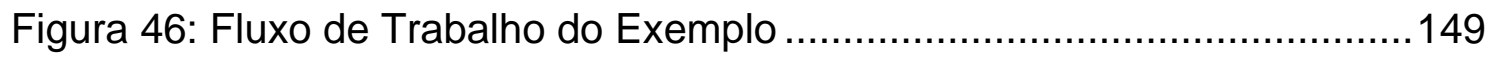

Figura 47: Opção Adicionar Item da Configuração ........................................... 151

Figura 48: Adição de um item a um pacote de trabalho................................151

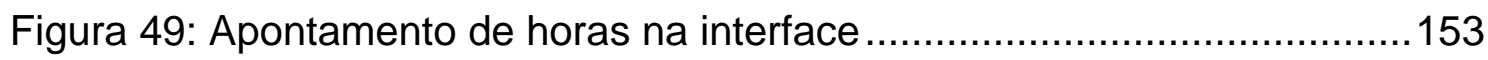




\section{LISTA DE TABELAS}

Tabela 1: Mapeamento entre os processos e grupos de processos do gerenciamento de projetos e as áreas de conhecimento ................................2 27

Tabela 2: Requisitos iniciais para a construção da interface ………………....99

Tabela 3: Conjuntos funcionais de casos de uso.......................................... 105

Tabela 4: Lista final de requisitos e funcionalidades....................................113

Tabela 5: Nomenclatura de arquivos do sistema MEGA ..............................130 


\section{LISTA DE SIGLAS}

\begin{tabular}{|c|c|}
\hline ACWP & Actual Cost of Work Performed \\
\hline BCWP & Budget Cost of Work Performed \\
\hline BOM & Bill of Material \\
\hline CAD & Computer Aided Design \\
\hline CAE & Computer Aided Engineering \\
\hline CAPP & Computer Aided Process Planning \\
\hline $\mathrm{CCM}$ & Configuration Change Management \\
\hline $\mathrm{Cl}$ & Configuration Item \\
\hline $\mathrm{CM}$ & Configuration Management \\
\hline CMBOK & Configuration Management Body of Knowledge \\
\hline CMM & Capability Maturity Model \\
\hline CMMI & Capability Maturity Model Integration \\
\hline CPM & Critical Path Method \\
\hline CVS & Concurrent version System \\
\hline DFx & Design for Excellence \\
\hline EAP & Estrutura Analítica do Projeto \\
\hline EDT & Estrutura de Desmembramento do Trabalho \\
\hline ERP & Enterprise Resource Planning \\
\hline ES & Engenharia Simultânea \\
\hline FICAS & Flow-based Infrastructure for Composing Autonomous Services \\
\hline FMEA & Failure Mode and Effects Analysis \\
\hline GED & Gerenciamento Eletrônico de Documentos \\
\hline GP & Gerenciamento de Projetos \\
\hline ICM & Institute of Configuration Management \\
\hline J2EE & Java to Enterprise Edition \\
\hline OBS & Object Breakdown Structure \\
\hline MRPII & Manufacturing Resource Planning \\
\hline PBS & Product Breakdown Structure \\
\hline PCM & Project Configuration Management \\
\hline PCP & Production Control Planning \\
\hline PDM & Product Data Management \\
\hline PDP & Processo de Desenvolvimento de Produto \\
\hline
\end{tabular}




$\begin{array}{ll}\text { PERT } & \text { Program Evaluation and Review Technique } \\ \text { PI-CEE } & \text { Project Information-Cooperative Enterprise Environment } \\ \text { PLM } & \text { Product Lifecycle Management } \\ \text { PMI } & \text { Project Management Institute } \\ \text { PMBOK } & \text { Project Management Body of Knowledge } \\ \text { PSL } & \text { Process Specification Language } \\ \text { PSPCM } & \text { Pratice Standard on Project Configuration Management } \\ \text { QFD } & \text { Qualify Function Deployment } \\ \text { RUP } & \text { Rational Unified Process } \\ \text { TI } & \text { Tecnologia da Informação } \\ \text { TV } & \text { Time Variance } \\ \text { UML } & \text { Unified Modeling Language } \\ \text { WBS } & \text { Work Breakdown Structure }\end{array}$





\section{SUMÁRIO}

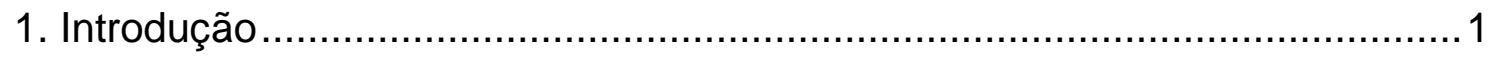

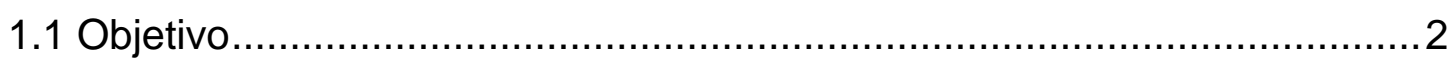

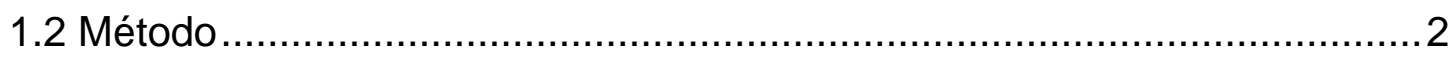

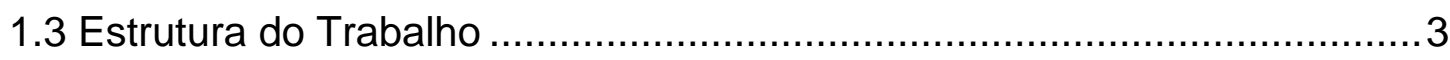

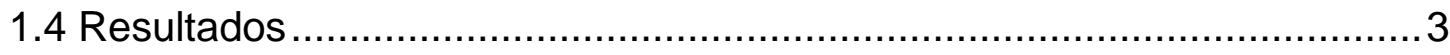

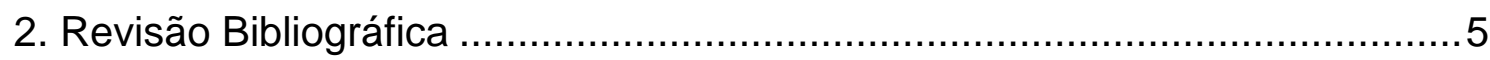

2.1 O Papel da Integração de Dados no Desenvolvimento de Produtos ......6

2.1.1 Processo de desenvolvimento de produto (PDP) ………............... 6

2.1.2 Desenvolvimento integrado de produtos..........................................

2.1.3 Dependência de Atividades no Desenvolvimento Integrado de

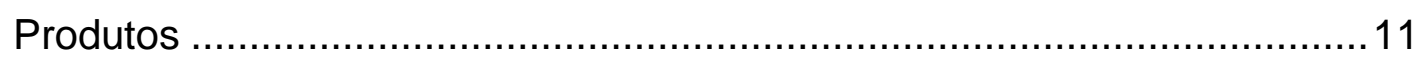

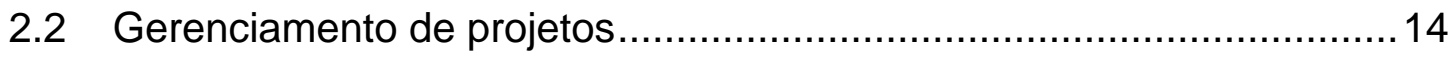

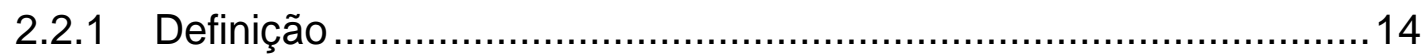

2.2.2 O contexto da Gerência de Projetos (GP) …………………..... 15

2.2.3 Corpo de Conhecimentos em Gerenciamento de Projetos ............. 16

2.2.3.1 Ciclo de Vida do Projeto ....................................................... 17

2.2.3.2 Grupos de Processos de Gerenciamento de Projetos ................. 18

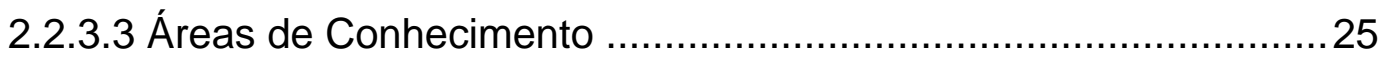

2.2.3.4 Técnicas utilizadas nos Processos de Gerenciamento de Projetos 30

2.3 Gerenciamento da Configuração de Produtos ........................................31

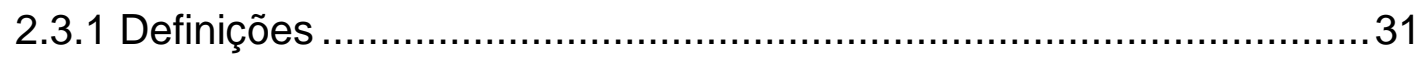

2.3.2 Áreas de Conhecimento do Gerenciamento da Configuração ............ 33

2.3.3 Atividades da Configuração de Produtos ............................................36

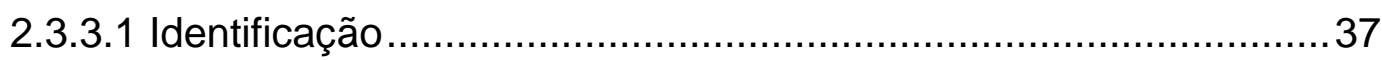

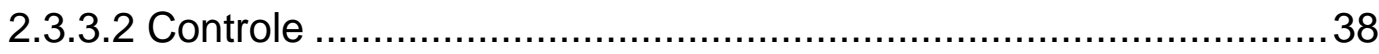

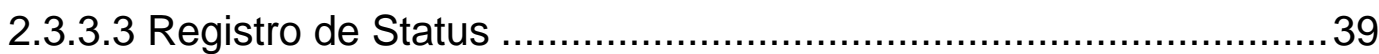

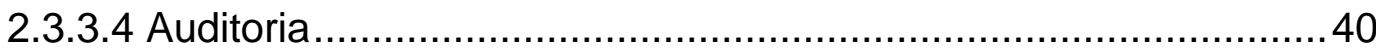

2.4 A estrutura de decomposição do trabalho (EAP - WBS) e seu papel no

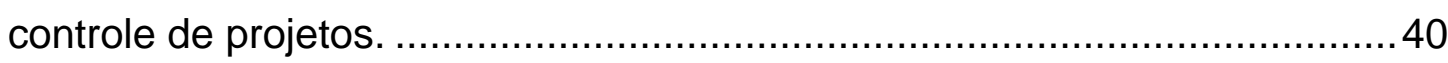

2.4.1 Planejamento do Escopo: Criação da WBS..................................... 42

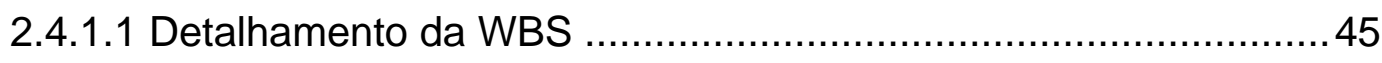

2.4.2 Planejamento do Tempo do Projeto...........................................47 
2.50 processo de gerenciamento da configuração do projeto.

2.5.1 Planejamento .52

2.5.2 Identificação .54

2.5.3 Gerenciamento de Mudanças de Configuração - Cofiguration Change Management (CCM) .55

2.5.4 Registro de Status e Métricas 57

2.5.5 Auditoria e Verificação 60

2.6 Sistemas de apoio ao gerenciamento de projetos 61

2.6.1 Sistemas comerciais de gerenciamento de projetos 61

2.6.2 Sistemas para gestão de projetos em código aberto 72

2.6.3 Sistemas de Gestão de Projetos Propostos em Trabalhos

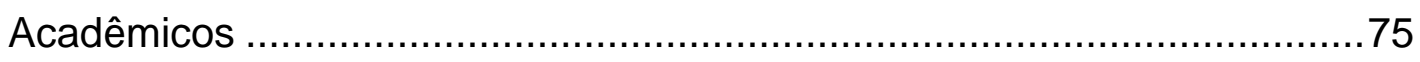

2.6.4 Considerações sobre o estado dos sistemas de GP...................82

3. Método. .84

3.1 Problema de Pesquisa. .84

3.2 Justificativa .85

3.3 Objetivo. .86

3.4 Contribuição científica. .86

3.5 Método .87

3.5.1 Referencial Teórico .87

3.5.2 Metodologia de Pesquisa. .88

3.5.3 Metodologia de Desenvolvimento .89

3.5.4 Etapas do Trabalho. .91

3.5.4.1 Etapa 1 - Levantamento de Requisitos Iniciais .........................91

3.5.4.2 Etapa 2 - Especificações dos Casos de Uso ...............................92

3.5.4.3 Etapa 3 - Especificação Técnica da Interface ...........................92

3.5.4.4 Etapa 4 - Modelagem da Base de Dados .............................. 92

3.5.4.5 Etapa 5 - Modelagem das Funcionalidades ..............................93

3.5.4.6 Etapa 6 - Exemplo de Aplicação da Interface ..........................93

4. Descrição da Interface entre Sistemas Gerenciadores de Projetos e a Configuração do Produto .................................................................. 94

4.1 Problemas e Requisitos Iniciais para Construção do Modelo . .94

4.1.1 Problemas no Gerenciamento de Projetos Relacionados à Configuração do Produto 
4.1.2 Requisitos Iniciais para a Construção da Interface .............................96

4.2 Análise de Requisitos e Especificação Técnica....................................99

4.2.1 Descrição Conceitual da Interface ........................................... 99

4.2.2 Especificação dos Casos de Uso............................................ 103

4.2.2.1 Casos de Uso: Integração Projeto-Produto ........................... 106

4.2.2 Lista Final de Requisitos e Funcionalidades .............................. 112

4.3 Modelagem da Interface ........................................................... 114

4.3.1 Base de Dados da Configuração - Modelagem de Classes............115

4.3.1.1 Descrição das Entidades ................................................. 116

4.3.2 Modelagem funcional para a Integração entre os Dados do Projeto e da Configuração do Produto .......................................................... 121

4.3.2.1 Integração Projeto e Produto ................................................ 122

4.3.2.2 Integração Pacote de Trabalho e Item da Configuração............ 124

5. Exemplo de Aplicação da Interface ................................................... 127

5.1 Descrição do Ambiente Atual ...................................................... 127

5.1.1 Descrição Geral do Sistema MEGA ....................................... 128

5.1.2 Gerenciamento da Configuração .......................................... 129

5.1.2.1 Organização dos Arquivos ............................................... 130

5.1.2.2 Sistema de Controle de Versões ..................................... 131

5.1 .3 Gerenciamento de Projetos ............................................... 135

5.1.3.1 Metodologia de desenvolvimento empregada.......................136

5.1.3.2 Microsoft Project .......................................................... 137

5.2 Descrição do Exemplo ......................................................... 143

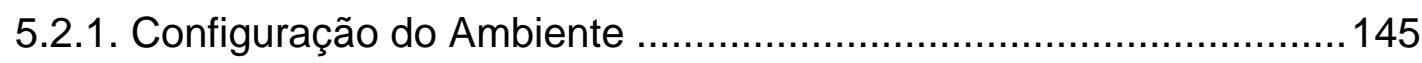

5.2.1.1 Detalhamento da WBS ................................................. 146

5.2.1.2 Integração Produto - Projeto ........................................... 147

5.2.1.3 Controle de Situações.................................................... 148

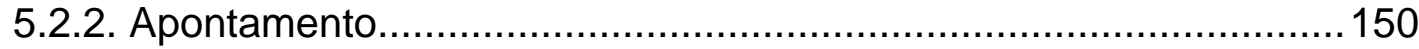

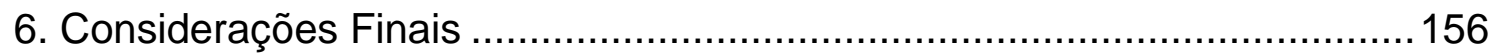

6.1 Conclusões e Contribuições ...................................................... 156

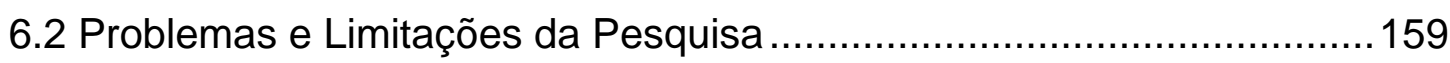

6.3 Sugestões para Trabalhos Futuros............................................ 160

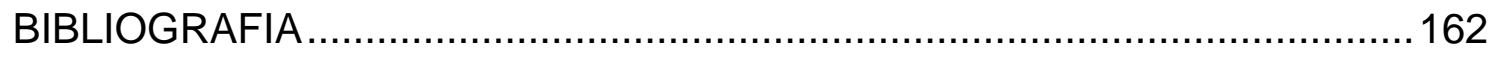

APÊNDICE A - CASOS DE USO DA INTERFACE ............................. 170 
APÊNDICE B - MODELAGEM FUNCIONAL DA INTERFACE.

181 



\section{Introdução}

A Gestão de Projetos tem estado em evidência na literatura de desenvolvimento de produtos. Trata-se de uma ferramenta essencial, considerando que todo desenvolvimento de um produto é um projeto que precisa ser gerenciado de acordo com as melhores práticas disponíveis na área. Apesar da evidência dada pelos profissionais, muitas vezes encarando-a como algo recente e novo, grande parte das técnicas de gerenciamento de projetos é originada na década de 50 e foi desenvolvida dentro do paradigma de projetos complexos, executados por grandes corporações verticalizadas e, portanto, com apoio praticamente exclusivo de equipes internas.

A partir do final dos anos 90, houve uma valorização destas técnicas e sua ampla difusão, porém, em um novo contexto.. A diminuição de níveis hierárquicos nas empresas e a terceirização foram os principais fatores impulsionadores para a aplicação destas práticas. Neste novo cenário, os projetos tiveram seu grau de complexidade acrescido seja pelo numero grande de atividades, seja pela divisão de projetos em subprojetos, ou mesmo projetos realizados por consórcios de empresas, na maioria das vezes em localidades físicas diferentes.

O acompanhamento do desempenho do projeto, conseqüentemente, vem se tornando um desafio, tanto pela dificuldade em obter as informações, devido a padrões e formatos distintos, quanto pela sua precisão, isto é, o quanto corresponde ao trabalho realizado. As soluções tradicionalmente adotadas na área de GP são baseadas em sistemas de apontamento de horas (denominados também de controle de tarefas), preenchidos por todos os participantes do projeto. Esta prática apresenta custos e barreiras crescentes, dado que o trabalho é realizado por pessoas em diferentes organizações, culturas ou conforme se aumenta a complexidade dos projetos. Uma estratégia muito utilizada pelos gerentes, nesses casos, é verificar o andamento do produto por meio da evolução dos itens de configuração do produto, isto é, as especificações.

Paralelamente, viu-se um reconhecimento nos últimos anos da importância da gestão dos projetos com bases em resultados verificáveis e a importância da padronização e comunicação do Plano de Projeto. O principal instrumento para a integração do plano é a Work Breakdown Structure (WBS). 
Trata-se da decomposição do trabalho necessário em itens gerenciáveis e identificação das atividades necessárias para a obtenção destes itens. Ela é a informação que norteia todas as áreas de planejamento do projeto, riscos, custos, etc.. O controle desses itens passou a ser algo fundamental para se manter a coerência dos planos e a comunicação entre a equipe de projeto, sendo uma das práticas reconhecidas na área de gestão de projetos.

Há espaço, portanto, para a criação de novas soluções que auxiliem no levantamento do trabalho efetivamente desenvolvido em cada atividade do projeto global, por meio da integração entre os itens identificados na WBS e os itens de configuração do produto. A gestão integrada dos itens, configuração e da WBS, poderá criar um mecanismo de apuração dos resultados individuais tendo-se como evidências as mudanças realizadas na configuração do produto, as quais representam resultados concretos e menos suscetíveis a possíveis falhas de comunicação, mesmo entre equipes de diferentes formações. Essa integração permitirá também a consolidação da visão global do desempenho do projeto com um menor esforço por parte do membro da equipe de projeto.

\subsection{Objetivo}

Este trabalho apresenta a especificação e modelagem de uma interface entre sistemas gerenciadores de projetos e os itens da configuração do produto, baseado no mapeamento do relacionamento entre itens: da WBS e da Configuração do Produto. A partir desta associação viabiliza-se a apuração do trabalho partindo-se do item alterado dos resultados produzidos, cuja informação pode então ser importada nos dados internos de acompanhamento do respectivo sistema gerenciador do projeto.

\subsection{Método}

Empregou-se a revisão bibliográfica para definir o escopo do problema de pesquisa e identificar o nível de conhecimento sobre o tema em questão. Em seguida, aplicou-se a pesquisa-ação como método base para desenvolvimento do trabalho, devido à carência de literatura e ferramentas acessíveis nesta área, e a necessidade de um levantamento detalhado de requisitos, especificação e modelagem da interface, exigindo a participação direta do pesquisador. Esta participação ocorreu em todas as fases: da 
especificação até o desenvolvimento da aplicação exemplo em uma empresa da área de software.

\subsection{Estrutura do Trabalho}

O capítulo 2 faz uma revisão bibliográfica, com os conceitos sobre engenharia simultânea no desenvolvimento de produtos, gerenciamento de projetos (GP) tradicional, análise comparativa entre softwares de GP e os problemas encontrados nesta área; trata ainda do gerenciamento da configuração do produto e suas funcionalidades culminando com uma seção específica direcionada ao gerenciamento da configuração do projeto. $\mathrm{O}$ capítulo 3 traz a descrição do método empregado, a justificativa, o objetivo e as etapas do trabalho; o capítulo 4 detalha a especificação e modelagem da interface proposta enquanto a seção seguinte - o capítulo 5 - traz um exemplo prático e objetivo de aplicação das funcionalidades da interface descrita. Finalmente, o capítulo 6 descreve as conclusões e resultados obtidos e também os problemas, limitações e perspectivas futuras.

\subsection{Resultados}

O trabalho apresenta uma síntese da literatura sobre os problemas encontrados no gerenciamento do projeto aliado ao gerenciamento da configuração do produto. Apresenta também uma compilação de requisitos para o desenvolvimento de soluções que visem solucionar os principais desafios identificados, com foco no caso das sistemáticas de apontamento e controle de projetos e, como resultado da principal, traz uma proposta de interface entre pacotes de trabalho existentes na WBS definida no sistema gerenciador de projetos e os itens da configuração do produto: as alterações realizadas nos mesmos têm seu início, andamento e término controlados no gerenciamento da configuração e essa informação é extraída e exportada para o sistema de gerenciamento do projeto para acompanhamento do andamento do projeto.

A experiência de realizar uma proposição e uma aplicação prática é descrita avaliando-se seu impacto e a viabilidade da proposta. Além disso, essas experiência foi analisada visando identificar os desafios e vantagens 
envolvidos na integração entre WBS e itens da configuração. Por meio do trabalho foi possível identificar adicionalmente temas para pesquisa futura indicando caminhos para o desenvolvimento de soluções integradas para o gerenciamento de itens de projeto. 


\section{Revisão Bibliográfica}

Este trabalho analisa a relação entre a Estrutura de Desmembramento do Trabalho (WBS) e o Gerenciamento da Configuração de Produtos, no contexto do desenvolvimento de sistemas de informação; mais especificamente, projetos de desenvolvimento de produtos. Portanto, os dois temas centrais da revisão bibliográfica são: o Gerenciamento da Configuração e o conceito e as técnicas relacionadas com a divisão do trabalho do projeto (a WBS). O estado da arte em relação a eles é descrito respectivamente nos itens 2.3 e 2.4 .

Os itens que os antecedem apresentam conceitos básicos, que apóiam a compreensão e a contextualização dos conteúdos presentes nestes dois itens principais. No primeiro, item 2.1, apresenta-se a definição de desenvolvimento de produto como um processo, justificando-a na necessidade de integração deste processo como um todo. Este item ajuda a contextualizar o trabalho, pois é justamente esta preocupação que motiva o estudo da integração entre dados do produto e dados do projeto. Igualmente importante é o item 2.2 que apresenta os conceitos básicos sobre gerenciamento de projetos empregados no decorrer do trabalho.

Os itens que sucedem os principais $\left(\begin{array}{lll}2.3 & \text { e } 2.4\end{array}\right)$ tratam de aprofundamentos. O item 2.5 descreve um padrão recente, em desenvolvimento por membros da organização PMI (Project Management Institute), que visa definir as melhores práticas e ferramentas para a gestão conjunta de dados do produto e da WBS, chamado Processo de Gestão da Configuração do Projeto. Aprofunda, portanto, o item 2.4. O último item da revisão trata especificamente dos sistemas de informação de apoio ao gerenciamento de projetos. Faz-se uma revisão bibliográfica sobre tais ferramentas separadas em classes distintas: comerciais (código-fechado), de código-aberto e protótipos publicados em revistas científicas. Demonstra-se justamente uma lacuna em termos de funcionalidades que apóiem a integração entre o gerenciamento de projetos e da configuração do produto. 


\subsection{O Papel da Integração de Dados no Desenvolvimento de Produtos}

\subsubsection{Processo de Desenvolvimento de Produto (PDP)}

Um processo de negócio compreende um conjunto de atividades organizadas entre si visando produzir um bem ou um serviço para um tipo específico de cliente (interno ou externo a empresa), como gestão financeira, produção, o no caso deste trabalho, o desenvolvimento de produtos (ROZENFELD, 2006).

Em uma organização qualquer, além dos processos, é preciso também gerenciar ações específicas e temporárias. Elas são denominadas de projetos, empreendimentos temporários, únicos e com um fim bem determinado (PMBOK, 2004).

Enquanto os projetos possuem objetivos únicos como custo do produto e data de lançamento, os processos possuem objetivos estabelecidos periodicamente como taxa de defeitos ou falhas num processo de fabricação. Para exemplificar, antes do lançamento, um determinado carro está em fase de projeto, conforme o processo de desenvolvimento de produto; após o lançamento, o projeto termina e aí temos os processos envolvidos como fabricação, aquisição de matéria-prima e processo de vendas. A figura 1 ilustra estas diferenças.
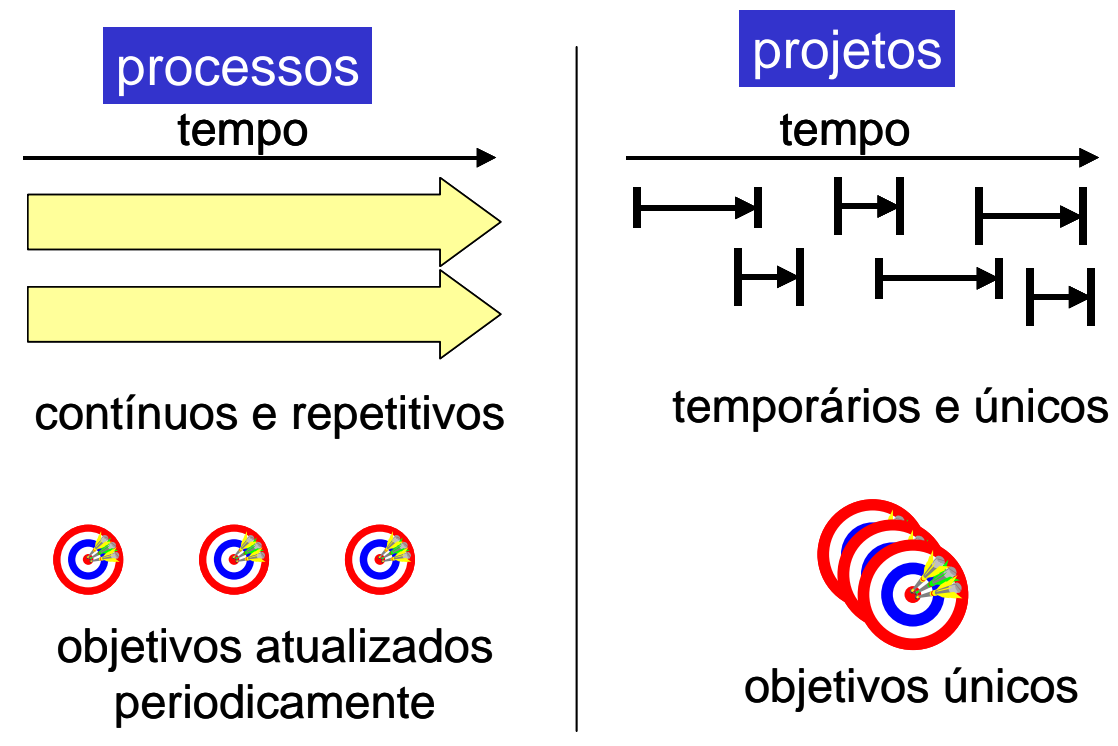

Figura 1: Processos versus Projetos

Fonte: ROZENFELD et al (2006) 
Para CLARK \& FUJIMOTO (1991), o processo de desenvolvimento de produto (PDP) corresponde ao “... processo pelo qual uma organização transforma dados sobre oportunidades de mercado e possibilidades técnicas em bens e informações para a fabricação de um produto comercial", ou seja, as necessidades dos clientes devem ser levantadas e transformadas em recursos para a fabricação do requerido produto.

O escopo do processo de desenvolvimento de produto, conforme apontado por ROZENFELD et al (2000), é cada vez mais amplo, cobrindo desde o planejamento estratégico até a retirada do produto do mercado.

Em termos práticos, a visão por processos significa analisar o desenvolvimento do produto como um conjunto de atividades ordenadas no tempo e com entradas e saídas claramente definidas. Baseado no levantamento realizado por AMARAL (2001), as vantagens da aplicação dessa visão são:

- Tornar claras as relações dentro da organização e entre a organização e o mercado (CLARK, 1991);

- Permitir a identificação de características que influenciam o desempenho deste processo que muitas vezes não estão relacionados às clássicas atividades de engenharia (CLARK, 1991);

- Ser uma visão comum a diferentes abordagens tais como reengenharia e sistemas de garantia de qualidade, entre outras; facilitando, portanto, a visão interdisciplinar (ROZENFELD et al, 2000);

- Permitir a discussão de problemas específicos, sem perder de vista o contexto e as diferentes visões do processo. Isto possibilitaria melhores decisões para os especialistas e também considerar fatores além daqueles relacionados com a área de conhecimento da sua especialização (ROZENFELD et al 2000);

- Fazer com que todas as pessoas possam visualizar o que elas fazem juntas e o que realmente agrega valor, ao invés do enfoque 
nas responsabilidades, hierarquias e funções individuais (DECHAMPS \& NAYA, 1997);

- Realçar o aprendizado, pois salienta claramente as penalidades decorrentes da falta de coordenação funcional (DECHAMPS \& NAYA, 1997).

Este trabalho adota o modelo de PDP descrito por ROZENFELD et al (2006), por possuir escopo amplo abrangendo todo o ciclo de vida do produto, a visão de projetos e trabalho colaborativo entre cada fase do processo e cuja gestão eficaz representa o objetivo deste trabalho. A figura 2 traz uma visão geral deste modelo:

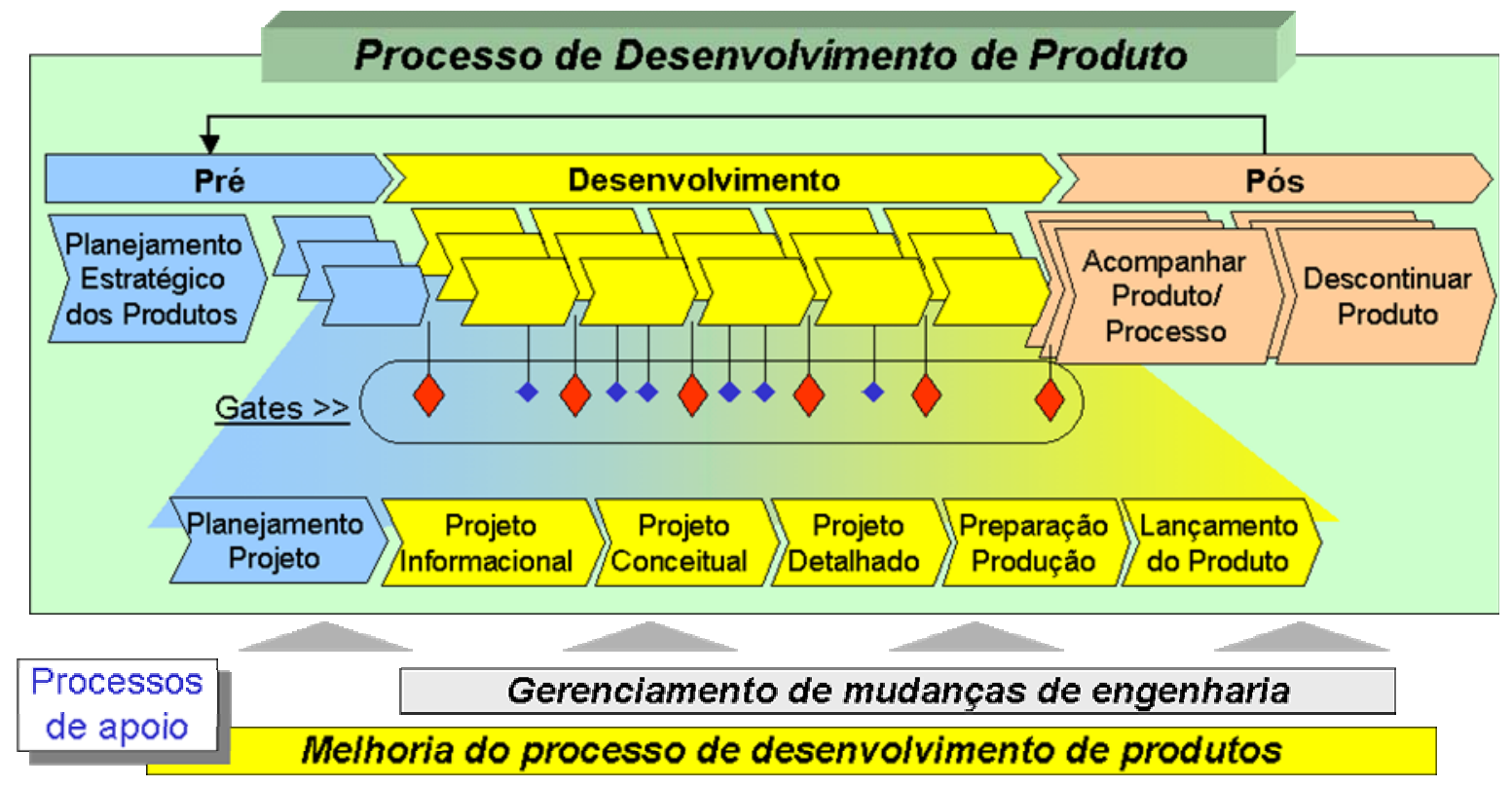

Figura 2: O Processo de Desenvolvimento de Produtos

Fonte: ROZENFELD et al (2006)

\subsubsection{Desenvolvimento integrado de produtos}

Uma característica diferencial e importante do PDP é o emprego de pessoas com formação e visões distintas, que fazem uso de diferentes áreas do conhecimento e, portanto, geralmente induzidas a valorizar os fatores derivados de sua área de formação (AMARAL, 2001). PUGH (1996) fez uma discussão avaliando o problema educacional de se focar os estudantes em disciplinas específicas, que ele chamou de Partial Design e, como 
contraponto, criou o termo Total Design, visando justamente a integração entre as mesmas, tema que foi bastante desenvolvido por CLAUSING (1994). Assim, um grande desafio é obter e transmitir uma visão integrada e comum que considere os aspectos destas diferentes disciplinas, o que é fundamental no aprimoramento da colaboração e compartilhamento dos conhecimentos entre os diferentes especialistas (AMARAL, 2001).

A necessidade de maior integração entre as áreas e funções da empresa durante o desenvolvimento de produtos é relativamente recente. Foi iniciada na década de 90 (ROZENFELD et al, 2006). Até este momento a abordagem utilizada é denominada de Engenharia Seqüencial, ou abordagem tradicional. O desenvolvimento é feito em seqüência, ou seja, cada estágio tem que ser completado para que o outro possa ser iniciado (SYAN, 1994). Há vários problemas com esta abordagem, dentre os quais:

- Alterações no produto que ocorram muito tardiamente aumentam significativamente os custos de desenvolvimento (ROZENFELD et al, 2000);

- Cada estágio só se inicia quando o anterior termina, o que aumento o tempo final de desenvolvimento (PRASAD, 1996);

- Parte significativa dos custos de manufatura (50 a 80\%) é decidida antes dos engenheiros de manufatura começarem a fazer parte do projeto (PRASAD, 1996);

- Prazos de lançamento freqüentemente não são cumpridos fazendo com que o produto final não seja mais viável ou aceito pelo mercado alvo (PRASAD, 1996);

- A especificação do produto é insuficiente levando a um grande número de alterações (SYAN, 1994);

- É dada pouca atenção à área de manufatura nas fases de projeto, causando alterações caras em ferramentas e outros equipamentos (SYAN, 1994).

A maior integração entre as áreas e, portanto, a aplicação da visão de processos no desenvolvimento de produtos foi motivada por estas dificuldades. 
Várias mudanças foram implementadas, todas elas visando uma maior integração entre as atividades relacionadas com o desenvolvimento de produtos, gerando uma nova abordagem. A literatura passou inicialmente a denominá-la de engenharia simultânea (do inglês, concurrent engineering) e mais recentemente de desenvolvimento integrado de produtos.

Engenharia Simultânea (ES): aumento no grau de paralelismo entre as atividades de desenvolvimento, com ênfase na realização simultânea das tarefas de projeto e planejamento de processo e,como se pode presumir, reflete o sentido oposto da engenharia seqüencial, ou seja, um estágio pode e deve ser iniciado antes do processo anterior terminar, o quanto mais cedo possível (figura 3). Mais formalmente, CLAUSING (1994), define como "o aumento da simultaneidade, foco na qualidade, custos e distribuição com ênfase na satisfação do cliente durante o processo de desenvolvimento de produtos, enfatizando também a melhora na integração da organização, na participação dos membros do time e nos relacionamentos estratégicos com fornecedores" fazendo uso de diversos métodos e técnicas da engenharia (como proposto no Total Design) tais como: QFD, FMEA, DFx, CAD/CAE, CAPP, PLM e assim por diante. São alguns princípios da engenharia simultânea:

- Sobreposição de tempo de um ou mais grupos de trabalho, atividades, tarefas, etc. (PRASAD, 1996);

- Decomposição em paralelo do processo de realização do produto em diferentes atividades que podem ser re-agregadas no final para compor o todo (PRASAD, 1996);

- Deve-se trabalhar em equipe, pregando-se a cooperação e confiança entre seus membros, assim como o compartilhamento de conhecimentos (ROZENFELD et al, 2006);

- Devem fazer parte desta equipe os clientes e fornecedores, enfim todos os parceiros da cadeia de suprimentos (ROZENFELD et al, 2006); 
- Agendamento paralelo de recursos para facilitar a transferência de informação entre os grupos de trabalho (PRASAD, 1996);

- As pessoas envolvidas no desenvolvimento devem considerar, desde o início, todos os elementos do ciclo de vida do produto, da concepção ao descarte, incluindo qualidade, custo, prazos e requisitos dos clientes (ROZENFELD et al, 2006);

- Enfatiza o atendimento das expectativas dos clientes (ROZENFELD et al, 2006).

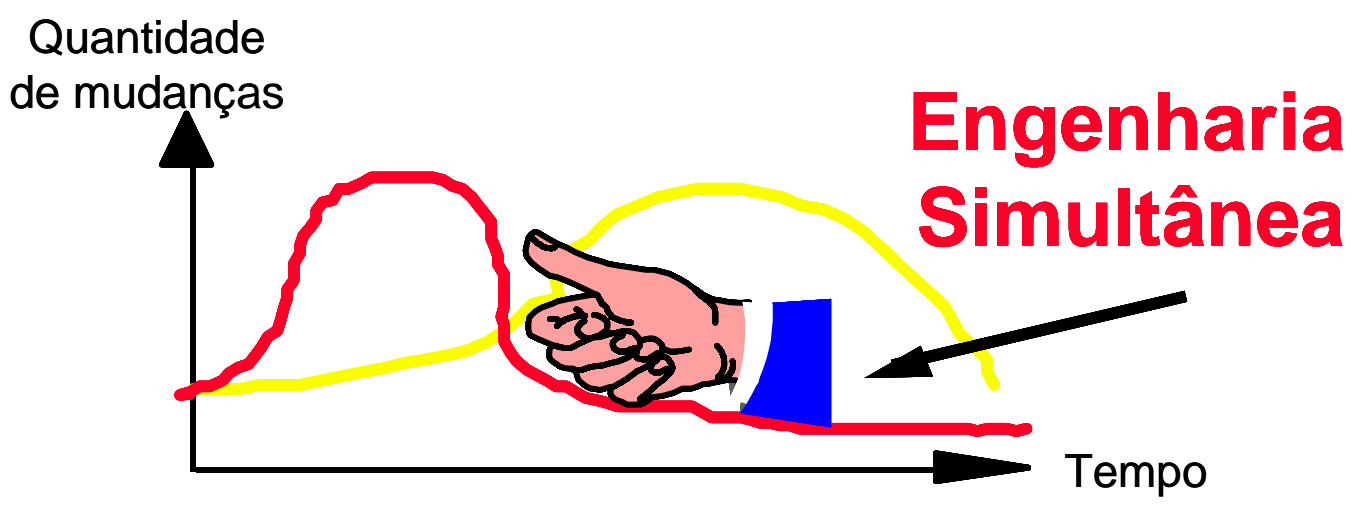

Figura 3: Mudanças devem acontecer o quanto antes na E. S.

Numa análise comparativa, percebe-se que a abordagem seqüencial tende a ter, na maioria das vezes, um custo maior devido ao tempo total de desenvolvimento e às modificações de especificações e/ou recursos nas fases avançadas do projeto, justamente os principais insumos da engenharia simultânea. Por outro lado, o gerenciamento de tantos recursos e informações simultaneamente aumenta consideravelmente a complexidade do gerenciamento e controle do projeto, pontos que este trabalho pretende atacar. Um fator fundamental nesta abordagem é a dependência e a integração entre as diversas atividades do desenvolvimento de produto.

\subsubsection{Dependência de Atividades no Desenvolvimento Integrado de Produtos}

A decomposição e o paralelismo identificam quais atividades podem acontecer simultaneamente ou ser executadas em sobreposição. Além disso, 
permitem formular estratégias para conduzir esta separação como a indexação, reestruturação ou a decomposição alternativa (PRASAD, 1996). Assumindo que uma atividade pode ser subdividida em tarefas, estas últimas podem se inter-relacionar de 4 formas (PRASAD, 1996):

- Tarefas dependentes: quando toda a informação requerida é originada diretamente da saída de uma outra tarefa;

- Tarefas semi-independentes: quando a transferência de informação da saída de uma tarefa para outra é apenas uma transferência parcial, significando uma interação fraca entre as tarefas;

- Tarefas independentes: quando nenhuma porção de informação da saída de uma ou outra tarefa é requerida para a realização de ambas as tarefas;

- Tarefas interdependentes: quando há intercâmbio de informação entre as tarefas, de forma que a realização de uma depende de informação gerada pela primeira e esta também depende da informação gerada pela segunda (no caso de duas tarefas, por exemplo).

A figura 4 ilustra a diferença entre os possíveis relacionamentos entre as atividades.

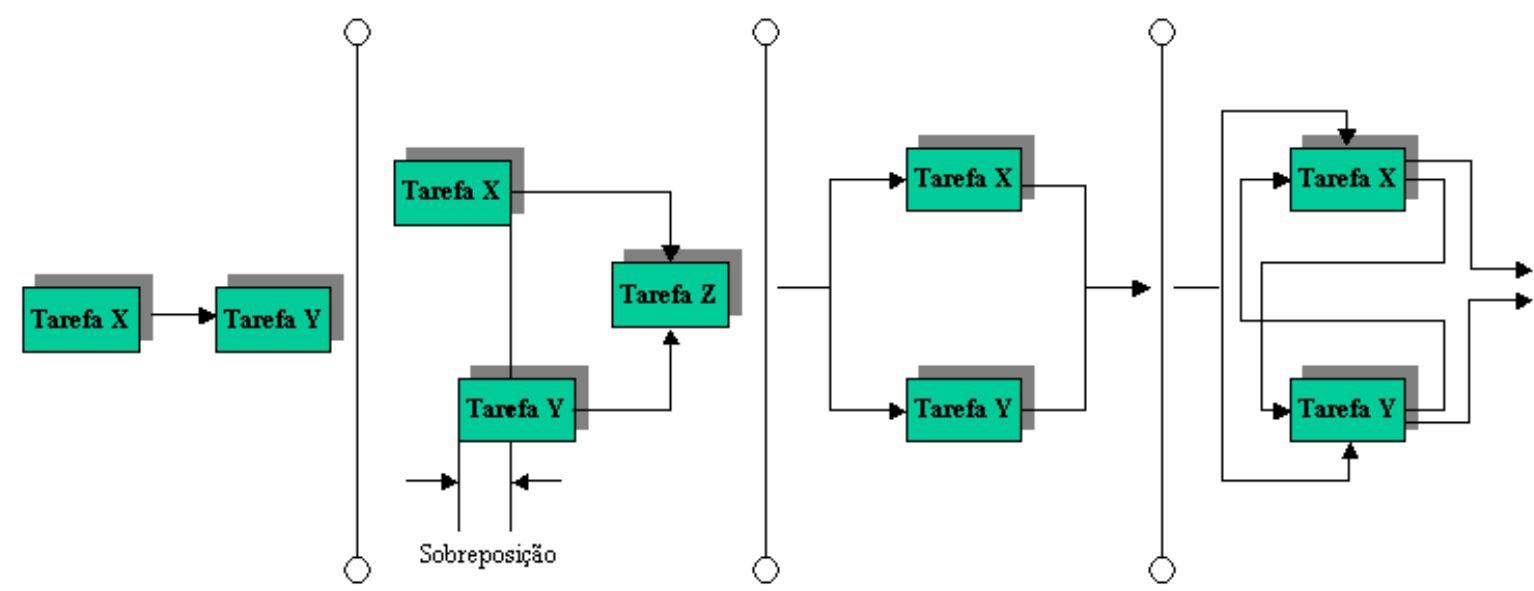

(a) Tarefas Dependentes

(b) Torefas Semi-Independentes

(c) Torefas Independentes

(d) Torefas Interdependentes 
Figura 4: Relacionamentos possíveis entre pares de atividades Fonte: PRASAD (1996)

Ainda de acordo com PRASAD (1996), a sobreposição entre duas tarefas representa o lapso de tempo para construir a informação requerida para o início de tarefas subseqüentes. Coordenar tarefas que exibem características dependentes ou independentes é complexo. Para os grupos de trabalho, entretanto, os desafios da engenharia simultânea são extremamente difíceis quando muitas tarefas são interdependentes; significando que elas estão acopladas e não podem ser separadas explicitamente em modo paralelo ou em série. Tarefas interdependentes (ou acopladas) levam mais tempo de design e muitas iterações antes de finalmente convergirem.

A engenharia simultânea preza pelo paralelismo e imediatismo mas, na prática, o que acontece é que grupos de tarefas mutuamente independentes raramente existem. Estrategicamente decompor tarefas interdependentes em uma série de tarefas dependentes, independentes e semi-independentes pode reduzir o tamanho dos grupos de trabalho e o número de iterações que são requeridas para obter uma solução razoável. Porém, amplia-se a quantidade de interfaces entre os grupos, havendo a necessidade de um esforço maior em termos de comunicação, de controle do projeto e controle dos documentos gerados. Portanto, o sucesso do emprego do conceito de engenharia simultânea e da integração do PDP é a utilização de técnicas e ferramentas de apoio ao projeto que auxiliem no controle das informações geradas e na comunicação entre as equipes.

Dois itens fundamentais neste aspecto são: o controle de informações relacionadas com o produto (gerenciamento de configuração) e o controle das atividades e entregas do projeto (gerenciamento da WBS e controle do projeto). As duas próximas seções tratam do cenário atual no gerenciamento e planejamento de atividades e recursos (gestão de projetos) e na gestão e controle das informações do produto (gestão da configuração). 


\subsection{Gerenciamento de projetos}

O desenvolvimento de um novo produto pode ser encarado como um projeto complexo ou junção de vários projetos que produzem resultados individuais e, cuja reunião, corresponde ao produto propriamente. Numa visão integrada de desenvolvimento, o gerenciamento destes projetos é de suma importância para o sucesso no produto final.

Este item da revisão bibliográfica traz como principal referência o PMBOK (2004) criado pelo PMI (Project Management Institute), o qual tem se tornado um padrão de fato na área. Aborda a definição de projeto, gerenciamento de projetos e o conjunto de conhecimentos relacionados.

\subsubsection{Definição}

A literatura traz várias definições sobre projeto:

- Empreendimento temporário, caracterizado por uma seqüência clara e lógica de eventos com início, meio e fim, que se destina a atingir um objetivo claro e definido, sendo conduzido por pessoas dentro de parâmetros de prazo, custo, recursos envolvidos e qualidade (HELDMAN, 2003);

- Esforço temporário para criar um produto quantificável (item final ou componente), serviço (funções de negócio para suporte ou distribuição) ou resultado exclusivo (documentos como, por exemplo, conhecimento aplicado de pesquisa científica). (PMBOK, 2004);

- Corresponde a todo trabalho que é feito em tempo determinado, isto é, com começo, meio e fim e que gera um produto singular (VERZUH, 2000);

- Conjunto de atividades com caráter único e temporário visando produzir bens ou serviços (ROZENFELD et al, 2004) - já visto no capítulo 1.

As organizações realizam o trabalho diário no intuito de atingir seus objetivos e a teoria do gerenciamento tradicional concentrou-se quase que exclusivamente nas operações permanentes como o processamento de 
pedidos, emissão de ordens de fabricação (VERZUH, 2000). Estas operações são repetitivas e contínuas com o objetivo de manter o negócio; já os projetos buscam atingir seus objetivos e, em seguida, terminar (PMBOK, 2004). Com a competição acirrada entre as empresas no desenvolvimento de novos produtos e, conseqüentemente, de novos projetos, criou-se a necessidade da aplicação de diversas disciplinas que variam de acordo com os desafios impostos em cada projeto.

O gerenciamento de projetos, de acordo com PMBOK (2004), consiste então na aplicação de conhecimentos, habilidades, ferramentas e técnicas às atividades do projeto a fim de atender os seus requisitos e com o objetivo de aumentar a eficiência, rapidez e a diminuição dos custos. Sua execução é responsabilidade do gerente de projeto e é realizado através da aplicação e integração de diversas atividades, denominadas processos de gerenciamento de projetos, por seu caráter atemporal conforme definido na seção 2.1.1. Estes processos são: iniciação, planejamento, execução, monitoramento e controle, e encerramento. Incluem diversas atividades como a identificação de necessidades, definição de objetivos atingíveis, distribuição de tarefas, alocação de recursos e controle de prazos e custos. As duas próximas seções tratam do contexto onde está incluído o gerenciamento de projetos e dos processos citados acima.

\subsubsection{O contexto da Gerência de Projetos (GP)}

O gerenciamento de projetos faz parte de um contexto mais amplo que inclui o gerenciamento de programas, gerenciamento de portfólios e escritórios de projetos, além dos próprios projetos e dos subprojetos que o compõem (PMBOK, 2004). Abaixo são descritas as definições:

- Programas: grupo de projetos relacionados de modo coordenado para a obtenção de benefícios e controle que não estariam disponíveis se eles fossem gerenciados individualmente. Podem incluir elementos de trabalho relacionado fora do escopo dos projetos distintos no programa como, por exemplo, um programa de obras para uma cidade com uma série de projetos individuais ou o programa de um novo modelo de veículo com os projetos 
individuais para o desenvolvimento de cada componente principal como transmissão, motor, câmbio e assim por diante;

- Portfólios: conjunto de projetos ou programas e outros trabalhos agrupados para facilitar o gerenciamento eficaz do conjunto a fim de atender aos objetivos de negócios estratégicos;

- Escritórios de projetos (PMO - Project Management Office): unidade organizacional que centraliza e coordena o gerenciamento de projetos e/ou programas sob seu domínio. Concentra-se no planejamento, na priorização e na execução coordenados de projetos e subprojetos vinculados aos objetivos gerais de negócios da matriz ou do cliente. Algumas características incluem entre outras: coordenação e compartilhamento de recursos entre projetos, gerenciamento centralizado da configuração e repositório centralizado em todos os projetos e monitoramento central de prazos e orçamentos;

- Subprojetos: divisão dos projetos em componentes mais facilmente gerenciáveis normalmente contratados por uma empresa externa ou outra unidade funcional executora.

\subsubsection{Corpo de Conhecimentos em Gerenciamento de Projetos}

Conforme descrito em PMBOK (2004), existe um conjunto exclusivo de conhecimentos em gerenciamentos de projetos que se sobrepõe às outras disciplinas de gerenciamento. Este conjunto de conhecimentos consiste em:

- Definição do ciclo de vida do projeto;

- Grupos de Processos de Gerenciamento de Projetos (já citados na seção 2.2.1):

- Iniciação;

- Planejamento;

- Execução;

- Monitoramento e Controle;

- Encerramento;

- Áreas de Conhecimento: 
- Integração;

- Escopo;

- Tempo;

- Custos;

- Qualidade;

- Recursos Humanos;

- Comunicações;

- Riscos

- Aquisições/Suprimentos.

\subsubsection{Ciclo de Vida do Projeto}

O ciclo de vida do projeto corresponde exatamente às fases que o projeto atravessa do início até o seu encerramento. Esta divisão é útil no sentido de facilitar a organização e melhor controle do gerenciamento. Vale ressaltar que estas fases não são iguais aos grupos de processo do gerenciamento de projetos: quando um projeto de grande porte é dividido em fases ou subprojetos, todos os processos do grupo de processos seriam repetidos para cada fase ou subprojeto (PMBOK, 2004).

A mudança de fase, dentro do ciclo de vida, acontece quando há algum tipo de transferência de conhecimento ou entrega de algum tipo de resultado, a qual, normalmente é validada e aprovada para o início da próxima fase. Entretanto ocorre que, muitas vezes, isto acaba acontecendo quando a próxima fase já teve início para poder dar um grau maior de paralelismo ao cronograma do projeto.

De acordo com PMBOK (2004), os principais pontos que o ciclo de vida deve definir são:

- Distribuição do trabalho entre as fases;

- Definição das datas de entrega e das datas de revisão e validação das mesmas;

- Distribuição das pessoas envolvidas em cada fase;

- Método de controle e aprovação das fases. 
As principais características comuns compartilhadas pelos ciclos de vida dos projetos são (PMBOK, 2004):

- Fases delimitadas pela transferência de informações técnicas ou entrega de componentes técnicos;

- Níveis de custos e de pessoal são baixos no início e final e atingem o valor máximo nas fases intermediárias;

- Risco de não atingir os objetivos é maior no início do projeto e vai diminuindo de acordo com o andamento do projeto;

- A capacidade dos participantes do projeto influenciar nas características finais do produto é maior no início e vai se tornando cada vez menor conforme o projeto continua.

A figura 5 mostra em exemplo típico de organização de fases dentro do ciclo de vida do projeto:

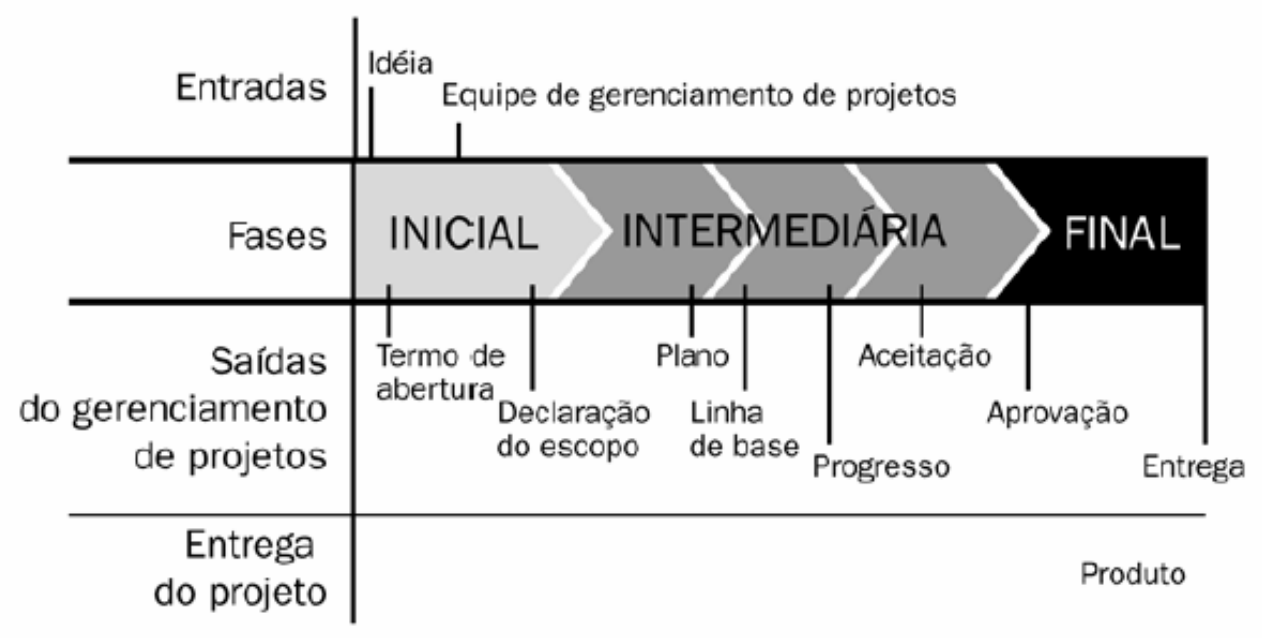

Figura 5: Seqüência típica das fases de um projeto

Fonte: PMBOK (2004)

\subsubsection{Grupos de Processos de Gerenciamento de Projetos}

O conjunto de técnicas e habilidades existente no gerenciamento de projetos é realizado através de processos que recebem entradas e geram saídas a fim de atender os objetivos propostos. Devido ao gerenciamento de 
projetos ser um empreendimento integrador, é necessário que cada processo seja adequadamente associado e conectado a outros processos para facilitar a sua coordenação (PMBOK, 2004). Em termos da integração, interação entre processos e dos objetivos a que eles atendem, os processos de gerenciamento de projetos foram divididos em cinco grupos de processos (PMBOK, 2004). Esses grupos e os processos (P1...Pn) que os compõem são descritos abaixo e resumidos na figura 6 :

- Grupo de Processos de Iniciação: define e autoriza o projeto ou uma fase do projeto;

- P1 - Desenvolver Termo de Abertura: trata da autorização do projeto necessário para documentação das necessidades de negócios e do novo produto, serviço ou resultado que deve satisfazer esses requisitos.

- P2 - Desenvolver Declaração do Escopo Preliminar: criar a definição de alto nível do projeto, abordando e documentando os limites e requisitos, métodos de aceitação e controle de alto nível do escopo.

- Grupo de Processos de Planejamento: define e refina os objetivos e planeja a ação necessária para alcançar os objetivos e o escopo para os quais o projeto foi realizado;

- P1 - Desenvolver Plano de Gerenciamento do Projeto: definir, preparar, integrar e coordenar todos os planos auxiliares em um plano de gerenciamento do projeto.

- P2 - Planejamento do Escopo: gerar documentação de como o escopo será definido, verificado e controlado e como Serpa criada e definida a estrutura analítica do projeto.

- P3 - Definição do Escopo: desenvolver declaração do escopo detalhada do projeto com base para futuras decisões do projeto.

- P4 - Criar WBS (Work Breakdown Strucuture, em português EAP - Estrutura Analítica do Projeto): subdividir as principais entregas do projeto e do trabalho 
do projeto em componentes menores e mais facilmente gerenciáveis.

- P5 - Definição da Atividade: identificar as atividades específicas que precisam ser realizadas para produzir as várias entregas do projeto.

- P6 - Seqüenciamento de Atividades: identificar e documentar as dependências entre atividades.

- P7 - Estimativa de Recursos da Atividade: estimar o tipo e quantidade de recursos para realizar cada atividade do cronograma.

- P8 - Estimativa de Duração da Atividade: estimar o número de períodos de trabalho que serão necessários para terminar as atividades do cronograma.

- P9 - Desenvolvimento do Cronograma: analisar os recursos necessários, restrições do cronograma, durações e seqüências de atividades para criar o cronograma do projeto.

- P10 - Estimativa de Custos: estimar uma aproximação dos custos dos recursos necessários para finalizar as atividades do projeto.

- P11 - Orçamento: agregar os custos estimados para estabelecer uma linha de base para os mesmos.

- P12 - Planejamento da Qualidade: identificar padrões de qualidade e os mecanismos para alcançá-los.

- P13 - Planejamento de Recursos Humanos: Identificar e documentar funções, responsabilidades e relações hierárquicas, além do plano de gerenciamento de pessoal.

- P14 - Planejamento das Comunicações: determinar necessidades de informação e comunicação entre as partes interessadas do projeto.

- P15 - Planejamento do Gerenciamento de Riscos: decidir como abordar, planejar e executar as atividades de gerenciamento de riscos do projeto. 
- P16 - Identificação de Riscos: determinar os riscos que podem afetar o projeto e documentar suas características.

- P17 - Análise Qualitativa de Riscos: priorizar riscos para análise ou ação adicional subseqüente através de avaliação e combinação de sua probabilidade de ocorrência e impacto.

- P18 - Análise Quantitativa de Riscos: analisar numericamente os efeitos dos riscos identificados nos objetivos gerais do projeto.

- P19 - Planejamento de Respostas a Riscos: desenvolver opções e ações para aumentar as oportunidades e reduzir as ameaças aos objetivos do projeto.

- P20 - Planejar Compras e Aquisições: determinar quando, como e quais recursos devem ser adquiridos.

- P21 - Planejar Contratações: documentar os requisitos de produtos, serviços e resultados e identificar possíveis fornecedores.

- Grupo de Processos de Execução: integra pessoas e outros recursos para realizar o plano de gerenciamento do projeto para o projeto;

- P1 - Orientar e gerenciar a execução do projeto: orientar as diversas interfaces técnicas para executar o trabalho definido resultando em informações sobre as entregas produzidas e sobre a quantidade de trabalho executada.

- P2 - Realizar a garantia da qualidade: aplicar as atividades de qualidade planejadas para garantir que 0 processo está realizando todos os processos necessários para atender os requisitos.

- P3 - Contratar ou mobilizar a equipe do projeto: obter os recursos humanos para terminar o projeto. 
- P4 - Desenvolver a equipe do projeto: melhorar as competências e interações entre os membros da equipe para aprimorar o desempenho do projeto.

- P5 - Distribuição das informações: disponibilizar as informações às partes interessadas no momento certo.

- P6 - Solicitar respostas de fornecedores: obter informações, cotações, licitações, ofertas ou propostas dos fornecedores.

- P7 - Selecionar fornecedores: revisar ofertas, escolher entre possíveis fornecedores e negociar contratos por escrito com os fornecedores selecionados.

- Grupo de Processos de Monitoramento e Controle: mede e monitora regularmente o progresso para identificar variações em relação ao plano de gerenciamento do projeto, de forma que possam ser tomadas ações corretivas quando necessário para atender aos objetivos do projeto;

- P1 - Monitorar e controlar o trabalho do projeto: coletar, medir e disseminar informações sobre o desempenho e avaliar as medições e as tendências para efetuar melhorias no processo.

- P2 - Controlar mudanças de forma integrada: controlar os fatores que criam mudanças para garantir que essas mudanças sejam benéficas, determinar se ocorreu uma mudança e gerenciar as mudanças aprovadas.

- P3 - Verificar escopo: formalizar as entregas terminadas do projeto.

- P4 - Controlar escopo: controlar as alterações de escopo do projeto.

- P5 - Controlar cronograma: controlar as alterações de cronograma do projeto.

- P6 - Controlar custos: controlar mudanças de orçamento e os fatores que influenciam suas variações.

- P7 - Controlar qualidade: monitorar resultados para verificar se eles estão dentro dos padrões de qualidade 
determinados e identificar formas de eliminar as causas que prejudicam o desempenho.

- P8 - Gerenciar a equipe do projeto: acompanhar o desempenho dos membros da equipe, coordenar mudanças para melhorar o desempenho do projeto e divulgar o retorno obtido com as mesmas.

- P9 - Gerar relatório de desempenho: coletar e distribuir informações relacionadas ao andamento do projeto, medição de progresso e previsão.

- P10 - Gerenciar as partes interessadas: gerenciar a comunicação a fim de satisfazer as necessidades das partes interessadas do projeto e resolver problemas com elas.

- P11 - Monitorar e controlar riscos: acompanhar os riscos identificados, monitorar riscos individuais, identificar novos riscos, executar planos de respostas a riscos e avaliar sua eficiência durante todo o ciclo de vida do projeto.

- P12 - Administrar contrato: gerenciar o contrato e a relação entre fornecedor e comprador, analisar e documentar o desempenho do fornecedor e gerenciar a relação contratual com o comprador externo do projeto.

- Grupo de Processos de Encerramento: formaliza a aceitação do produto, serviço ou resultado e conduz o projeto ou uma fase do projeto a um final ordenado.

- P1 - Encerrar o projeto: finalizar todas as atividades em todos os grupos de processos para encerrar formalmente o projeto ou uma fase deste.

- P2 - Encerrar o contrato: terminar e liquidar cada contrato aplicável ao projeto ou a uma fase deste. 


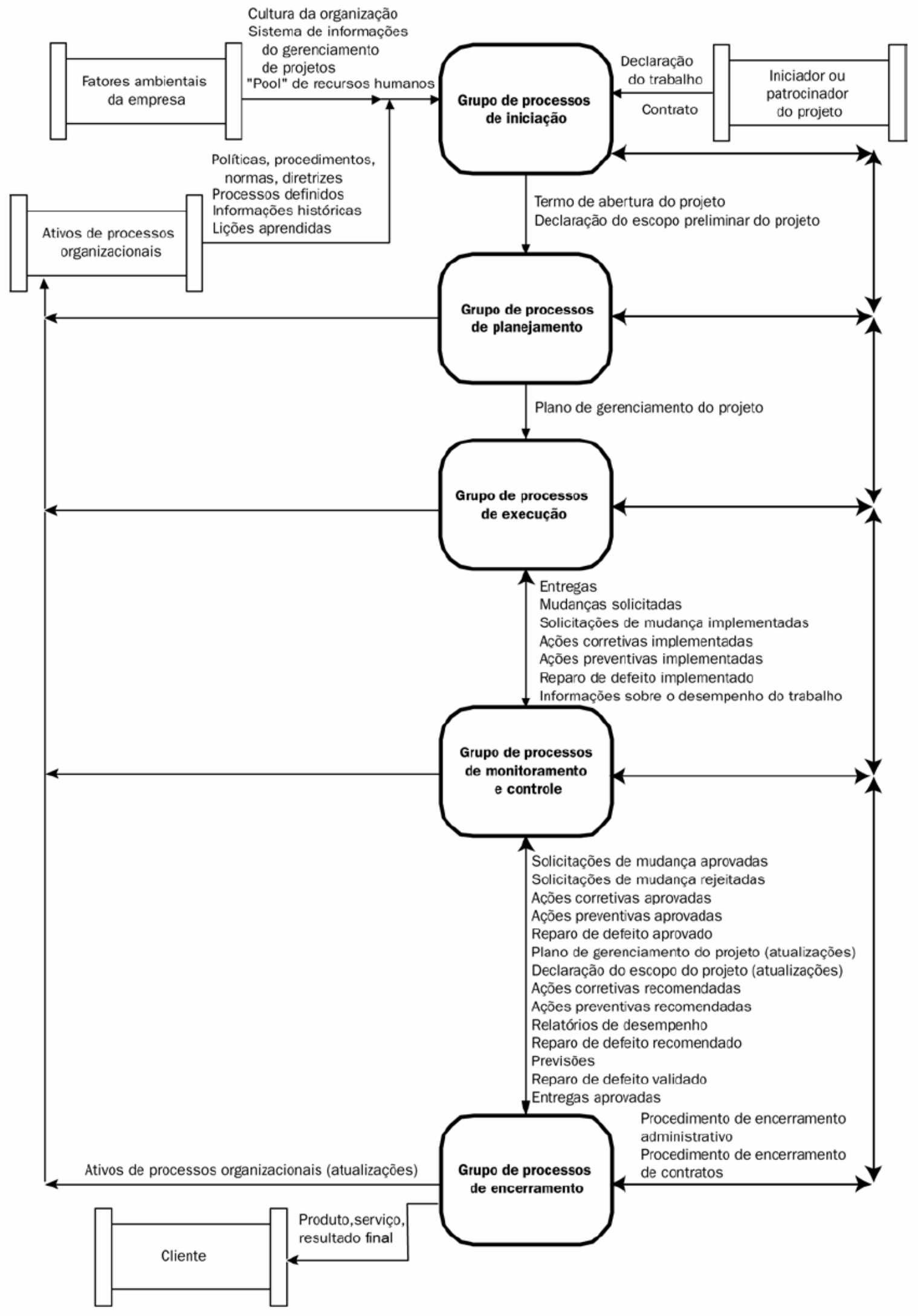

Figura 6: Principais interações entre os grupos de processos

Fonte: PMBOK (2004) 


\subsubsection{3 Áreas de Conhecimento}

A seção anterior listou 44 processos de gerenciamento de projetos divididos em cinco grupos de processos de acordo com as interações e integrações entre eles. Do ponto de vista de áreas de conhecimento em gerenciamento de projetos, ou seja, campos de conhecimento que reúnem técnicas e habilidades afins, estes grupos e processos podem ser organizados em nove áreas distintas (PMBOK, 2004):

- Integração: inclui os processos e atividades necessárias para identificar, definir, combinar, unificar, e coordenar os diversos processos e atividades de gerenciamento essenciais para o término do projeto;

- Escopo: inclui os processos necessários para garantir que o projeto inclua todo o trabalho necessário, e somente ele, para terminar o projeto com sucesso. Em resumo, trata da definição e controle do que está e do que não está incluído no projeto;

- Tempo: inclui os processos para garantir que as atividades do projeto serão concluídas dentro do prazo e constitui foco deste trabalho. Define a duração da atividade e o seu seqüenciamento;

- Custos: inclui os processos envolvidos no planejamento, estimativa, orçamento e controle de custos, de modo que seja possível terminar o projeto dentro do prazo;

- Qualidade: inclui todas as atividades da organização executora que determinam as responsabilidades, os objetivos e as políticas de qualidade, de modo que o projeto atenda às necessidades que motivaram sua realização;

- Recursos Humanos: determina funções, responsabilidades e relações hierárquicas do projeto e cria o plano de gerenciamento de pessoal;

- Comunicações: constitui os processos necessários para garantir a geração, coleta, distribuição, armazenamento, recuperação e destinação final das informações sobre o projeto de forma oportuna e adequada e apuração de desempenho; 
- Riscos: inclui os processos que tratam da realização de identificação, análise, respostas, monitoramento/controle e planejamento do gerenciamento de riscos, visando aumentar a probabilidade e o impacto dos eventos positivos e diminuir dos eventos adversos;

- Aquisições/Suprimentos: reúne os processos para comprar ou adquirir produtos, serviços ou resultados necessários de fora da equipe do projeto para realizar o trabalho planejado.

A tabela 1 mostra a relação entre processos de gerenciamento de projetos, grupos de processos de gerenciamento de projetos e as áreas de conhecimento: 


\begin{tabular}{|c|c|c|c|c|c|}
\hline \multirow[b]{2}{*}{$\begin{array}{l}\text { Processos de área } \\
\text { de conhecimento }\end{array}$} & \multicolumn{5}{|c|}{ Grupos de processos de gerenciamento de projetos } \\
\hline & $\begin{array}{c}\text { Grupo } \\
\text { de processos } \\
\text { de iniciação }\end{array}$ & $\begin{array}{c}\text { Grupo } \\
\text { de processos } \\
\text { de planejamento }\end{array}$ & $\begin{array}{c}\text { Grupo } \\
\text { de processos } \\
\text { de execuçāo }\end{array}$ & $\begin{array}{c}\text { Grupo } \\
\text { de processos } \\
\text { de monitoramento } \\
\text { e controle }\end{array}$ & $\begin{array}{c}\text { Grupo } \\
\text { de processos } \\
\text { de encerramento }\end{array}$ \\
\hline $\begin{array}{l}\text { 4. Integração } \\
\text { do gerenciamento } \\
\text { de projetos }\end{array}$ & $\begin{array}{l}\text { Desenvolver o termo } \\
\text { de abertura } \\
\text { do projeto } \\
\text { Desenvolver a } \\
\text { declaração do escopo } \\
\text { preliminar do projeto }\end{array}$ & $\begin{array}{l}\text { Desenvolver o plano } \\
\text { de gerenciamento } \\
\text { do projeto }\end{array}$ & $\begin{array}{l}\text { Orientar e gerenciar } \\
\text { a execução } \\
\text { do prcjeto }\end{array}$ & $\begin{array}{l}\text { Monitorar e controlar } \\
\text { o trabalho do projeto } \\
\text { Controle integrado } \\
\text { de mudanças }\end{array}$ & Encerrar o projeto \\
\hline $\begin{array}{l}\text { 5. Gerenciamento } \\
\text { do escopo } \\
\text { do projeto }\end{array}$ & & $\begin{array}{l}\text { Planejamento } \\
\text { do escopo } \\
\text { Definição do escopo } \\
\text { Criar EAP }\end{array}$ & & $\begin{array}{l}\text { Verificaçāo } \\
\text { do escopo } \\
\text { Controle do escopo }\end{array}$ & \\
\hline $\begin{array}{l}\text { 6. Gerenciamento } \\
\text { de tempo } \\
\text { do projeto }\end{array}$ & & $\begin{array}{l}\text { Definição da } \\
\text { atividade } \\
\text { Seqũenciamento } \\
\text { de atividades } \\
\text { Estimativa } \\
\text { de recursos } \\
\text { da atividade } \\
\text { Estimativa } \\
\text { de duração } \\
\text { da atividade } \\
\text { Deservolvimento } \\
\text { do cronograma }\end{array}$ & & $\begin{array}{l}\text { Controle do } \\
\text { cronograma }\end{array}$ & \\
\hline $\begin{array}{l}\text { 7. Gerenciamento } \\
\text { de custos } \\
\text { do projeto }\end{array}$ & & $\begin{array}{l}\text { Estimativa } \\
\text { de custos } \\
\text { Orçamentação }\end{array}$ & & Controle de custos & \\
\hline $\begin{array}{l}\text { 8. Gerenciamento } \\
\text { da qualidade } \\
\text { do projeto }\end{array}$ & & $\begin{array}{l}\text { Planejamento } \\
\text { da qualidade }\end{array}$ & $\begin{array}{l}\text { Realizar a garantia } \\
\text { da qualidado }\end{array}$ & $\begin{array}{l}\text { Realizar o controle } \\
\text { da qualidade }\end{array}$ & \\
\hline $\begin{array}{l}\text { 9. Gerenciamento } \\
\text { de recursos } \\
\text { humanos } \\
\text { do projeto }\end{array}$ & & $\begin{array}{l}\text { Planejamento } \\
\text { de recursos } \\
\text { humanos }\end{array}$ & $\begin{array}{l}\text { Contratar ou } \\
\text { mobilizar } \\
\text { a equipe do projeto } \\
\text { Deservolver a equipe } \\
\text { do projeto }\end{array}$ & $\begin{array}{l}\text { Gerenciar a equipe } \\
\text { do projeto }\end{array}$ & \\
\hline $\begin{array}{l}\text { 10. Gerenciamento } \\
\text { das } \\
\text { comunicações } \\
\text { do projeto }\end{array}$ & & $\begin{array}{l}\text { Planejamento das } \\
\text { comunicações }\end{array}$ & $\begin{array}{l}\text { Distribuição das } \\
\text { informaçōes }\end{array}$ & $\begin{array}{l}\text { Relatório de } \\
\text { desempenho } \\
\text { Gerenciar as partes } \\
\text { interessadas }\end{array}$ & \\
\hline $\begin{array}{l}11 \text { Gerenciamento } \\
\text { de riscos } \\
\text { do projeto }\end{array}$ & & $\begin{array}{l}\text { Planejamento } \\
\text { do gerenciamento } \\
\text { de riscos } \\
\text { Identificação } \\
\text { de riscos } \\
\text { Análise qualitativa } \\
\text { de riscos } \\
\text { Análise quantitativa } \\
\text { de riscos } \\
\text { Planejamento } \\
\text { de respostas } \\
\text { a riscos }\end{array}$ & & $\begin{array}{l}\text { Monitoramento } \\
\text { e controle } \\
\text { de riscos }\end{array}$ & \\
\hline $\begin{array}{l}12 \text { Gerenciamento } \\
\text { de aquisiçōes } \\
\text { do projeto }\end{array}$ & & $\begin{array}{l}\text { Planejar compras } \\
\text { e aquisiçōes } \\
\text { Planejar contrataçōes }\end{array}$ & $\begin{array}{l}\text { Solicitar respostas } \\
\text { de fornecedores } \\
\text { Selecionar } \\
\text { fornecedores }\end{array}$ & $\begin{array}{l}\text { Administração } \\
\text { de contrato }\end{array}$ & $\begin{array}{l}\text { Encerramento } \\
\text { do contrato }\end{array}$ \\
\hline
\end{tabular}

Tabela 1: Mapeamento entre os processos e grupos de processos do gerenciamento de projetos e as áreas de conhecimento Fonte: PMBOK (2004)

A área de integração é a responsável pela sinergia entre as outras áreas. Do gerenciamento da integração são gerados os três principais documentos do projeto (PMBOK, 2004): 
- Termo de abertura do projeto: autorização formal do projeto;

- Declaração do escopo do projeto: aborda as características e limites do projeto e seus produtos associados, além dos métodos de aceitação e controle do escopo;

- Plano de gerenciamento do projeto: determina como o projeto é executado, monitorado, controlado e encerrado. É formado pelos planos e documentos gerados pelos processos relacionados às outras áreas de conhecimento do gerenciamento de projetos. É atualizado e revisado pelo processo de controle integrado de mudanças.

A figura 7 mostra a relação entre os três documentos e as áreas de conhecimento. 


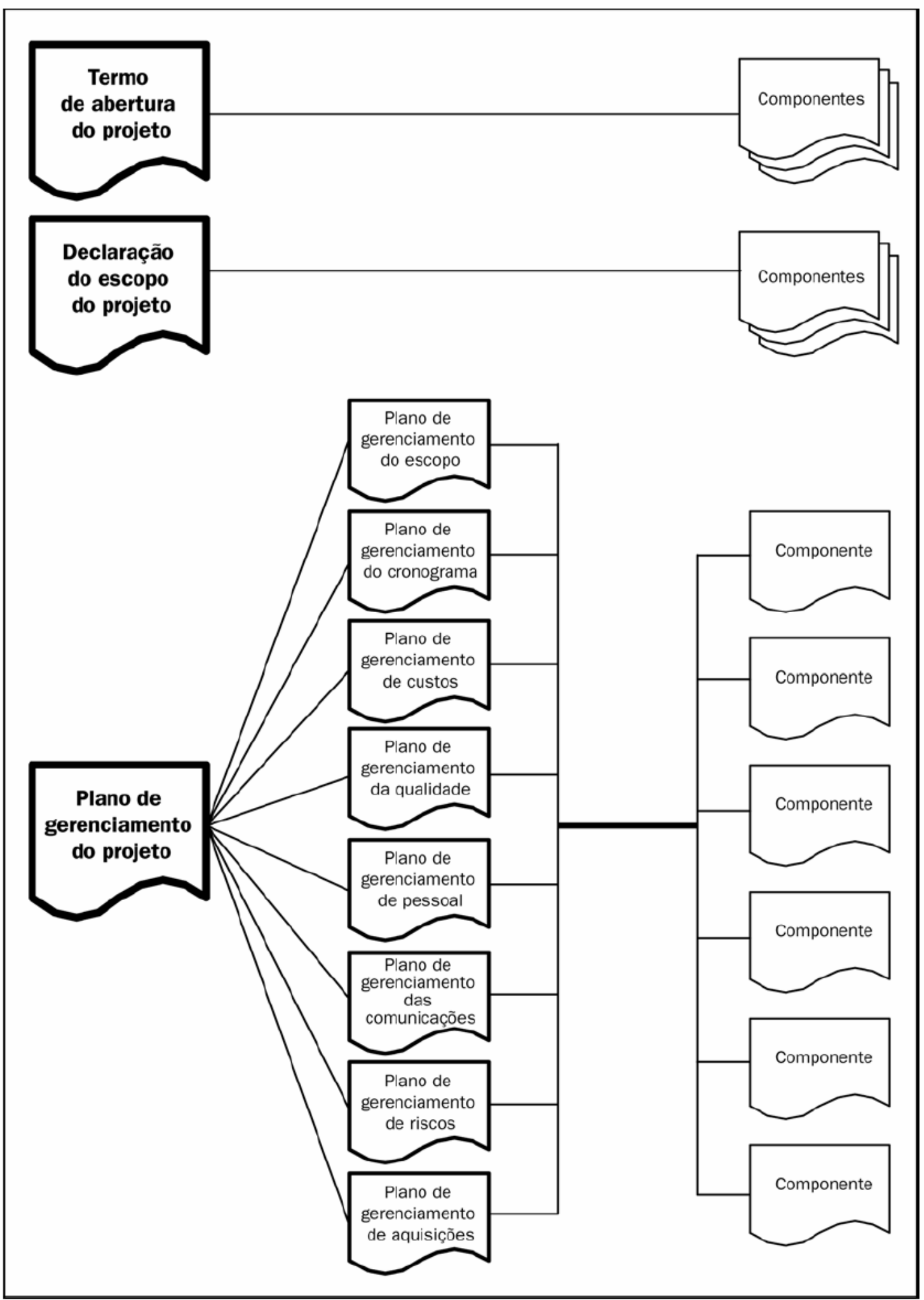

Figura 7: Documentos do projeto e as áreas de conhecimento Fonte: PMBOK (2004) 


\subsubsection{Técnicas utilizadas nos Processos de Gerenciamento de Projetos}

Nos diversos processos existentes dentro dos planos de gerenciamento do projeto, são utilizadas técnicas de apoio, seja para a definição da atividade, medição de desempenho ou mesmo divisão do trabalho do projeto em seus diversos pacotes de trabalho. As principais técnicas são descritas abaixo:

- Análise da Rede: através da dependência entre as atividades, utiliza a precedência entre as atividades para determinar a seqüência das mesmas;

- Método do Caminho Crítico - CPM (Critical Path Method): corresponde à seqüência mais longa possível de atividades entre o início e o fim do projeto; o aumento na duração de uma das atividades do caminho aumenta o tempo total do projeto.

- Gráfico de Gantt: uma representação gráfica de informações relacionadas ao cronograma. Em um gráfico de barras típico, as atividades do cronograma ou os componentes da estrutura analítica do projeto são listados verticalmente no lado esquerdo do gráfico, as datas são mostradas horizontalmente na parte superior e as durações das atividades são exibidas como barras horizontais posicionadas de acordo com as datas (PMBOK, 2004).

- Técnica de Avaliação e Revisão de Programas (Projetos) PERT (Program Evaluation and Review Technique): cálculo de cronogramas a partir da análise de rede e do caminho crítico considerando aspectos de tempo com medidas incertas, custos e recursos. Em tempos anteriores era considerado praticamente sinônimo de gerenciamento de projetos, mas, na atualidade, os cálculos envolvidos são realizados por computadores e o aprendizado da técnica está mais envolvido no entendimento do uso eficiente do tempo, recursos e custo dentro do projeto;

- $\quad$ Análise do Valor Agregado: uma metodologia de gerenciamento usada para integrar o escopo, o cronograma e os recursos e para medir objetivamente o desempenho e o progresso do projeto. Para medir o desempenho, o custo orçado do trabalho realizado (ou seja, o valor agregado) é determinado e comparado ao custo 
real do trabalho realizado (ou seja, o custo real). O progresso é medido pela comparação entre o valor agregado e o valor planejado (PMBOK, 2004).

\subsection{Gerenciamento da Configuração de Produtos}

O sucesso de um projeto de desenvolvimento de um novo produto é altamente dependente do gerenciamento da configuração, como visto na seção 2.2, em processos como no planejamento do projeto, controle de mudanças, escopo e cronograma e comunicações PMBOK (2004). Esta seção trata das definições, áreas de conhecimento, itens da configuração, atividades e análise comparativa dos sistemas relacionados ao gerenciamento da configuração do produto.

\subsubsection{Definições}

SAMARAS \& CZERWINSKI (1971) são os responsáveis pela definição clássica do termo configuração do produto: "uma descrição completa do conjunto de características físicas do produto (peso, forma, tamanho, materiais, processos, etc) e seu desempenho (série de medições, precisão, estabilidade, confiabilidade, etc.)"; para RANDOM (1980), configuração corresponde aos componentes de um produto resultando na sua conformação externa. A palavra configuração é originada do latim com (com, junto) e figurare (formar), o que leva ao significado de como um determinado produto é formado pela junção de suas partes; de maneira mais formal corresponde ao arranjo relativo dos componentes ou elementos de um produto.

Com base em LYON (2000), pode-se definir gerenciamento da configuração do produto (CM - Configuration Management) como 0 processo de gerenciar as alterações do produto incluindo projeto, desenvolvimento, integração, teste, produção, distribuição, manutenção e suporte. Em outras palavras, gerencia as alterações e integrações geradas por ações técnicas e administrativas sobre as características do produto em todo o seu ciclo de vida (SAMARAS \& CZERWINSKI, 1971). Para MIL-HDBK-61 (2005), corresponde ao processo de estabelecer e manter a consistência do desempenho de um produto, seus atributos físicos e funcionais com seus 
requisitos, projetos gráficos e informação operacional ao longo do seu ciclo de vida. É a identificação única do produto com armazenamento controlado, controle de mudanças e registro de status do produto e seus componentes durante todo o seu ciclo de vida.

O objetivo geral do gerenciamento da configuração é garantir ao comprador que o respectivo produto corresponda exatamente às suas expectativas (funcionalmente e fisicamente como definido pelos desenhos e especificações contratuais) garantindo performance, qualidade e confiabilidade equivalentes nos futuros produtos do mesmo tipo a serem fabricados. Para SAMARAS \& CZERWINSKI (1971) os cinco maiores fatores para atingir esse objetivo geral são:

- Definição de toda a documentação necessária para o projeto do produto, fabricação e teste;

- Descrições completas e corretas da configuração aprovada que incluem desenhos, listas de peças, especificações, procedimentos de teste e manuais de operação;

- Rastreabilidade do produto resultante e seus componentes às suas descrições;

- Identificação completa e precisa de cada material, peça, item semi-acabado e acabado relacionados ao produto;

- Cadastro e controle precisos e completos de todas as alterações nas descrições do produto e no produto em si.

\section{Fases do Ciclo de Vida de Obtenção do Produto}

O gerenciamento da configuração opera em todas as fases do ciclo de vida para obtenção do produto: da concepção à produção, distribuição e suporte (MIL-HDBK-61, 2005) como pode ser visto na figura 8: 


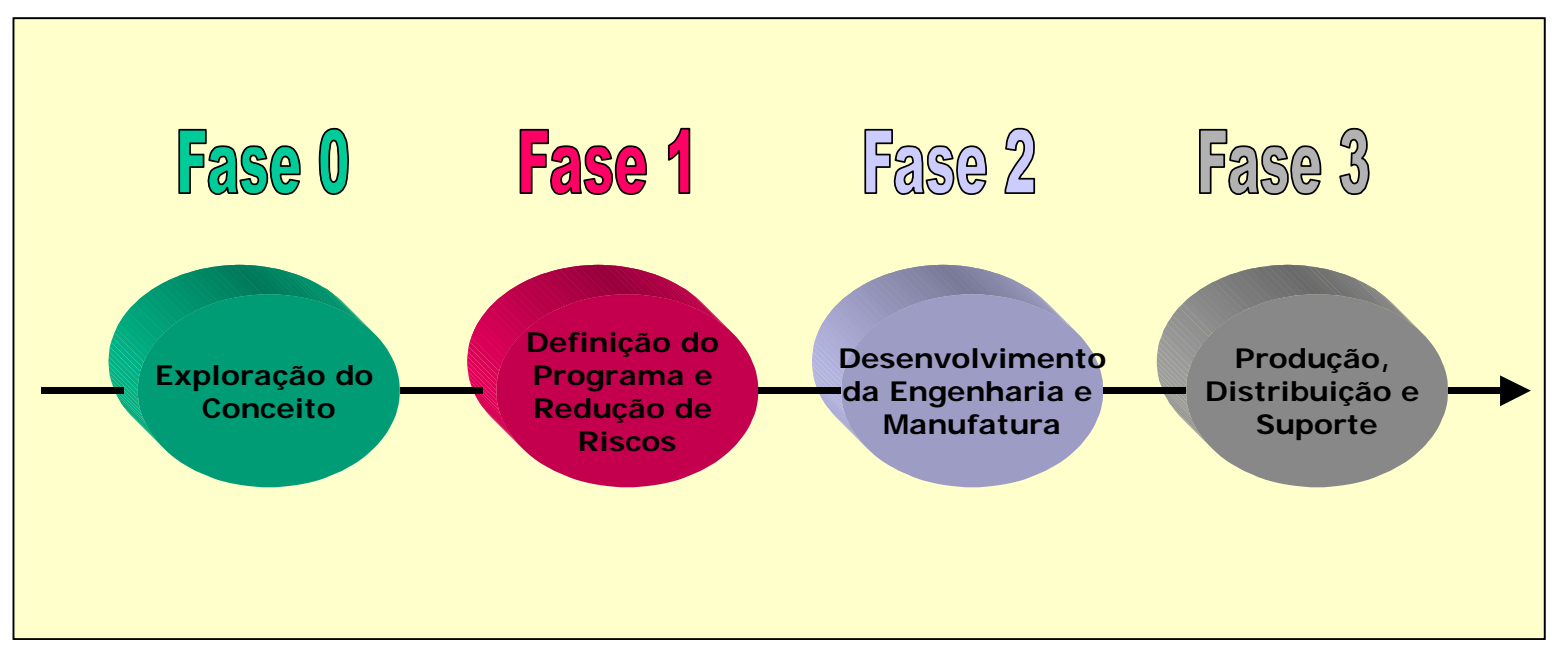

Figura 8: Fases do Ciclo de Vida para o Gerenciamento da Configuração Fonte: MIL-HDBK-61 (2005)

CMBOK (2006) descreve as fases da seguinte forma:

- Fase 0: estudo conceitual com o propósito de identificar, definir e avaliar as vantagens, desvantagens, riscos, custos, etc. de conceitos operacionais promissores e alternativas de design para o produto;

- Fase 1: definição e refinamento do(s) conceito(s) e das alternativas mais promissoras; as funcionalidades levantadas são decompostas em subsistemas de níveis mais baixos;

- Fase 2: finalização de um projeto estável para um produto que obtém os requisitos de desempenho e tem capacidade de ser produzido, distribuído e suportado. As capacidades do produto são demonstradas através de testes de validação de pressupostos de projeto e o planejamento de distribuição é iniciado;

- Fase 3: correção das deficiências encontradas durante as atividades de teste e avaliação da fase 2 início da produção e distribuição do produto.

\subsection{2 Áreas de Conhecimento do Gerenciamento da Configuração}

Como no caso do gerenciamento dos projetos, as áreas de conhecimento envolvidas no gerenciamento da configuração do produto 
correspondem aos diversos campos do conhecimento com suas técnicas e habilidades utilizadas no gerenciamento da configuração. São elas (CMBOK, 2006):

- Planejamento da Configuração: forma que uma solução de CM pode ser implementada e quais os pontos-chave devem ser estabelecidos. Composto de 4 fases: preparação, transição, implementação e adaptação/melhoria contínua;

- Ferramentas: há uma grande variedade no uso e nas características individuais das ferramentas utilizadas no gerenciamento da configuração que incluem tanto software como hardware. Podem ser reunidas num único sistema chamado de Sistema de Gerenciamento de Configuração (Configuration Management System), ou como um subsistema do sistema de gerenciamento de projetos global, que corresponde a um conjunto de procedimentos formais documentados usados para: aplicar orientação e supervisão técnico-administrativas para identificar e documentar as características funcionais e físicas de um produto, resultado, serviço ou componente; controlar quaisquer mudanças feitas nessas características; registrar e relatar cada mudança e o andamento de sua implementação e dar suporte à auditoria dos produtos, resultados ou componentes para verificar a conformidade com os requisitos. Exemplos de sistemas de gerenciamento da configuração são os sistemas PDM (Product Data Management - Gerenciamento dos Dados do Produto) e os sistemas PLM (Product Lifecycle Management Gerenciamento do Ciclo de Vida do Produto). Isoladamente ou reunidas num único sistema, as ferramentas de gerenciamento da configuração basicamente se dividem em 5 categorias:

- Controle de versão: sistema de controle de mudanças composto responsável pela definição de como as entregas e a documentação são controladas, alteradas e aprovadas. Como exemplo, nos sistemas de tecnologia da informação, um sistema de controle de mudanças pode incluir as especificações (scripts, código fonte, linguagem de 
definição de dados, etc.) de cada componente de software; inclui também repositório de dados acessado através das funcionalidades de check-in (inclusão) e check-out (retirada) e utilizado para criação das linhas de base do projeto e geração de relatórios efetivos para controle de mudanças;

- Automação do registro de rastreamento de problemas: a gravação dos problemas ocorridos e as ações corretivas tomadas diminuem drasticamente a quantidade total de problemas no sistema ou projeto e provém efetividade nas informações relacionadas ao controle de status;

- Automação da biblioteca: sistemas de rastreamento para os arquivos físicos do sistema e áreas de armazenamento de dados. Normalmente são sistemas caseiros utilizando o banco de dados e software que estiver disponível para a equipe responsável pelo gerenciamento da configuração. Basicamente trata da identificação, autorização de acesso de um usuário a uma determinada informação armazenada e sua respectiva recuperação;

- Gerenciamento do fluxo de trabalho: automatiza a seqüência de processos para o projeto como um todo. Pode gerar altos ganhos no caso de problemas de processamento por reduzir o tempo de espera para o processo seguinte a ser iniciado;

- Gerenciamento de requisitos: normalmente é desenvolvido localmente ou comprado à parte. Pode ser simples como uma planilha ou uma ferramenta de análise de requisitos inter-relacionados gerando documentação de requisitos;

- $\quad$ Atividades: as principais correspondem à identificação, controle, registro de status e auditoria (tratadas na seção 2.3.3);

- Projeto: relação com atividades do gerenciamento do projeto como planejamento do projeto, estimativas, métricas, orçamento e controles de custo (tratada na seção 2.3.5); 
- Riscos: processo sistemático de identificar, analisar e responder ao risco, maximizando a possibilidade de eventos positivos e minimizando a possibilidade de eventos negativos;

- Aquisição: processo de adquirir consultoria, ferramentas, sistemas envolvendo o gerenciamento da configuração, similarmente ao processo homônimo do gerenciamento de projetos;

- Métricas: a coleção de dados para medição envolve 3 fatores: qual informação o gerenciamento de projetos requer para a tomada de decisão no devido momento; qual informação o gerenciamento da configuração necessita para monitorar o fluxo de trabalho, processos, qualidade, etc. e finalmente o direcionamento e motivação envolvidos como, por exemplo, o padrão CMM nível 4.

\subsubsection{Atividades da Configuração de Produtos}

Como já visto na seção anterior, o gerenciamento da configuração é composto por atividades distintas, mas inter-relacionadas, no sentido do atingir o objetivo de manter a consistência do desempenho do produto e controlar suas alterações. A figura 9 mostra uma visão geral das principais atividades relacionadas ao gerenciamento da configuração e o seu relacionamento com o ciclo de vida do produto: 


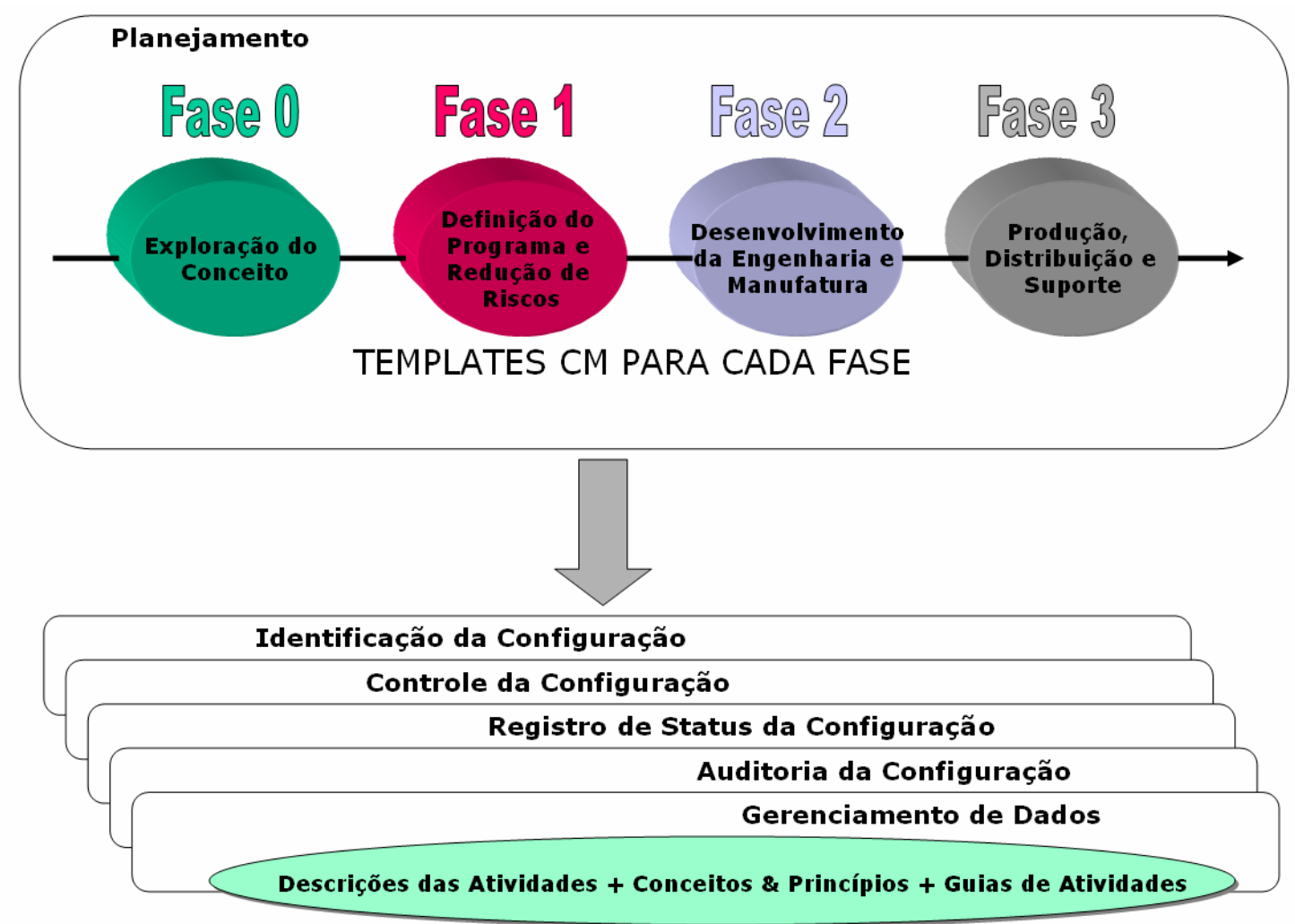

Figura 9: Ciclo de vida do produto e atividades do gerenciamento. da configuração

Fonte: MIL-HDBK-61 (2005)

\subsubsection{Identificação}

De acordo com MIL-HDBK-61 (2005), a identificação da configuração estabelece e mantém, progressivamente, a base definitiva atual para o controle e registro de status de um sistema e dos seus itens da configuração por todo o seu ciclo de vida. É responsável pela criação e liberação formal de toda a documentação técnica.

LYON (2000) define item da configuração como um objeto físico que se deseja identificar e controlar através do seu ciclo de vida; para MIL-HDBK-61 (2005) corresponde a unidade básica do gerenciamento da configuração onde será associada a documentação, controle de mudanças, registro de status e como a auditoria será conduzida.

A atividade de identificação inclui (MIL-HDBK-61, 2005): 
- Seleção dos itens da configuração nos níveis apropriados da estrutura de produto para facilitar a documentação, controle e suporte;

- Permissão de várias visões a partir da mesma estrutura incluindo hardware, software, serviços, dados e facilidades para a coleta relacionada a custos.

- Determinação do tipo de documentação para cada item da configuração visando definir parâmetros de performance, atributos físicos e funcionais;

- Determinação da autoridade apropriada de controle da configuração para cada documento consistente com o planejamento de suporte logístico para o item da configuração associado;

- Geração de identificadores para os Cl's e para a documentação da configuração;

- Manutenção dos identificadores e liberação de acesso à documentação da configuração;

- Geração de linhas de base para a atividade de controle da configuração dos itens da configuração.

\subsubsection{Controle}

O controle da configuração é o procedimento sistemático para proposição, avaliação, coordenação e submissão das alterações de configuração do produto à aprovação. De acordo com MIL-HDBK-61 (2005) as principais funções desta atividade são:

- Permissão de ótimo posicionamento do projeto e desenvolvimento em relação ao grau apropriado e profundidade dos procedimentos de alterações durante o ciclo de vida de um item da configuração;

- Processamento e implementação eficientes de alterações da configuração que mantêm ou aumentam a disponibilidade, resistência, capacidade de troca e interoperabilidade; 
- Garantia de alterações completas, precisas e pontuais na documentação gerenciadas pela autoridade apropriada de controle da configuração;

- Eliminação da proliferação de alterações desnecessárias.

\subsubsection{Registro de Status}

Corresponde à criação e organização da base de conhecimento necessária para a performance do gerenciamento da configuração. Além disso, provém alta confiabilidade na origem da informação da configuração para suportar todas as atividades do programa/projeto incluindo gerenciamento do programa, engenharia de sistemas, fabricação, desenvolvimento e manutenção de software, suporte logístico, modificação e manutenção MIL-HDBK-61 (2005). As principais tarefas são:

- Registro da documentação da configuração atual aprovada e os identificadores associados a cada item da configuração;

- Registro e relação do status de alterações de engenharia propostas do início à aprovação final para implementação contratual;

- Registro e relação do status de todas as maiores e críticas requisições para alterações, as quais afetam a configuração de um item da configuração;

- Registro e relação dos resultados de auditorias da configuração para incluir o status e disposição final de discrepâncias identificadas e ações tomadas;

- Registro e relação do status de implementação de alterações autorizadas;

- Rastreabilidade de todas as alterações sobre a documentação original da configuração liberada de cada item da configuração;

- Relação da efetividade e status da instalação de alterações na configuração para todo o sistema e itens da configuração em todos os locais, incluindo alterações de projeto, produção, modificação, aperfeiçoamento e de manutenção; 
- Registro dos identificadores dos arquivos digitais e representações documentais de todas as versões dos documentos e software que tenham sido distribuídos, ou tornado acessíveis eletronicamente, no suporte do contrato.

\subsubsection{Auditoria}

Esta atividade corresponde a verificar se as funcionalidades física e funcional do produto estão dentro das especificações e requisições de alteração através de operações e testes (CMBOK, 2006). Estabelece um alto nível de confiança na documentação da configuração utilizada como base para o controle da configuração e também serve como suporte do produto através de todo o seu ciclo de vida. Nesta atividade, as principais funções são (MILHDBK-61, 2005):

- Verificação da configuração inicial de um item da configuração e da incorporação de alterações de engenharia aprovadas, para garantir que $o$ item atinja os requisitos de desempenho $\mathrm{e}$ requisitos da configuração documentados;

- Auditoria dos registros da verificação da configuração e do produto físico para validar que um programa de desenvolvimento alcance seus requisitos de performance e a documentação ou item da configuração sendo auditado é consistente com os requisitos previstos para o produto.

\subsection{A estrutura de decomposição do trabalho (EAP - WBS) e seu papel no controle de projetos.}

Com o plano de gerenciamento do projeto é gerada uma estimativa inicial das atividades a serem realizadas juntamente com o tempo e recursos a serem gastos. Como visto na tabela 1 (seção 2.2.3.3), este processo pertence ao grupo que sucede ao dos processos de iniciação.

Os resultados do projeto correspondem às entregas (do inglês, deliverables) produzidas pelo mesmo em suas diversas fases culminando com o produto final e cuja apuração, dentro do projeto, é parte central da proposta deste trabalho. Incluem tanto as saídas que compõem o produto ou serviço do 
projeto, como os resultados auxiliares, como documentação e relatórios de acompanhamento (PMBOK, 2004). Para viabilizar esta apuração é necessário definir quais resultados se quer alcançar e controlar quando os mesmos estarão finalizados e quais os recursos responsáveis. Observando novamente a tabela 1 verifica-se que estas respostas são obtidas dentro dos grupos de processos responsáveis pela definição do trabalho a ser feito e em seguida pela apuração do quanto foi realizado comparado ao que foi previsto. Estes processos correspondem, no foco deste trabalho, aos processos de planejamento e monitoramento e controle e são resumidos abaixo:

- Planejamento:

- Integração: plano de Gerenciamento do Projeto responsável por determinar como 0 trabalho e 0 gerenciamento da configuração serão realizados;

- Escopo: criação da WBS;

- Tempo: definição, seqüenciamento e duração da atividade, estimativa de recursos e cronograma;

- Monitoramento e Controle:

- Integração: monitoramento e controle do trabalho do projeto, controle integrado de mudanças;

- Escopo: verificação e controle do escopo;

- Tempo: controle do cronograma,

- Comunicações: relatórios de desempenho.

A finalidade deste trabalho é propor uma interface para apontamento de resultados através da integração das atividades da WBS do projeto e a configuração do produto e, dessa forma, serão detalhados os processos relacionados à WBS: o planejamento do escopo e do tempo e os requisitos que a WBS deve suportar para atender às funcionalidades previstas na interface. Os processos relacionados à configuração do produto, basicamente os que envolvem definição e controle do trabalho dentro do projeto, serão descritos na seção 2.5 dedicada ao gerenciamento da configuração do projeto. 


\subsubsection{Planejamento do Escopo: Criação da WBS}

De acordo com PMBOK (2004, p. 112), a WBS é "a decomposição hierárquica orientada à entrega do trabalho a ser executado pela equipe do projeto, para atingir os objetivos do projeto e criar as entregas necessárias" sendo assim responsável pela organização e definição do escopo total do projeto. A sigla WBS derivada do inglês Work Breakdown Structure e também é conhecida como EAP - Estrutura Analítica do Projeto (PMBOK, 2004) - e EDT - Estrutura de Desmembramento do Trabalho (VERZUH, 2000).

A WBS subdivide o projeto em suas partes menores e mais facilmente gerenciáveis (PMBOK, 2004), de forma que cada nível descendente representa uma definição cada vez mais detalhada do projeto até chegar ao nível mais baixo da WBS chamado de pacote de trabalho (veja figura 10). Neste nível, o custo e o cronograma do trabalho podem ser estimados de forma confiável (PMBOK, 2004) Esta subdivisão é base do planejamento do projeto, ou seja, todos os outros planos de gerenciamento nela se baseiam e, se bem realizada, pode se transformar no segredo do sucesso de um projeto (VERZUH, 2000). O autor lista as seguintes facilidades derivadas da criação da WBS:

- Fornecimento de uma ilustração detalhada do escopo do projeto: embora a declaração do projeto defina o escopo no nível conceitual, uma visão abrangente do escopo do projeto pode ser obtida somente com uma WBS;

- Monitoramento do progresso: os pacotes de trabalho da WBS transformam-se na base da monitoria do progresso já que cada uma é uma unidade mensurável do trabalho;

- Criação de estimativas precisas de custos e cronogramas: a WBS irá detalhar os custos de equipamento, mão-de-obra e materiais de cada tarefa;

- Monitoramento das equipes de projeto: cada membro da equipe quer receber atribuições claras dos trabalhos e o sentido do modo como seu trabalho se encaixa no trabalho geral. Uma boa WBS faz as duas coisas e, caso a participação dos membros 
na construção da WBS seja possível, obtém-se um aumento no comprometimento da equipe com o planejamento.

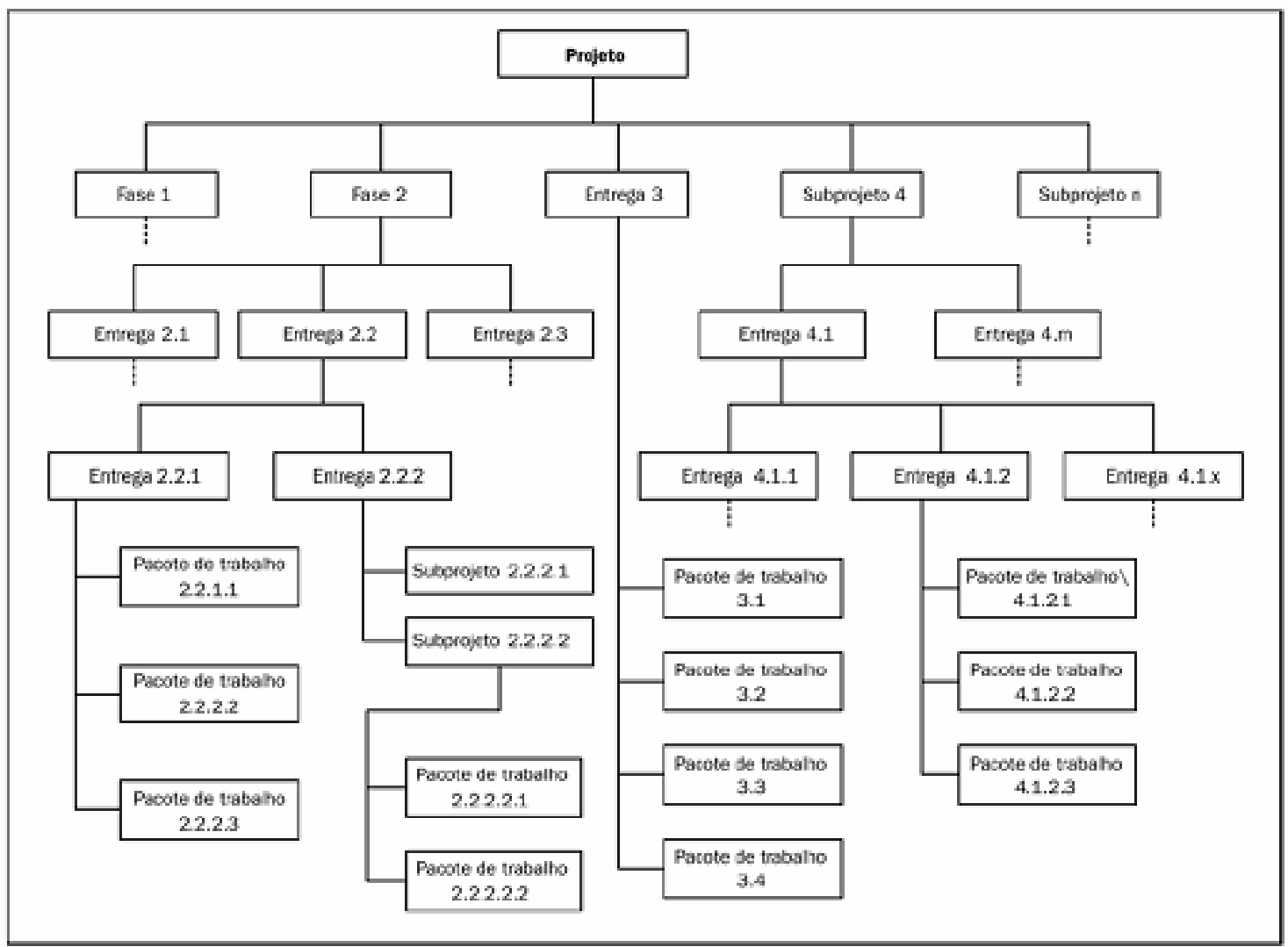

Figura 10: Exemplo de WBS

Fonte: PMBOK (2004)

É necessário reconhecer quais entregas necessitam de maior ou menor nível de decomposição, pois níveis excessivos muito detalhados podem gerar um esforço de gerenciamento improdutivo, com ineficiência no uso de recursos e realização do trabalho. Para PMBOK (2004), a decomposição do trabalho normalmente contém as seguintes atividades:

- Identificação das entregas e do trabalho realizado;

- Estruturação e organização da WBS;

- Decomposição dos níveis mais altos da WBS em componentes de nível mais baixo (ver seção 2.4.1.1);

- Desenvolvimento e atribuição de códigos de identificação aos componentes da WBS; 
- Verificar se o grau de decomposição do trabalho é necessário e suficiente.

Uma WBS de um projeto anterior pode ser usada como um modelo para a criação de um novo projeto até porque é comum, dentro de uma organização, setor ou área de aplicação, os projetos possuírem uma estrutura padronizada relacionada ao modelo de ciclo de vida de projeto adotado. A estruturação e a organização das entregas e dos pacotes de trabalho dentro da WBS podem variar de acordo com as necessidades de controle e gerenciamento o que acaba por gerar diferentes modelos de WBS como, por exemplo, usar as principais entregas e subprojetos como primeiro nível (figura10); usar as fases do ciclo de vida como primeiro nível e as entregas no segundo nível (figura 11), ou ainda usar os diversos componentes do produto final do projeto para estruturar a decomposição (figura 12).

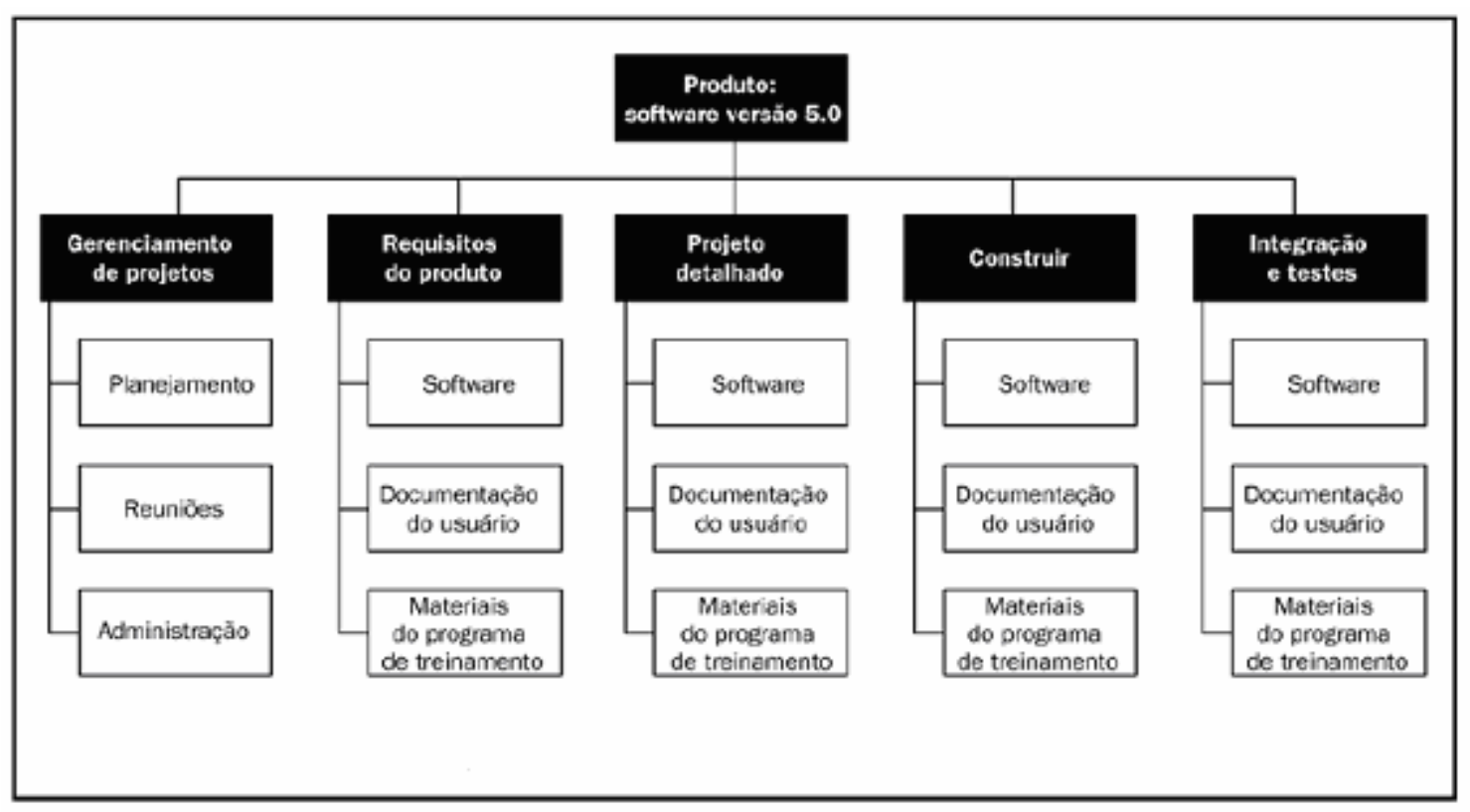

Figura 11: Exemplo de WBS estruturada por fase Fonte: PMBOK (2004) 


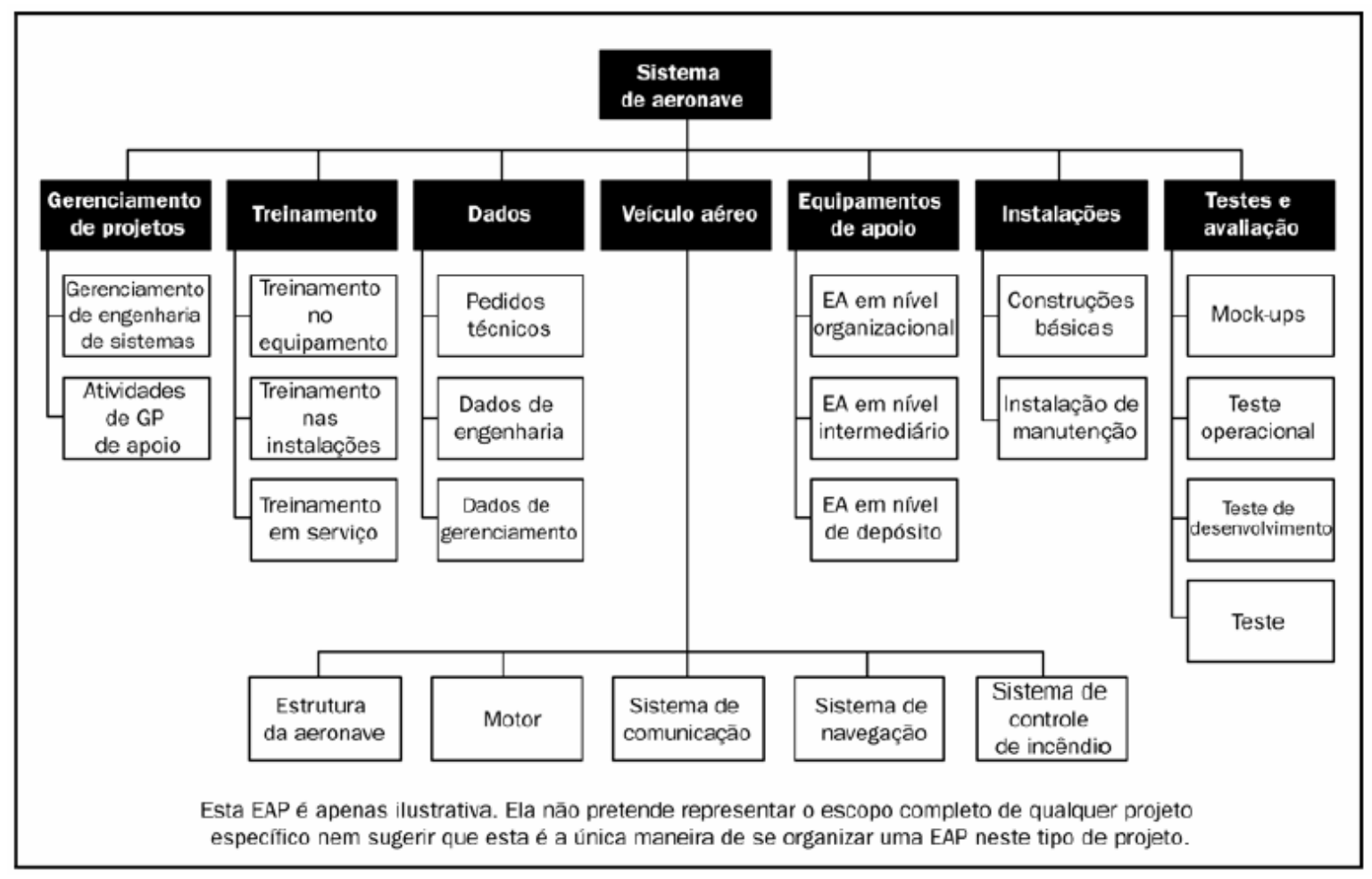

Figura 12: Exemplo de WBS organizada pelos itens do sistema de aeronave

Fonte: PMBOK (2004)

\subsubsection{Detalhamento da WBS}

A WBS do projeto pode representar qualquer combinação entre entregas e pacotes de trabalho. Pode haver inúmeros modos de subdividir o trabalho do projeto em uma hierarquia de pacotes de trabalho e o critério básico é facilitar o fluxo do trabalho e manter as atividades sincronizadas; em seguida, é realizada a ordenação dos pacotes de trabalho e utilizadas ferramentas como o caminho crítico, que calcula as possíveis datas de início e término para cada pacote (ICM, 2003).

Na seção anterior foram mostrados alguns exemplos de WBS seguindo diferentes critérios de divisão. De acordo PMI (2001), a criação da WBS deve partir da identificação das principais entregas e sua decomposição deve ser realizada até alcançar o nível de pacotes de trabalho gerenciáveis. Além disso, existem alguns fatores a serem observados PMI (2001):

- Cada elemento da WBS deve representar uma única e tangível entrega; 
- Cada elemento da WBS deve representar uma subordinação de todos os elementos listados diretamente abaixo dele;

- Cada elemento subordinado deve pertencer a um único pai;

- As entregas deverão ser logicamente decompostas até o nível que representa como eles serão produzidos (pacotes de trabalho);

- As entregas deverão ser claramente definidas para eliminar a duplicação de esforços dentro dos elementos da WBS, através das organizações ou entre os responsáveis pela finalização do trabalho;

- As entregas devem ter seu tamanho limitado, dentro do possível, para facilitar o controle e gerenciamento;

- Todos os elementos da WBS deverão ser compatíveis com as estruturas organizacionais;

- Um esquema de codificação representando uma estrutura hierárquica deve ser usado para os elementos da WBS.

Seguindo estes fatores e, conforme observado em ICM (2003), uma WBS baseada na divisão do projeto em seus componentes principais, não é recomendada, pois torna o fluxo de trabalho e o controle de mudanças mais complexo. A figura 13 descreve esta abordagem e torna claro o gerenciamento fica orientado às atividades de alto nível e quaisquer alterações necessárias em itens pertencentes a uma atividade posterior, envolverá um novo esforço de gerenciamento para as atividades anteriores e os itens que requisitarem alterações. A idéia, ainda segundo ICM (2003) e que é utilizada como referencial para este trabalho, é estender a WBS de forma a relacionar os pacotes de trabalho diretamente aos itens da configuração facilitando o fluxo de trabalho, ordenação e também o controle de mudanças. Dessa forma, todo o trabalho realizado sobre os componentes do produto pode ser relacionado aos pacotes de trabalho realizado fornecendo um acompanhamento automático da execução das atividades do projeto.

As seções 4 e 5 descreverão a modelagem e aplicação prática dos fatores relacionados ao detalhamento da WBS do projeto. 


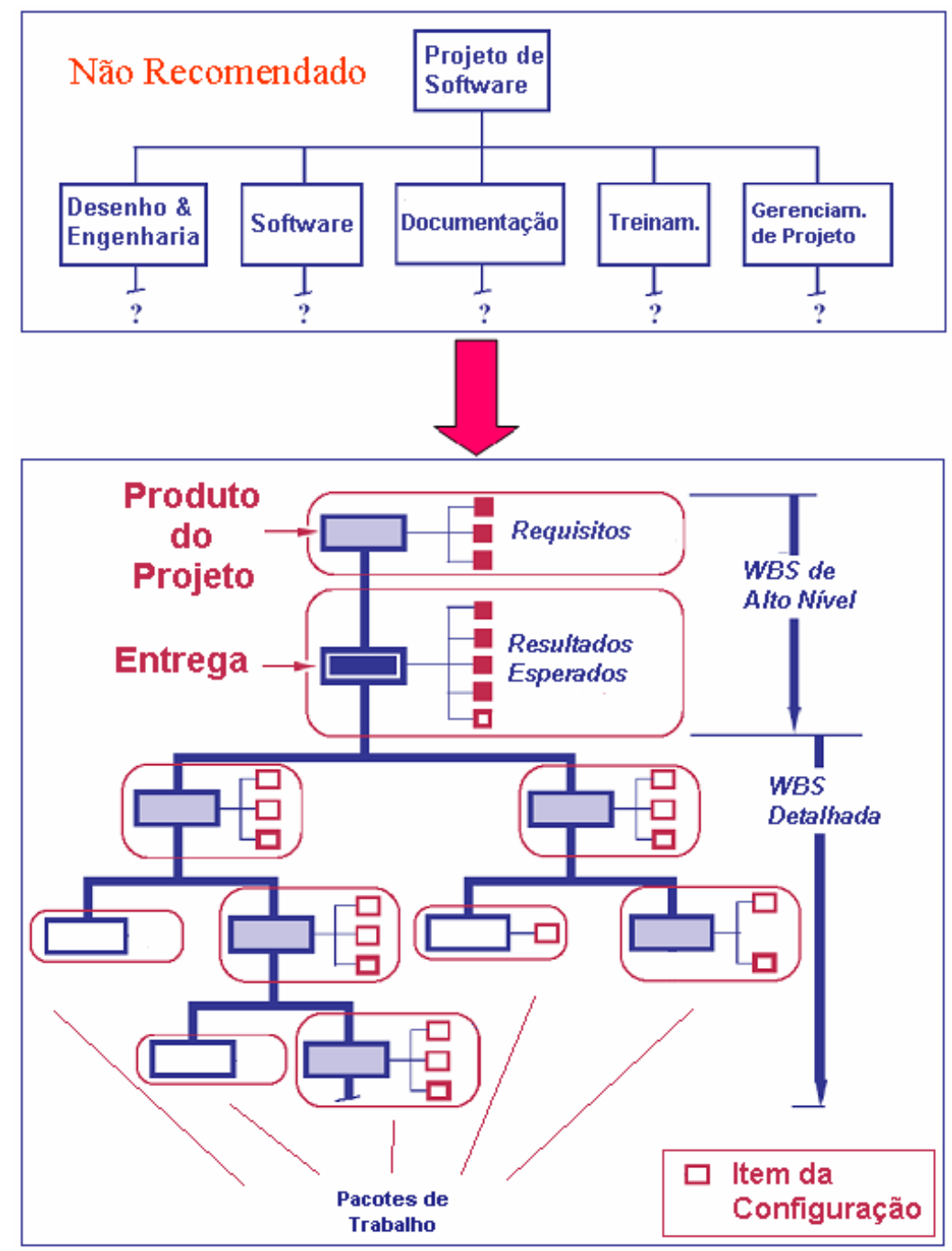

Figura 13: Detalhamento da WBS

Fonte: Adaptado de ICM (2003)

\subsubsection{Planejamento do Tempo do Projeto}

O planejamento do tempo do projeto envolve todos os processos requeridos para que o projeto seja concluído dentro do prazo previsto. Está relacionado ao objetivo deste trabalho, pois o constituirá a base para a medição do trabalho realizado e restante de um projeto e sua comparação com as quantidades aqui previstas. Basicamente, refere-se às definições envolvendo a decomposição dos pacotes de trabalho definidos na seção anterior em componentes menores chamados de atividades (PMBOK, 2004) e, além disso, do desenvolvimento e controle do cronograma. Seus processos são descritos abaixo: 
- Definição da atividade: identificação e decomposição dos pacotes de trabalho em componentes menores - as atividades do cronograma no intuito de fornecer base para a estimativa, elaboração de cronogramas, execução, e monitoramento e controle do trabalho do projeto;

- Seqüenciamento das atividades: identificação e documentação dos relacionamentos lógicos entre as atividades (PMBOK, 2004). As atividades identificadas são colocadas na seqüência correta, ou seja, quais atividades possuem dependência entre si e quais podem ser realizadas simultaneamente (VERZUH, 2000). Uma ferramenta bastante utilizada para o seqüenciamento de atividades é método de diagrama de precedências (MDP), que utiliza retângulos, chamados nós, para representar as atividades, e os conectam por setas para mostrar as dependências entre as atividades (figura 14). Os tipos de dependência são (VERZUH, 2000):

- Término para início: a iniciação da atividade sucessora depende do término da atividade antecessora;

- Início para início: a iniciação da atividade sucessora depende da iniciação da atividade antecessora;

- Término para término: o término da atividade sucessora depende do término da atividade antecessora;

- Início para término: a iniciação da atividade sucessora depende do término da atividade antecessora (menos comum); 


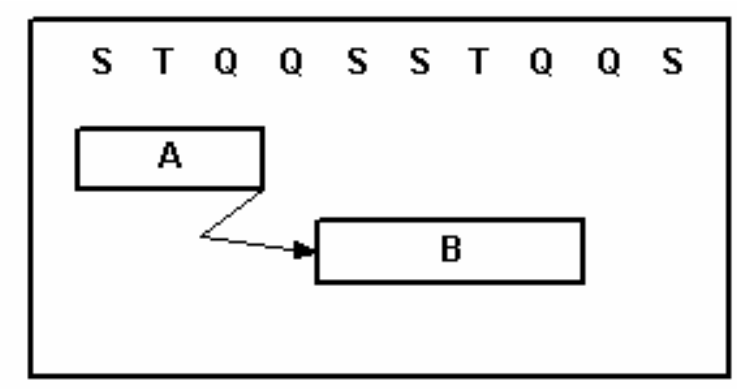

A atividade A precisa terminar antes da atividade B poder começar

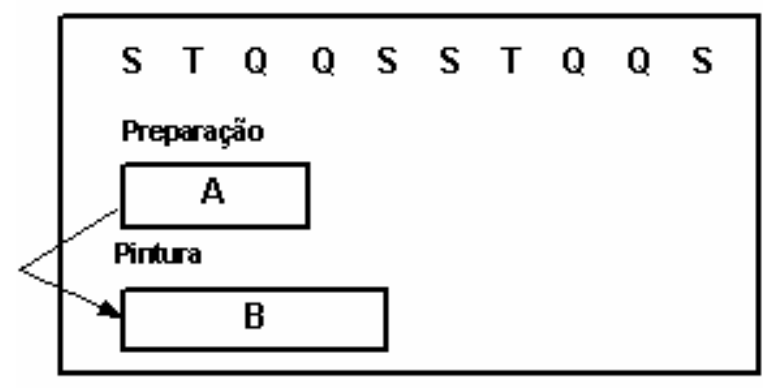

A atividade $A$ precis a começar antes da atividade $B$ poder começar

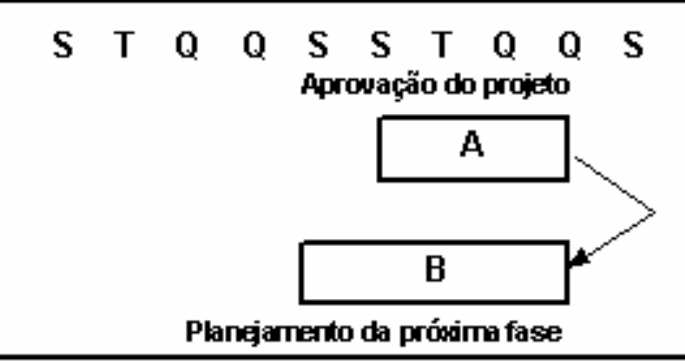

A atividade A precisa terminar antes da atividade $B$ poder terminar

Figura 14: Exemplos de Relações de precedência entre as atividades

Fonte: VERZUH (2000)

- Estimativa de recursos da atividade: o cronograma deve ser ajustado de acordo com a limitação de recursos (pessoas, equipamentos ou material) visando otimizar o uso dos mesmos (VERZUH, 2000) e também com a disponibilidade dos mesmos para a realização das atividades (PMBOK, 2004). O objetivo é usar de maneira consistente e contínua o menor número possível de recursos evitando a remoção e adição de recursos várias vezes durante o projeto e também alocação excessiva ou insuficiente;

- Estimativa de duração da atividade: deve haver uma estimativa sobre a quantidade de mão-de-obra, equipamentos e matérias- 
primas necessários para a duração da tarefa. Normalmente as estimativas de mão-de-obra e equipamentos são expressas em horas e, dependendo do projeto, as de matéria-prima podem nem existir, como no caso de projetos de software. Há também casos de orçamento de preço fixo, como nas terceirizações, onde o orçamento pode já incluir a mão-de-obra, equipamentos e matérias-primas no preço final (VERZUH, 2000; PMBOK, 2004).

- Desenvolvimento e controle do cronograma: determina as datas de início e término das atividades do projeto (PMBOK, 2004). Com a duração de cada atividade calculada e a seqüência de tarefas determinada, torna-se possível calcular a duração total do projeto (VERZUH, 2000), embora possa ser revisto em etapas posteriores ao planejamento, caso haja algum problema com recursos, custos ou mesmo escopo do projeto (VERZUH, 2000; PMBOK, 2004). Nesta etapa, são utilizadas várias técnicas como a técnica de avaliação e revisão de programas (PERT - Program Evaluation and Revision Tecnique, baseada na análise dos diagramas de rede); o método do caminho crítico (CPM - Critical Path Method) para calcular as máximas faixas de tempo onde cada atividade deve ser agendada com recursos ilimitados e a análise WHAT-IF que calcula diversos cenários para o projeto com influências de fatores como atrasos e antecipações de atividades (PMBOK, 2004). .Estas técnicas são voltadas ao cálculo do cronograma; já para a visualização, a ferramenta mais utilizada é o gráfico de Gantt, que reúne tanto informações do cronograma, quanto dos relacionamentos das atividades num gráfico de barras dentro de uma linha do tempo, como mostrado na figura 15. 


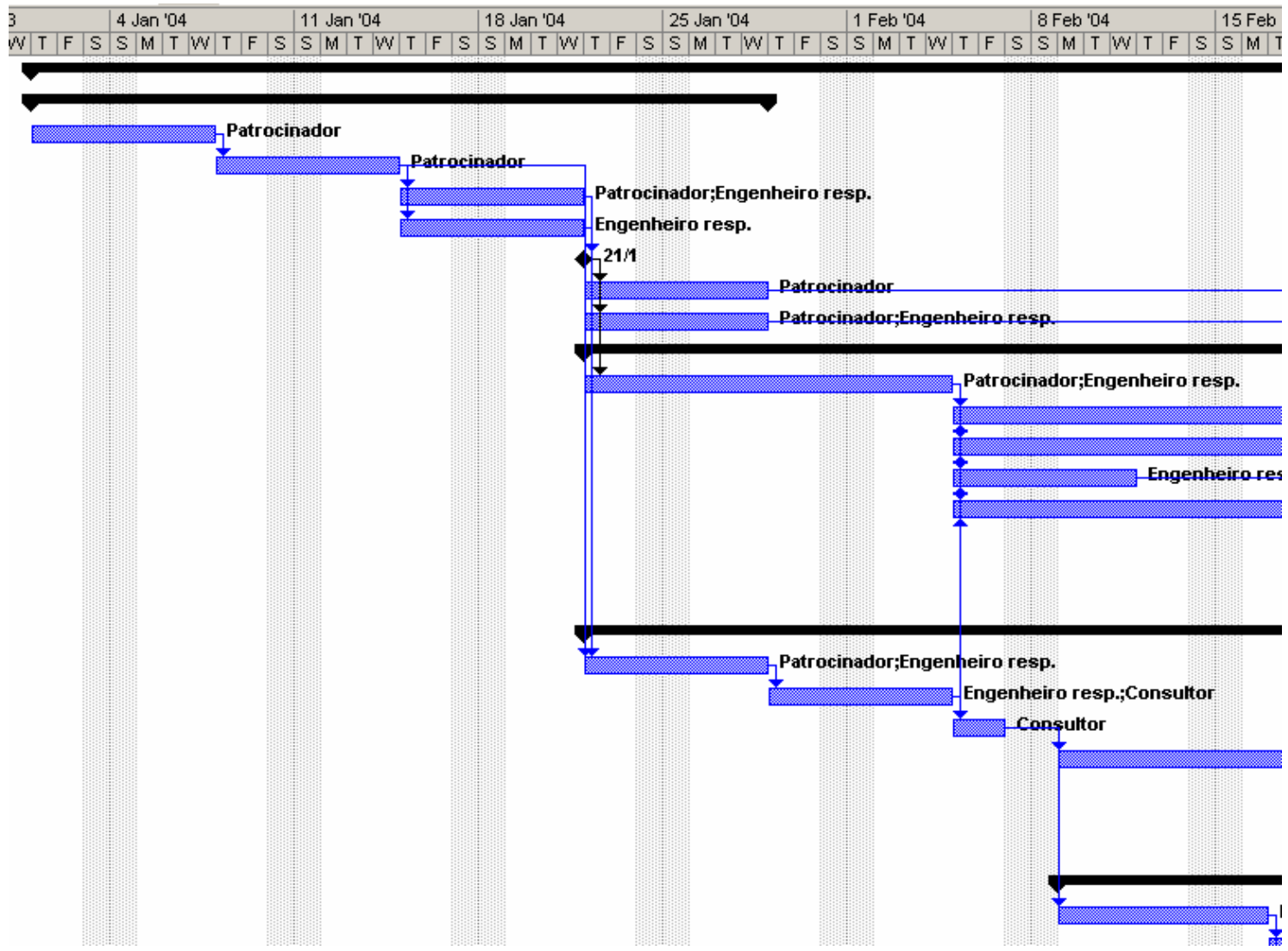

Figura 15: Gráfico de Gantt

\subsection{0 processo de gerenciamento da configuração do projeto}

Recentes trabalhos como PSPCM (2006) e CMBOK (2006), abordam especificamente o papel do gerenciamento da configuração dentro do gerenciamento de projetos. Eles descrevem a coleção de processos, atividades, ferramentas e métodos usados para gerenciar os itens da configuração durante o seu ciclo de vida no contexto do gerenciamento de projetos. Procuram integrar, portanto, os conceitos de gerenciamento da configuração do produto com a gestão dos elementos da estrutura de desmembramento do projeto. Esta proposta está sendo realizada dentro de um grupo de trabalho do PMI com o nome de Gerenciamento da Configuração do Projeto - Project Configuration Management (PCM).

De acordo com PSPCM (2006), um projeto é geralmente organizado com um patrocinador (stakeholder) do projeto atuando como um simples ponto de contato com as partes interessadas do projeto. A função típica do patrocinador é delegar os requisitos do projeto para o respectivo nível do gerenciamento da configuração ao time do projeto através do gerente do 
projeto. Isso deve ser considerado porque a saída do projeto pode ser uma interface ou uma entrada para o processo ou sistema da configuração. Para pequenos ou simples projetos onde o mínimo de planejamento ou coordenação é requerido, o gerente de projeto pode também agir como gerente da configuração. Em projetos grandes ou complexos, um gerente da configuração em separado pode ser apontado para realizar o controle e efetivação das alterações nos itens da configuração e também a comunicação entre o time do projeto e os patrocinadores.

Para PSPCM (2006), os principais benefícios do PCM são:

- Manter a integridade dos itens da configuração;

- Interfaces de comunicação ficam mais claras e contém informação aplicável;

- Informação histórica sobre as entregas dos itens da configuração (resultados do projeto) pode ser utilizada através da vida do produto;

- Integração entre planejamento, execução e controle de mudanças ajuda a manter a sincronização entre os requisitos e resultados do projeto;

- Garantir que somente mudanças aprovadas são incorporadas a um item da configuração revisado.

Os principais processos envolvendo a integração entre gerenciamento de projetos e gerenciamento da configuração, e que serão descritos nas seções seguintes, são (PSPCM, 2006):

- Planejamento;

- Identificação;

- Controle de Mudanças;

- Registro de Status e Métricas;

- Auditoria.

\subsubsection{Planejamento}

No nível de projeto, a configuração é contextualizada através do plano de gerenciamento da configuração do projeto que pode incluir:

- Autorizações, papéis, responsabilidades e disciplinas envolvidas; 
- Identificação dos itens controlados (itens da configuração);

- Processos e procedimentos de controle de mudanças da configuração;

- Registro de status e definições de métricas;

- Lista de auditorias e seu relacionamento com os agendamentos do projeto.

A figura 16 ilustra a comunicação entre os gerenciamentos da configuração do produto e do projeto:

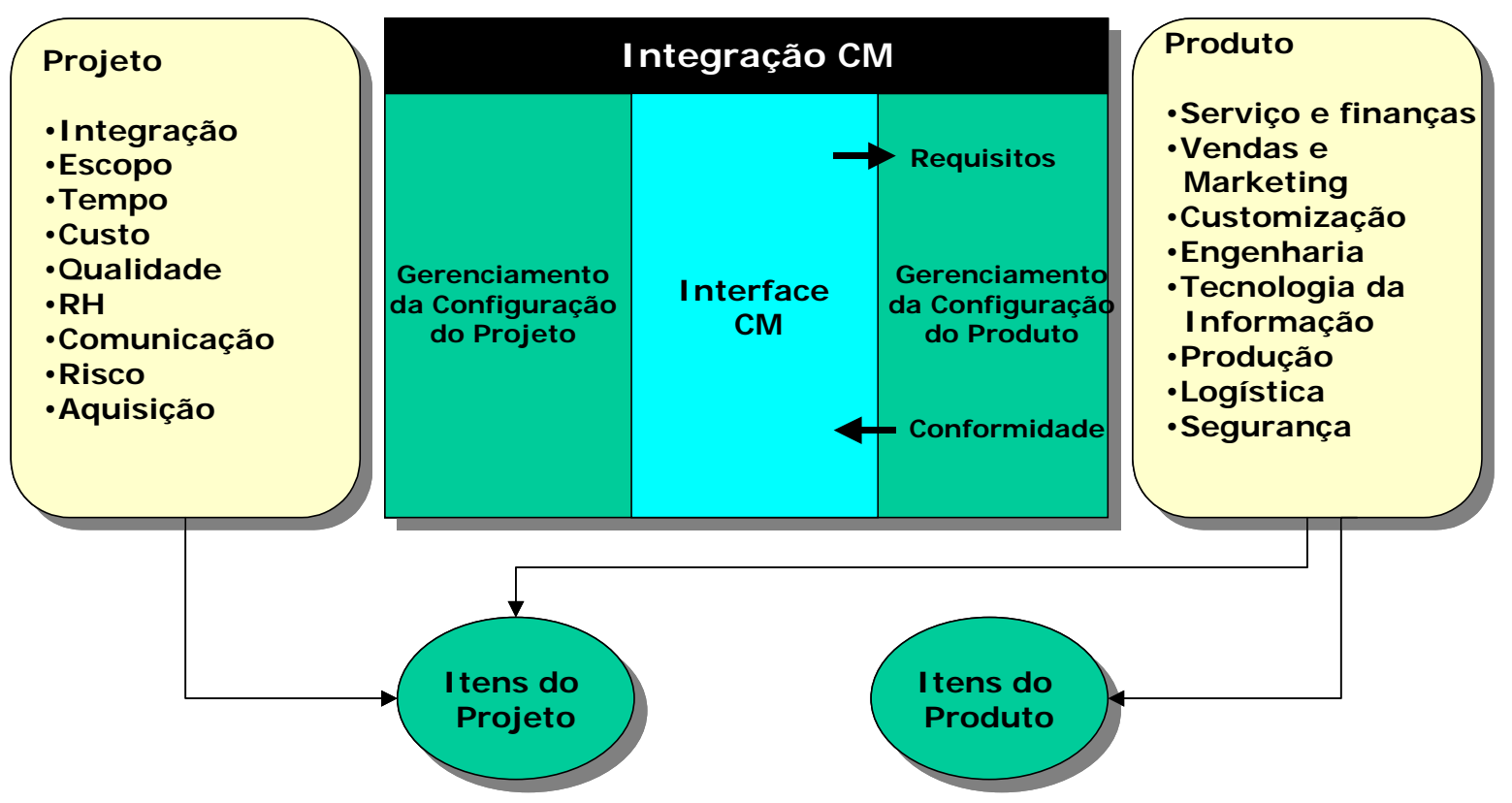

Figura 16: Comunicação entre gerenciamento da configuração do projeto e o gerenciamento da configuração do produto

Fonte: PSPCM (2006)

$\mathrm{Na}$ figura acima, percebe-se que os itens do projeto fazem parte do escopo tanto do produto quanto do projeto, através da aplicação das áreas de conhecimento no desenvolvimento das atividades relacionadas aos itens do produto. 


\subsubsection{Identificação}

Durante o ciclo de vida do projeto, a informação é uma necessidade para ajudar a direcionar e gerenciar o projeto e, dessa forma, a criação, modificação e armazenamento dessa informação é parte essencial do projeto. A função da identificação no gerenciamento da configuração é manter uma base de informação para o controle de mudanças e o registro de status dos itens da configuração (CMBOK, 2006). Esta seção discute o que deve ser identificado no projeto que deve se colocado sobre o controle do gerenciamento da configuração, como listado abaixo:

- Informação: desde o início do projeto, diversos documentos e artefatos são criados para ajudar a gerenciar o projeto e prover a comunicação entre os membros da equipe, patrocinadores, gerenciamento, entre outros. Como exemplo de informação que deve estar sobre o controle do gerenciamento da configuração do projeto (informação que pode variar de um projeto para outro), cita-se informações sobre alterações do produto, documentos de planejamento, WBS do projeto, agendamento das atividades, contratos, etc;

- Estrutura: organização da informação do projeto. O mais básico requisito de estruturação dos documentos do projeto é um sistema de arquivos que torna possível organizar a informação para o armazenamento eficiente, recuperação e uso. Também pode endereçar outras necessidades do projeto, incluindo:

- Formato da informação: no formato eletrônico ou gravação física, a informação precisa estruturada de forma balanceada para propiciar o balanceamento certo entre acessibilidade, indexação de armazenamento, segurança e recuperação;

- Acesso rápido: informação freqüentemente usada pelo gerente e time do projeto deve ser facilmente acessível;

- Ampla disponibilidade: a localidade de acesso à informação também deve ser facilitada aos interessados, como, por exemplo, as redes de computadores que 
viabilizam o acesso a uma mesma informação a partir de localidades diferentes;

- Aceso seguro: o acesso deve ser limitado somente às pessoas com determinado nível de acesso para proteger informações pessoais e organizacionais;

- Backup: deve haver um plano de recuperação de dados perdidos ou tornados indisponíveis incluindo a periodicidade do processo e detalhes de recuperação para itens específicos;

- Retenção da informação: ocasionalmente, ocorrem situações onde informações mais antigas que tenham sido substituídas por informações atuais, necessitam referência e, para isso, um plano de acesso a informações de versões antigas para futura referência pode ser útil em alguns projetos;

- Identificação do item da configuração: a identificação é uma estrutura organizada descrevendo a composição dos objetos, ou melhor, itens da configuração de um projeto. Normalmente, os processos do projeto resultam em estabelecer linhas de base aprovadas e informações relacionadas ao longo do tempo, de forma a refletir as diferenças entre o previsto e realizado do projeto. A identificação da configuração enfatiza as entregas finais do projeto bem como os eventos ou efeitos significantes e apresenta ambos ao gerente e cliente ou patrocinador com pontos efetivos de realização. Itens com nível de significância suficiente para possuírem controle podem consistir de itens físicos, documentos, formulários e registros.

\subsubsection{Gerenciamento de Mudanças de Configuração - Cofiguration Change Management (CCM)}

O gerenciamento da configuração é um subsistema do gerenciamento de projetos como um todo (PMBOK, 2004). Os processos de PCM são utilizados quando gerenciando as restrições de escopo, tempo, custo e qualidade do projeto. O controle de mudanças é um elemento crucial no 
gerenciamento destas restrições, desde que ele determina os processos e procedimentos utilizados para administrar alterações nos itens da configuração. A aplicação dos princípios de controle de mudanças sobre as os itens de entrega do projeto produz diversos benefícios, incluindo:

- A versão correta do item da configuração está em uso pela equipe do projeto;

- Alterações nos itens da configuração são feitas somente por indivíduos com níveis de acesso autorizados pelo gerente da configuração;

- Um meio de notificar as partes interessadas de que as alterações aprovadas sobre os itens da configuração estão em curso;

- Um registro das alterações no item da configuração é mantido para suporte a auditoria e atividades de fechamento do projeto.

O controle de mudanças possui um fluxo de fases individuais para efetivação de uma alteração dobre um item da configuração:

- Linha de Base (Baseline): última versão liberada pelo gerenciamento da configuração;

- Submeter: preparar a requisição, garantir que é fornecida a informação adequada para permitir a realização apropriada do impacto;

- Verificar: garantir que toda a informação necessária para realizar uma avaliação foi disponibilizada. Estabelecer relacionamentos entre a alteração proposta e os itens modificados;

- Avaliar: avaliar o impacto da alteração proposta. Os impactos na tecnologia, custos, agendamento, gravação, segurança, e impactos de contrato deverão ser avaliados. Identificar as pessoas responsáveis por realizar a avaliação é potencialmente difícil. Existem requisitos contraditórios para garantir que todos os impactos foram identificados e para manter o processo tão rápido quanto possível por não requisitar uma avaliação desnecessária;

- Revisar: considerar a o impacto da alteração proposta. A autoridade requerida para aprovar uma mudança irá variar com o 
tipo e o status dos itens afetados. Uma alteração proposta pode perfeitamente ser rejeitada. Identificar itens os quais atualmente necessitarão ser alterados e estabelecer/ajustar os pacotes de trabalho;

- Implementar: fazer as alterações, rastrear o progresso, e reportar o status para o sistema de rastreamento. Estabelecer relacionamento entre o registro alterado e os itens afetados pela alteração. Atualizar a versão liberada;

- Concluir: garantir que o processo de alteração foi conduzido corretamente e que existem evidências que as alterações foram implementadas de forma satisfatória. Aprovar a alteração e reportar para o sistema de rastreamento.

\subsubsection{Registro de Status e Métricas}

Esta seção trata da manutenção e relatórios de informação sobre os itens da configuração e ações relacionadas como, por exemplo, as mudanças pendentes no sistema. Um projeto pode utilizar o registro de status para disseminar informação, validar e verificar ações, e serve como mecanismo de acompanhamento para todo o processo de gerenciamento da configuração do projeto. Este tópico inclui:

- Repositório de informações: é um lugar (base de dados, biblioteca ou sistema de arquivos) onde a informação do projeto é depositada para controle de versão, armazenamento e de acesso. Um projeto pode ter um ou mais repositórios. O registro de status engloba a aquisição e entrada de informação para dentro do repositório e a organizar de forma estruturada na forma de hierarquias, ou seja, os identificadores, estrutura interna e as relações entre os componentes e sua documentação interna. Esta estrutura normalmente é representada graficamente no formato de árvore ou lista identada. De acordo com CMBOK (2006), nas fases iniciais do projeto, são criadas hierarquias entre os itens físicos e o produto final. São chamadas de estrutura do produto (PBS - Product Breadown Structure) ou lista de materiais (BOM - Bill of Material), são geradas com a finalidade de 
compra de matérias-primas e controle de desempenho e que representam o mais baixo nível de estruturação dos itens da configuração durante seu ciclo de vida; ligando os itens físicos (itens primários) a seus documentos e itens e documentos secundários (ferramentas, equipamentos, processo de fabricação) obtém-se uma estrutura mais geral chamada de estrutura de objetos (OBS - Object Breakdown Structure) como visto na figura 17; após a fase inicial são agregadas outras informações como atividades, hardware, software, serviços, treinamento, recursos, custos, entre outros, que acabam por formar a WBS do projeto (descrita na seção 2.4), onde os itens da configuração representam sua unidade elementar. A partir da informação disponibilizada no repositório, são desenvolvidas métricas no nível de testes comparativos, de versão e de produção para análise em conjunção com o histórico de revisões para todo o hardware, software e documentação;

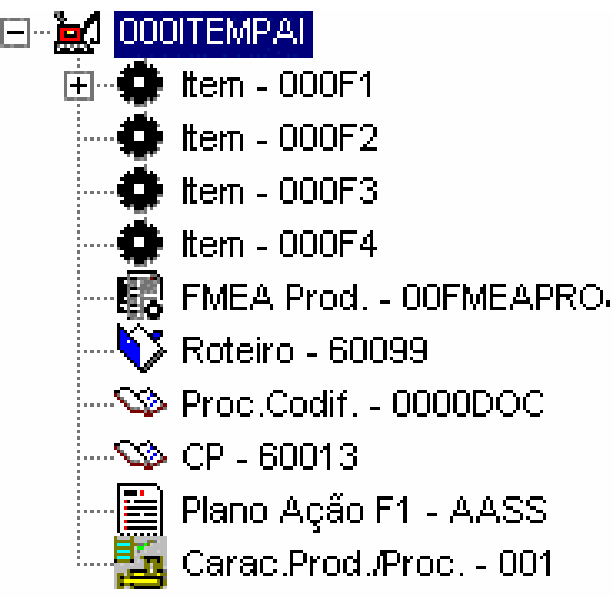

Figura 17: Exemplo de estrutura de objetos

- Relatórios: o registro de status e os relatórios de métricas produzem informação para o projeto. Esta informação pode ser usada para gerar uma métrica para a linha de base, controlar as alterações para esta métrica e rastrear as melhorias obtidas com a métrica para o projeto ao longo do tempo. As informações relacionadas são:

- Status: no contexto do gerenciamento da configuração do projeto, requer o controle sobre todos os itens de 
configuração do projeto informando sua situação durante o seu ciclo de vida, tal como se o mesmo está aprovado, revisado, cancelado, obsoleto, entre outras. Além disso, o registro de status documenta a situação de alterações aprovadas e através dele é possível emitir relatórios de rastreamento da implementação destas alterações;

- Métricas: são uma ferramenta de comunicação utilizada pelo gerente do projeto para controle de acesso do projeto e determinar a necessidade de melhorias para algum processo. Com as métricas é possível rastrear o que foi alterado, quando e por quem, qual o impacto terá sobre o que foi alterado e qual o efeito sobre a nova informação. Para maximizar a utilização, os dados obtidos podem ser apresentados em formatos mais amigáveis ao gerente do projeto como gráficos e tabelas;

- Testes comparativos (benchmarking): correspondem à comparação de processos, ferramentas e técnicas com outros projetos. Pode ser utilizado para comparar qualquer aspecto de um sistema como tempo de treinamento, curva de aprendizado, tempos de resposta no acesso a informações e, no caso do gerenciamento da configuração do projeto, produz itens da configuração com múltiplos propósitos voltados para assegurar a qualidade dos processos e gerar ações corretivas baseadas nas análises de variância sobre os dados obtidos;

- Medidas de desempenho: variam de acordo com o tipo de aplicação e expressam-se na forma de indicadores chave de desempenho, dos tipos quantitativos (valores objetivos que podem ser medidos) e qualitativos (visão abstrata voltada a uma determinação específica relacionada ao projeto);

- Estatísticas operacionais: correspondem aos gráficos de controle, relatórios de acompanhamento de usuários e 
clientes. Também podem ser utilizadas para medir a estabilidade de um processo no decorrer do tempo;

- Relatórios periódicos: o registro de status provém relatórios periódicos sobre o controle de mudanças e a situação dos itens da configuração. Estes relatórios podem prover o seguinte tipo de informação:

- Data e responsável pela criação da linha de base;

- Localização e autorização de acesso à linha de base;

- Requisições de alterações e sua situação (nova, ativa, aprovada, cancelada, etc);

- Notificações de alterações e sobre os itens alterados e afetados;

- Situação da implementação das mudanças e auditorias planejadas.

- Análise: ajuda a determinar se o processo de gerenciamento de mudanças está funcionando como planejando no sentido de aprimorar o sistema como um todo. O tráfego de dados pode ser usado para monitorar os níveis de desempenho. A variação dos dados de medição pode ser relacionada a diversas causas. Alterações do ambiente, o procedimento e equipamento de medição, e outros numerosos fatores podem causar impacto nos dados de medição capturados.

\subsubsection{Auditoria e Verificação}

A finalidade da auditoria e verificação é garantir que a composição dos itens da configuração do projeto e as alterações nestes itens são registradas, acessadas, aprovadas, rastreadas e corretamente implementadas. O processo de auditoria e verificação assegura:

- A finalização da definição da documentação do projeto;

- A integridade dos itens da configuração;

- O histórico dos itens da configuração pode ser reproduzido; 
- A rastreabilidade dos itens da configuração do projeto através do processo de gerenciamento do projeto;

- Os objetivos dos itens da configuração foram alcançados através da comparação sistemática com os requisitos levantados com os resultados iniciais, intermediários e finais do teste, análise, demonstração ou inspeção;

- O acesso às quantidades e configuração dos itens sobressalentes;

- A determinação da configuração e equipamentos instalados atualmente;

- Os resultados da auditoria e controle de mudanças.

\subsection{Sistemas de apoio ao gerenciamento de projetos}

Existem várias ferramentas disponíveis para apoiar o gerenciamento de projetos. Nesta revisão a análise foi dividida entre sistemas comerciais, sistemas em código aberto e sistemas propostos pela comunidade científica. Os dois primeiros tipos se constituem em ferramentas disponíveis para o uso das empresas, diferenciando-se, os primeiros, por serem comercializados no sistema tradicional de licenças baseado na aquisição ou aluguel. Já os sistemas de código-aberto possuem modalidades distintas de licença na qual o código pode ser consultado e alterado pelo usuário. Os sistemas identificados na literatura científica são protótipos que testam novos conceitos e funcionalidades.

\subsubsection{Sistemas comerciais de gerenciamento de projetos}

Um sistema de gerenciamento de projetos é um conjunto de ferramentas, técnicas, metodologias, recursos e procedimentos usados para gerenciar um projeto (PMBOK, 2004). Ele pode ser formal ou informal e ajuda o gerente de projetos a conduzir um projeto ao seu término de modo eficaz. Do ponto de vista computacional, são ferramentas computacionais voltadas para o gerenciamento de projetos de maneira genérica. São softwares que automatizam os cálculos de análises matemáticas, nivelamento dos recursos, monitoramento, estimativa de custos, controle de documentos, comunicação, 
anais de riscos, entre outros e, conseqüentemente, permitem uma rápida avaliação sobre diversas alternativas para o cronograma (PMBOK, 2004). Aumentam a capacidade humana de monitorar as datas planejadas e comparálas com as datas reais, facilitando assim a previsão de efeitos de mudanças das atividades do projeto.

GARTNER (2005) realizou um estudo comparativo detalhado sobre os principais sistemas relacionados ao gerenciamento de projetos e portfólios em Tecnologia da Informação (TI). Dada a pertinência do estudo e a impossibilidade de se realizar uma avaliação própria diante do tempo e recursos disponíveis neste projeto, optou-se por apresentar à seguir um resumo das afirmações e resultados obtidos por este instituto. Deve-se atentar para o fato de que as opiniões são as do instituto e não puderam ser verificadas, bem como, por questões de propriedade intelectual, não serão apresentadas em detalhes a metodologia de avaliação. O objetivo é apenas demonstrar uma visão geral dos sistemas.

Os critérios de avaliação foram:

- Tamanho do mercado e posicionamento do sistema no mesmo;

- Influência da competição, tecnologia e requisitos dos clientes nas oportunidades de mercado;

- Dinâmicas que afetam o mercado;

- Perspectivas futuras do mercado;

- Configuração do gerenciamento de processos/projetos para aplicações da organização e ferramentas de suporte.

Os sistemas avaliados incorporam a maioria das nove áreas de conhecimento definidas por PMBOK (2004) e já descritas na seção 2.2.3.3: as três áreas principais que correspondem ao tempo, custos e recursos e as áreas adicionais, ou seja, escopo, aquisições, integração, comunicação, riscos e qualidade. Já em relação aos fornecedores dos sistemas, que serão chamados, neste texto, pelo termo em inglês vendors, os critérios para inclusão no estudo foram (GARTNER, 2005):

- Atividade no mercado nos últimos três anos; 
- Conquista de novos clientes, ou base instalada com aquisição de novas licenças;

- Conformidade com as necessidades do mercado;

- Profunda experiência de software, educação de negócios e integridade;

- Faturamento anual maior que 10 milhões de dólares ou alto grau de inovação trazido ao mercado.

Neste estudo foi utilizada uma ferramenta gráfica chamada "quadrante mágico" (figura 18), que corresponde a um gráfico cartesiano constituído de dois eixos: o eixo vertical chamado "Habilidade para Executar", que corresponde diretamente à operação do sistema, e o horizontal denominado "Visão do Vendor", referente à estratégia de posicionamento do vendor no mercado. No quadrante formado com estes dois eixos são distribuídas quatro regiões (Líderes, Desafiantes, Nicho e Visionários) de acordo com o resultado obtido da análise comparativa feita com cada vendor. 


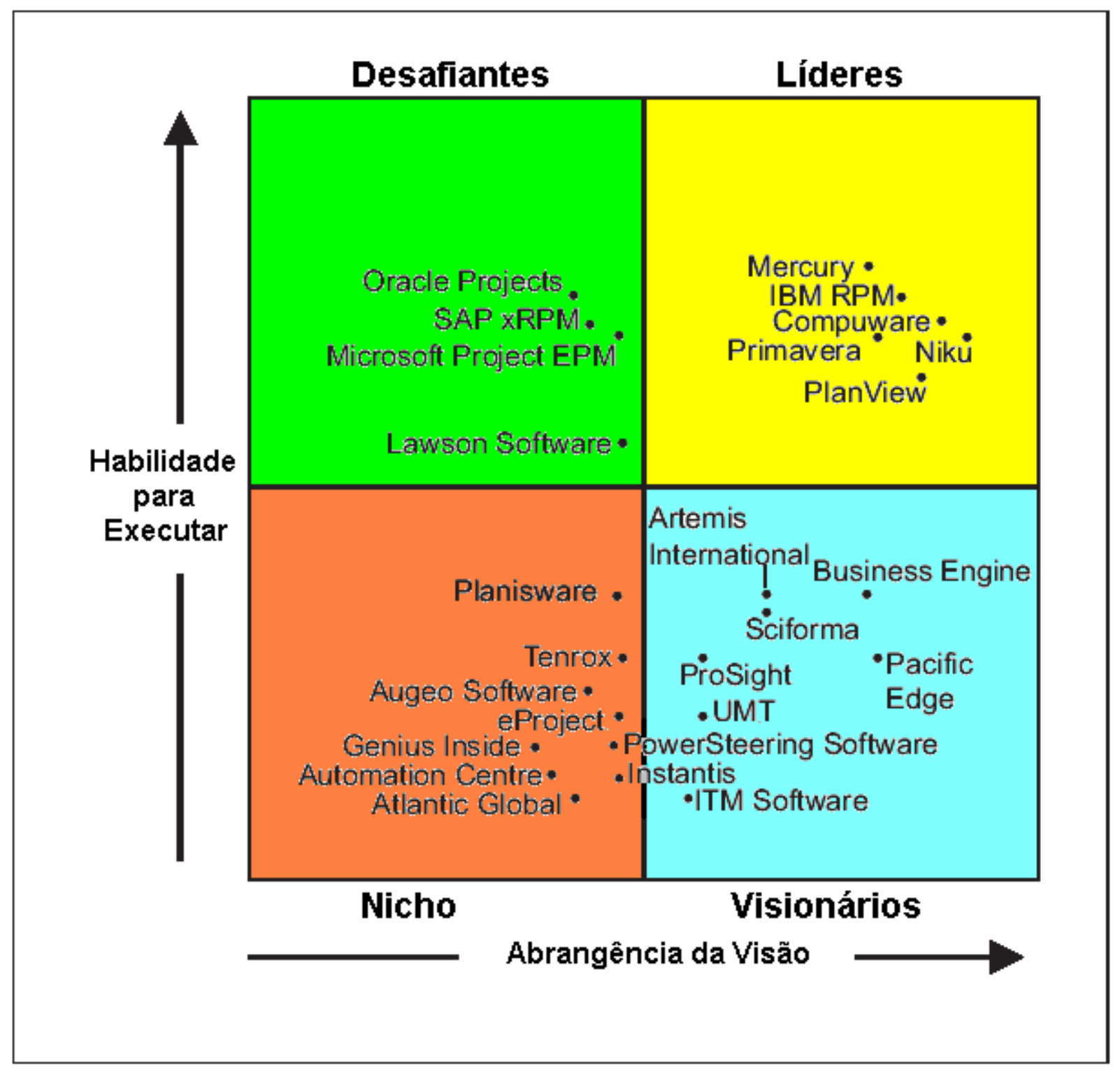

Figura 18: Quadrante Mágico comparativo dos Sistemas para Gerenciamento de Projetos em TI

Fonte: GARTNER (2005)

Habilidade para Executar - Critérios:

- Lucratividade, nível e crescimento de rendimento e dos vendors: pequenos lucros ou prejuízos não são viáveis num longo prazo, mas pode ter seu peso diminuído neste estudo, se o distribuidor estiver em fase de crescimento e a lucratividade for adiada devido a questões estratégicas, tais como pesquisa e desenvolvimento intensivos ou operações de aquisição ou fusão. 
Uma base instalada substancial pode tanto contribuir para a viabilidade do vendor, como fortalecer o suporte do investidor;

- Equipe de gerenciamento do vendor: níveis de educação, experiência de negócio e entendimento dos mercados de software em geral com relação ao time de gerenciamento do vendor representam um fator vital na operação do sistema;

- Integridade: cumprimento dos contratos do vendor com seus clientes, fornecedores, parceiros, imprensa e colaboradores refletem o nível de comprometimento de gerenciamento sênior com a companhia e com a indústria como um todo;

- Aprofundamento funcional das ferramentas de aplicação do sistema: um sistema maduro e de qualidade só é conseguido num prazo médio de 10 anos, e ocorre que muitas aplicações possuem um grande número de funcionalidades implementadas de forma superficial e disfarçadas por um grande número de versões lançadas em espaços curtos de tempo (por exemplo, uma aplicação com 2 anos de vida e já na versão 8);

- Serviço e suporte: a visão do vendor criticamente afeta sua habilidade de prover serviço e suporte de qualidade. O vendor pode diminuir os recursos voltados para o suporte ou deixar de investir no mesmo por um aumento de demanda com a finalidade de aumentar a margem de lucro;

- Vendas e Marketing: apesar dos canais de vendas terem importância (por exemplo, integradores de sistemas), uma força de vendas diretas, com suporte de qualidade, representa uma importância de igual valor. Uma equipe de vendas inexperiente, ou com poucos recursos pode prejudicar bastante a operação do vendor. $\mathrm{O}$ acesso a mercados internacionais aumenta bastante a operação do vendor, mas para isto, a função de vendas e marketing é tão importante quanto os atributos do produto. 
Visão - Critérios:

- Abrangência do Sistema: avalia se uma determinada solução excede a básica funcionalidade dos processos, agregando maior valor aos mesmos como, por exemplo, funcionalidades nativas de integração de serviços de $\mathrm{TI}$, agendamento e ferramentas de contas de usuários de projetos;

- Plataformas Suportadas: a gama de plataformas suportadas, variando de sistemas operacionais (como Windows, Unix e Linux), bancos de dados (por exemplo, DB2, Oracle e SQL Server), servidores de aplicação (como J2EE e .NET) e sistemas ERP (Oracle, SAP, BAAN), entre outras, pode fazer a diferença entre clientes que podem possuir desde uma plataforma com um sistema operacional e um banco de dados, a um sistema multiplataforma com servidores de aplicação e diferentes bancos de dados, pois será essencial que o sistema gerenciador de projetos possua mecanismos de integração para a(s) plataforma(s) requisitadas;

- Colaboração: possuir funcionalidades de colaboração como workflow (fluxo de trabalho), gerenciamento do conhecimento do projeto, gerenciamento de documentos e funcionalidades relacionadas podem fazer a diferença para os tomadores de decisão responsáveis por adquirir sistemas de gerenciamento de projetos;

- Funcionalidades Específicas: muitos vendors atingem diversos mercados que compartilham de 65 a 80 por cento das características centrais de um sistema de gerenciamento de projetos como planejamento, agendamento e nivelamento de recursos. Possuir características específicas de uma determinada área ou mercado pode ser um diferencial competitivo, no caso da TI, possuir suporte ao CMMI (Capability Maturity Model Integration - Integração do Modelo de Maturidade da Capacidade), terminologia da $\mathrm{TI}$, dados dos recursos refletindo o conjunto de habilidades relacionadas à TI, e assim por diante; 
- Tecnologia e mercado: é ponto-chave para o desempenho futuro do vendor. A dinâmica do mercado com o aparecimento de novas tecnologias como telefonia celular e sem fio (wireless), Web Services, por exemplo, pode se transformar em desvantagens competitivas para o vendor;

- Gerenciamento de recursos: uma visão limitada consiste simplesmente em manter uma base de dados com os perfis dos recursos; já uma visão mais profunda estes recursos são classificados de acordo com suas habilidades e o gerenciamento possui funcionalidades para alocação, nivelamento, análise da capacidade e desempenho dos recursos;

- Serviços de suporte: correspondem ao nível de comprometimento da empresa em prover integração, consultoria e outros tipos de suporte. Uma medida da visão do vendor é a confiança em aplicações de terceiros para integração, controle de mudanças, entre outros serviços. Em contrapartida, a falta de confiança indica uma perda no comprometimento com a excelência, que pode resultar em um serviço realizado por terceiros com treinamento abaixo do necessário. As margens de lucro para serviços nesta categoria de software são mais baixas que as de vendas de produtos, mas o uso apropriado de provedores de serviços comprometidos, com treinamento adequado, mostra uma visão de mercado de longo prazo.

\section{Líderes:}

Para estar na liderança, não basta o sistema ter funcionalidade do produto profunda e abrangente, mas também o vendor deve estar em compasso com os avanços da tecnologia e comprometimento com um serviço de excelência.

- Compuware: em 2004, a Compuware executou seu plano de integração entre as suas soluções de gerenciamento de projetos (Changepoint PPM Solution) e a de medição de qualidade (Compuware Application Solution's Quality Index), e que unida a uma nova ferramenta de workflow culminou com o 
lançamento da versão 10 da solução Changepoint. A Compuware é um vendor availado em 1,2 bilhão de dólares com altíssima capacidade de operação em gerenciamento de projetos e portfólios, possui um número significativo de receita advinda de sua base de muitas organizações de grande porte;

- IBM: com a aquisição em 2004 da empresa SystemCorp e seu produto PMOffice, que foi incorporado a linha IBM Rational com o nome de IBM Rational Portfolio Manager. Beneficiado pelo uso interno do produto na área de consultoria da IBM (responsável pela especificação de muitas funcionalidades visionárias e necessidades de desempenho) e também pelo laboratório de testes, a IBM desenvolveu uma solução escalável, integrada ao Tivoli para suporte ao ITIL (Information Technology Information Library) e com suporte ao RUP - Rational Unified Process, para o desenvolvimento de projetos;

- Mercury: com a versão 6 do seu produto - Mercury IT Governance Center - ganhou funcionalidades para o gerenciamento de projetos grandes e complexos, evitando que os usuários fossem obrigados a criar subprojetos para gerenciar as dependências. Esta nova versão exibe visão na confiabilidade do suporte, via workflows definidos com controles e automação de relatórios e que, com a política de preços aplicada pelo vendor, acabou aumentando a lucratividade da empresa;

- Niku \& Computer Associated (CA): em 2005, a Computer Associated incorporou a Niku, num negócio de 350 milhões de dólares e a nova versão do seu sistema, o Clarity v. 7.5, que trouxe funcionalidades de particionamento do sistema para flexibilidade local. A companhia mostrou visão de mercado ao adicionar uma ferramenta para análise do portfólio e priorização, bem como o módulo Service Connect, para mapear requisições de trabalho não pertencentes ao projeto, além de explorar o canal de vendas, no sentido de abrir novos mercados como, por exemplo, o mercado europeu. 
- PlanView: também em 2005, esta empresa reestruturou o sistema PlanView Enterprise em três módulos: Enterprise Portfólio, Project Portfólio e Service Portfólio. Acompanhando este prisma, o vendor incorporou as melhores práticas em TI em áreas como análise de investimento e otimização de recursos. $\mathrm{O}$ Enterprise Portfólio oferece ferramentas para análise de investimentos, priorização e alinhamento com finanças e recursos humanos. O Project Portfólio disponibiliza aos gerentes a análise dependências interprojetos, estimativa ed trabalho e alocação de recursos. Já o Service Portfólio o padrão de distribuição de serviços ITIL, como a IBM. A PlanView teve um grande impulso em suas operações com o investimento de 25 milhões de dólares do fundo APAX Partners no final de 2004.

- Primavera: A empresa está adquirindo novos clientes, dentro da área de gerenciamento de projetos e portfólios, baseada na excelência em gerenciamento de serviços para T.I, o qual freqüentemente não requer funcionalidades completas para agendamento e ajustes de preços e mais opções de distribuição para os seus clientes. Sua solução integrada é altamente escalável e seu gerenciamento de portfólio é traz o diferencial de poder apresentar dois portfólios em um; a maioria dos vendors oferece múltiplos portfólios e também múltiplas instâncias, mas apresentar ambos em uma única visão é uma característica única.

\section{Desafiantes}

Este grupo oferece produtos ou serviços limitados, mas que ainda podem impulsionar seu canal de vendas, sua presença internacional e base instalada.

- Lawson Software: com a versão 5.2 da solução Service Automation (SA), lançada no início de 2005, houve avanços no gerenciamento financeiro, comercial, dos recursos e da flexibilidade. Os avanços no gerenciamento do portfólio incluíram maior suporte ao gerenciamento da configuração; entretanto, com deficiência no suporte ao gerenciamento do ciclo de vida do projeto, onde as funcionalidades para modelagem gráfica do 
workflow ou os ciclos de vida do projeto pré-definidos para projetos já em andamento são considerados insuficientes;

- Microsoft: o principal diferencial é a disseminação de uso do Microsoft Project. A colaboração com o Office (conjunto de ferramentas para automação de escritório como softwares de edição de texto, planilha de cálculo e apresentação) e com o Outlook (correio eletrônico) impulsionou a adoção da sua solução Enterprise Project Management (EPM) em empresas de médio porte em pouco tempo, com melhores facilidades para implantação;

- Oracle: a solução Oracle Projects Family Pack M adiciona características de priorização suportando alinhamento estratégico, justificação financeira e posicionamento de investimentos. Nos últimos anos, a ferramenta de custos do projeto foi incluída em uma aplicação mais ampla, com finalidade de gerenciamento de projetos e portfólios. A solução traz melhorias na análise do valor agregado e a maior presença de atuação reside no setor de serviços e projetos de engenharia e construção;

- SAP: a SAP continua a se empenhar sua estratégia de marketing sobre a solução XRPM sobre a sua base instalada. Isto não a impediu de conquistar novos clientes, mesmo sem aprimorar a arquitetura de seu sistema ERP (Enterprise Resuorce Planning - Planejamento dos Recursos da Empresa), cuja implementação se encontra em desenvolvimento. Recentes funcionalidades incorporadas ao XRPM incluem o suporte ao desenvolvimento de novos produtos, gerenciamento do portfólio, uma aplicação de gerenciamento de projetos e portfólios para variante de serviços profissionais e portfólios específicos Six-Sigma.

\section{Visionários}

Um conjunto mais nítido de líderes vem emergindo nos últimos anos e deve se concretizar como tal por volta de 2008. Estes gerenciadores de projetos e portfólios visionários encenam implementações com configurações 
do produto alternativas e combinadas e serviços com preços mais acessíveis, 0 que aponta que eles manterão o passo com o crescimento do mercado.

- Artemis: a solução Enterprise Edition-based Ártemis 7 teve grande avanço no mercado com a adoção da plataforma Java 2. A nova versão oferece uma funcionalidade aprimorada de orçamento baseado no desempenho do projeto. Apesar do Sucesso em TI e outros segmentos em gerenciamento de projetos e portfólios, a Artemis tem acumulado prejuízo nos últimos anos;

- Business Engine: a empresa estendeu sua visão do produto introduzindo um novo do alinhamento para a análise e priorização do portfólio, o qual está disponível como um produto autônomo ou integrado com a Business Engine Network. A Business Engine reestruturou significativamente sua organização das vendas, e contratou o responsável pela estratégia de vendas da PeopleSoft (recentemente adquirida pela Oracle). O objetivo é um crescimento significativo de vendas para obter um ano lucrativo após prejuízos acumulados de períodos anteriores. Para isso, o vendor recebeu um investimento adicional de 4 milhões de dólares da Oak Investment Partners;

- ITM: a versão 2 da solução Business Suíte da ITM Software é composta de sete módulos direcionados à TI para 0 gerenciamento de projetos, recursos (incluindo os vendors), finanças e conformidades. Pequena, mas em crescimento, a ITM já participa do mercado por três anos, com uma solução de custos mais acessíveis;

- Pacific Edge: a empresa levantou um investimento adicional e a solução Portfolio Edge chegou à versão 3.0, enfatizando 0 planejamento financeiro, com funcionalidades de suporte ao workflow e templates (modelos pré-definidos) de processos. Em 2004, o vendor recebeu 12 milhões de dólares em fundos de risco e anunciou uma parceria com a Troux Technologies;

- Prosight: a ProSight continua a enfatizar o setor público, onde obtêm ganhos significativos. Sua parceria com o Microsoft, 
através da qual ela revende o Project Server como parte de uma implementação ProSight, integra melhor a gerência de projeto com a gerência de portfólio da aplicação. Em conseqüência, ProSight está adicionando mais de sua própria solução para aprimorar as funcionalidades do Project Server. As características de suporte e adequação ao Federal Information Security Management Act adicionadas ao produto podem capturar a atenção de clientes potenciais do setor público americano;

- United Management Techmologies (UMT): com a versão 3.2 de sua solução, a empresa expandiu sua solução inovadora de análise do portfólio e priorização com uma integração com o Microsoft Project Server, permitindo assim a fusão de processos de gerenciamento de projetos e portfólio. Seu sistema inclui scorecards (cartões de marcação) definidos pelo usuário, características do gerenciamento integrado do portfólio do projeto e da aplicação, capacidades estendidas de relatórios, agregação de dados dentro da organização e visões sumarizadas do portfólio, e a priorização e otimização no nível de programa.

\section{Nicho}

O mercado de nicho representa necessidades específicas de um determinado grupo de clientes. Produtos da Automation Centre e Genius Inside aprimoraram a tecnologia da IBM Lotus/Domino para gerenciamento de projetos e portfólios. Geograficamente, a Genius opera principalmente na Europa, onde a Augeo Software e a Planisware são também particularmente fortes. A Atlantic Global está estabelecida no Reino Unido e está iniciando operação na América do Norte. As aplicações da Instantis e PowerSteering fornecem as funcionalidades do gerenciamento de projetos e portfólios integradas ao gerenciamento da qualidade sob uma abordagem via Six-Sigma.

\subsubsection{Sistemas para gestão de projetos em código aberto}

Nós últimos anos vem sendo desenvolvidas ferramentas de gerenciamento de projetos que oferecem um menor custo de aquisição, são os chamados softwares de código aberto. Estes sistemas permitem que seus usuários desenvolvam e personalizem o programa para melhor atender às suas 
necessidades. O desenvolvimento destas ferramentas é feito por uma comunidade de colaboradores, ao invés de uma empresa de software, o que permite também um menor custo de serviço de suporte em relação aos softwares proprietários. Os problemas são enviados para estas comunidades e solucionados conforme o engajamento dos seus membros, geralmente sem custo adicional para o usuário.

De acordo com a OSI (2004), as características da licença de um software para que este seja considerado de código aberto são:

- Redistribuição livre: a licença de distribuição não deve restringir a venda ou cessão do software, também não deve cobrar direitos de propriedade ou outras taxas pela venda do programa;

- Código fonte: o programa deve incluir o seu código fonte e deve permitir o acesso a ele, da mesma forma a versão compilada. Quando o produto não for distribuído com o código fonte, deve haver uma forma claramente anunciada de obtê-lo, sem custo, via Internet;

- Trabalhos derivados: a licença deve permitir a realização de modificações e de criação de sistemas derivados, os quais devem ser distribuídos sob os mesmos termos da licença do software original;

- Não discriminar pessoas ou grupos: a licença não deve discriminar nenhuma pessoa ou grupo de pessoas;

- Distribuição da Licença: os direitos vinculados ao programa devem aplicar-se a todo aquele para o qual o programa é redistribuído, sem que haja necessidade que as partes levem, a efeito, uma licença adicional.

- Uma licença não deve ser específica para determinado produto: os direitos vinculados a um programa não devem depender do uso de uma distribuição de software específica. Se o programa é extraído daquela distribuição e usado, ou distribuído nos termos da licença do programa, todas as partes para as quais o programa é redistribuído devem ter os mesmos direitos que são concedidos às pessoas que receberam o software original; 
- Integridade do código fonte do autor: a licença somente pode restringir a distribuição do código fonte em forma modificada se ela permitir a distribuição de patches (correções) junto com o código fonte original, com o objetivo de modificar o programa durante a compilação. A licença deve permitir explicitamente a distribuição de software compilado a partir do código fonte modificado. A licença pode exigir que trabalhos derivados tenham diferentes nomes ou diferentes números de versão que o software original;

- Uma licença não deve contaminar outro software: a licença não deve impor restrições a outro sistema distribuído junto com o software licenciado. Por exemplo, a licença não deve insistir que todos os outros programas distribuídos no mesmo meio sejam de código aberto;

- A licença deve ser tecnologicamente neutra: a licença não deve exigir que o programa utilize uma tecnologia especifica nem ao menos um estilo de interface.

RORIZ et al (2004) realizaram um levantamento das ferramentas de código-aberto sobre gerenciamento de projetos e, em 2004, encontraram dezenas de ferramentas; cerca de 50 comunidades na internet propondo soluções com licenças do tipo software livre. Utilizando critérios como quantidade de informações postadas nas comunidades, funcionalidades e links com usuários, apenas 17 foram consideradas minimamente evoluídas e em estado de desenvolvimento. As demais foram consideradas pouco desenvolvidas: seja porque não estavam mais sendo discutidas ou porque eram ferramentas simples dentro de comunidades não consolidadas; geralmente pessoas que publicavam uma pequena solução como código livre e não conquistaram a adesão de colaboradores para o projeto. Entre as 17 identificadas, os autores escolheram as quatro mais promissoras. Instalaram e testaram cada uma delas segundo critérios previamente desenvolvidos e cobrindo as áreas de conhecimento do PMI. O resultado é que elas imitavam funcionalidades das ferramentas comerciais mais tradicionais: como o MS Project Desktop e o Primavera. Nenhuma delas abrangendo todas as 
funcionalidades e com ênfases distintas. Algumas mais fortes na parte gráfica e outras nas funcionalidades de compartilhamento de documentos e de apontamento dos resultados do projeto.

\subsubsection{Sistemas de Gestão de Projetos Propostos em Trabalhos Acadêmicos}

Com relação à pesquisa acadêmica, existem alguns trabalhos específicos sobre ferramentas para gerenciamento de projetos onde 0 problema da cooperação é a principal meta das propostas encontradas:

LI, W. D., Fuh J. Y. H., Wong, Y. S. (2004): desenvolvimento de um sistema para suporte a engenharia colaborativa e concorrente através da Web, ferramentas visualização e análise da manufatura baseados em tecnologias Java e Web. A arquitetura é dividida em três módulos: O módulo de desenho colaborativo, onde são gerados os desenhos CAD e exportados em um formato visualizável na Web; o módulo de análise da manufatura é responsável por funções como reconhecimento de features (características específicas), planejamento de processo, análise de peças e que também possuem uma interface de exportação para o formato Web; e, por último, o módulo de visualização Web, onde o usuário pode visualizar o trabalho gerado pelos outros dois módulos via Internet, seleção e manipulação da informação podendo gerar requisição de serviços e alterações para os outros dois módulos. Limitações existentes correspondem ao não gerenciamento dedicado dos dados (banco de dados, sistema PDM) e problemas de performance na visualização de figuras complexas em 3D que exigem uma mudança na tecnologia de visualização para diminuição da largura de banda. A figura 19 traz um esquema prático do sistema. 


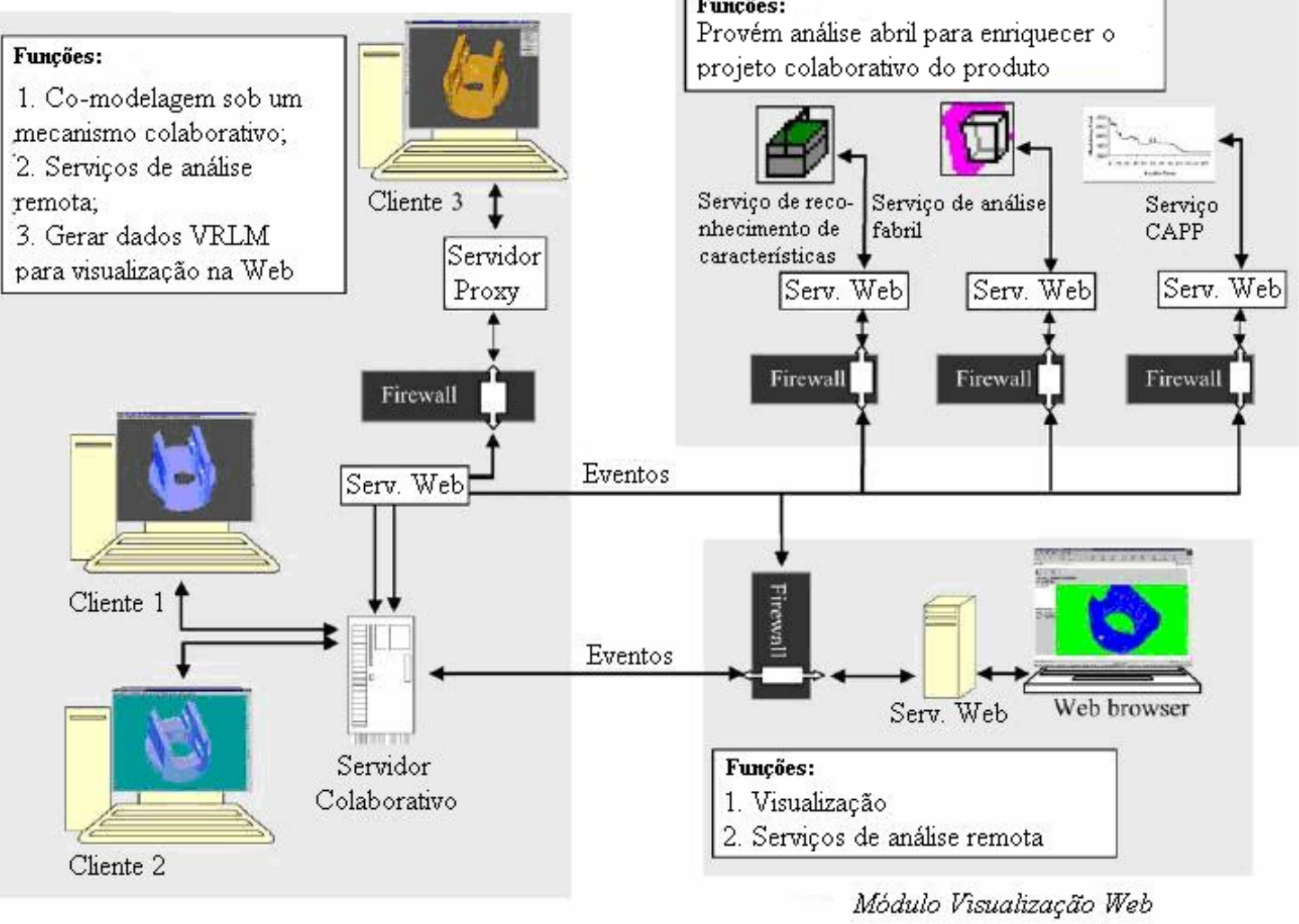

Figura 19: Sistema integrado para engenharia colaborativa na Web Fonte: LI, W. D., Fuh J. Y. H., Wong, Y. S. (2004)

Um problema desta abordagem, dentro da visão deste trabalho é também sua principal qualidade, ou seja, o foco na engenharia de produto, mas com ausência total na área de gerência de projetos, o que torna difícil saber o andamento global produto em questão, bem como a dificuldade na alocação dos recursos e o controle dos prazos.

HAMERI \& PUITTINEN (2003): sistema voltado para o gerenciamento de projetos distribuídos utilizando tecnologias WEB para disseminar o conhecimento e aumentar a eficiência e taxa de sucesso do projeto. Seu modelo conceitual é dividido em cinco camadas: gerenciamento de estruturas (incluindo a PBS - Product Breakdown Structure e a WBS - Work Breakdown Strucuture, esta última já discutida na seção relativa ao GP); gerenciamento da comunicação para gerenciar o tráfego de informação entre os membros do projeto; gerenciamento de recursos que trata do agendamento, 
alocação, controle de status e estatísticas de uso; a camada de processo cuida da análise dos resultados e tempos de duração de cada atividade individual até o projeto como um todo; e a última camada corresponde à camada de visualização na Web que apóia as outras camadas e torna acessível o projeto a qualquer membro em qualquer localização que possua conexão com a Internet. A figura 20 traz um exemplo da interface do sistema.
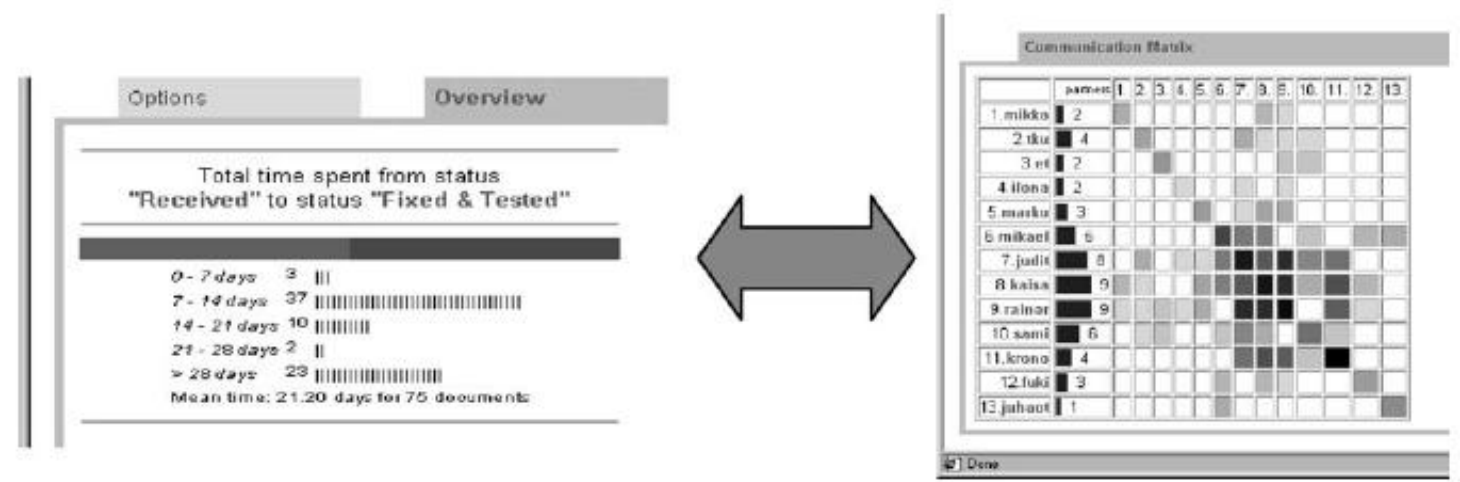

Figura 20: Visualização Web do tempo de duração do processo e o comportamento da comunicação Fonte: HAMERI \& PUITTINEN (2003)

Em uma primeira análise sobre este sistema pode-se apontar a carência de detalhe ao tratamento do controle de acesso dos usuários, parte vital para um ambiente de GP distribuído. Conseqüentemente, fica prejudicada a estrutura definida para apontamento efetivo das tarefas e resultados. Além disso, os estudos de casos foram realizados em empresas isoladas, o que acaba por desconsiderar o caráter distribuído proposto, apesar de disponibilizar mecanismos para isso, como estruturas de dados e ferramentas de comunicação.

VAVASSORI (2000): proposta para realizar o planejamento e o gerenciamento de projetos baseado na tecnologia de agentes e aplicações. As aplicações correspondem à interface onde se dá o planejamento e gerenciamento do projeto, distribuído ou não, enquanto os agentes são as entidades (no caso programas) responsáveis pela consistência entre os projetos relacionados. A arquitetura geral é apresentada na figura 21: 


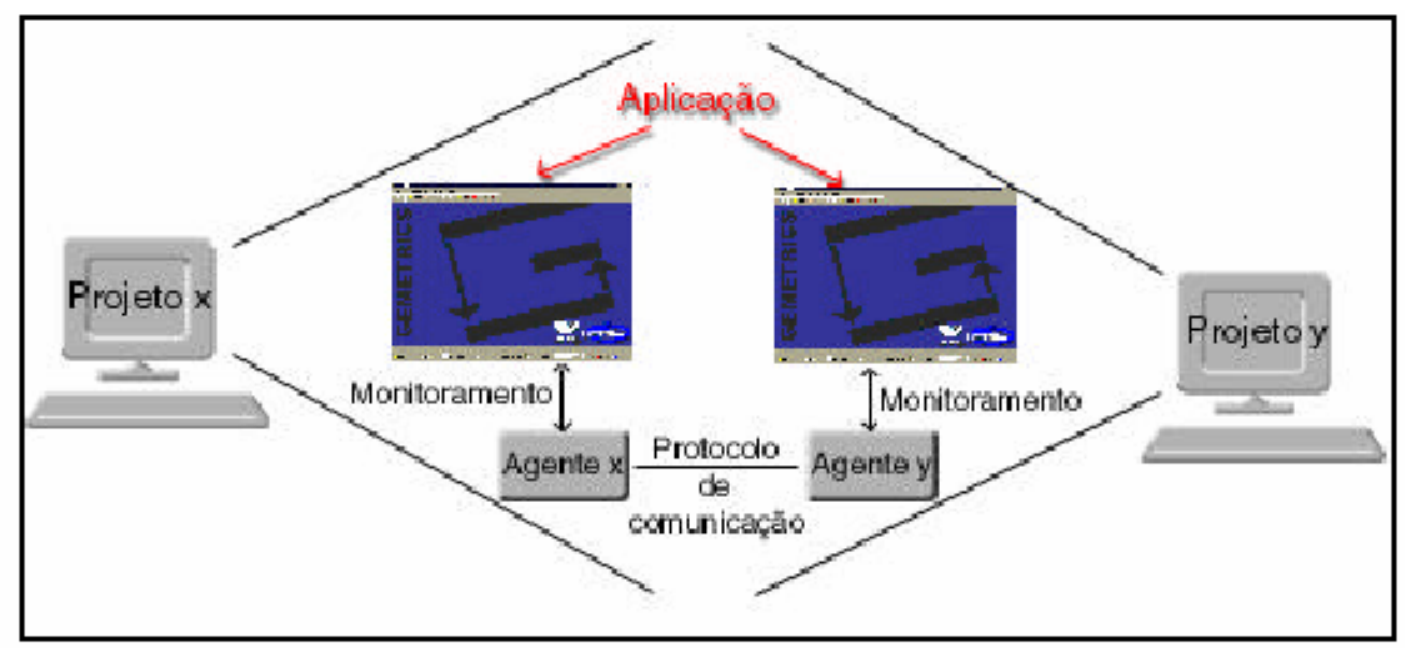

Figura 21: Arquitetura proposta

Fonte: VAVASSORI (2000)

A função do agente é monitorar a base de dados da aplicação e, conforme as situações percebidas neste ambiente, o agente utiliza um protocolo de comunicação específico para informar as alterações de um projeto para os demais projetos correlacionados. Algumas das responsabilidades dos agentes são: manter a coerência com os vínculos existentes entre atividades de diferentes projetos coordenando as relações de dependência, atualizar a visão global do gerenciamento através reunindo as atividades dos projetos correlacionados e manutenção de arquivos de log para controle de mensagens enviadas e reenvio de mensagens recusadas por algum problema na rede ou em algum agente.

A figura 22 mostra um exemplo do gráfico de Gantt com relação aos diferentes projetos cooperados: 


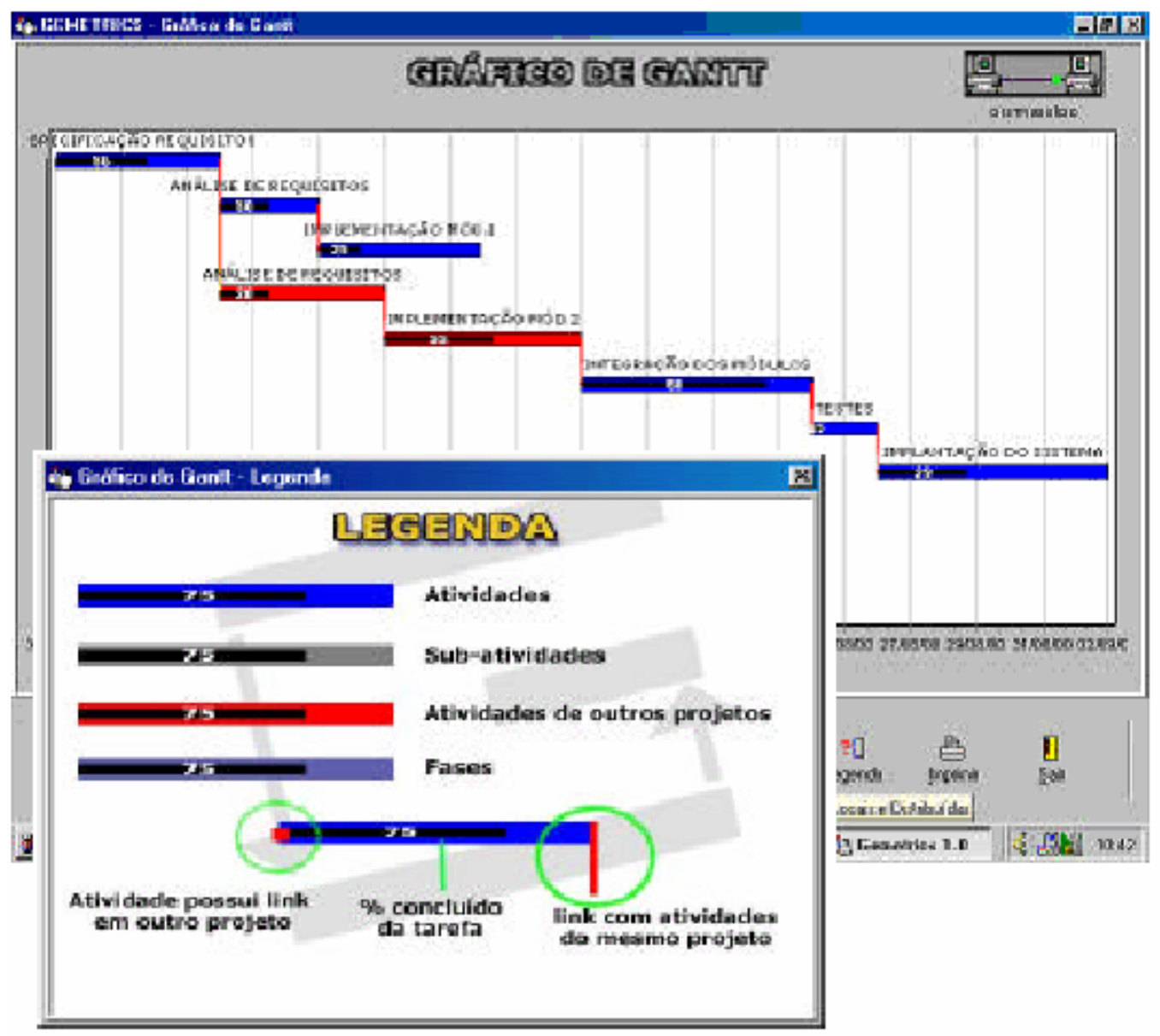

Figura 22: Gráfico de Gantt com projetos cooperados Fonte: VAVASSORI (2000)

Como no caso visto em HAMERI \& PUITTINEN (2003), não há nenhum detalhamento sobre o tratamento ao acesso dos usuários ao sistema, focalizando basicamente os mecanismos de comunicação. Não há uma estrutura centralizada para armazenamento das estruturas de dados, o que aumenta bastante a complexidade do trabalho dos agentes em manter 0 sincronismo dos dados através do envio de mensagens e que aumenta a cada inclusão de um novo nó/membro no ambiente distribuído.

CHENG et al. (2003): ferramenta para integração de sistemas heterogêneos como Primavera e MSProject através da tecnologia chamada Web Services. Os Web Services são componentes desenvolvidos para suportar funcionalidades básicas como ler ou gravar a duração de uma atividade. Para 
coordenar os diversos serviços a ferramenta possui um gerenciador centralizado, O FICAS (Flow-based Infrastructure for Composing Autonomous Services - Infra-estrutura para serviços autônomos compostos baseada em fluxo), que é responsável por distribuir a informação pela Web de forma concisa e coerente entre os diferentes aplicativos de visualização de dados. Em relação à origem de dados, a arquitetura necessita de um mecanismo de conversão do seu formato original (como arquivos do MS Project ou Primavera, por exemplo) para um formato padrão, no qual o sistema está baseado. Para a conversão de dados é preciso o desenvolvimento de programas específicos a cada plataforma, os Wrappers, e o formato padrão escolhido foi a PSL - Process Specification Language (Linguagem de Especificação de Processos), devido à sua capacidade no processamento de grandes volumes de informação e também pelas funcionalidades lógicas para a resolução de conflitos e verificação de consistência (figuras 23 e 24).

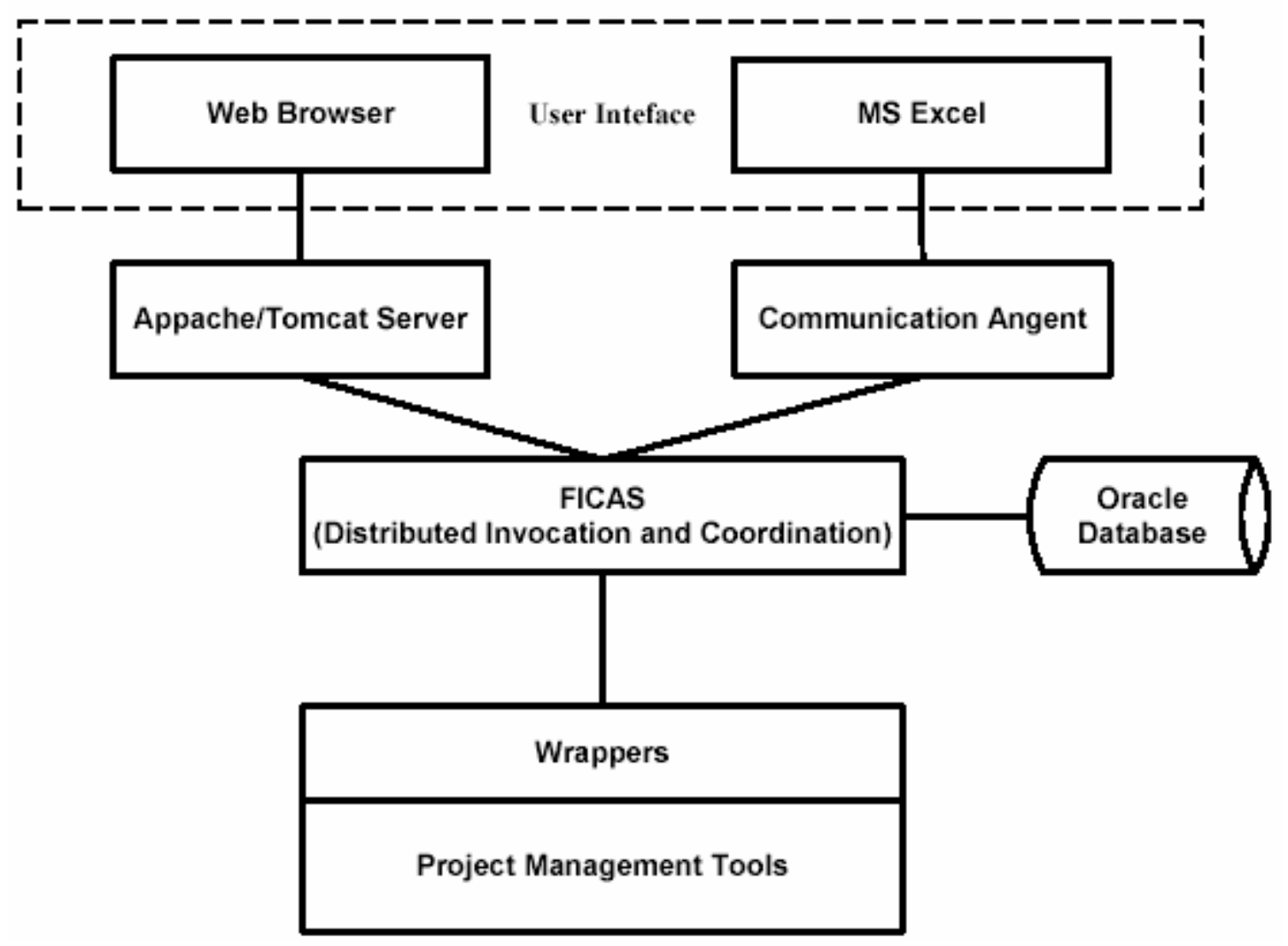

Figura 23: Arquitetura do Sistema

Fonte: CHENG et al. (2003) 


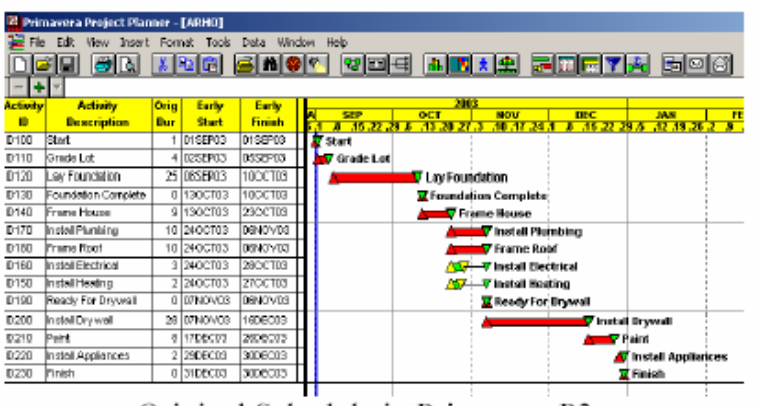

Original Schedule in Primavera P3

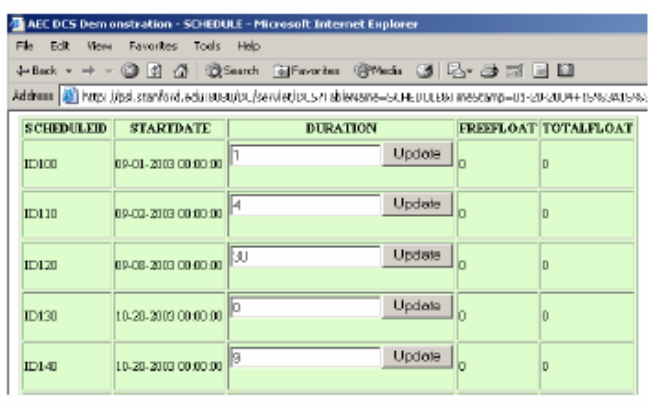

Review Updated Schedule Online

Figura 24: Visualização dos dados do Primavera no Web browser

Focada na comunicação entre os ambientes heterogêneos, possui o repositório de dados, o que capacita um ambiente de consolidação capaz de sincronizar as diferentes origens de dados, mas também falha ao não detalhar o mecanismo de acesso centralizado de usuários e demais recursos e também no tratamento dos apontamentos de tarefas e resultados dos projetos.

\section{OKUBO et al (2000): O PI-CEE - Project Information-Cooperative} Enterprise Environment (Ambiente para Informação e Cooperação de Projeto na Empresa) baseia-se na arquitetura Server-Integrated (Integrada pelo Servidor), que, por sua vez, é derivada em um modelo de negócio para construir sistemas empresariais. Corresponde a uma evolução do modelo de três camadas (apresentação, aplicação e de dados) para desenvolvimento de sistemas, com o acréscimo da camada de modelo de negócios, cuja função é flexibilizar mudanças de banco de dados, midleware (plataforma de comunicação) e de interface com o usuário. A implementação foi feita utilizando a linguagem Java e, através da Internet, utiliza localizações distribuídas para os membros do projeto. Através do modelo de negócio o sistema habilita funcionalidades de replicação e de notificação customizável no nível de usuário, o que garantiu o efetivo compartilhamento de informações. A figura 25 dá uma visão geral desta arquitetura: 


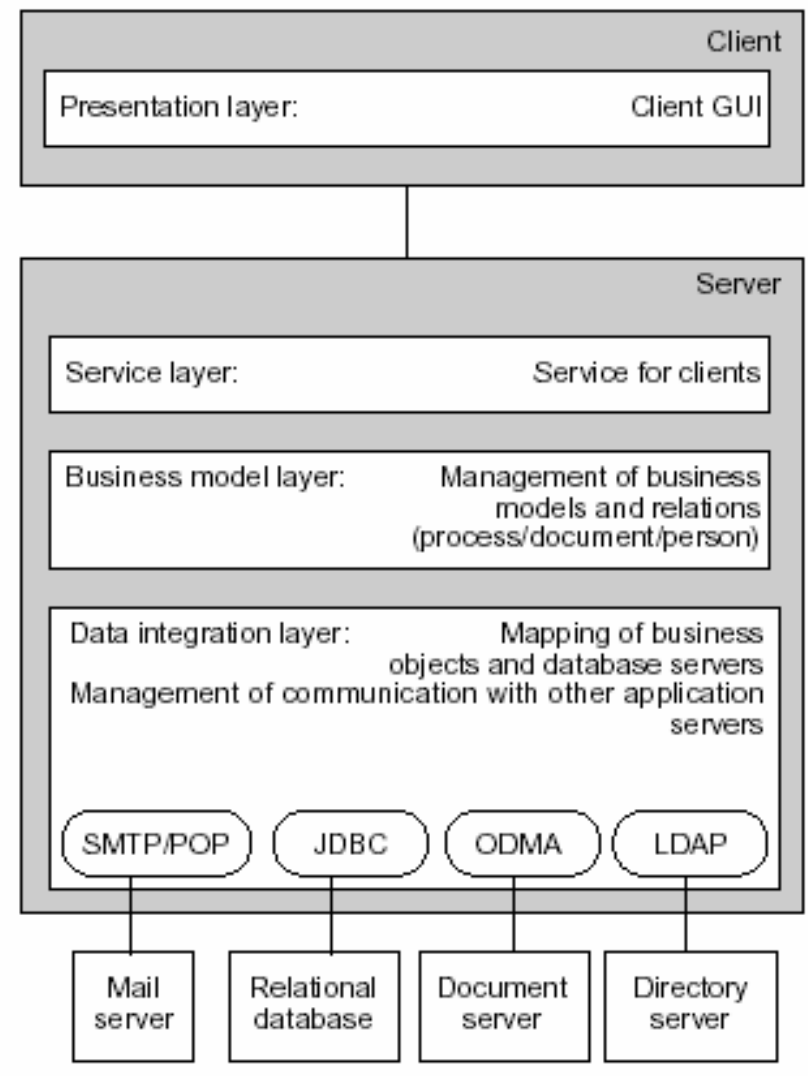

Figura 25: Visão geral da arquitetura Fonte: OKUBO et al (2000)

Pelo próprio foco na modelagem de negócios, não há no trabalho uma descrição de como são tratadas as atividades dos diferentes projetos, se há ou não uma WBS centralizada e se os objetos de negócio podem ser relacionados aos resultados dos projetos. Como nos sistemas anteriores, também falha no requisito de apontamento para monitoramento do projeto global como um todo.

\subsubsection{Considerações sobre o estado dos sistemas de GP}

A análise das três classes de sistemas de gestão de projetos demonstra claramente que a ênfase maior tem sido nas etapas iniciais do projeto, isto é, a integração entre a gestão de portfólio e os projetos em si. O tema da integração entre a estrutura do produto e a WBS é pouco explorado. Há casos apenas de sistemas propostos por pesquisadores o que denota que esta área se encontra em um estágio inicial.

Um fato interessante a observar é o desenvolvimento de um modelo de práticas para a gestão das configurações de projeto, incluindo WBS e 
Configuração do Produto, discutida pelo PMI (PSPCM, 2006). Esse esforço indica um início de estudos no sentido de integrar a gestão destes dois tipos de informações, sobre o produto e sobre o projeto, de maneira integrada, formando as bases para o que, no futuro, possa ser conhecido como Gerenciamento da Configuração do Projeto. Para que isso seja possível, é preciso entender os problemas e desenvolver práticas e tecnologias que permitam a união destes dados. Com o desenvolvimento deste modelo, espera-se dar início a uma nova geração de sistemas gerenciadores de projetos, que implementem uma abordagem aprofundada sobre a configuração do produto e, dessa forma, viabilizem o acompanhamento da execução do projeto ligado diretamente às alterações dos itens da configuração. 


\section{Método}

Numa pesquisa científica, é essencial embasar-se de referenciais teóricos e abordagens metodológicas que possuam plena aceitação do seu respectivo público alvo. Este capítulo descreve a metodologia de pesquisa adotada: a partir do problema de pesquisa definido, as justificativas e os objetivos a serem alcançados e, por fim, o enquadramento dentro de um referencial teórico e sua abordagem, justificando a escolha do método.

\subsection{Problema de Pesquisa}

As organizações (empresas públicas e privadas, instituições acadêmicas), com o desenvolvimento das técnicas de gerenciamento, estão desenvolvendo projetos cada vez mais complexos, compostos de muitas atividades e executados de forma distribuída, ou seja, entre empresas ou entre departamentos de uma organização ou universidade que estejam em localidades diferentes. Os esforços caminham no sentido de desenvolver produtos de maneira cooperada e seguindo um projeto global comum. Além disso, os modernos recursos computacionais possuem um poder de processamento maior que no passado recente, e assim, muitas dificuldades, como comunicação e distância, estão sendo vencidas permitindo uma maior integração.

No capítulo 2 deste trabalho, o PMBOK (2000) definiu que 0 gerenciamento de projetos (GP) é composto por um conjunto de atividades, conhecidas como processos do gerenciamento de projetos. As ferramentas computacionais desenvolvidas para a área de GP seguiram este paradigma, ou seja, privilegiaram o gerenciamento de atividades/tarefas, recursos e comunicações, com pouco ou nenhum foco sobre as questões dos projetos cooperados e da configuração do produto (CHO, 2001). Neste caso, o apontamento do trabalho realizado em cada subprojeto fica a cargo de cada subgerente, o que dificulta o acompanhamento do projeto global. Além disso, em cada subprojeto, como nos projetos com número de atividades reduzido, o lançamento do trabalho realizado no projeto/subprojeto é feito em momentos diferentes do momento de alteração da configuração do produto e da geração dos resultados, o que pode gerar dados incorretos e/ou imprecisos. A partir desse raciocínio, é apresentado o seguinte problema de pesquisa: 
"Como realizar o apontamento efetivo de atividades integrado às alterações na configuração do produto e dos resultados/entregas produzidos a partir de sistemas de acessíveis a pequenas organizações?".

\subsection{Justificativa}

A revisão bibliográfica demonstrou que os sistemas de gerenciamento de projeto em geral dependem do lançamento manual do trabalho realizado nos projetos. Mesmo havendo sistemas que gerenciam a configuração dos produtos, na prática, eles são implementados separadamente e não há integração que faça a ponte entre os resultados, mudanças na configuração, e a atualização dos itens da WBS.

Há vários trabalhos sobre gerenciamento de projetos focando, principalmente, a comunicação entre projetos, como em LI et al. (2004) e HAMERI \& PUITTINEN (2003). Pôde-se perceber que mesmo nos sistemas de código-aberto e nos protótipos e modelos propostos pela literatura científica, poucos trabalhos focam especificamente o tema.

Avança também o conceito de gestão do ciclo de vida de produtos (PLM), no qual se discutem soluções integradas para o desenvolvimento de produto, porém este aspecto específico da integração também não é discutido ou apresentado em detalhes. Além disso, a maioria das soluções integradas existentes são caras e demandam muito esforço de implantação.

Portanto, apesar da proximidade dos conceitos de gestão da WBS e configuração e a importância de um estreito relacionamento entre estes elementos, a solução deste problema ainda não foi sistematizada e compreendida. Isso se deve às origens diferenciadas de cada um destes sistemas, que só agora, com o conceito de PLM e a sofisticação dos sistemas de gestão de projetos, começam a fazer parte da agenda de pesquisa.

$\mathrm{Na}$ prática, as empresas não fazem uso do fluxo de trabalho para finalizar o trabalho planejado no projeto. Muitas vezes, os lançamentos do trabalho realizado não correspondem ao trabalho desenvolvido, devido às alterações no produto não serem sincronizadas ao apontamento. Além disso, a resolução do problema de pesquisa viabiliza o gerenciamento do apontamento 
do projeto integrado à configuração sem necessitar da aquisição de sistemas complexos, como os sistemas PLM, e de alto custo, normalmente acessível apenas para as grandes corporações. Além disso, empresas que se relacionam com empresas possuidoras destes sistemas normalmente se vêem obrigadas a adquirirem o sistema para poder integrar suas informações ou implementar uma interface adequada.

O tema deverá ser uma preocupação atual forte, dado que a união entre gestão da configuração e da WBS começa a ser discutida pelo PMI. Esta organização identificou uma carência no tema e está trabalhando no desenvolvimento de um padrão para integrar as duas gestões, da WBS e da configuração, sob o rótulo da Gestão da Configuração de Projetos (PSPCM, 2006).

\subsection{Objetivo}

O objetivo do trabalho é: especificar e modelar uma interface entre os pacotes de trabalho da WBS dos sistemas de gerenciamento de projetos e os itens da configuração do produto para o acompanhamento do trabalho do projeto integrado às alterações nos itens da configuração.

A especificação e modelagem da interface entre os sistemas de gerenciamento do projeto e da configuração devem estar focadas na apuração do trabalho realizado, ou seja, derivadas diretamente das alterações realizadas no produto e não mais, a partir dos lançamentos manuais periódicos no sistema de gerenciamento do projeto. A meta da interface é garantir a efetividade da informação e fornecer subsídios para ambientes, onde o acompanhamento do trabalho é complexo como, por exemplo, os projetos distribuídos.

\subsection{Contribuição científica}

Ao propor uma interface específica, espera-se contribuir de duas maneiras: de forma mais ampla, para os usuários e profissionais que utilizam estes sistemas, o trabalho busca identificar os problemas envolvidos nesta integração e um conjunto de requisitos que devem ser atendidos para que ela 
possa ocorrer; como segunda contribuição, os pesquisadores e profissionais da área de sistemas para gestão de projetos, de configuração e do ciclo de vida de produto poderão beneficiar-se adicionalmente da especificação e teste de uma solução viável possível, a qual pode ser estendida, aperfeiçoada ou reutilizada em pesquisas sobre o tema.

\subsection{Método}

Dentre os inúmeros conceitos de método científico, este trabalho adota a definição de ABBAGNANO (1970) no qual é "um procedimento de investigação ordenado, repetível e auto-corrigível, que garanta a obtenção de resultados válidos", pois é voltado para o uso de técnicas ou métodos de pesquisa.

As seções 3.5.1, 3.5.2 e 3.5.3 tratam, respectivamente, do referencial teórico, da abordagem e do método de pesquisa propriamente dito.

\subsubsection{Referencial Teórico}

Uma pesquisa deve ser enquadrada dentro de sua área mais abrangente, com o objetivo de relacionar as correntes que estudam os métodos de pesquisa da área selecionada. Esse enquadramento é chamado de referencial teórico e diferentes referenciais influem diferentemente na compreensão da realidade e conseqüentemente nos resultados obtidos (PÁDUA, 1996).

O referencial adotado neste trabalho foi o referencial positivista devido aos seguintes fatores:

- Busca fatos ou causas de um fenômeno, dando pouca importância aos aspectos subjetivos dos indivíduos (PATTON, 1980);

- Assume que existe no mundo uma verdade objetiva que pode ser revelada por método científico cujo enfoque é a mensuração sistemática e estatística de relacionamentos entre variáveis (CASSEL, 1994); 
- Tem como característica a formulação de hipóteses que serão testadas por meio de experimentos ou análises estatísticas (KAPLAN \& DUCHON, 1988);

- Uma pesquisa puramente positivista segue o paradigma hipotético-dedutivo (PATTON, 1980). Neste ponto, vale ressaltar que o critério da verificabilidade foi trocado pelo da falseabilidade (MARTINS, 1995), ou seja, as hipóteses continuam válidas até o momento que possam ser refutadas.

\subsubsection{Metodologia de Pesquisa}

O principal resultado deste trabalho é a especificação e modelagem de uma interface entre sistemas que corresponde a uma solução computacional (software). Em ambos, a intervenção do pesquisador é direta, o que segundo DANE (1990) caracteriza o método de pesquisa participante-observador (participant-as-observer), também rotulado como pesquisa-ação. A ausência de literatura e ferramentas computacionais que resolvessem o problema de pesquisa acaba por determinar a influência do pesquisador na pesquisa e conseqüentemente na escolha do método.

No sentido de justificar a escolha do método pode-se citar o trabalho de GUMMENSON (2000), que relacionou as principais características da pesquisa-ação:

- Pesquisadores conduzem a ação;

- A pesquisa-ação sempre envolve resolver um problema e contribuir para a ciência;

- É interativa, ou seja, pesquisadores e clientes (consumidores finais dos resultados da pesquisa) estão sempre trocando informações o que gera novos ajustes no desenvolvimento do trabalho;

- Visa desenvolver entendimento holístico e reconhecer complexidade, pois a natureza tecnológico-social das organizações envolve tanto a visão clara de como o sistema da 
organização trabalha, quanto os subsistemas informais gerados pelas pessoas que a compõem;

- Fundamentalmente, a pesquisa-ação objetiva a mudança, ou seja, entendimento, planejamento e implementação de um conceito, no sentido de mudanças em firmas de negócios e outros tipos de organizações;

- Requer o entendimento dos valores éticos existentes no local onde a pesquisa será aplicada;

- Pode utilizar todos os tipos de métodos de coleta de dados: qualitativos ou quantitativos;

- Há a necessidade de um amplo conhecimento por parte do pesquisador sobre o ambiente ou organização na qual se desenrolará a pesquisa, visando que o mesmo saiba identificar quando a pesquisa esteja tomando rumos incorretos;

- Deveria ser aplicada em tempo real e aceitável na forma retrospectiva, se este caso passado puder ser usado como mecanismo de intervenção dentro da organização no presente.

Apesar da correspondência do método escolhido em relação à solução proposta, não se pode deixar de expor as limitações do método, que se baseia nas características gerais dos sistemas gerenciadores de projetos e da configuração do produto, mas que pode ser conflitante em pontos específicos de cada sistema. Exemplos disso são: a flexibilidade de configuração/inclusão de funcionalidades, o mecanismo interno de acompanhamento do projeto e a importação/exportação de informações (recursos do projeto, por exemplo). Dessa forma, o método de trabalho não pode ser generalizado, pois todas as possibilidades de refutação não podem ser atingidas, devido ao trabalho tratar apenas de casos particulares de aplicação. Além disso, existe a influência do pesquisador na avaliação e análise dos resultados.

\subsubsection{Metodologia de Desenvolvimento}

A especificação e modelagem da interface utilizaram a linguagem UML (Unified Modeling Language), que é um padrão mundial na modelagem de 
sistemas devido à sua característica de representar os comportamentos dinâmico e estático de um sistema através de seus diagramas. A metodologia se baseou nas etapas iniciais da metodologia RUP (PROBASCO, 2000), como pode ser visto na figura 26.

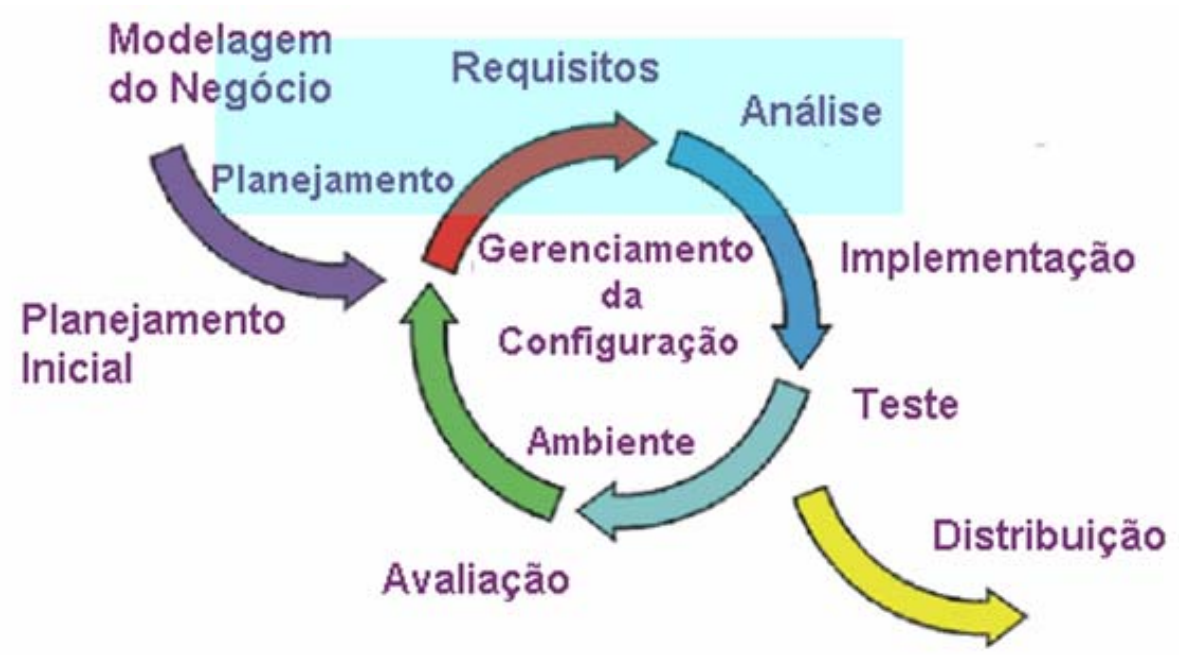

Figura 26: Metodologia RUP

Fonte: PROBASCO (2000)

Além disso, foram utilizados esquemas gráficos e textos descritivos para detalhar a organização e funcionalidades dos componentes. A metodologia adotada contém os seguintes passos, considerando a parte relacionada aos requisitos e análise, pois o planejamento será visto na seção seguinte (seção 3.4.4) que trata das etapas do trabalho:

- Análise de Requisitos: definição do escopo da solução. Partindo do ponto de vista do usuário, foram levantadas as informações relevantes, quais respostas ele deve fornecer, requisitos específicos como performance e grau intuitivo da interface. Foi representada através da especificação de casos de uso, incluindo diagramas e fluxos de eventos;

- Especificação: refinamento do escopo direcionado a delimitar a área de atuação do sistema. Contém a lista de requisitos definitiva e as funcionalidades que o sistema deve suportar dentro do escopo definido. 
- Modelagem: extração das entidades relevantes para armazenamento de informações na base de dados e mapeamento do fluxo de informações entre as entidades. Foram utilizados os diagramas de classes;

- Exemplo: detalhamento da construção de um exemplo de solução em um ambiente real a partir de da especificação e modelagem propostas.

\subsubsection{Etapas do Trabalho}

De acordo com o método pesquisa-ação adotado (GUMMENSON, 2000), é necessário realizar um planejamento voltado ao desenvolvimento do trabalho com objetivo final de resolver o problema de pesquisa. Neste sentido, as atividades descritas na metodologia devem ser organizadas dentro de um intervalo de tempo e numa seqüência correta para a geração de resultados parciais e culminando com o resultado final e que corresponde ao objetivo do trabalho: a especificação e modelagem da interface proposta. Ressaltando o fato que o pesquisador foi quem conduziu o desenvolvimento das atividades planejadas, o qual está de acordo com o método adotado, são detalhadas abaixo as etapas do trabalho de pesquisa:

\subsubsection{Etapa 1 - Levantamento de Requisitos Iniciais}

Através da revisão bibliográfica sobre gerenciamento de projetos e da configuração do produto, as abordagens dos diferentes sistemas de gerenciamento do projeto com relação ao acompanhamento do projeto e seu relacionamento com a configuração foram detalhadas. Como resultado obtevese os requisitos iniciais a serem suportados pela interface. Etapas derivadas:

- E1.1: avaliação do acompanhamento de projetos nos sistemas de gerenciamento de projetos;

- $\quad$ E1.2: controle de alterações na configuração do produto no projeto;

- E1.3: compilação dos problemas no gerenciamento de projetos e da configuração;

- E1.4: compilação dos requisitos iniciais. 


\subsubsection{Etapa 2 - Especificações dos Casos de Uso}

Com base nos requisitos iniciais, foram levantadas as situações, do ponto de vista do usuário, dentro do gerenciamento de projetos e da configuração do produto, relacionadas diretamente às alterações de um item da configuração e à mensuração e exportação do trabalho realizado para o sistema gerenciador de projetos. Foram utilizados diagramas de caso de uso da UML, fluxo de eventos e condições anteriores e posteriores. Etapas derivadas:

- E2.1: dados do projeto-produto;

- E2.2: importação dos recursos e pacotes de trabalho;

- E2.3: associação do item da configuração ao pacote de trabalho;

- E2.4: controle de status;

- E2.5: apontamento do trabalho;

- $\quad$ E2.6: controle de aprovações;

- $\quad$ E2.7: exportação de informações do apontamento.

\subsubsection{Etapa 3 - Especificação Técnica da Interface}

A partir dos casos de uso, esta etapa trouxe como resultados a lista definitiva de requisitos e a lista de funcionalidades da interface. Etapas derivadas:

- E3.1: lista final de requisitos;

- $\quad$ E3.2: lista de funcionalidades.

\subsubsection{Etapa 4 - Modelagem da Base de Dados}

Da especificação técnica e dos casos de uso foram extraídas as entidades relevantes e seus relacionamentos pertencentes à interface, cujas informações devem ser armazenadas em tabelas numa base de dados. A modelagem é realizada através de diagramas de classe da UML. Etapas derivadas:

- E4.1: projeto, produto e relacionamentos;

- E4.2: pacotes de trabalho, itens da configuração, recursos, dependências entre pacotes e relacionamentos; 
- E4.3: controle de status e relacionamentos.

\subsubsection{Etapa 5 - Modelagem das Funcionalidades}

Utilizando diagramas de seqüência da UML, foram mapeados os fluxos de informações entre as entidades para detalhamento das funcionalidades da interface. Etapas derivadas:

- E5.1: projeto e produto;

- E5.2: pacotes de trabalho, itens da configuração, recursos e dependências entre pacotes;

- E5.3: apontamento;

- E5.4: controle de status e aprovações;

- $\quad$ E5.5: exportação de informações do apontamento;

\subsubsection{Etapa 6 - Exemplo de Aplicação da Interface}

Com base em um ambiente de desenvolvimento de produto controlado por um sistema gerenciador de projetos e alterações dos componentes controladas por um sistema gerenciador da configuração (controle de versões), foram detalhadas as adaptações e implementações a serem realizadas, a partir da especificação e modelagem, para a criação de uma solução exemplo para a interface proposta. Etapas derivadas:

- E6.1: base de dados;

- E6.2: interface projeto-produto;

- E6.3: Interface pacote de trabalho - item da configuração;

- E6.4: controle de status e aprovações;

- $\quad$ E6.5: exportação de informações do apontamento;

A próxima seção traz os detalhes de modelagem e especificação, enquanto a seção 5 descreve a aplicação de uma solução exemplo. 


\section{Descrição da Interface entre Sistemas Gerenciadores de Projetos e a}

\section{Configuração do Produto}

Esta seção descreve a especificação e modelagem da interface é organizada da seguinte forma: inicialmente, na seção 4.1, é detalhada uma lista de requisitos iniciais exigidos para a interface proposta; a seção 4.2 trata da especificação técnica, com a descrição dos casos de uso e o levantamento final de requisitos, enquanto a seção 4.3 descreve a modelagem realizada para a solução de interface com uma descrição detalhada de seus componentes.

\subsection{Problemas e Requisitos Iniciais para Construção do Modelo}

Como contribuição inicial deste trabalho, e a partir da análise da literatura consultada, obteve-se uma lista com os principais problemas encontrados no gerenciamento de projetos e da configuração e, com base neste levantamento, uma compilação de requisitos para a interface proposta.

\subsubsection{Problemas no Gerenciamento de Projetos Relacionados à Configuração do Produto}

Segue abaixo uma síntese da literatura consultada sobre os principais problemas encontrados no gerenciamento do projeto e da configuração do produto:

a) Comunicação: ocorrência de muito re-trabalho devido a conflitos de informações e informações não recebidas a tempo pelas partes envolvidas, cujo principal problema é o fluxo incorreto de informações entre as partes (ALSHAWI \& INGIRIGE, 2003; HAMERI \& PUITTINEN, 2003);

b) Automação nas práticas de gerenciamento: há problemas que variam desde o conflito entre a documentação eletrônica e a prática cultural da documentação impressa (muito comum na indústria da construção); até o alto grau de especialização das ferramentas de TI (Tecnologia da Informação) e que possuem nenhum ou rígidos mecanismos de interligação, gerando um nível baixo de integração e 
visão global do fluxo de informação entre os vários níveis do projeto (ALSHAWI \& INGIRIGE, 2003). Além disso, há problemas de padronização e incompatibilidade entre hardware e software e ferramentas de apoio à tomada de decisão com relação às múltiplas entradas existentes derivadas dos diversos subprojetos pertencentes ao projeto global (ALSHAWI \& INGIRIGE, 2003; KOVÁCS \& PAGANELLI, 2003);

c) Padronização no gerenciamento do projeto: o gerenciamento de projetos é normalmente realizado de acordo com a experiência pessoal dos gerentes, o que gera muita variação nas práticas de gerenciamento e pode criar um impacto significante na capacidade de coordenar e controlar a informação do projeto (ALSHAWI \& INGIRIGE, 2003). A diversidade de projetos gera um alto grau de complexidade no planejamento de difícil aplicação na padronização (KOVÁCS \& PAGANELLI, 2003);

d) Segurança: deve haver um mecanismo de proteção dos dados de cada subprojeto, que podem ter segredos de negócio, principalmente em ambiente de comunicação globalizada como a Internet (RUPP \& STEINER, 2003). A tecnologia não é mais barreira para a segurança de acesso em um ambiente de acesso global como a Internet (HAMERI \& PUITTINEN, 2003);

e) Escalabilidade: o sistema deve ser adaptável aos diferentes tipos de projetos; deve ter a possibilidade de permitir a entrada de novos projetos dentro do projeto global, ou ainda, disponibilizar novos recursos aos projetos existentes (RUPP \& STEINER, 2003; KOVÁCS \& PAGANELLI, 2003);

f) Facilidade de Uso: a variação dos possíveis usuários nos diferentes tipos de projetos, a interface do sistema deve ser intuitiva (RUPP \& STEINER, 2003);

g) Representação unificada e generalizada das atividades dos projetos: compreendendo itens materiais e não materiais como, por 
exemplo, produtos, conhecimento, documentos que precisam ser organizados em projetos complexos (KOVÁCS \& PAGANELLI, 2003);

h) Integração com os sistemas locais de planejamento e gerenciamento: o sistema deve salvaguardar a autonomia dos projetos locais e os investimentos em tecnologia da informação, como os planejamentos de projetos locais (KOVÁCS \& PAGANELLI, 2003). Para isso, torna-se necessário o desenvolvimento de ferramentas para a colaboração entre os sistemas heterogêneos (CHENG et al., 2003);

i) Estruturas e documentos: os projetos devem ser organizados em entidades que possam mapear todo o conjunto de informações necessárias para um ambiente distribuído, como eventos, documentos dos mais variados tipos, subprojetos, recursos, atividades, interrelacionamentos e controles de versão e status. Exemplos comuns são a estrutura do produto e a WBS do projeto (HAMERI \& PUITTINEN, 2003). Uma estruturação da WBS com relação aos principais componentes do projeto (figura 10, seção 2) não é recomendada, por dificultar a subdivisão em pacotes de trabalho e o controle de mudanças; o melhor é estruturar considerando a estrutura dos itens da configuração e as entregas (ICM, 2003; PMI, 2001).

\subsubsection{Requisitos Iniciais para a Construção da Interface}

Tomando como base os problemas levantados na seção anterior e a revisão bibliográfica, obteve-se uma lista de requisitos necessários para possíveis sistemas de gerenciamento e que a interface proposta neste trabalho deve suportar. A tabela 2 descreve os requisitos e sua aplicação na interface:

\begin{tabular}{|l|l|}
\hline \multicolumn{1}{|c|}{ Requisitos } & Aplicação na I nterface \\
\hline Relacionamento entre & Os pacotes de trabalho oriundos do \\
as atividades da WBS e & detalhamento da WBS devem possuir relação \\
itens da configuração/ & direta com os itens da configuração afetados, \\
resultados (Requisitos & ou seja, deve ser possível, a partir de um item \\
a, b, g, i) & da estrutura de produto saber quais \\
& atividades/pacotes de trabalho estão \\
\hline
\end{tabular}




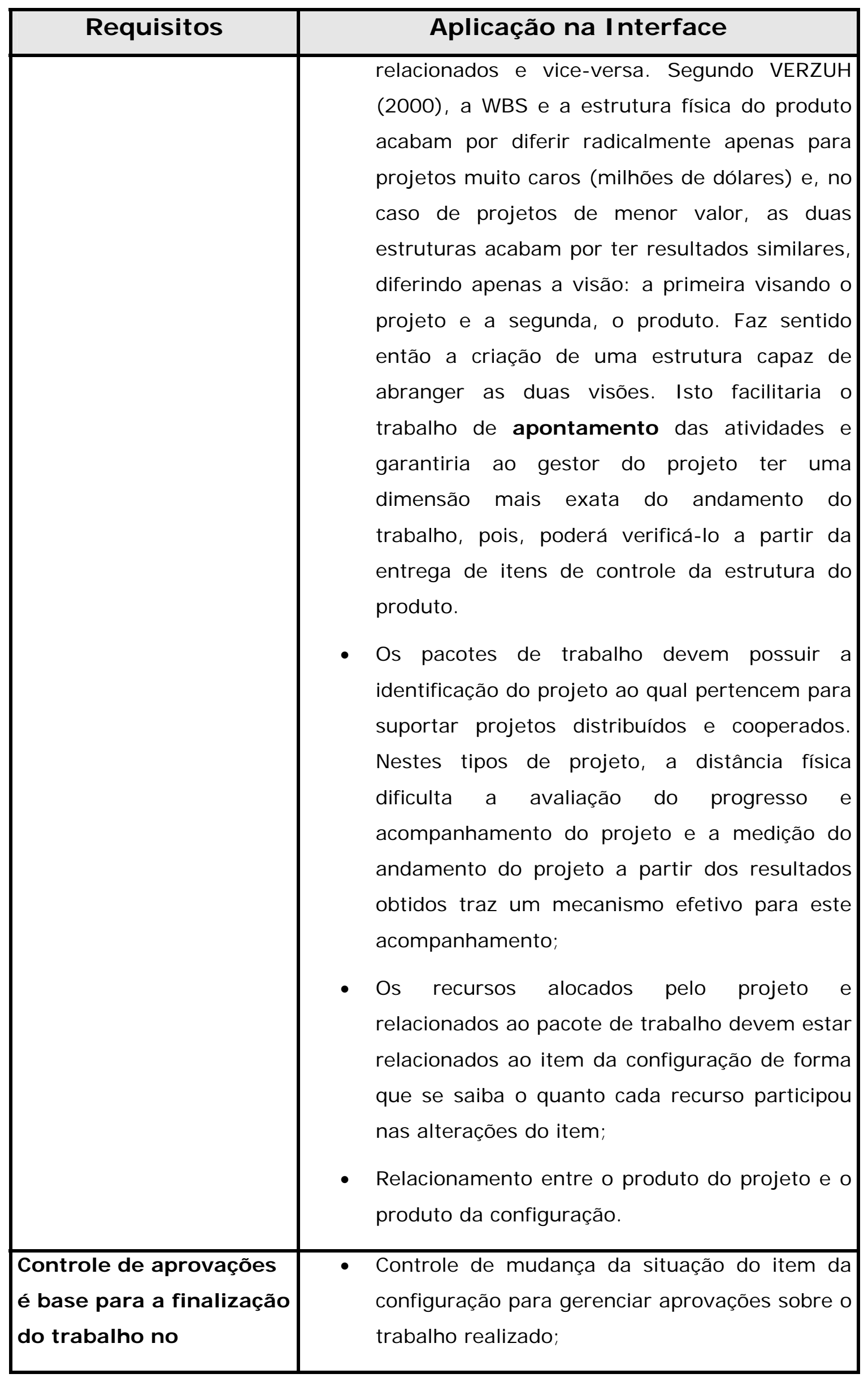




\begin{tabular}{|c|c|}
\hline Requisitos & Aplicação na I nterface \\
\hline $\begin{array}{l}\text { apontamento dos } \\
\text { resultados (Requisitos } \\
\text { b, c) }\end{array}$ & $\begin{array}{l}\text { - A aprovação do item da configuração indica que } \\
\text { o mesmo está finalizado e liberado para } \\
\text { entrega. Deve haver um mecanismo que possa } \\
\text { armazenar o trabalho gasto durante as } \\
\text { alterações realizadas sobre o item da } \\
\text { configuração até sua aprovação/finalização; } \\
\text { - Controle nos itens da configuração e pacotes de } \\
\text { trabalho sem itens associados para lançamento } \\
\text { dos dados relacionados ao trabalho realizado. }\end{array}$ \\
\hline $\begin{array}{l}\text { Acessibilidade aos itens } \\
\text { da configuração } \\
\text { relacionada à alocação } \\
\text { de recursos do projeto } \\
\text { ( Requisito d) }\end{array}$ & $\begin{array}{l}\text { - Recursos da configuração devem ser possuir } \\
\text { correspondente único no projeto (por exemplo, } \\
\text { recursos mão-de-obra do projeto devem } \\
\text { corresponder a um único usuário na } \\
\text { configuração); } \\
\text { - Acesso de um usuário do projeto a um } \\
\text { determinado nível da configuração do produto } \\
\text { deve ser restrito aos itens de configuração } \\
\text { associados aos pacotes de trabalho a ele } \\
\text { alocado. }\end{array}$ \\
\hline $\begin{array}{l}\text { Base de dados da } \\
\text { configuração do projeto } \\
\text { ( Requisitos a, g, h, i) }\end{array}$ & $\begin{array}{l}\text { - Projeto/produto para controle de projetos } \\
\text { distribuídos e cooperados } \\
\text { - Pacotes de trabalho para relacioná-los aos itens } \\
\text { da configuração e também poder fazer a } \\
\text { integração com o sistema gerenciador de } \\
\text { projetos; } \\
\text { - Itens da configuração; } \\
\text { - Relacionamento dos pacotes de trabalho com } \\
\text { os itens da configuração; } \\
\text { - Relacionamento dos recursos da configuração } \\
\text { com os recursos do projeto. } \\
\text { Controle de Situação. }\end{array}$ \\
\hline
\end{tabular}




\begin{tabular}{|c|c|}
\hline Requisitos & Aplicação na Interface \\
\hline $\begin{array}{l}\text { Mecanismo de troca de } \\
\text { informações entre a } \\
\text { configuração do produto } \\
\text { e o gerenciamento do } \\
\text { projeto ( Requisitos e, h) }\end{array}$ & $\begin{array}{l}\text { - Importação de dados, pacotes de trabalho e } \\
\text { recursos do sistema de gerenciamento do } \\
\text { projeto para o sistema de gerenciamento da } \\
\text { configuração; } \\
\text { - Exportação do apontamento medido do } \\
\text { trabalho realizado na configuração do produto } \\
\text { para ser gravado nos campos-chave de } \\
\text { acompanhamento do projeto no sistema de } \\
\text { gerenciamento de projetos. }\end{array}$ \\
\hline
\end{tabular}

Tabela 2: Requisitos iniciais para a construção da interface

\subsection{Análise de Requisitos e Especificação Técnica}

A partir dos requisitos iniciais foram desenvolvidos os casos de uso relacionados à construção de uma interface que possibilite o lançamento de horas trabalhadas no projeto a partir das alterações realizadas sobre os itens da configuração do produto. Inicialmente, na seção 4.2.1, é realizada uma descrição informal do funcionamento desejado para a interface proposta. A seção 4.2.2 trata do detalhamento dos casos de usos extraídos da descrição informal enquanto a. seção 4.2.3, como resultado da etapa anterior, traz uma compilação final de requisitos e funcionalidades necessárias para a modelagem da interface.

\subsubsection{Descrição Conceitual da Interface}

Segue abaixo um texto com a descrição na forma narrativa para 0 funcionamento da interface e, logo a seguir, é mostrado um diagrama conceitual da interface:

"O gerente de projetos deve, inicialmente, criar a WBS do projeto e, em seguida, realizar o detalhamento das atividades até o nível de pacotes de trabalho. No ambiente da configuração do produto, o gerente da configuração deve acessar a interface e informar quais produtos e quais projetos relacionados a eles serão controlados. Para cada projeto informado, devem ser importados os recursos (apenas o tipo mão-de- 
obra será suportado) e os pacotes de trabalho relacionados; questões de conflitos e nivelamento de recursos ficarão a cargo exclusivo do sistema gerenciador de projetos. Para os pacotes de trabalho, também serão importadas as respectivas dependências.

No momento do acesso do usuário participante do projeto à interface, deve ser verificado se o usuário está cadastrado no ambiente da configuração. Em caso positivo, o usuário deve selecionar o produto e projeto de trabalho; neste ponto, a interface deve verificar se o usuário pertence à lista de usuários importados para o projeto. Com o usuário autorizado, são exibidos os pacotes de trabalho disponíveis para alteração: os pacotes devem estar relacionados ao usuário e dentro de uma dependência onde os possíveis pacotes antecessores/sucessores já tenham liberado a restrição. $O$ usuário pode então selecionar um pacote de trabalho disponível e associar itens da configuração para alteração: no primeiro acesso ao item deve iniciar o apontamento automático, que só se encerrará na aprovação das alterações (descrita mais adiante). No momento que o usuário terminar seu acesso ao item, o sistema deve solicitar a informação da quantidade de trabalho restante estimada. 0 trabalho de alteração do usuário no item só termina quando o usuário informar que a quantidade restante é zero e, neste momento, a alteração do item está pronta para ser finalizada. Enquanto o item não estiver finalizado, outro usuário não pode efetuar modificações. Deve poder ser realizada uma operação de finalização de trabalho semelhante nos pacotes de trabalho que não possuem relacionamento com itens da configuração.

A aprovação ou finalização de apontamento de um item (o pacote não terá situação e será finalizado diretamente pela atribuição da quantidade realizada) deve ser vinculada a uma determinada situação do item da configuração e é executada sobre os itens que tiveram todas as alterações realizadas (quantidade de trabalho restante igual a zero). Deve possibilitar a alteração da situação de um item da configuração e também da configuração de situações que indiquem que o item está em um estado de aprovado/finalizado ou bloqueado. Itens não aprovados devem ser encaminhados para nova modificação pelo responsável da modificação 
original. Este controle, para dar flexibilidade às possíveis regras de apontamento do término do trabalho, também deve possibilitar a existência de uma lista usuários associados a determinadas situações do item, que possam aprovar diretamente o mesmo, mas também fazer apenas uma verificação, sem direito de aprovação, criando um requisito que, se não for satisfeito, restringe uma futura aprovação.

A interface deve viabilizar uma forma de disponibilizar os dados levantados com o apontamento para o sistema de gerenciamento do projeto."

Da descrição acima, criou-se uma primeira visão (figura 27), de nível conceitual, do objetivo definido para a interface: viabilizar a troca de informações geradas as atividades do projeto e na alteração dos produtos envolvidos na configuração para acompanhar o desenvolvimento efetivo do trabalho realizado. Conseqüentemente, acabam sendo envolvidos neste contexto direta ou indiretamente, todos os sistemas relacionados ao projeto e ao produto como os sistemas de gerenciamento de projetos, gerenciamento da configuração, controle do fluxo de trabalho, cálculo de custos, etc. Além disso, verifica-se que o escopo de atuação da interface se encontra dentro da configuração do produto: enquanto o gerenciamento de projetos corresponde a uma fonte de informações para processamento (pacotes de trabalho) e posterior gravação (apontamentos), na configuração, além da comunicação de dados, a interface também gerencia, por exemplo, acesso aos dados e gravações dos itens da configuração. 


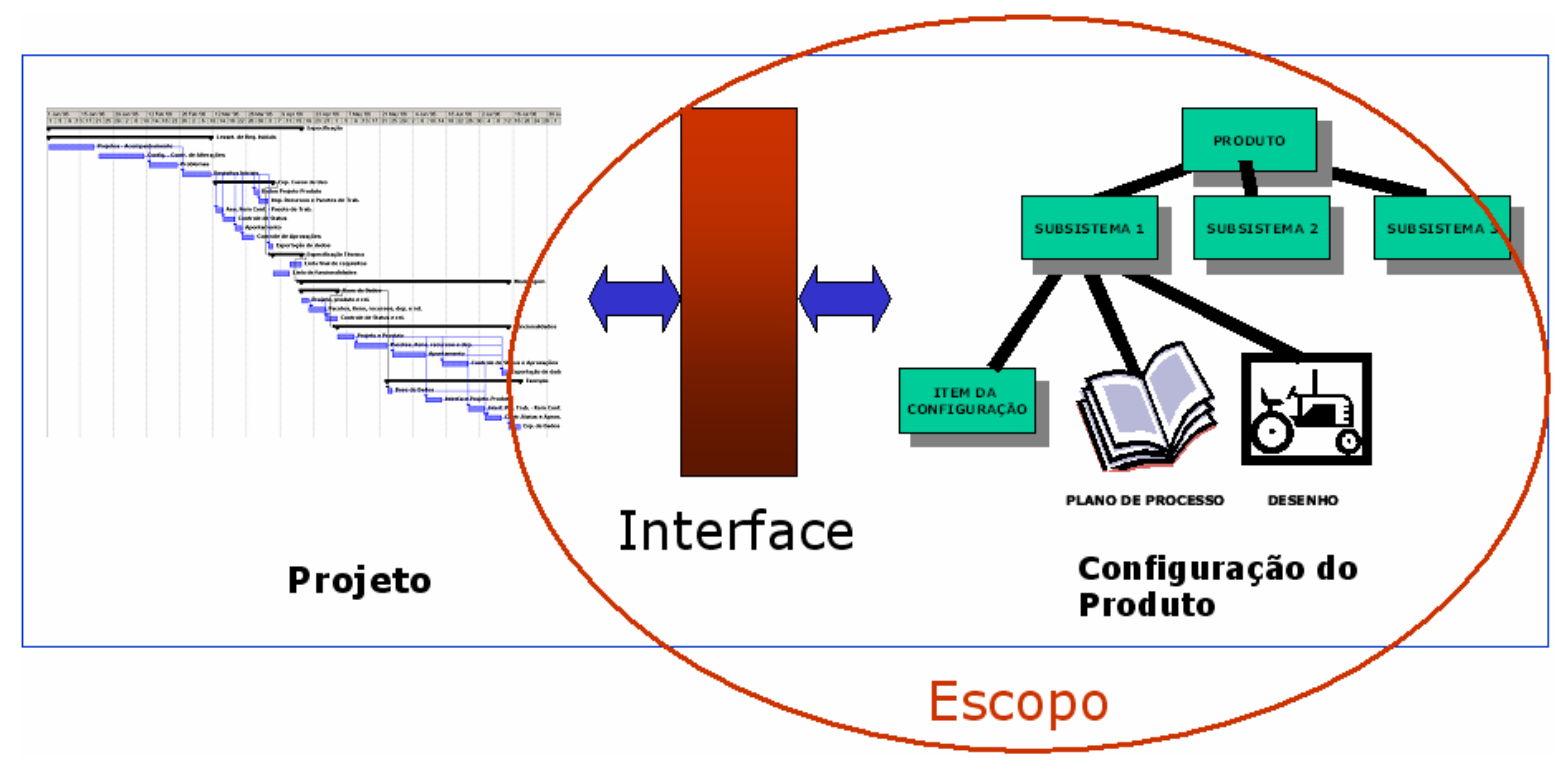

Figura 27: Visão conceitual da interface

Observando a figura 27, verifica-se que a área de atuação da interface é a configuração do produto (o apontamento de horas é derivado das as alterações nos itens da configuração), mas também é necessário obter informações da WBS do projeto, para saber quais atividades (pacotes de trabalho). Basicamente, estas informações estão relacionadas diretamente ao pacote de trabalho como nome da atividade, quantidade de horas de trabalho planejada, etc.

De acordo com a descrição informal apresentada, devido às funcionalidades de relacionamento do item ao pacote de trabalho e controle de situações é necessário que a WBS, além das suas informações originais, disponibilize mais três informações:

- Pacote de Trabalho: para indicar se a atividade da WBS corresponde a um pacote de trabalho (relacionada à operação de detalhamento);

- Permissão de Associação de Itens: para cada pacote de trabalho, informar se pode haver associação de itens da configuração ao pacote de trabalho pela interface;

- Processo de Aprovação: campo para indicar se os possíveis itens pertencentes ao pacote ao serem finalizados terão que 
passar pelo processo de aprovação pela lista de usuários de aprovação.

\subsubsection{Especificação dos Casos de Uso}

Esta seção detalha os casos de uso levantados a partir da descrição informal da interface. O detalhamento dos casos de uso será baseado no modelo de casos de uso descrito em KULAK \& GUINEY (2004) e que segue a seguinte estrutura:

Descrição: <Relato sucinto das ações e eventos ocorridos no caso de uso> . Atores: <Entidades externas que interagem diretamente com o sistema>. Atores Secundários: < Entidades externas com ação indireta no sistema> Fluxo de Eventos:

Fluxo Básico:

- <Seqüência principal de eventos para execução do processo principal que é o objetivo do caso de uso>.

\section{Fluxos Secundários:}

- <Seqüências alternativas para processos menos comuns no caso de uso $>$.

\section{Fluxos de Exceção:}

- <Seqüências incomuns geradas por erro de processamento>.

Pré-Condições: <Situações que devem estar efetivas antes do início do caso de uso >.

Pós-Condições: <Resultados do processamento do caso de uso $>$.

Para a modelagem gráfica são utilizados os diagramas de casos de uso da UML. O diagrama geral de casos de uso resultado da análise da descrição informal da seção 4.2.1 é apresentado na figura 28: 


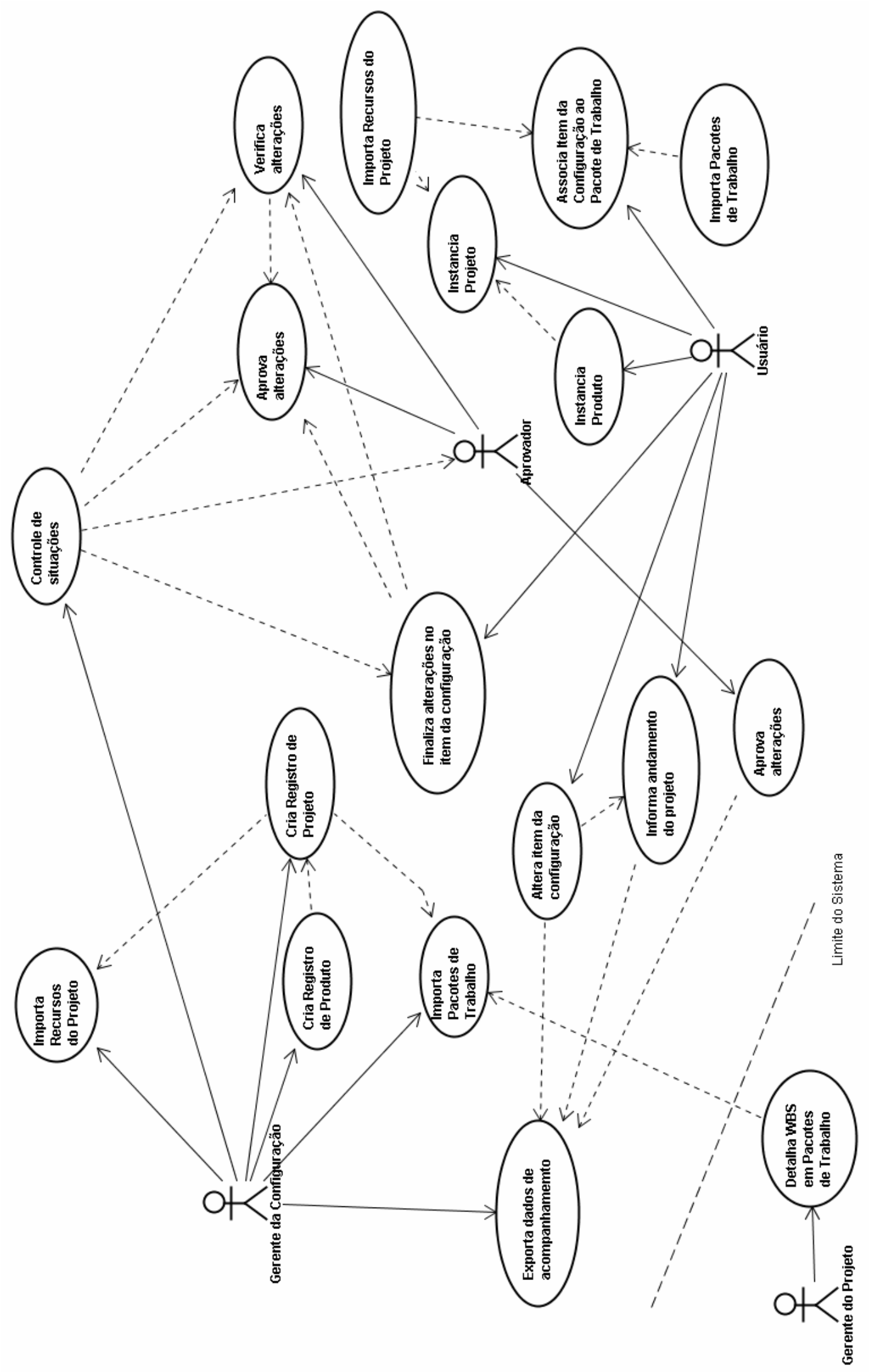

Figura 28: Casos de Uso da Interface 
Observa-se que além das ações e eventos que acontecem dentro do âmbito da interface, a ação Detalhamento da WBS e o respectivo ator (gerente do projeto) estão fora do escopo de funcionamento, pois são executadas no gerenciamento do projeto.

Para facilitar a descrição, os casos de uso apresentados foram divididos em 4 conjuntos funcionais: integração projeto-produto, integração pacote de trabalho-item da configuração, controle de situações e apontamento. A tabela 3 lista os casos de uso pertencentes a cada conjunto funcional.

\begin{tabular}{|c|l|}
\hline Conjunto Funcional & \multicolumn{1}{c|}{ Casos de Uso } \\
\hline Integração Projeto-Produto & - Registro de produto \\
& - Registro de projeto \\
& - Importação de recursos \\
- Importação de pacote de trabalho \\
Integração Pacote de Trabalho & - Instância de produto \\
- Item da Configuração & - Instância de projeto \\
& - Associação item da configuração/ \\
Controle de Situações & - Controle de situações \\
& - Verificação de alterações \\
Apontamento & - Aprovação de alterações \\
& - Finalização de alterações \\
& - Exportação de dados \\
\hline
\end{tabular}

Tabela 3: Conjuntos funcionais de casos de uso

A seção 4.2.2.1 descreve detalhadamente o grupo de casos de uso integração projeto-produto; para a descrição dos demais grupos de casos de uso consultar o apêndice $\mathbf{A}$. 


\subsubsection{Casos de Uso: Integração Projeto-Produto}

Este grupo de casos uso envolve o fluxo de eventos relacionado exclusivamente ao projeto e ao produto.

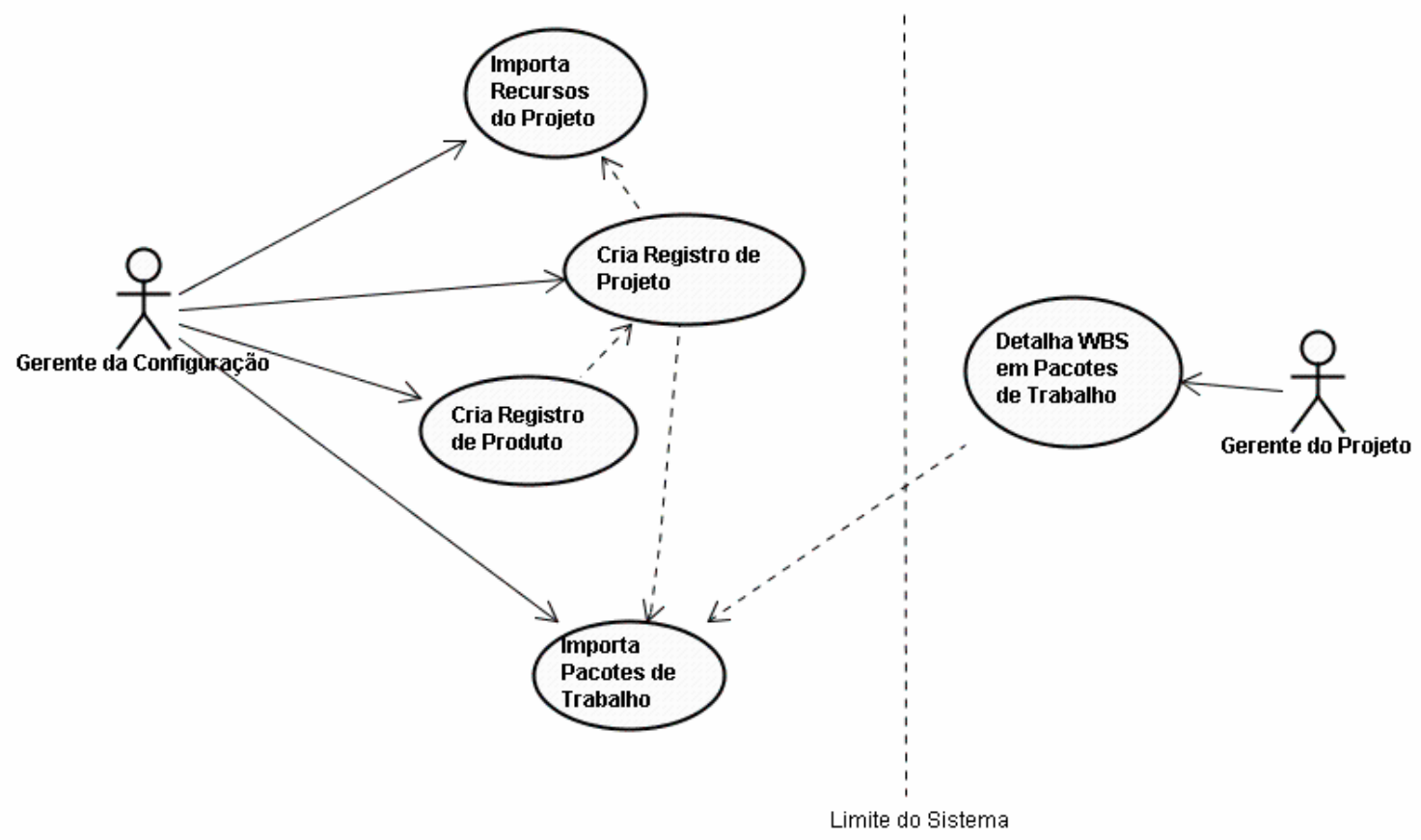

Figura 29: Casos de Uso: Integração Projeto-Produto

\subsection{Caso de Uso: Registro de Produto}

Descrição: Cadastro de produtos disponíveis para apontamento de projetos. Atores: Gerente da Configuração.

Atores Secundários: Nenhum.

\section{Fluxo de Eventos:}

Fluxo Básico:

- Gerente da Configuração fornece a chave de acesso;

- A interface verifica se a chave é válida e apresenta os produtos já cadastrados;

- A partir da lista de produtos o Gerente da Configuração pode criar um novo registro e apagar ou consultar um registro de produto existente. Para maiores detalhes, verificar fluxos secundários;

Fluxos Secundários:

- Criação de novo produto: 
- É aberto um cadastro para informar o código, nome, descrição, versão e diretório de base na configuração;

- A interface verifica se o código e nome do produto já existem;

- Após o término da entrada de informações e confirmação, os dados são gravados e disponibilizados;

- Consulta ao produto:

- Apresenta uma lista dos produtos existentes;

- São apresentados e liberados para alteração, os mesmos campos para a criação do produto, exceto o código que não pode ser alterado;

- A interface verifica se a informação do nome foi alterada e se já existe;

- O gerente confirma a gravação dos dados e estes são disponibilizados;

\section{- Exclusão do produto:}

- De forma semelhante à consulta, também é exibida uma lista com os produtos cadastrados;

- O usuário seleciona e confirma um produto para exclusão;

- A interface verifica se não existem projetos cadastrados relacionados;

- Com o produto sem relacionamentos, a exclusão é confirmada e os dados atualizados;

Fluxos de Exceção:

- Fornecimento de chave inválida: o gerente pode conectar novamente ou sair da interface;

- Código ou nome do produto já cadastrado: caso estas informações já existam em algum outro cadastro de produto, na criação/alteração de um registro de produto, o cadastro não é confirmado;

- Existência de projetos associados ao produto: ao excluir um produto, caso exista algum projeto associado, a operação não é confirmada; 
Pré-Condições: Não há.

Pós-Condições: Produto cadastrado.

\subsection{Caso de Uso: Registro de Projeto}

Descrição: Cadastro de projetos desenvolvidos sobre um produto.

Atores: Gerente da Configuração.

Atores Secundários: Nenhum.

\section{Fluxo de Eventos:}

Fluxo Básico:

- A interface apresenta os produtos já cadastrados;

- O Gerente seleciona um produto;

- A interface lista os projetos cadastrados para o produto;

- A partir da lista de projetos o Gerente da Configuração pode criar, apagar ou consultar um registro de projeto. Para maiores detalhes, verificar fluxos secundários;

\section{Fluxos Secundários:}

- Criação de novo projeto:

- É aberto um cadastro para informar o código, nome do projeto, descrição, versão e arquivo(s) no sistema operacional utilizados pelo sistema de gerenciamento do projeto;

- A interface verifica se o código e nome do projeto já existem;

- Após o término da entrada de informações e confirmação, os dados são gravados e disponibilizados;

- Consulta ao projeto:

- Apresenta uma lista dos projetos existentes para o produto;

- São apresentados e liberados para alteração, os mesmos campos para a criação do projeto, exceto o código que não pode ser alterado;

- A interface verifica se a informação do nome foi alterada e se já existe; 
- A interface verifica se já existem apontamentos para o projeto;

- O gerente confirma a gravação dos dados e estes são disponibilizados;

\section{- Exclusão do projeto:}

- De forma semelhante à consulta, também é exibida uma lista com os projetos cadastrados;

- O usuário seleciona e confirma um projeto para exclusão;

- A interface verifica se não existem apontamentos realizados;

- A exclusão é confirmada e os dados atualizados;

\section{Fluxos de Exceção:}

- Código ou nome do projeto já cadastrado: caso estas informações já existam em algum outro cadastro de projeto, na criação/alteração de um registro de projeto, o cadastro não é confirmado;

- Existência de apontamentos para o projeto: ao excluir um produto ou alterar o diretório dos arquivos relacionados ao sistema gerenciador do projeto, caso exista algum apontamento de trabalho realizado, a operação não é confirmada;

Pré-Condições: Produto cadastrado.

Pós-Condições: Projeto cadastrado.

\subsection{Caso de Uso: Importação de Recursos (Usuários)}

Descrição: Cadastro, no ambiente da configuração, dos recursos do tipo mãode-obra (usuários) usados nos projetos cadastrados.

Atores: Gerente da Configuração.

Atores Secundários: Gerente do Projeto.

\section{Fluxo de Eventos:}

\section{Fluxo Básico:}

- A partir de um projeto selecionado, a interface fornece uma lista de arquivos de recursos exportados;

- Gerente seleciona arquivo para importação; 
- Recursos associados ao produto e projeto. É verificado se o recurso já existe como usuário do ambiente da configuração. Para maiores detalhes, verificar fluxos secundários;

\section{Fluxos Secundários:}

- Verificação do recurso: a interface compara o recurso importado com os usuários já existentes no ambiente da configuração e, caso ele não exista, ele é criado como um usuário da configuração seguindo um modelo padrão de usuários de projeto, definido pelo Gerente da Configuração;

\section{Fluxos de Exceção:}

- Usuário já existe: se o recurso já existir na configuração, seu cadastro não é confirmado, e apenas é liberada sua associação ao produto e projeto;

Pré-Condições: Produto e projeto cadastrados, modelo de usuário de projeto cadastrado na configuração e arquivo de recursos do projeto exportado pelo Gerente do Projeto;

Pós-Condições: Recurso do projeto cadastrado como usuário da configuração e relacionado ao produto e projeto.

\subsection{Caso de Uso: Importação de Pacotes de Trabalho}

Descrição: Cadastro dos pacotes de trabalho disponíveis para associação aos itens da configuração.

Atores: Gerente da Configuração.

Atores Secundários: Gerente do Projeto.

\section{Fluxo de Eventos:}

\section{Fluxo Básico:}

- A partir de um projeto selecionado, a interface fornece uma lista de arquivos de pacotes de trabalho exportados;

- Gerente seleciona arquivo para importação;

- Pacotes são associados ao produto e projeto e ao usuário responsável na configuração;

- É verificado se o recurso existe como usuário do ambiente da configuração. Para maiores detalhes, verificar fluxos secundários; 
- São importados os campos código, datas de início e de fim planejadas, total de trabalho planejado e os campos de controle para verificação associação de itens e habilitação do processo de aprovação para o pacote;

- A partir da lista de pacotes de trabalho do projeto é possível excluir um pacote desnecessário. Para maiores detalhes verificar fluxos secundários;

- Após a importação dos pacotes, são importadas as suas dependências de cada um. Para maiores detalhes verificar fluxos secundários;

\section{Fluxos Secundários:}

- Exclusão de pacote de trabalho:

- É exibida uma lista composta dos pacotes de trabalho importados;

- O usuário seleciona e confirma um pacote para exclusão;

- O sistema verifica se não existem apontamentos realizados para o pacote;

- A exclusão é confirmada e os dados atualizados;

- Importação das dependências: são cadastradas as relações entre pacotes antecessores, juntamente com a regra de dependência (por exemplo, início de um pacote deve ocorrer depois do início ou término de outro). ;

\section{Fluxos de Exceção:}

- Recurso não existe: se o recurso não for encontrado como usuário da configuração a importação do pacote não é confirmada;

- Pacotes com apontamento: no caso de uma nova importação, ou exclusão de um pacote de trabalho, se já houver algum apontamento associado ao pacote ou algum item pertencente a ele, a operação não é confirmada;

Pré-Condições: Produto e projeto cadastrados, WBS detalhada em pacotes de trabalho, arquivo de pacotes de trabalho exportados pelo Gerente do Projeto. 
Pós-Condições: Pacotes de trabalho e dependências entre pacotes cadastrados.

\subsubsection{Lista Final de Requisitos e Funcionalidades}

Com base no levantamento dos casos de uso, gerou-se uma lista definitiva dos requisitos técnicos e funcionalidades a serem suportados pela interface proposta:

\begin{tabular}{|c|c|c|}
\hline $\begin{array}{c}\text { Grupo } \\
\text { Funcional } \\
\end{array}$ & Requisitos & Funcionalidades \\
\hline $\begin{array}{l}\text { Projeto - } \\
\text { Produto }\end{array}$ & $\begin{array}{l}\text { Deve armazenar dados de } \\
\text { produtos e projetos; } \\
\text { Deve armazenar } \\
\text { relacionamento entre } \\
\text { produto e projeto; } \\
\text { - } \text { Recursos do projeto } \\
\text { devem ser os usuários da } \\
\text { interface para alteração } \\
\text { da configuração; } \\
\text { - Informações de Pacotes } \\
\text { de trabalho, dependências } \\
\text { entre pacotes e recursos } \\
\text { devem poder ser } \\
\text { acessadas no ambiente da } \\
\text { configuração do produto. }\end{array}$ & 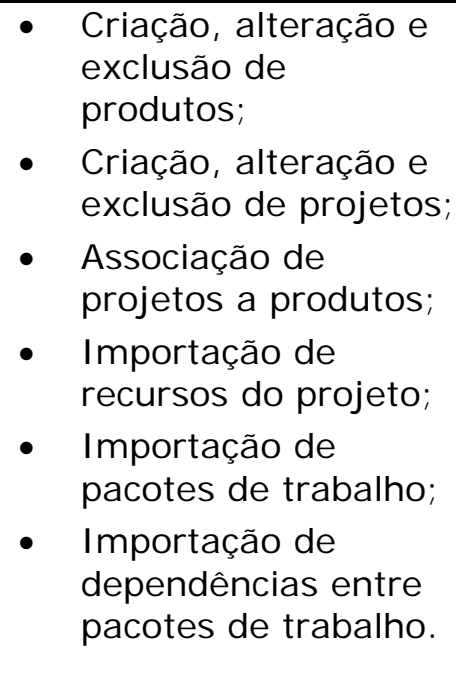 \\
\hline $\begin{array}{l}\text { Pacotes de } \\
\text { Trabalho - } \\
\text { I tens da } \\
\text { Configuração }\end{array}$ & $\begin{array}{l}\text { - } \text { Alterações nos itens da } \\
\text { configuração devem ser } \\
\text { associadas a pacotes de } \\
\text { trabalho; } \\
\text { - Caso o item ainda não } \\
\text { exista, deve ser possível } \\
\text { criá-lo na configuração; } \\
\text { - } \text { Acesso a um pacote de } \\
\text { trabalho deve considerar } \\
\text { os recursos alocados e as } \\
\text { dependências entre } \\
\text { pacotes na WBS; } \\
\text { Gravação do item na } \\
\text { configuração só deve } \\
\text { acontecer quando as } \\
\text { alterações estiverem } \\
\text { finalizadas; } \\
\text { Enquanto um item estiver } \\
\text { em processo de alteração } \\
\text { por um usuário, nenhum } \\
\text { outro deve ter acesso de } \\
\text { gravação ao mesmo item. }\end{array}$ & $\begin{array}{l}\text { - Instância de produto; } \\
\text { - } \quad \text { Instância de projeto; } \\
\text { - } \text { depálise das } \\
\text { pacote de trabalho; } \\
\text { - Exclusão de pacotes; } \\
\text { - Criação e alteração } \\
\text { de item na } \\
\text { configuração para o } \\
\text { pacote de trabalho: } \\
\text { - Associar item da } \\
\text { configuração ao } \\
\text { pacote de trabalho: } \\
\text { - Controlar acesso de } \\
\text { gravação ao item da } \\
\text { configuração. }\end{array}$ \\
\hline Controle de & $\begin{array}{l}\text { Deve controlar bloqueio } \\
\text { das alterações sobre um }\end{array}$ & $\begin{array}{ll}- & \text { Cadastro de } \\
& \text { situações possíveis }\end{array}$ \\
\hline
\end{tabular}




\begin{tabular}{|c|c|c|}
\hline $\begin{array}{c}\text { Grupo } \\
\text { Funcional } \\
\end{array}$ & Requisitos & Funcionalidades \\
\hline Situações & $\begin{array}{l}\text { item da configuração; } \\
\text { - Deve aprovar/finalizar } \\
\text { alterações sobre um item } \\
\text { da configuração. No caso } \\
\text { de não aprovação de um } \\
\text { item, o mesmo deve ser } \\
\text { encaminhado ao usuário } \\
\text { para nova alteração; } \\
\text { - Mecanismo de } \\
\text { aprovação/finalização } \\
\text { deve poder ser associado } \\
\text { a um grupo de usuários } \\
\text { para aprovação de uma } \\
\text { mesma alteração no item } \\
\text { da configuração; } \\
\text { Reprovação em um item } \\
\text { deve implicar na } \\
\text { continuação da alteração } \\
\text { por parte do usuário que } \\
\text { originalmente alterou o } \\
\text { item e solicitou a } \\
\text { aprovação. }\end{array}$ & $\begin{array}{l}\text { para os itens da } \\
\text { configuração; } \\
\text { - Cadastro das } \\
\text { mudanças possíveis } \\
\text { de situação; } \\
\text { - Cadastrar hierarquia } \\
\text { de status; } \\
\text { - Associar usuários à } \\
\text { hierarquia de status: } \\
\text { - Trocar status; } \\
\text { - Cadastrar lista de } \\
\text { assinaturas para } \\
\text { status; } \\
\text { - Verificar liberação da } \\
\text { lista de assinaturas } \\
\text { para o status; } \\
\text { - Verificar bloqueio de } \\
\text { status; } \\
\text { Verificar aprovação } \\
\text { de status. }\end{array}$ \\
\hline Apontamento & $\begin{array}{l}\text { Deve haver medição } \\
\text { automática do trabalho } \\
\text { realizado nos itens da } \\
\text { configuração associados } \\
\text { às alterações; } \\
\text { - Deve possibilitar } \\
\text { apontamento manual para } \\
\text { pacotes de trabalho; } \\
\text { - Controlar término do } \\
\text { trabalho através do } \\
\text { preenchimento da } \\
\text { quantidade de trabalho } \\
\text { restante; } \\
\text { Calcular quantidade } \\
\text { restante do pacote de } \\
\text { trabalho a partir das } \\
\text { quantidades restantes } \\
\text { individuais dos itens; } \\
\text { Apontamento do } \\
\text { item/pacote deve se } \\
\text { encerrar com a gravação } \\
\text { da data de término; } \\
\text { Deve disponibilizar } \\
\text { mecanismo de exportação } \\
\text { de dados. }\end{array}$ & $\begin{array}{l}\text { - Iniciar medição de } \\
\text { apontamento; } \\
\text { - Gravar dados de } \\
\text { apontamento para o } \\
\text { pacote de trabalho; } \\
\text { - Gravar dados do } \\
\text { apontamento para o } \\
\text { item da } \\
\text { configuração; } \\
\text { - Calcular quantidade } \\
\text { restante para pacote } \\
\text { de trabalho; } \\
\text { - Finalizar } \\
\text { apontamento. }\end{array}$ \\
\hline
\end{tabular}

Tabela 4: Lista final de requisitos e funcionalidades 


\subsection{Modelagem da Interface}

Esta seção visa realizar a modelagem dos processos necessários para suporte à implementação das funcionalidades levantadas com os casos de uso especificados na seção 4.2. Uma visão geral do esquema funcional da interface é apresentada na figura 30:

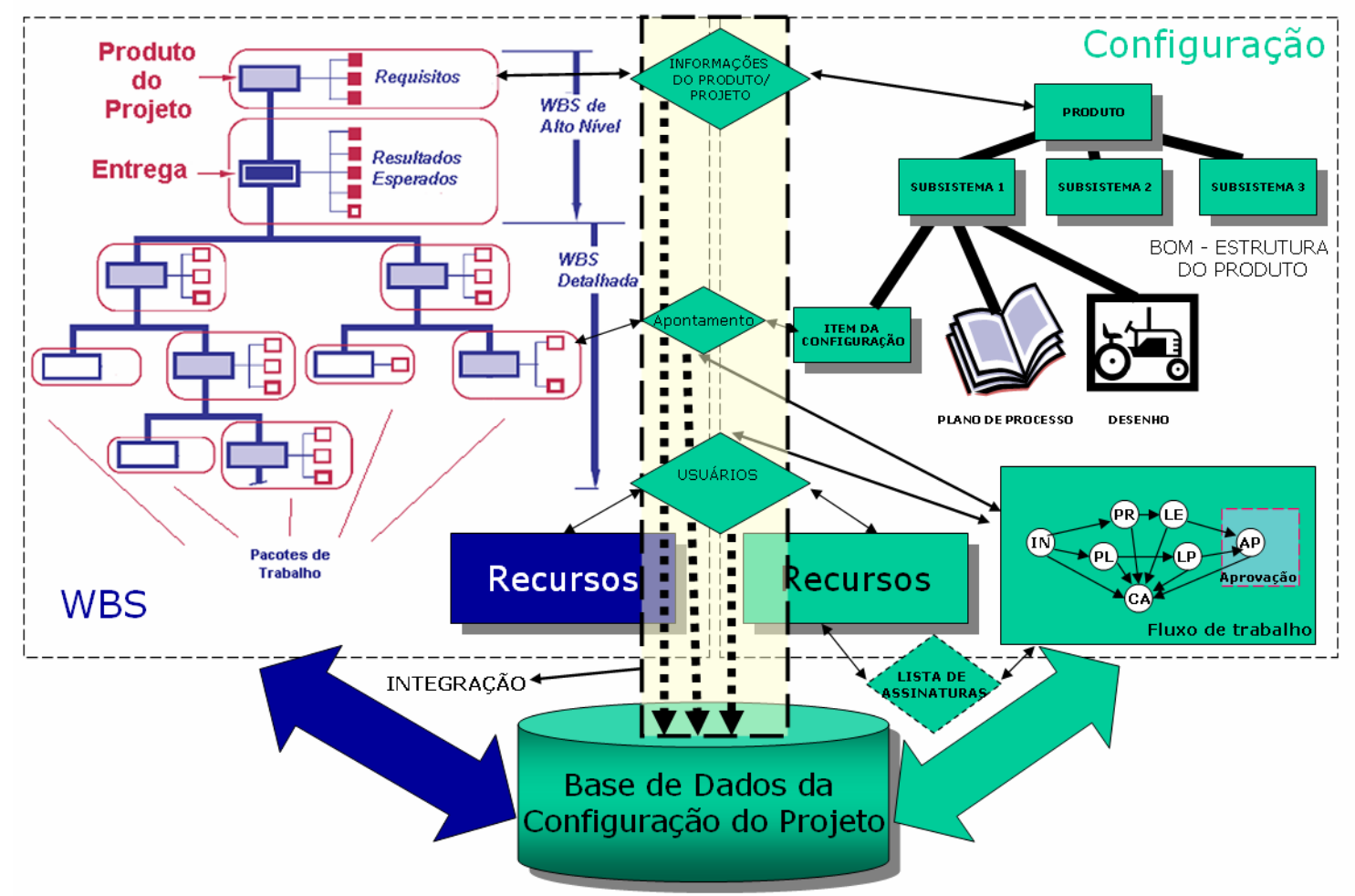

Figura 30: Visão geral funcional da interface

Como já visto, o escopo de atuação da interface está no gerenciamento da configuração e, dessa forma, podem ser observados quatro conjuntos funcionais de elementos para modelagem (o detalhamento da WBS foi tratado na revisão bibliográfica da seção 2):

- Base de dados da configuração;

- Integração de dados da configuração e projeto;

- Controle de situações (fluxo de trabalho);

- Apontamento do trabalho realizado.

A seção 4.3.1 apresenta a modelagem de classes de objetos para a interface que determina a estrutura da base de dados da configuração, enquanto a seção 4.3.2 descreve a modelagem funcional para a integração de 
dados da configuração e do projeto. As modelagens referentes ao controle de situações e ao apontamento podem ser conferidas no apêndice B.

\subsubsection{Base de Dados da Configuração - Modelagem de Classes}

A partir dos casos de uso especificados na seção 4.2, torna-se viável a extração das classes e relacionamentos existentes entre as entidades para a organização da informação em tabelas numa base de dados. Esta modelagem se concentra nas entidades, relacionamentos e funcionalidades e assim são considerados apenas os atributos básicos de cada entidade, pois diferentes tipos de atributos podem ser necessários dependendo do ambiente onde a interface for implementada como, por exemplo, atributos de integridade com o sistema operacional ou de gerenciamento do projeto.

Analisando os casos de uso, foram extraídas as seguintes classes, de acordo com seu grupo funcional, que servirão de base para a criação das tabelas da base de dados:

- Integração de dados: produto, projeto, pacote de trabalho, item da configuração e usuários (recursos). Dos relacionamentos obtêm-se as classes de dependências (pacotes de trabalho), e itens_pacotes (itens da configuração associados ao pacote de trabalho);

- Controle de situações: a classe de status representa a entidade básica para o cadastro de situações. Da associação entre pares de status deriva-se a classe hierarquia_status e da funcionalidade de aprovação é gerada a classe lista_assinaturas que relaciona a entidade status à entidade de usuários e classe derivada lista_assinaturas_itens para relacionar o processamento da lista definida com a aprovação individual de cada item;

- Apontamento: corresponde diretamente ao relacionamento entre produto, projeto, pacotes de trabalho e itens da configuração associado a uma linha de tempo gerando a classe historico_apontamentos.

A figura 31 apresenta o diagrama de classes simplificado para a interface (os atributos serão descritos na próxima seção). Devido a esta 
interface não ter que necessariamente ser implementada em um ambiente de orientação a objetos, decidiu-se não incluir os métodos de cada classe nesta seção e incorporá-los a lista de funções associada ao fluxo de dados de cada conjunto funcional.

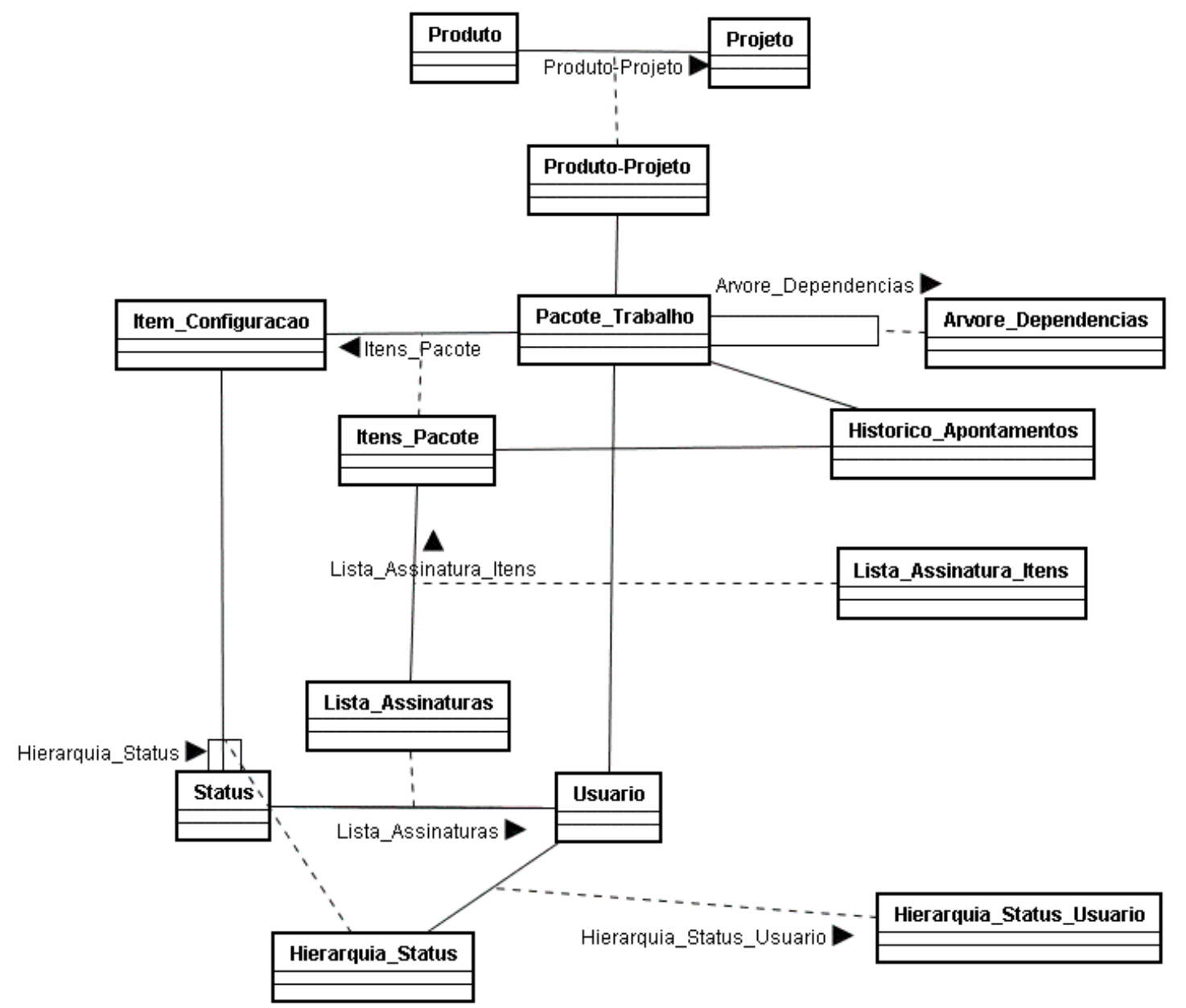

Figura 31: Diagrama de classes da interface

\subsubsection{Descrição das Entidades}

São descritas nesta seção, as estruturas básicas das tabelas relacionadas às classes modeladas. Para cada tabela, são listados os campos básicos essenciais para uso da interface e marcados com (CP) os que fazem parte da chave primária; os campos descritos como "Identificador interno" são gerados automaticamente pelo sistema e não podem ser alterados: 
- Produto: Dados do produto base para desenvolvimento do projeto. Campos básicos:

- Codigo_Produto (CP): Identificador interno;

- Nome: Nome do produto;

- Descricao: Descrição do produto;

- Versao: Versão atual do produto;

- Diretorio_Trabalho: Diretório da configuração no sistema operacional onde se encontram os arquivos eletrônicos do produto;

- Projeto: Dados do projeto de criação/alteração do(s) produto(s). Campos básicos:

- Codigo_Projeto (CP): Identificador interno;

- Nome: Nome do projeto;

- Descricao: Descrição do projeto;

- Arquivo: Caminho no sistema operacional onde se encontra o arquivo eletrônico relacionado ao projeto;

- Produto_Projeto: Relacionamento entre produtos e projetos. Campos básicos:

- Codigo_Produto (CP): Identificador interno do produto;

- Codigo_Projeto (CP): Identificador interno do projeto;

- Pacote_Trabalho: Dados dos pacotes de trabalho importados da WBS do projeto. Campos básicos:

- Codigo_Pacote (CP): Identificador interno;

- Codigo_WBS: Código do pacote na WBS do projeto;

- Codigo_Produto: Identificador interno do produto;

- Codigo_Projeto: Identificador interno do projeto;

- Descrição_WBS: Descrição do pacote na WBS do projeto; 
- Codigo_Usuario: Identificador interno do usuário na interface;

- Codigo_Usuario_WBS: Representa o usuário do projeto ao qual o pacote foi alocado. Neste trabalho é considerado que o pacote de trabalho é executado por um único recurso para simplificação do processo de apontamento do trabalho;

- Data_Inicio_Planejada: Data de início planejada;

- Data_Termino_Planejada: Data de término planejada;

- Quantidade_Trabalho_Planejada: Quantidade de trabalho total planejada para o pacote;

- Data_Inicio_Real: Data de início real;

- Data_Termino_Real: Data de término real;

- Quantidade_Trabalho_Realizada: Quantidade de trabalho realizado até o momento atual;

- Quantidade_Trabalho_Restante: Quantidade de trabalho restante atual estimada;

- Flag_Item_Configuracao: Habilita associação de itens da configuração;

- Flag_Aprovacao: Habilita o processo de aprovação nos itens da configuração associados;

- Flag_Fantasma: Utilizado para processamento de aprovação por lista de assinaturas (ver seção 4.3.4);

- Item_Configuracao: Dados do item da configuração do produto. Campos básicos:

- Codigo_Item (CP): Identificador do item na configuração;

- Nome: Nome do item na configuração;

- Descrição: Descrição do item;

- Arquivo_Configuracao: Caminho para o arquivo eletrônico relacionado ao item na configuração;

- Status: Situação do item; 
- Itens_Pacote: Dados dos itens da configuração que serão alterados pelo pacote de trabalho. Campos básicos:

- Codigo_Pacote (CP): Identificador interno do pacote de trabalho;

- Codigo_Item (CP): Identificador do item na configuração;

- Porcentagem_Pacote: Paticipação proporcional do item no pacote de trabalho;

- Data_Inicio_Real: Data de início real;

- Data_Termino_Real: Data de término real;

- Quantidade_Trabalho_Realizada: Quantidade de trabalho realizado até o momento atual;

- Quantidade_Trabalho_Restante: Quantidade de trabalho restante atual estimada;

- Arvore_Dependencias: Relacionamento de dependências entre os pacotes. Campos básicos:

- Codigo_Pacote (CP): Identificador interno do pacote de trabalho;

- Codigo_Pacote_Antecessor (CP): Identificador interno do pacote de trabalho antecessor;

- Usuario: Dados dos usuários importados do projeto e que serão cadastrados na configuração. Campos básicos:

- Codigo_Usuario (CP): Identificador interno;

- Codigo_Usuario_Configuracao: Identificador do usuário na configuração;

- Nome: Nome do usuário;

- Descrição: descrição do usuário;

- Status: Informação sobre situações de um item da configuração. Campos básicos:

- Status (CP): Situação;

- Descrição: Descrição da situação;

- Flag_Bloqueio: Impede alterações no item da configuração 
- Flag_Aprovacao: Define se o status é de aprovação/finalização do item da configuração;

- Hierarquia_Status: Lista com os pares das possíveis trocas de status na interface. Campos básicos:

- Codigo_Hierarquia (CP): Identificador interno;

- Status_Anterior: Status de origem na troca de situação do item;

- Status_Posterior: Status de destino na troca de situação do item

- Hierarquia_Status_Usuario: Trocas de status possíveis para um determinado usuário: Campos básicos:

- Codigo_Hierarquia (CP): Identificador interno da hierarquia;

- Codigo_Usuario (CP): Identificador interno do usuário;

- Lista_Assinaturas: Relacionamento de usuários com status de aprovação, para gerar uma lista de operações de verificação e/ou aprovação por usuário que devem ser executadas para cada troca de situação cujo destino seja o status associado. Campos básicos:

- Codigo_Lista (CP): Identificador interno;

- Status: Situação;

- Codigo_Usuario: Identificador interno do usuário;

- Flag_Aprovacao: Campo lógico para indicar se é uma aprovação (caso afirmativo) ou verificação (negativo);

- Lista_Assinaturas_Itens: Relacionamento para apontamento das operações de aprovação processadas pela lista de assinarturas:

- Codigo_Lista (CP): Identificador interno da lista de assinaturas;

- Codigo_Pacote (CP): Identificador interno do pacote de trabalho; 
- Codigo_Item (CP): Identificador do item na configuração;

- Flag_Operacao_Concluida: Campo lógico para indicar se a operação configurada para o usuário da lista foi executada;

- Historico_Apontamentos: Dados de registro sobre os apontamentos de trabalho realizado na configuração do produto. Campos básicos:

- Codigo_Apontamento (CP): Identificador interno;

- Codigo_Pacote: Identificador interno do pacote de trabalho;

- Codigo_Item: Identificador interno do item da configuração;

- Data_Inicio_Apontamento: Data de início da alteração no item;

- Hora_Inicio_Apontamento: Hora de início da alteração no item;

- Data_Termino_Apontamento: Data de término da alteração no item;

- Hora_Termino_Apontamento: Hora de término da alteração no item;

- Quantidade_Trabalho_Realizado: Quanitdade de trabalho realizada na alteração;

- Quantidade_Trabalho_Restante: Quantidade de trabalho restante.

\subsubsection{Modelagem funcional para a Integração entre os Dados do Projeto e da Configuração do Produto}

A integração entre os dados do projeto e da configuração do produto consiste em, basicamente, criar um conjunto de funcionalidades para o cadastro e configuração dos relacionamentos entre os pacotes de trabalho e recursos do projeto e os itens da configuração do produto, utilizando a modelagem de tabelas, realizada na seção 4.3.1, relacionando produto e projeto. A seção 4.3.2.1 descreve as funcionalidades relacionadas diretamente 
às entidades de produto e projeto, enquanto a seção 4.3.2.2 trata das funcionalidades associadas aos pacotes de trabalho e itens da configuração.

\subsubsection{Integração Projeto e Produto}

Corresponde ao cadastro e configuração envolvendo diretamente as entidades produto e projeto, ou seja, representam as funcionalidades básicas de suporte a todo o funcionamento da interface.

\section{Funcionalidades:}

1. Instanciar usuários da configuração:

a. Armazenar internamente na interface o usuário do ambiente da configuração (por exemplo, usuário do sistema operacional ou do sistema de gerenciamento da configuração);

b. Armazenar lista com todos os usuários da configuração;

\section{Listar produtos existentes:}

a. Criar tela para listar produtos criados para apontamento de projeto pela interface;

b. Recuperar as informações gravadas na tabela produto e exibir listagem em tela;

\section{Cadastrar produto:}

a. Na tela de listagem de produtos, criar funcionalidades de seleção de vários produtos;

b. Para os produtos selecionados criar opções de consulta e exclusão. A consulta abre uma tela com os detalhes do produto para alteração e a exclusão apaga o registro do produto da base de dados. As operações de exclusão ou alteração do nome do produto só são permitidas se não houver nenhum apontamento de trabalho realizado para o produto (verificar seção 4.3.5);

c. Ainda na tela de listagem de produtos, criar opção para inclusão de produtos. São exibidos os mesmos dados da consulta (tabela produto) todos vazios para preenchimento. Verificar se o produto já foi cadastrado e em caso negativo gravar os dados na base.

4. Listar e Cadastrar projeto: semelhante ao cadastro de produtos, mas utilizando a tabela projeto; 


\section{Associar produto-projeto:}

a. Na tela de seleção de produtos, criar opção para associar projeto;

b. Criar tela para listar projetos já associados, possibilitando a criação de novos projetos;

c. Para os projetos selecionados, após confirmação, devem ser gravados registros de relacionamento na tabela produto-projeto;

d. Na associação de cada projeto executar funções de importação dos recursos (item 6) e pacotes de trabalho (item 7);

\section{Importar recursos (mão-de-obra) do projeto:}

a. Na tela de associação de projetos, criar campo de entrada para cada projeto do arquivo de recursos exportados do projeto;

b. Ler os recursos do arquivo e verificar se existe usuário na configuração com o mesmo nome. Em caso negativo, abrir tela para seleção entre os usuários da configuração, o correspondente ao recurso;

c. Caso o usuário da configuração ainda não esteja cadastrado na tabela usuario da base de dados da configuração, fazer o cadastro gerando o identificador interno do usuário e associando-o ao identificador do usuário na configuração;

d. Armazenar uma lista interna relacionando o identificador do usuário na WBS com o identificador interno do usuário gerado pela interface a ser utilizado na importação de pacotes de trabalho;

e. Não permitir a associação do projeto, caso o arquivo de recursos não seja fornecido;

\section{Importar pacotes de trabalho:}

a. Na tela de associação de projetos, criar campo de entrada para cada projeto do arquivo de pacotes de trabalho exportados do projeto;

b. Ler os pacotes de trabalho do arquivo e gravar informações na tabela pacote_trabalho, juntamente com os identificadores de produto e projeto instanciados;

c. Caso exista mais de um recurso associado ao pacote de trabalho, abortar o processo e exibir mensagem que a interface não suporta a operação; 
d. Procurar na lista interna de recursos (item 6.d), pelo identificador do usuário na WBS, qual o respectivo usuário na interface e gravar identificador na tabela pacote_trabalho;

e. Na leitura de cada pacote, gerar lista interna com a relação de entre o pacote e seus pacotes dependentes. Caso algum dos pacotes cadastrado como antecessor não tenha sido exportado da WBS, esta dependência é excluída da lista. Por fim, a lista final de dependências é gravada na tabela arvore_dependencias.

\subsubsection{Integração Pacote de Trabalho e Item da Configuração}

Corresponde aos processos envolvendo diretamente o relacionamento entre os pacotes de trabalho do projeto e os itens da configuração do produto para suporte ao apontamento do trabalho realizado a partir das alterações realizadas na configuração.

\section{Funcionalidades:}

1. Instanciar produto:

a. A partir de uma tela de seleção de produtos descrita na seção 4.3.2.1 (item 2.a), criar opção para armazenar internamente o identificador do produto selecionado;

b. Exibir mensagem de aviso informando produto atualmente selecionado na interface;

\section{Instanciar projeto:}

a. A partir da tela de projetos associados ao produto descrita na seção 4.3.2.1 (item 5.b), criar opção para armazenar internamente o identificador do projeto selecionado;

b. Exibir mensagem de aviso informando projeto atualmente selecionado na interface;

3. Analisar dependências dos pacotes de trabalho do projeto para o usuário:

a. Ler todos os pacotes do projeto associados ao usuário (tabela pacote_usuario);

b. Marcar pacotes finalizados; 
c. Para cada pacote não finalizado, caso haja dependência, ler a tabela de dependências (arvore_dependencias) e verificar se o pacote antecessor já foi finalizado. Caso as dependências estejam finalizadas, marcar o pacote como disponível e caso contrário, marcar como pendente;

\section{Listar pacotes de trabalho disponíveis ao usuário:}

a. Criar tela para listar os pacotes associados e a sua situação de acordo com o processamento do item 3.c;

b. Incluir opções de filtro dos pacotes pela situação;

c. Exibir a tela dos pacotes após as seleções de produto e projeto (painel de trabalho do usuário no projeto);

\section{Listar itens da configuração:}

a. Incluir opção de seleção de itens na tela de listagem dos pacotes de trabalho. Exibir o status dos itens que já estejam cadastrados na tabela item_configuracao;

b. Abrir tela de seleção de arquivos a partir do diretório de configuração associado ao produto corrente;

c. Incluir funcionalidade de troca de status para itens já existentes na tabela item_configuração;

d. Para cada item selecionado, verificar situação e permitir a seleção apenas para itens sem pendência de processamento de lista de assinaturas;

e. Incluir filtro para selecionar itens com trabalho realizado (quantidade realizada diferente de zero e quantidade restante igual a zero), mas ainda não aprovados e, portanto, não finalizados;

\section{Criar item da configuração para o pacote de trabalho:}

a. Criar interface para entrada das informações do item da configuração (tabela item_configuração). No campo de status, exibir uma lista apenas com os status disponíveis para o usuário e só permitir associação de um status que não bloqueie o item para alteração;

b. Requisitar inclusão do item na configuração do produto;

7. Associar item da configuração ao pacote de trabalho:

a. Verificar se existe algum apontamento pendente para o item através da consulta à tabela itens_pacote verificando se há algum pacote 
com quantidade trabalhada realizada e quantidade trabalhada restante diferentes de zero. Caso exista, exibir mensagem e não permitir a associação;

b. Verificar se o pacote permite associação de itens (campo flag_item_configuração da tabela pacote_trabalho); caso contrário, exibir mensagem e não permitir a associação;

c. Gravar relacionamento de cada item selecionado ao pacote de trabalho (tabela itens_pacote);

8. Abrir seção de alteração do item da configuração:

a. Na tela de seleção de itens, criar opção para abrir seção de alteração apenas para itens associados;

b. Requisitar liberação de acesso de gravação ao item na configuração do produto;

c. Caso o item esteja sendo modificado por outro usuário exibir mensagem de aviso e interromper operação;

d. Iniciar processo interno de medição do trabalho;

9. Gravar alterações no item da configuração:

a. Na tela de seleção de itens, criar opção de gravação;

b. Requisitar gravação de alterações do item na configuração;

10. Encerrar seção de alteração do item da configuração:

a. Na tela de seleção de itens, criar opção para encerramento da seção:

b. Requisitar bloqueio de acesso à gravação do item na configuração:

c. Finalizar processo interno de medição do trabalho;

d. Exibir tela para cadastro da quantidade de trabalho restante para o item;

11. Localizar pacotes relacionados a um item da configuração:

a. Na tela de seleção de itens, criar opção de localização de pacotes;

b. Criar tela com listando os pacotes já associados ao item. Ler as tabelas itens_pacote e pacote_trabalho usando como filtro o item da configuração selecionado e listar as informações dos pacotes associados. 


\section{Exemplo de Aplicação da Interface}

O objetivo desta seção é demonstrar a viabilidade da interface apresentada. Para tal, foi necessário escolher um ambiente de desenvolvimento de produtos que faça uso de ferramentas ou sistema para gerenciamento da configuração e que organize o trabalho através de projetos utilizando as técnicas existentes para gerenciamento, de preferência com o uso de algum sistema. O ambiente escolhido é compatível com um dos objetivos deste trabalho, pois corresponde a uma organização que não possui sistemas integrados de grande porte, tais como sistemas PLM.

Esta seção está organizada em 2 subseções: a seção 5.1 descreve a situação atual do ambiente escolhido com relação à sua atuação no mercado, produtos, e as funcionalidades adotadas para gerenciamento da configuração e de projetos, enquanto a seção 5.2 detalha as adaptações e desenvolvimentos realizados no sistema atual, ambos baseados na interface proposta para demonstrar a viabilidade e vantagens potenciais.

\subsection{Descrição do Ambiente Atual}

Para aplicação do exemplo foi escolhida uma empresa de pequeno porte atuante no desenvolvimento de software na área de sistemas ERP (Enterprise Resource Planning) e com uma definição clara de processos de gerenciamento da configuração e com o trabalho organizado e gerenciado por projetos. Esta empresa chama-se ORION-ASP e seu portfólio se concentra basicamente em dois produtos: o sistema MEGA que consiste basicamente de um sistema ERP voltado para o setor de móveis e vestuário e o sistema MEGA-Light que é um sistema mais enxuto focado na área comercial e direcionado para o gerenciamento de cadeias de distribuição de produtos.

O exemplo de aplicação da interface é direcionado ao desenvolvimento do produto MEGA, versando, portanto, sobre a gestão de projetos de software e considerando as ferramentas utilizadas para gerenciamento da configuração e de projetos na empresa. 


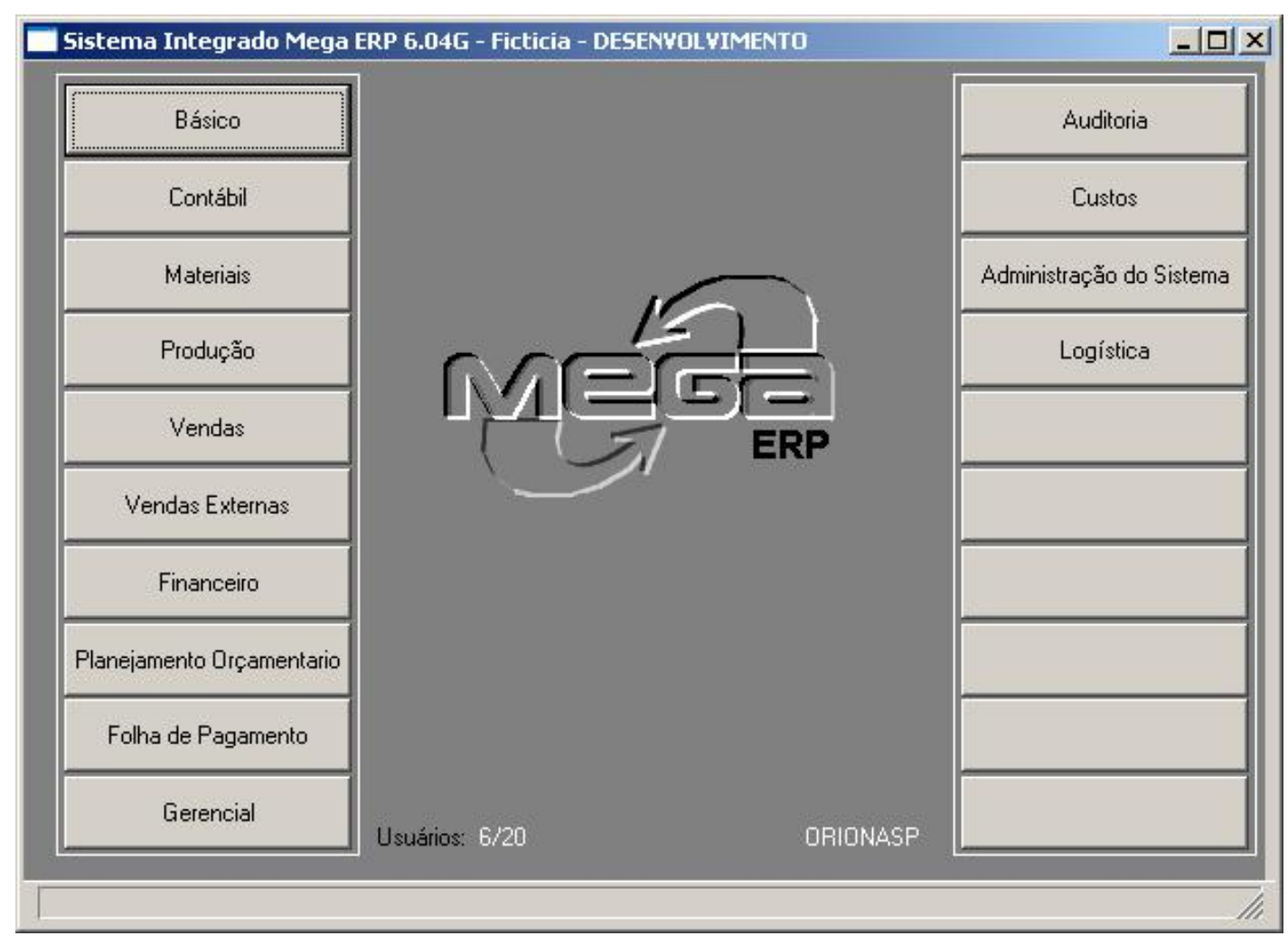

Figura 32: Tela inicial do sistema MEGA

\subsubsection{Descrição Geral do Sistema MEGA}

Como um sistema ERP, o sistema MEGA constitui um sistema de módulos integrados com funcionalidades para o gerenciamento de uma empresa produtiva, desde a engenharia e venda do produto até a parte de folha de pagamento dos funcionários, apuração de custos e gestão contábil. Como diferencial em relação a outros sistemas ERP existentes no mercado, há a implementação do conceito grade (vetor de atributos), que permite a inclusão de complementos em cada um dos produtos cadastrados (por exemplo, lista de cores e tamanhos). Esta característica faz com que a solução tenha uma aderência não apenas a processos produtivos e comerciais tradicionais, mas também a processos produtivos e comerciais específicos das empresas de calçados, confecções, móveis, ou quaisquer outras que utilizam o conceito grade, reduzindo consideravelmente o re-trabalho nos cadastramentos, planejamentos e controles.

O sistema é composto dos seguintes módulos (ORION, 2006): 
- Básico: contém os cadastros comuns aos demais módulos e parâmetros de personalização do sistema;

- Contábil: contabilidade; custo fiscal; escrita fiscal; controle patrimonial;

- Financeiro: contas a pagar; contas a receber; contas correntes; caixa e bancos; fluxo de caixa;

- Materiais: compras; recebimento; controle de estoque; controle de qualidade;

- Vendas: formação de preço de venda; tabelas de preço, pedidos de vendas, gerencial de vendas; faturamento; controle de cotas/previsão de vendas; vendas externas;

- Produção: PCP; MRPII; engenharia de produto; ficha técnica; formação e controle de custo padrão e real;

- Pessoal: folha de pagamento; ponto eletrônico; serviço social/benefícios; medicina do trabalho;

- Gerencial: informações resumidas de cada módulo com as estatísticas chaves, modeladas pela própria empresa;

- Planejamento Orçamentário: definição e acompanhamento do planejamento orçamentário anual;

- Auditoria: revisão de informações essenciais da empresa, auditadas conforme regras estabelecidas internamente.

\subsubsection{Gerenciamento da Configuração}

Por ser um produto pertencente à indústria do software, o produto MEGA é composto basicamente por um conjunto de arquivos digitais, os quais representam diretamente os itens da configuração. Estes arquivos se dividem entre os componentes diretos dos módulos (gerados pelo desenvolvimento do sistema), arquivos ligados à base de dados e toda a documentação relacionada como manuais, testes, projetos, versões, procedimentos internos e assim por diante. Os módulos são manipulados através da ferramenta PROGRESS que possui um gerenciador de banco de dados relacional e um ambiente de desenvolvimento que gera arquivos de três tipos: .W (programas com interface 
gráfica - janelas), .I (includes - trecho de código compartilhado) e .P (programas sem interface gráfica).

O gerenciamento da configuração adotado utiliza o controle de mudanças dos arquivos e, para isso, foram tomadas 2 ações: organização dos arquivos no sistema operacional e adoção de sistema específico para controle de versões.

\subsubsection{Organização dos Arquivos}

Para facilitar o gerenciamento, os arquivos da configuração do produto foram divididos em 3 categorias: comercial, controladoria e manufatura (figura 33). Esta divisão corresponde à estrutura do produto e é base para o gerenciamento da configuração tratada na próxima seção. Além disso, os arquivos também fora nomeados com prefixos de acordo com a sua área de funcionalidade como mostrado na tabela 5 :

\begin{tabular}{|c|c|l|}
\hline Prefixo & Área & \multicolumn{1}{|c|}{ Exemplo } \\
\hline GE & Básico & GEACCUST.W - Centros de Resultado \\
MT & Materiais & MTAPRODU.W- Produtos \\
PR & Produção & PRAPLCCS.W - Planos de Produção \\
CS & Custos & CSAPREVD.W - Previsão de Vendas \\
VD & Vendas & VDAPEDID.W - Pedidos de Vendas \\
FN & Financeiro & FNATITUL.W - Títulos Financeiros \\
CT & Contábil & CTAPLANO.W - Plano de Contas \\
RH & Pessoal & RHFUNCI.W - Cadastro de Funcionários \\
WM & Centros de & WMVROTAS.W - Rotas de Distribuição \\
& Disribuição & \\
\hline
\end{tabular}

Tabela 5: Nomenclatura de arquivos do sistema MEGA 


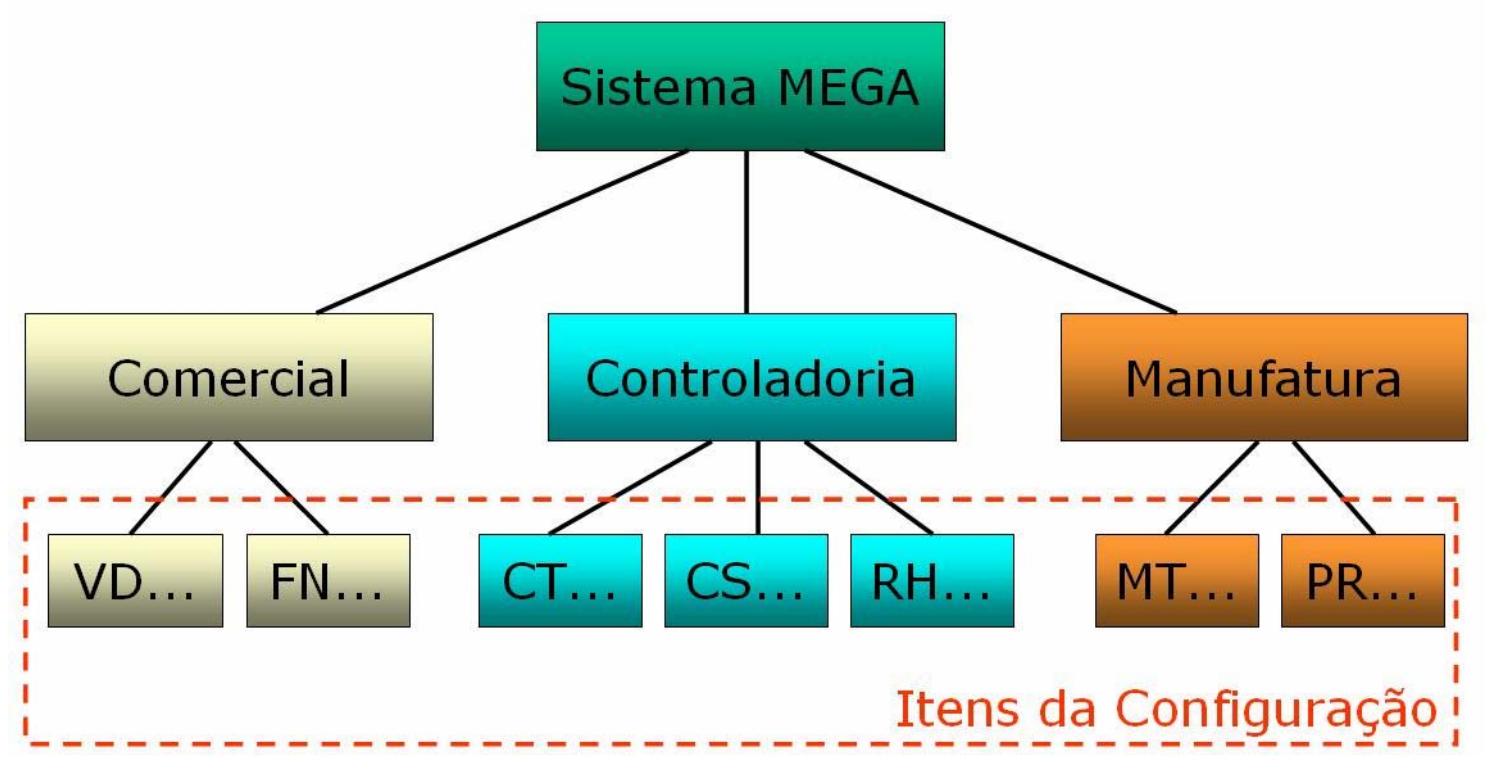

Figura 33: Configuração da estrutura do produto MEGA

\subsubsection{Sistema de Controle de Versões}

O sistema adotado pela empresa para controle de alterações entre as versões liberadas do produto MEGA foi o CVS em conjunção com a interface gráfica denominado TortoiseCVS, explicado à seguir.

\section{CVS}

O CVS, ou Concurrent Version System (Sistema de Versões Concorrentes) é um sistema de controle de versão que permite que se trabalhe com diversas versões de arquivos organizados em um diretório e localizados local ou remotamente, mantendo-se suas versões antigas e os logs de quem e quando manipulou os arquivos (WIKIPÉDIA, 2006). É especialmente útil para se controlar versões de um software durante seu desenvolvimento, ou para composição colaborativa de um documento e pode ser baixado gratuitamente tendo o seu código aberto.

O CVS utiliza uma arquitetura cliente-servidor: um servidor armazena as versões gravadas do projeto (repositório) e seu histórico, e os clientes se conectam a esse servidor para obter uma cópia completa do projeto, trabalhar nessa cópia e então devolver suas modificações. Para o sistema MEGA, optou- 
se por servidores executando Linux e clientes Windows conectados em uma rede local. Vários clientes podem editar cópias do mesmo projeto de maneira concorrente com duas possibilidades de configuração: na primeira, quando os usuários confirmam suas alterações, o servidor tenta fazer uma fusão delas; já na segunda, os arquivos são bloqueados nos clientes e liberados apenas para o primeiro cliente a requisitar permissão de alteração.

Clientes podem comparar diferentes versões de um arquivo, pedir um histórico completo das alterações, ou baixar uma determinada versão do projeto, ou de uma data específica, não necessariamente a versão mais atual. Muitos projetos de código aberto permitem acesso anônimo para leitura, o que significa que qualquer pessoa pode baixar ou comparar versões sem necessidade de autenticação; somente para salvar mudanças é necessário informar a senha nesses casos. Clientes também podem usar o comando "update" (atualizar) para manter suas cópias locais atualizadas com a última versão do servidor. Isso elimina a necessidade de se fazer diversos recargas de todo o projeto.

Como principais limitações, os arquivos em um repositório CVS não podem ser renomeados, eles devem ser explicitamente removidos e readicionados; o protocolo do CVS não permite que os diretórios sejam movidos ou renomeados e cada um dos arquivos do subdiretório em questão deve ser individualmente removido e re-adicionado.

\section{TortoiseCVS}

TortoiseCVS é um cliente CVS para Windows, onde é possível executar comandos do CVS através de uma interface gráfica mais amigável para execução dos comandos de controle disponibilizados pelo CVS (TORTOISE, 2006).

Após a configuração inicial da ferramenta para acessar o repositório do CVS, torna-se possível visualizar a situação dos arquivos da configuração diretamente sobre o sistema operacional: os arquivos criados e alterados ficam marcados, e são diferenciados daqueles que continuam sincronizados com o repositório do CVS, conforme figura 34: 


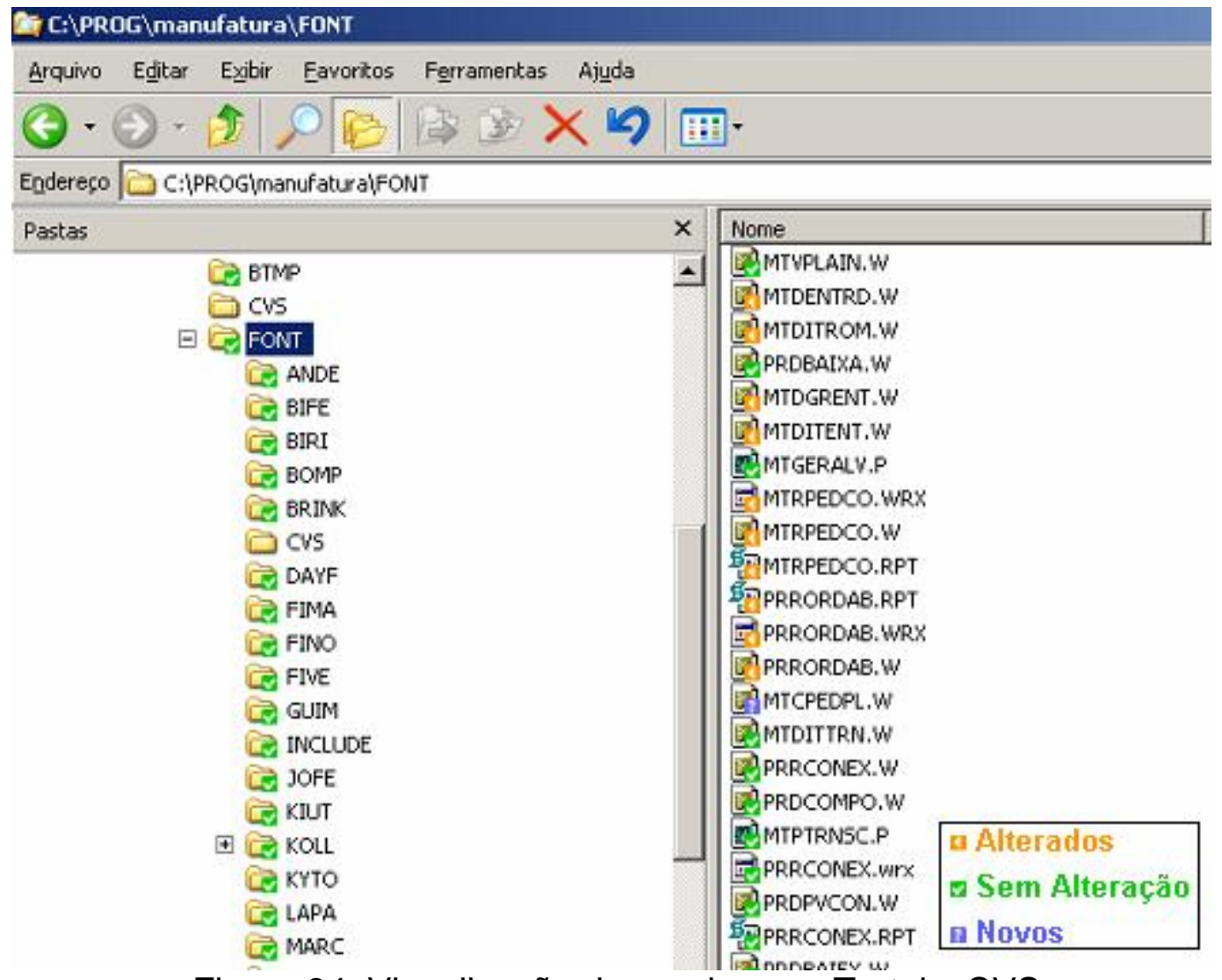

Figura 34: Visualização de arquivos no TortoiseCVS

Além da visualização, a ferramenta gráfica habilita um menu (figura 35) onde são disponibilizadas diversas opções de comandos sobre o CVS como:

- Gráfico de Revisões: gráfico seqüencial com marcadores de versão e histórico de alterações;

- Marcadores: rótulos associados aos arquivos para controle e para recuperação em bloco de arquivos;

- Histórico: descritivo com as alterações realizadas para aquela versão do arquivo;

- Atualizar: sincronização dos arquivos com o repositório;

- Remover: retirada do arquivo do controle do CVS;

- Ramo: bifurcação no gráfico seqüencial para armazenar versões específicas do arquivo;

- Obter Módulo/Arquivo: inclusão um arquivo ou conjunto de arquivos dentro do controle de alterações do CVS. 


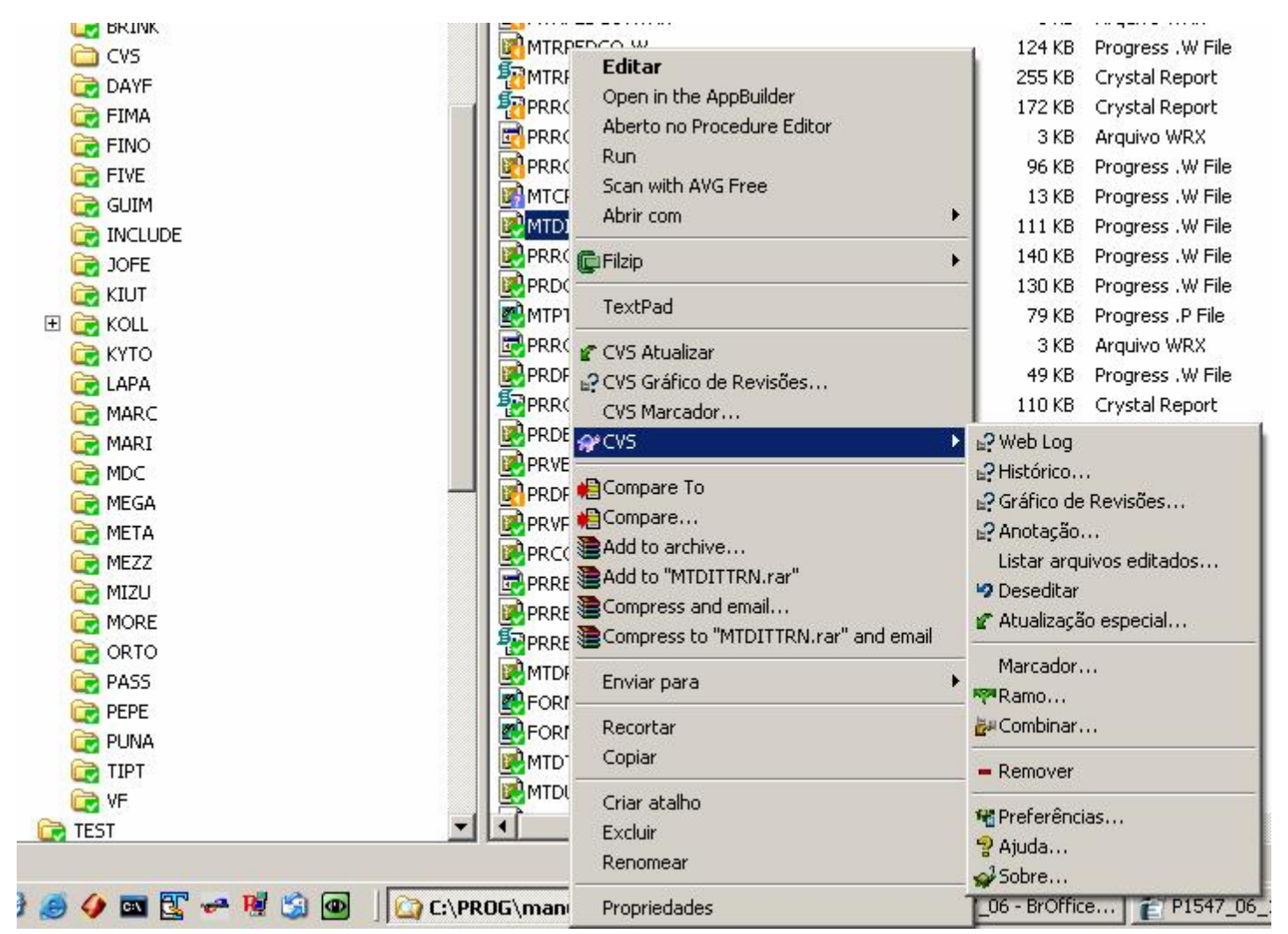

Figura 35: Menu do TortoiseCVS

Como exemplo, com a opção Gráfico de Revisões, é exibido um gráfico em formato de árvore com uma lista das versões alteradas, bifurcações de versões específicas e, caso configurado um software de comparação, pode-se fazer a comparação direta para verificar todas as alterações ocorridas entre qualquer uma das versões exibidas (figura 36). 


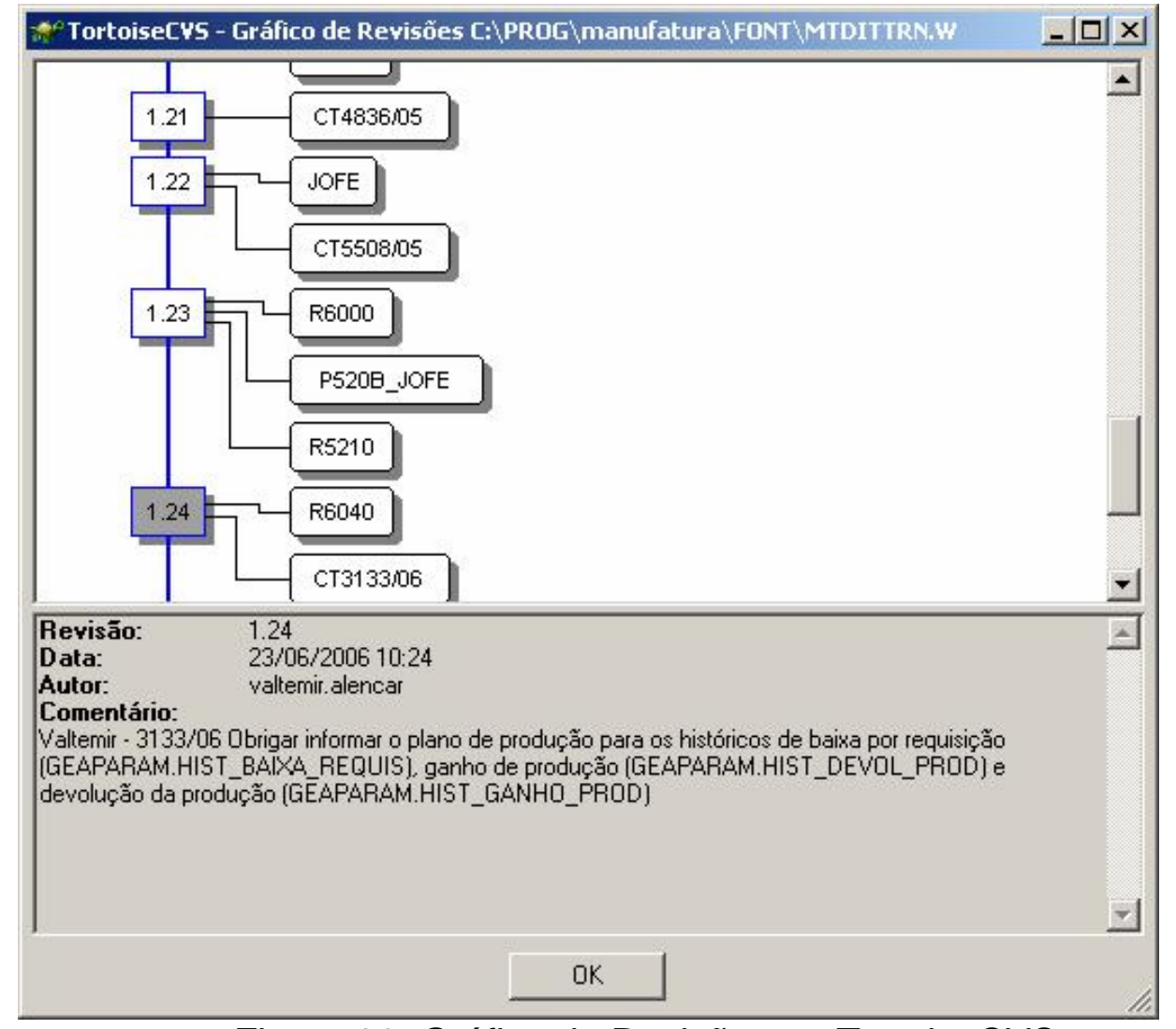

Figura 36: Gráfico de Revisões no TortoiseCVS

\subsubsection{Gerenciamento de Projetos}

As versões do sistema MEGA são liberadas aos clientes de duas formas: patches e releases. Os patches são correções mais urgentes e menores e são liberados em períodos curtos de tempo (dias e semanas); já as releases representam versões maiores com correções mais complexas e implementações de novas funcionalidades e que devem ser devidamente planejadas, com data prevista de liberação (normalmente a cada um ou dois meses), ordenação das atividades de implementação e alocação dos recursos necessários. Como já visto na revisão bibliográfica, este procedimento caracteriza a necessidade da organização trabalho em projetos e que foi adotado pela empresa, após uma experiência anterior de priorização semanal de trabalho, que não gerou os resultados esperados.

Os projetos para as novas versões do sistema MEGA iniciam com uma sessão de reuniões da diretoria e consultores para levantamento das necessidades dos clientes e do mercado para seleção dos desenvolvimentos a serem planejados. Decidido o que será parte da nova versão do MEGA, o procedimento na ORION-ASP é necessário realizar o planejamento, controlar a 
execução, captar os apontamentos do trabalho realizado e gerar uma análise comparativa do previsto $x$ realizado.

As seções seguintes descrevem a metodologia de desenvolvimento adotada, e a utilização das ferramentas Microsoft Project para gerenciamento do projeto e o software proprietário MEGA-Atend para o apontamento do trabalho.

\subsubsection{Metodologia de desenvolvimento empregada}

O processo de desenvolvimento do produto adotado pela empresa ORION-ASP é próprio da empresa, baseado em práticas e metodologias conhecidas. Utiliza seis atividades básicas:

- Análise de Requisitos - Especificação: levantamento dos requisitos para o desenvolvimento de uma nova funcionalidade, aderência do sistema a um processo existente no cliente, reprodução de problemas encontrados em clientes, etc. Os principais documentos gerados nesta etapa são Diagramas de Casos de Uso, Especificação Técnica e Protótipos (projeto gráfico) e Pré-Análise para gerar a previsão de horas demandada pelo projeto (horas orçadas para o projeto);

- Análise: documento com varredura do processo(s) afetado(s)/criado(s) com relação a alterações base de dados, arquivos da configuração envolvidos, fluxo de dados, modelagem Entidade-Relacionamento, detalhamento de funcionalidades a serem implementadas/corrigidas, alterações de interface e cálculo de pontos de função (modelo de medição do tempo gasto para desenvolver partes de um software);

- Desenvolvimento: atividade de manipulação direta sobre os itens da configuração (arquivos de programas) para implementação das funcionalidades previstas na Análise;

- Teste: atividade que envolve analistas, suporte técnico e consultores. Deriva-se dos casos de uso dos processos e de documentos de casos de teste e possui ambiente exclusivo na 
configuração para sua execução com documentação de levantamento, acompanhamento e correção de erros;

- Documentação: documentos referentes às novas implementações e correções liberadas nos respectivos patches e releases do sistema MEGA a partir dos quais são derivados os manuais e arquivos de ajuda (help);

- Finalização: gravação final no repositório do CVS, dos itens da configuração, distribuição do produto para os respectivos clientes, acompanhamento das atualizações e auditoria das atividades realizadas para melhoria contínua do processo.

\subsubsection{Microsoft Project}

As releases do sistema MEGA envolvem um conjunto grande de alterações liberadas periodicamente, tornando necessário organizar o trabalho a ser realizado em projetos, ou seja, cada nova release é sempre um novo projeto dentro da ORION-ASP. Para auxiliar neste gerenciamento foi escolhida a ferramenta Microsoft Project como sistema gerenciador dos projetos de releases.

Como já dito na seção 2.2, o trabalho do projeto deve ser dividido em porções menores até alcançar o nível ideal de gerenciamento. Dentro da empresa, o trabalho é primariamente organizado em chamados técnicos (detalhados na seção seguinte), que correspondem a agrupamentos das atividades definidas na metodologia (análise, implementação, etc.). Na maioria dos casos, correspondem às entregas (deliverables) do projeto, pois a eles estão atreladas datas de controle e um conjunto de modificações no produto, exceto os chamados voltados a atividades internas e serviços como reuniões e treinamentos. Dessa forma, para a criação da WBS do projeto para cada release, acontecem reuniões da diretoria e consultores para a seleção de quais chamados técnicos serão incluídos ou não. Inicialmente há o agrupamento dos chamados que compõem a criação de uma nova funcionalidade no sistema formando os níveis mais altos da WBS, e por fim desmembra-se o chamado em suas atividades da metodologia que formam os pacotes de trabalho do 
projeto. A figura 37 mostra um exemplo de WBS no Microsoft Project para um projeto de versão do sistema MEGA:

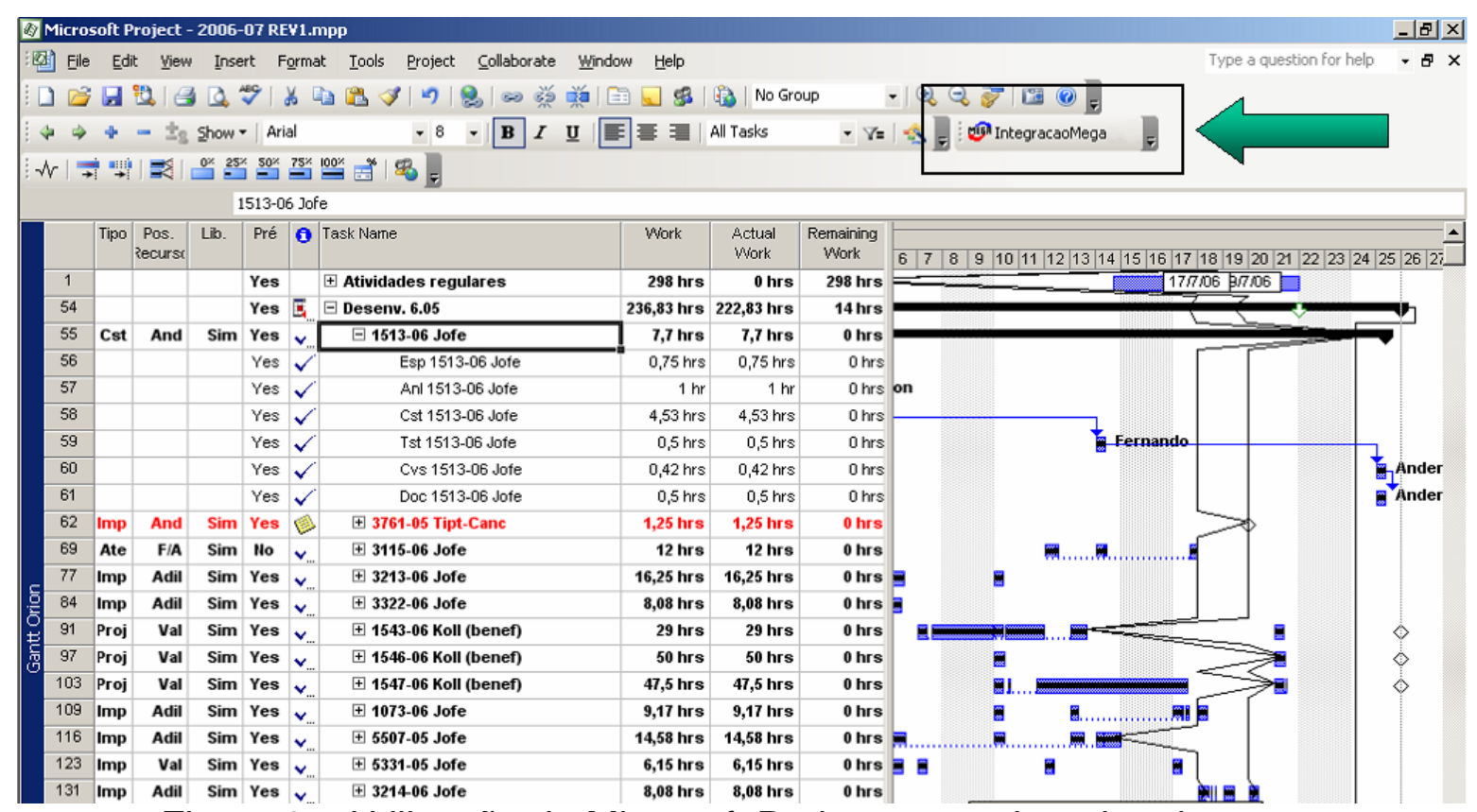

Figura 37: Utilização do Microsoft Project em projeto de release

O gerenciamento dos chamados técnicos é realizado pelo sistema MEGA-Atend e nele está contido o descritivo para cada chamado (por exemplo, "Alteração de notas de entrada para beneficiamento" e "Criação de transações de estoque em remessas para terceiros") e será descrito na próxima seção. No canto superior direito da figura 37 , está realçada a função de importação de dados dos chamados técnicos gravados pelo Mega-Atend: é utilizado para fazer a carga inicial dos chamados relacionados ao projeto e depois para importar as quantidades de horas gastas nas atividades de cada chamado. As informações são exportadas pelo Sistema MEGA-Atend em arquivos formatados (por exemplo, planilhas ou texto separado por vírgula) e, para importação no Microsoft Project, é utilizado o recurso de mapeamento de tarefas (figura 38). Com este recurso é possível associar campos de arquivos a campos da planilha de atividades do Microsoft Project como o descritivo da atividade, data de início, data de finalização, quantidade de trabalho atual e assim por diante. A importação inicial dos chamados e sua posterior organização geram a linha de base do projeto; depois, com a importação dos 
apontamentos, é feita a comparação entre o trabalho previsto e realizado (parcial ou total, dependendo do momento da importação), e gerada a análise do desempenho de cada participante do projeto.
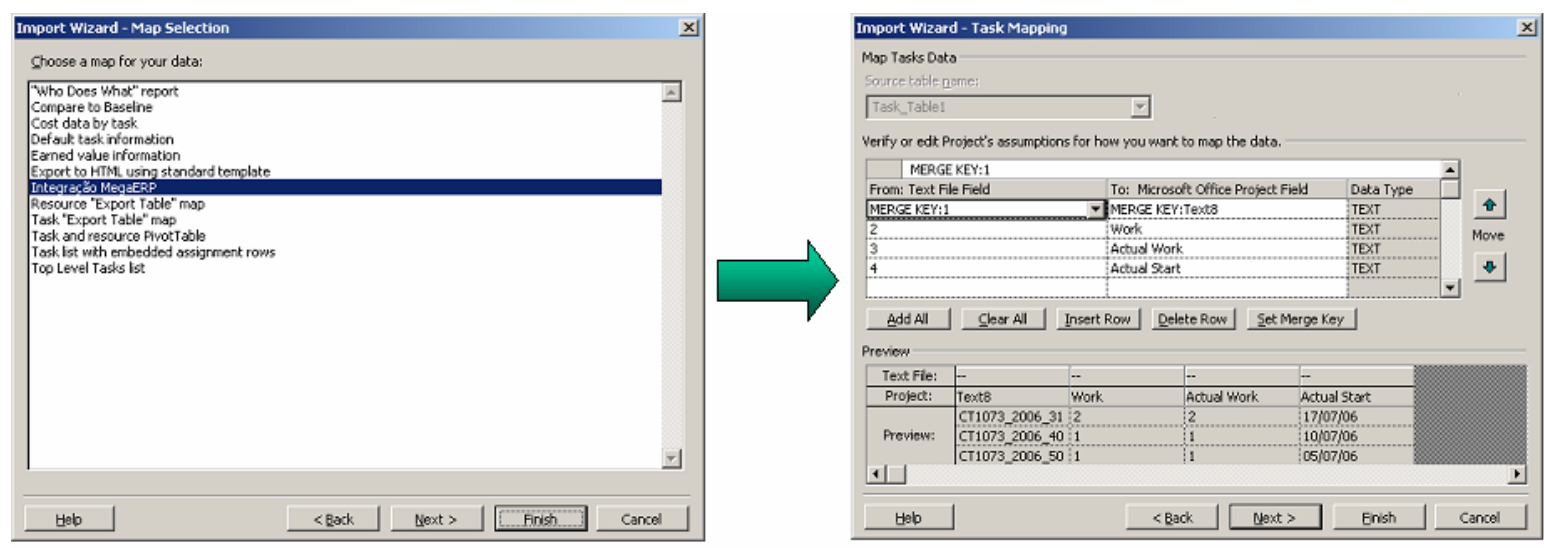

Figura 38: Criação de mapas de importação de arquivos para o Microsoft Project

\subsubsection{O Sistema MEGA-Atend.}

Para realizar o controle do trabalho realizado pelos seus colaboradores, a empresa ORION-ASP decidiu utilizar o conhecimento adquirido no ambiente ERP no apontamento da quantidade de itens produzidos em cada plano de produção, para adaptar o sistema MEGA no sentido de considerar a empresa uma fábrica de software: os colaboradores são os recursos alocados para a produção das atividades (produtos), e a quantidade relacionada a cada atividade correspondem ao tempo gasto na sua execução. O resultado desta adaptação foi o sistema MEGA-Atend, cujas principais características e relações com o sistema MEGA são:

- Chamado Técnico (C.T.): é o mecanismo primário de controle do trabalho na empresa e seu objetivo é registrar uma ou mais atividades de projetos, correções, atendimentos realizados a clientes, reuniões, etc. Corresponde diretamente ao pedido de venda e sua função principal é agrupar as atividades (produtos) para agendamento (priorização) e posterior apontamento (figura 40); 


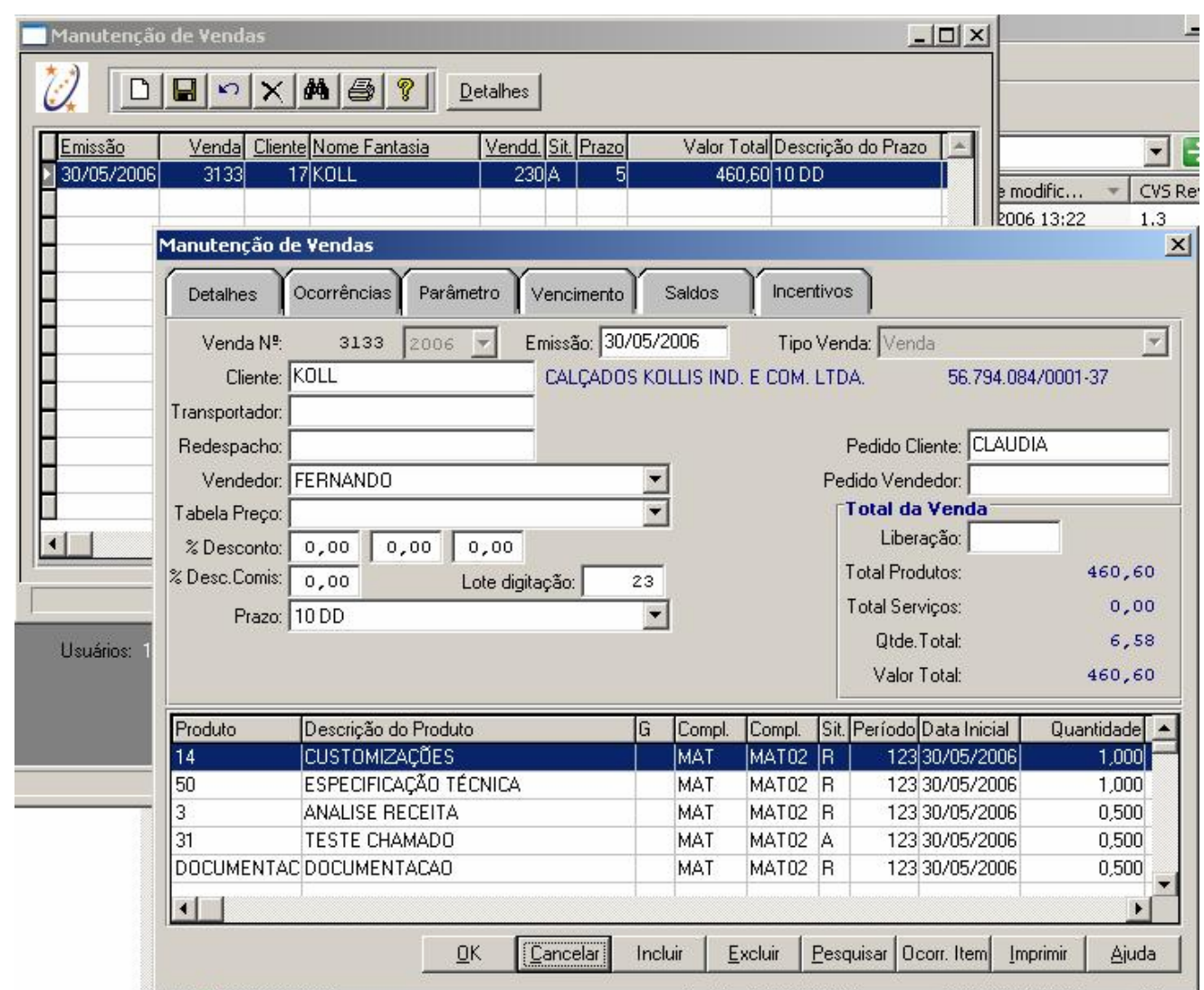

Figura 39: Sistema MEGA-Atend: Chamado Técnico

- Atividades: conforme já mencionado, são os produtos relacionados ao chamado técnico e que devem ser produzidos pelos colaboradores. Estas atividades derivam-se diretamente da metodologia de trabalho empregada gerando produtos como análise, especificação, customização, além de atividades secundárias como, por exemplo, reunião, atendimento e levantamento. As atividades possuem uma situação de controle que varia de acordo com os valores: Aberto $(A)$, Produção $(P)$, Cancelado (C), Realizado ( $R$ ) e Finalizado ( $F)$. Além disso, nas atividades são gravados valores relacionados à pré-análise (previsão inicial) e também à análise (resultado dos pontos de função do documento de análise) para futura comparação do trabalho previsto versus trabalho realizado. Conforme já descrito na seção anterior (5.1.3.2), as atividades representam os pacotes de trabalho da WBS do projeto dentro do sistema de apontamento; 
- Recursos: este ponto deveria se relacionar aos equipamentos e operações do ERP, mas devido ao sistema MEGA não possuir uma implementação aprofundada, optou-se no passado por utilizar os centros de resultados e setores produtivos para representar as pessoas envolvidas nas atividades: as atividades são agrupadas num plano de produção/centro de resultado; como a baixa é feita por centro de resultado e setor, foi implementado um setor simbólico associado ao centro e somente a ele para a realização das baixas (apontamentos) das atividades;

- Agendamento: as atividades necessitam alocação no tempo, numa determinada seqüência e a um determinado conjunto de recursos, da mesma forma que os produtos de um pedido de venda devem ter sua data de produção planejada, reservada e encaminhada à produção. Isso é feito por meio da geração de planos de produção relacionados a uma ou mais atividades dos chamados técnicos. É neste momento que a situação da atividade muda de $(A)$ para $(P)$;

- Apontamento: ao término da produção é necessário apontar a quantidade de produtos produzidos que nem sempre é igual a planejada, podendo variar de acordo com o aproveitamento do material ou algum saldo de matéria-prima que tenha restado de uma ordem de produção anterior. No caso das atividades, esta quantidade se refere ao total de horas de trabalho gastas e que a base de informação para saber 0 andamento dos chamados técnicos e, por conseguinte, do projeto que C.T. pertença; 


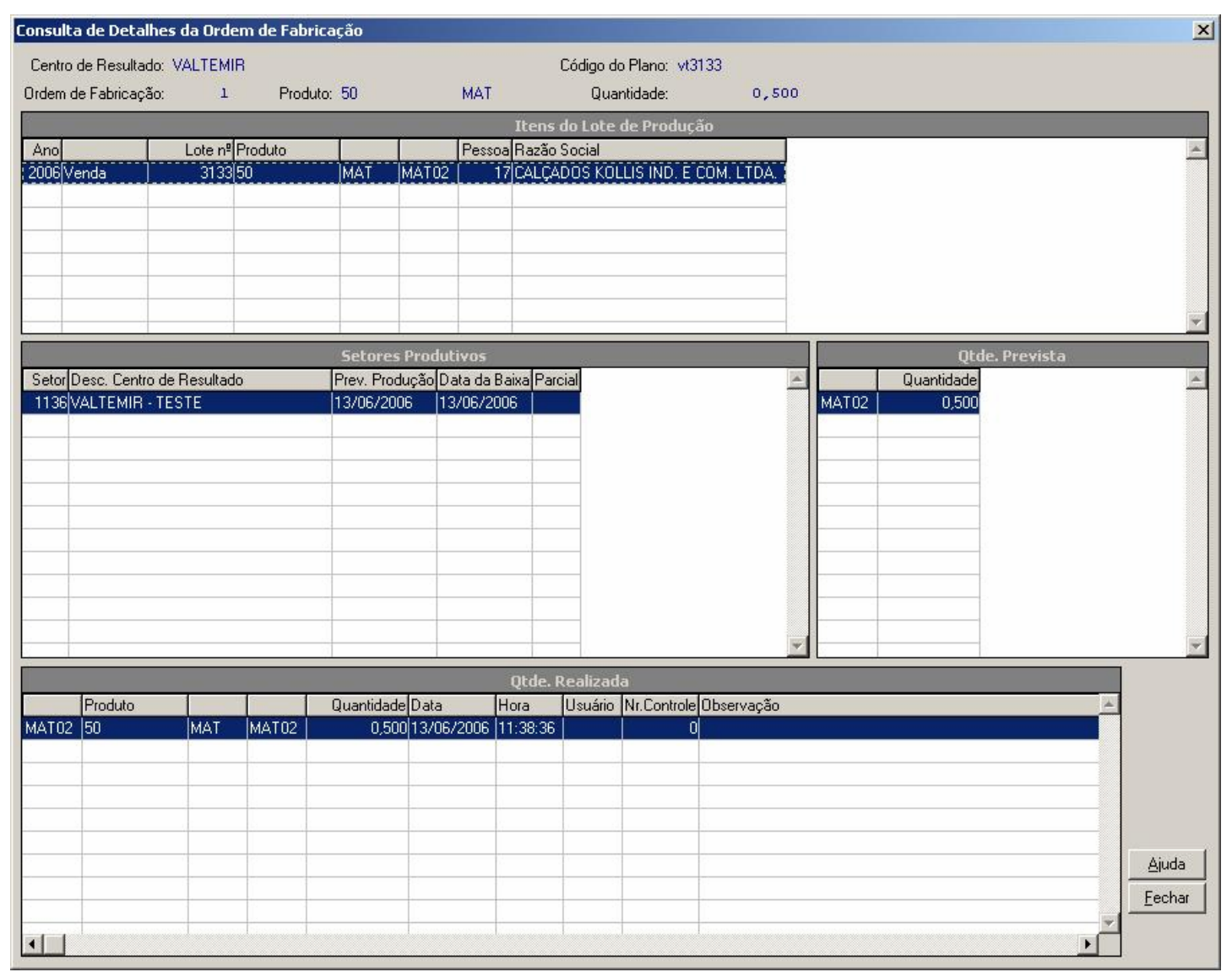

Figura 40: Apontamento de atividades no Sistema MEGA-Atend

- Cadastro de Projetos: como já dito na seção anterior, o Microsoft Project é a ferramenta utilizada para o gerenciamento dos projetos. Após o planejamento da WBS no Project é necessário realizar o acompanhamento do trabalho realizado que, como já visto, é feito através do sistema MEGA-Atend. Dessa forma, para um melhor resultado é necessária alguma forma de integração entre os dados de ambos os sistemas, o que é feito através do Cadastro de Projetos. Através dele, é possível relacionar os chamados técnicos pertencentes a um determinado projeto, mas há a limitação de se conseguir alocar, dentro de um mesmo chamado, atividades planejadas para diferentes projetos. Este cadastro influencia diretamente o projeto em dois momentos: inicialmente, na criação da WBS, as atividades são importadas a partir dos chamados que serão produzidos (entregas) e delas serão extraídos os pacotes de trabalho; e no momento após o apontamento, onde são importadas as quantidades de horas 
gastas na realização do trabalho. Para viabilizar esta importação (descrita na seção 5.1.3.2), o sistema MEGA-Atend possui uma funcionalidade de exportação dos dados envolvendo o Cadastro de Projetos e os chamados técnicos vinculados, como visto na figura 41:

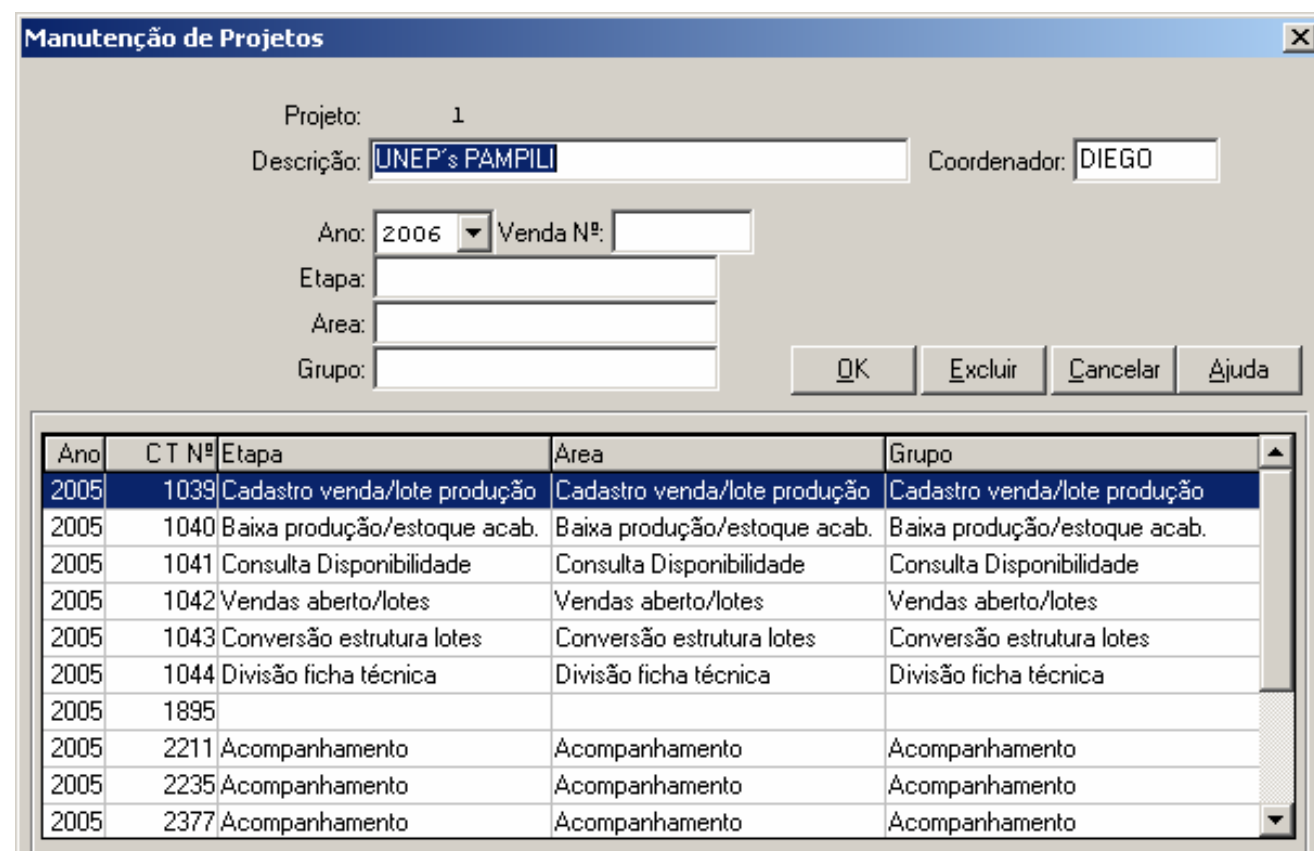

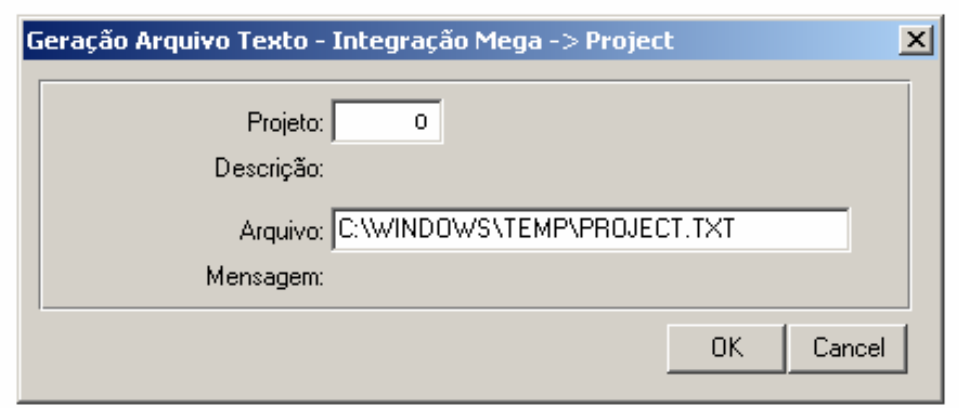

Figura 41: Exportação do Cadastro de Projetos

\subsection{Descrição do Exemplo}

Esta seção descreve a implementação de um exemplo de aplicação da interface proposta, com base no ambiente de projeto e de configuração do sistema MEGA descrito na seção anterior. $O$ ambiente gerenciado através do TortoiseCVS é bastante flexível e permite mapear e programar diversos comandos para executar as funcionalidades de permissão de alteração de arquivo diretamente do repositório do CVS, enquanto o Microsoft Project 
fornece facilidades de integração dos dados, seja via arquivos de importação/exportação ou através da criação dos dados do projeto diretamente em uma base de dados. Através da ferramenta PROGRESS, foi possível a implementação das funcionalidades descritas na seção 4 e, além disso, através do gerenciador de banco de dados existente na ferramenta, viabiliza-se a criação das tabelas referentes à modelagem da base de dados, inclusive armazenando visões de integração para os dados do Microsoft Project que, neste exemplo foram gravados em uma base dados Access.

Para melhorar o entendimento das funcionalidades, a descrição desta seção utiliza a estrutura da própria interface, conforme já explicitado nas seções referentes à especificação e modelagem: detalhamento da WBS, integração produto - projeto, integração pacote de trabalho - item da configuração, controle de situações e apontamento de trabalho realizado. O objetivo final é demonstrar a viabilidade da interface através de um exemplo prático, com a descrição de como as configurações, estruturas, fluxos de informações e funcionalidades implementadas operariam em um projeto exemplo.

O projeto escolhido como exemplo é relacionado ao produto MEGA. Basicamente, são utilizados as atividades da WBS do desenvolvimento do produto e o ambiente de configuração de seus componentes para demonstrar a dinâmica de funcionalidades da interface no sentido de acompanhamento do trabalho realizado. O exemplo descreve a execução de um projeto de desenvolvimento de uma release do sistema MEGA, a partir de uma relação de chamados técnicos selecionados para implementação criados como atividades do projeto; o nome dos recursos foi alterado, por fins de privacidade. A figura 42 mostra a tela inicial da interface, ilustrando os projetos cadastrados, recursos (usuários), tarefas finalizadas e tarefas em andamento para um determinado recurso, obedecendo às respectivas dependências. 


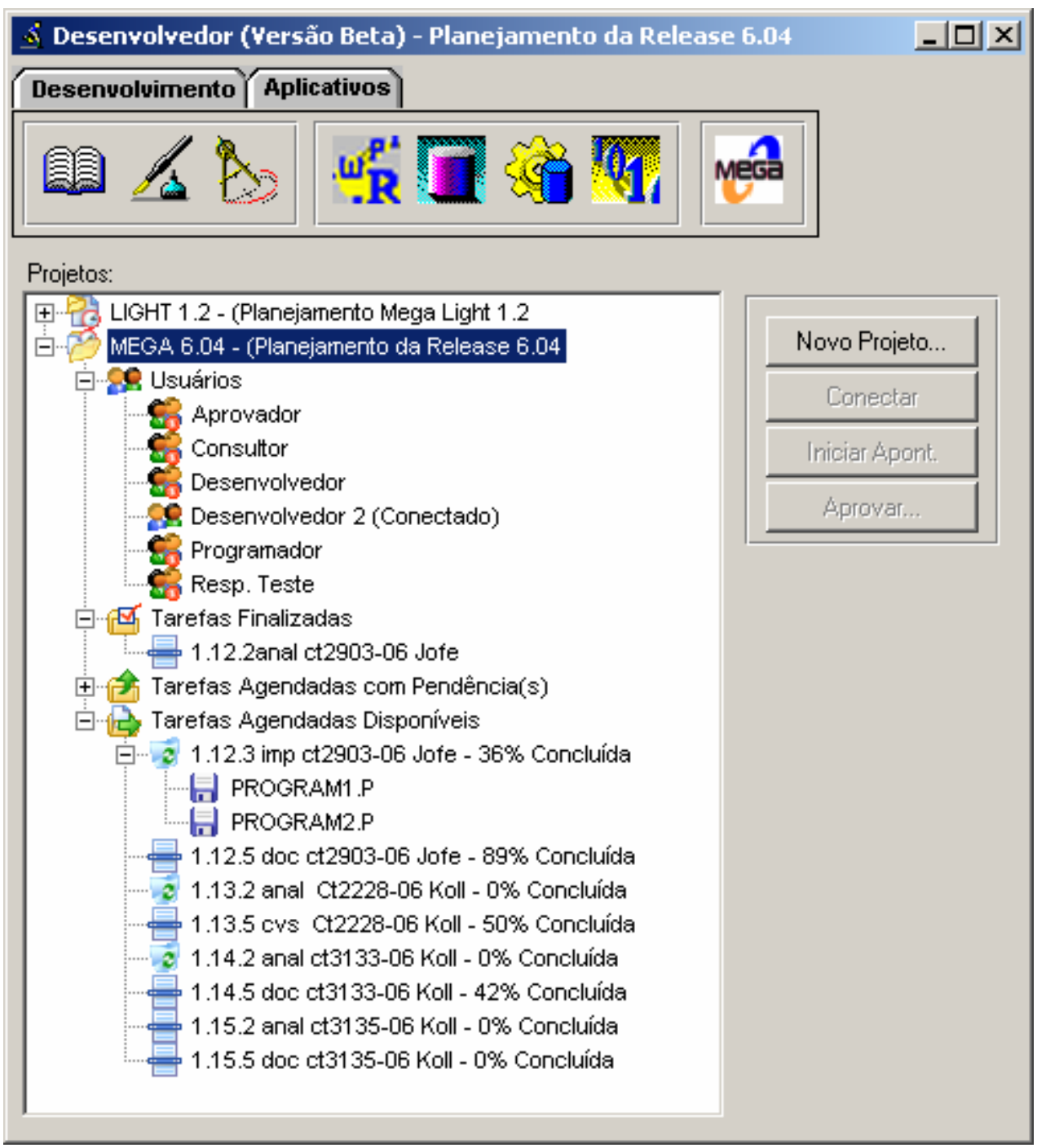

Figura 42: Tela inicial da interface

A partir de um recurso (usuário da configuração) conectado ao software, são carregadas as informações do projeto selecionado e exibidas em formato de árvore (treeview). A descrição do exemplo é dividida em duas seções: a seção 5.2.1 trata das atividades administrativas de configuração da interface (e que só devem ser acessadas pelo gerente da configuração), enquanto a seção 5.2.2 descreve a utilização prática de um desenvolvedor do projeto no apontamento do trabalho realizado.

\subsubsection{Configuração do Ambiente}

Esta seção descreve as estruturas criadas na base de dados, interfaces implementadas e a lógica interna de funcionamento do sistema com base na especificação e modelagem da interface, descritas ao longo da seção 4. 


\subsubsection{Detalhamento da WBS}

Para que seja realizado o agendamento das atividades e alocação de recursos para sua realização é preciso definir os pacotes de trabalho. No caso deste exemplo, os pacotes de trabalho correspondem diretamente às atividades contidas nos chamados técnicos (seção 5.1.3.3). A figura 43 mostra a visão geral da WBS para a release 6.04 do produto MEGA e Microsoft Project:

\begin{tabular}{|c|c|c|c|}
\hline & $\begin{array}{l}\text { Pacote de } \\
\text { Trabalho }\end{array}$ & $\begin{array}{l}\text { Ass. Item da } \\
\text { Configuraçẫo }\end{array}$ & Atividade \\
\hline 1 & Ho & Ho & $\square$ Desenv. 6.04 \\
\hline 2 & Ho & Ho & $Ð$ ct2075-06 - Criar conexão múltipla de base de dados no Atualizador do Sistema \\
\hline 4 & Ho & Ho & $\Psi$ ct2687/06 - Criar opção de desconexão de usuários do sistema a partir do Atualizador \\
\hline 9 & Ho & Ho & $\mp$ ct0163-06 - Correção na formatação de quantidades das ordens de serviço \\
\hline 15 & Ho & Mo & $\mp$ ct1479-06 - Otimização no processo de cálculo de consumo \\
\hline 18 & No & Ho & $\mp$ ct1066-06 - Alteração na valorização do sistema Pós-Cálculo \\
\hline 20 & Ho & Ho & $\mp$ ct1769-06 - Incluir operação posterior no rel. de Ordens de Serviço \\
\hline 27 & Ho & Ho & $\mp$ ct5965-05 - Interface de Emissão de Saldos \\
\hline 34 & Ho & Ho & $\mp$ ct2633-06 - Mecanismo de filtro nos Planos de Inspeção \\
\hline 40 & No & Ho & † ct2634-06 - Impressão Planos de Inspeção \\
\hline 45 & Ho & No & $\Psi$ ct2694-06 - Geração de diferenças na conciliação da Contabildiade \\
\hline 53 & Ho & Ho & \pm ct2919-06 - Atualização de Ficha Técnica \\
\hline 60 & Ho & Ho & $\Psi$ ct2903-06 - Gestão de saldos na Baixa de Estoque \\
\hline 67 & Ho & Ho & $\Psi$ ct2228-06 - Geração de etiquetas de romaneio por Plano de Produção \\
\hline 73 & Ho & Ho & $Ð$ ct3133-06 - Classificação de requisição de materiais \\
\hline 80 & Ho & Ho & $Ð$ ct3135-06 - Apontamento de materiais consumidos por Ordem de Corte \\
\hline 87 & Ho & Ho & $\mp$ Liberacao Release 6.04 \\
\hline 92 & Ho & Ho & $\boxplus$ Testes Release 6.04 \\
\hline
\end{tabular}

Figura 43: Visão geral da WBS de uma release do produto MEGA no Microsoft Project

Para o controle das atividades com relação à importação para a interface, foram adicionados dois campos na WBS: um para indicar o nível de pacote de trabalho e outro para indicar se o pacote deve permitir associação a itens da configuração. Para as atividades mapeadas como pacotes de trabalho e com associação a itens da configuração, também foi criado um campo para determinar se o pacote requer aprovação e que será utilizado pela interface para determinar a forma de finalizar o apontamento do trabalho realizado, conforme foi explicado na modelagem realizada da seção 4.

Para fins didáticos, selecionou-se uma das atividades da WBS para exemplificar o processo completo de configuração da interface. A figura 44 
mostra a atividade selecionada, seus respectivos pacotes de trabalho, os campos de controle e os recursos associados:

\begin{tabular}{|c|c|c|c|c|c|}
\hline & $\begin{array}{l}\text { Pacote de } \\
\text { Trabalho }\end{array}$ & $\begin{array}{l}\text { Ass. Hem da } \\
\text { Configuraçấo }\end{array}$ & Atividade & Recursos & $\begin{array}{l}\text { Requer } \\
\text { Aprovaçấo }\end{array}$ \\
\hline 20 & No & No & † ct1769-06 - Incluir operação posterior no rel. de Ordens de Serviço & & No \\
\hline 27 & No & No & $\square$ ct5965-05 - Interface de Emissão de Saldos & & No \\
\hline 28 & Yes & Yes & Especificação & Consultor & No \\
\hline 29 & Yes & Yes & Análise & Desenvolvedor 2 & No \\
\hline 30 & Yes & Yes & Implementação & Desenvolvedor 2 & Yes \\
\hline 31 & Yes & Yes & Teste & Resp. Teste & No \\
\hline 32 & Yes & Yes & Documentação & Desenvolvedor 2 & Yes \\
\hline 33 & Yes & No & Aprovaçẫo de Alteraçốes & Aprovador & No \\
\hline 34 & No & No & Ð ct2633-06 - Mecanismo de filtro nos Planos de Inspeção & & No \\
\hline 40 & No & No & † ct2634-06 - Impressão Planos de Inspeção & & No \\
\hline 45 & No & No & † ct2694-06 - Geração de diferenças na conciliação da Contabildiade & & No \\
\hline 53 & No & No & Đ ct2919-06 - Atualização de Ficha Técnica & & No \\
\hline 60 & No & No & $\boxplus$ ct2903-06 - Gestão de saldos na Baixa de Estoque & & No \\
\hline 67 & No & No & Ð ct2228-06 - Geração de etiquetas de romaneio por Plano de Produção & & No \\
\hline 73 & No & No & $\boxplus$ ct3133-06 - Classificação de requisição de materiais & & No \\
\hline 80 & No & No & $\boxplus$ ct3135-06 - Apontamento de materiais consumidos por Ordem de Corte & & No \\
\hline
\end{tabular}

Figura 44: Pacotes de trabalho utilizados no exemplo

Explicando os valores dos campos: o item especificação é um pacote de trabalho que possui um documento associado na configuração (item da configuração), mas que não necessita de uma aprovação por parte de um usuário aprovador; a atividade de implementação é semelhante, mas requer aprovação e a atividade de aprovação é um pacote de trabalho que não possui item associado e também não requer aprovação, pois representa o trabalho do usuário associado (Aprovador) no processo de aprovação dos itens alterados. A lista de recursos associada já corresponde aos recursos que serão utilizados neste exemplo. Para disponibilizar as informações relativas aos pacotes de trabalho e recursos, basta exportar o projeto em formato conveniente como texto ou planilha.

\subsubsection{Integração Produto - Projeto}

Para o cadastro de produtos e projetos, associação de projetos a produto, importação de recursos e de pacotes de trabalho foram criadas específicas conforme pode ser visto na figura 45 : 


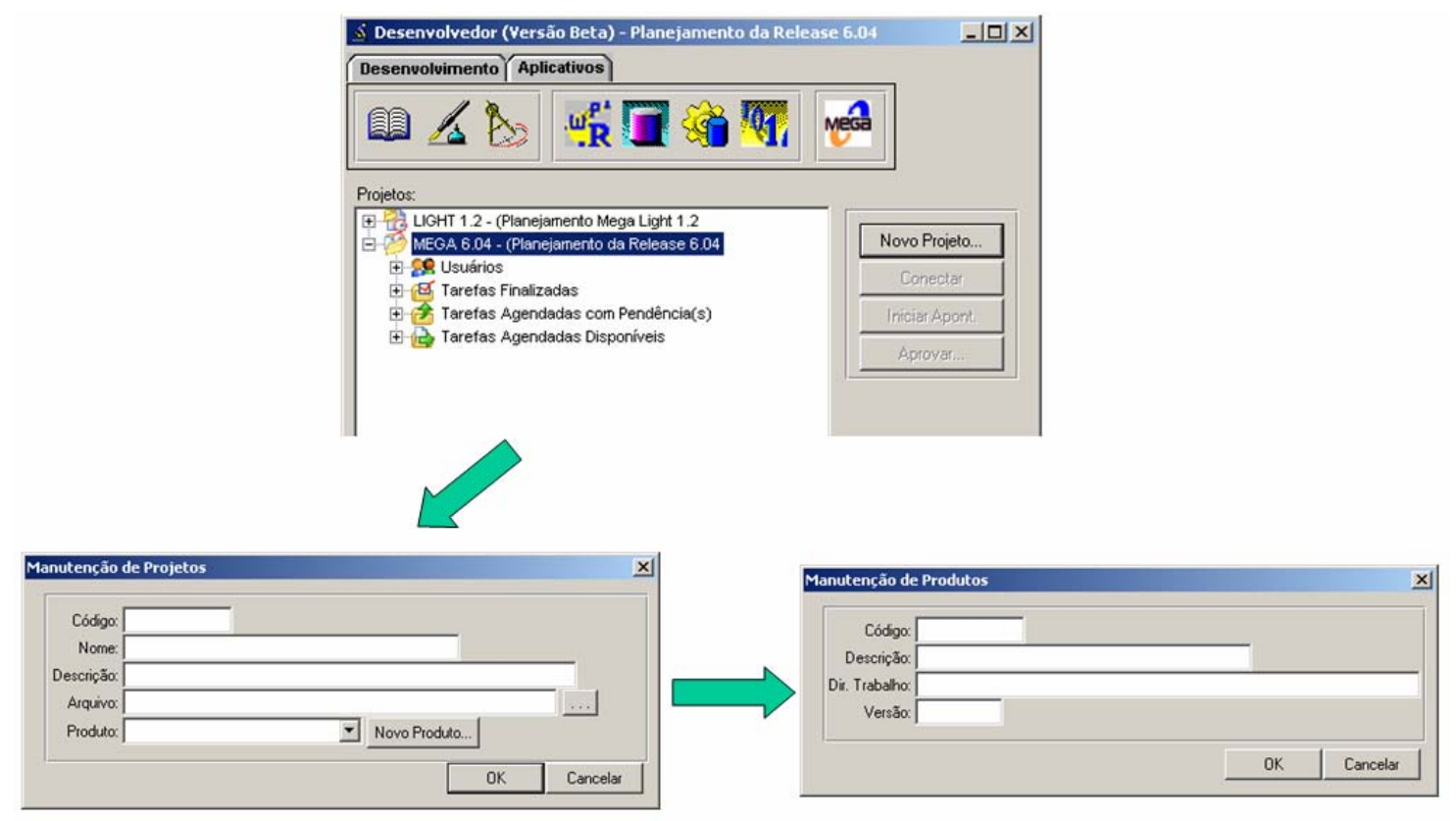

Figura 45: Cadastro de produtos e projetos

Continuando com o exemplo e lembrando a interface utiliza o TortoiseCVS para validar o usuário conectado no programa com o usuário do sistema operacional (usuário da configuração), de acordo com a WBS da seção anterior. O exemplo da figura mostra o cadastro do produto MEGA e o projeto Release 6.04 associados. Os recursos (Consultor, Desenvolvedor 2, ...), pacotes de trabalho (Especificação, Análise, ...) e dependências são importados através da leitura direta das tabelas da base de dados do Microsoft Project. Para o projeto da release 6.04, as dependências importadas seguem a seguinte seqüência: a análise necessita da especificação, o desenvolvimento da análise e assim por diante até a aprovação de alterações que depende da documentação. A interface armazena a atribuição realizada na WBS se os pacotes tiverem associação a itens da configuração e, em caso positivo, se estes pacotes devem passar por processo de aprovação. Além disso, para cada pacote, a interface carrega as informações planejadas de data de início e término e trabalho previsto.

\subsubsection{Controle de Situações}

Para o controle de situações foram implementados os cadastros de status (situações), hierarquia de status para estabelecer o fluxo de trabalho e 
situações de aprovação e a lista de assinaturas também relacionada à aprovação. A configuração do controle de situações pode gerar fluxos de trabalhos complexos através das combinações que podem ser feitas entre as situações e seus atributos de bloqueio ao item da configuração e de finalização do trabalho (ver apêndice B). Por isso, neste exemplo, os dados considerados foram simplificados:

- Status: as situações possíveis neste exemplo são:

- Em Desenvolvimento (ED): não bloqueia alterações e não finaliza trabalho no item;

- Aprovado (AP): bloqueia alterações no item e finaliza o trabalho no item.

- Hierarquia de Status/Fluxo de Trabalho: neste exemplo, o fluxo de trabalho resultante é bastante simplificado, como mostrado na figura 46. Neste caso, só há duas possibilidades de mudança de status: de AP para ED (liberação para alteração) e ED para AP (aprovação). Como o acesso às trocas é controlado, para os usuários Aprovador e Consultor são associadas às duas opções; já para os demais usuários apenas a opção de liberar para alteração (AP para ED). Esta configuração só é válida para itens de pacotes que requisitem aprovação; para pacotes sem este configuração fica liberada a outra opção;

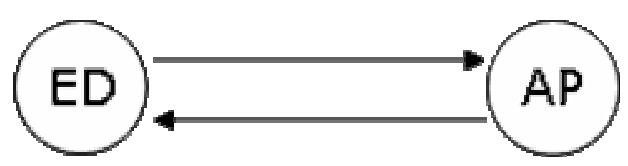

Figura 46: Fluxo de Trabalho do Exemplo

- Controle de Aprovações: para um status de aprovação (AP), pode ser associada uma lista de assinaturas para executarem ações de verificação e aprovação, conforme descrito na seção 4 . Neste exemplo, a configuração para a lista relaciona o usuário Aprovador para aprovação e o Consultor como verificação. Com 
esta configuração, para todos os pacotes configurados para aprovação, seus itens deverão sempre ser verificados primeiramente pelo usuário Consultor, para posterior aprovação do usuário Aprovador. A verificação e alteração através da geração automática de um pacote de trabalho "fantasma", pois não sofrem medição de tempo, que é associado ao item alterado e a todos os membros da lista de assinaturas; após a validação da lista, a associação dos pacotes é excluída e item fica aprovado.

\subsubsection{Apontamento}

Esta seção descreve um exemplo prático de utilização da interface para o apontamento do trabalho, de acordo com as configurações estabelecidas ao longo da seção 5.2.1. É listada a seqüência básica de tarefas para um usuário do projeto que está alterando a configuração do produto:

- Seleção de produto e projeto: a figura 42 mostra a instância do o produto MEGA e do projeto da release 6.04 associados ao recurso Desenvolvedor 2 do projeto e da configuração;

- Pacotes de trabalho: Ainda na figura 42, são mostrados na sua parte inferior, os pacotes (alocados para o usuário) já finalizados, pendentes e em alteração ou prontos para iniciar alteração (com as dependências finalizadas). Para ilustrar, observa-se o pacote 1.12.2 (associado a uma atividade de análise) finalizado que, automaticamente, libera a pendência que impedia o início do pacote 1.12.3 (pacote associado a uma implementação). Este pacote permite associação de itens da configuração, mas não requer aprovação e assim o próprio usuário finaliza o trabalho no pacote;

- Itens da Configuração: para os pacotes de trabalho liberados para associação de itens da configuração é liberada a opção Adicionar Item para associar itens da configuração. Usando o exemplo do pacote 1.12.3 (que foi configurado na WBS para receber associação de itens da configuração), interface é gerada 
uma lista com os arquivos disponíveis na configuração. As figuras 47 e 48 ilustram a associação do item da configuração PROGRAMA1.P ao pacote;

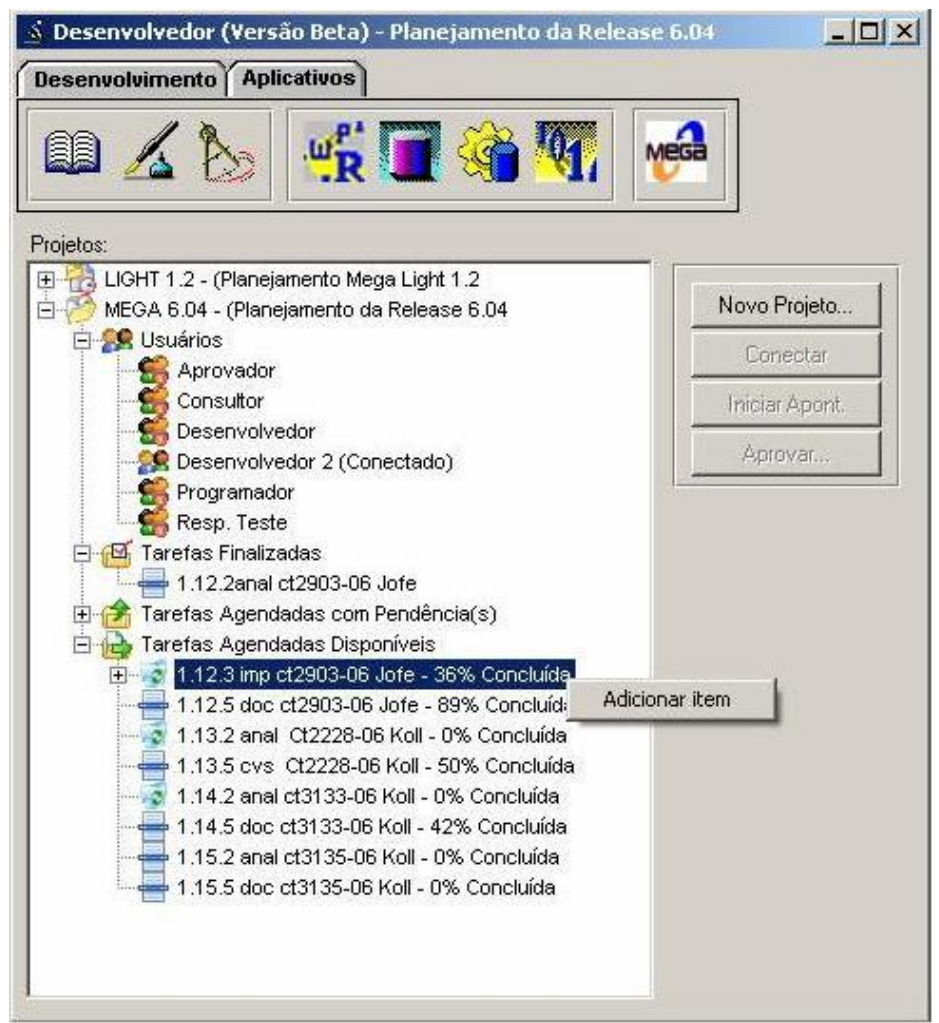

Figura 47: Opção Adicionar Item da Configuração

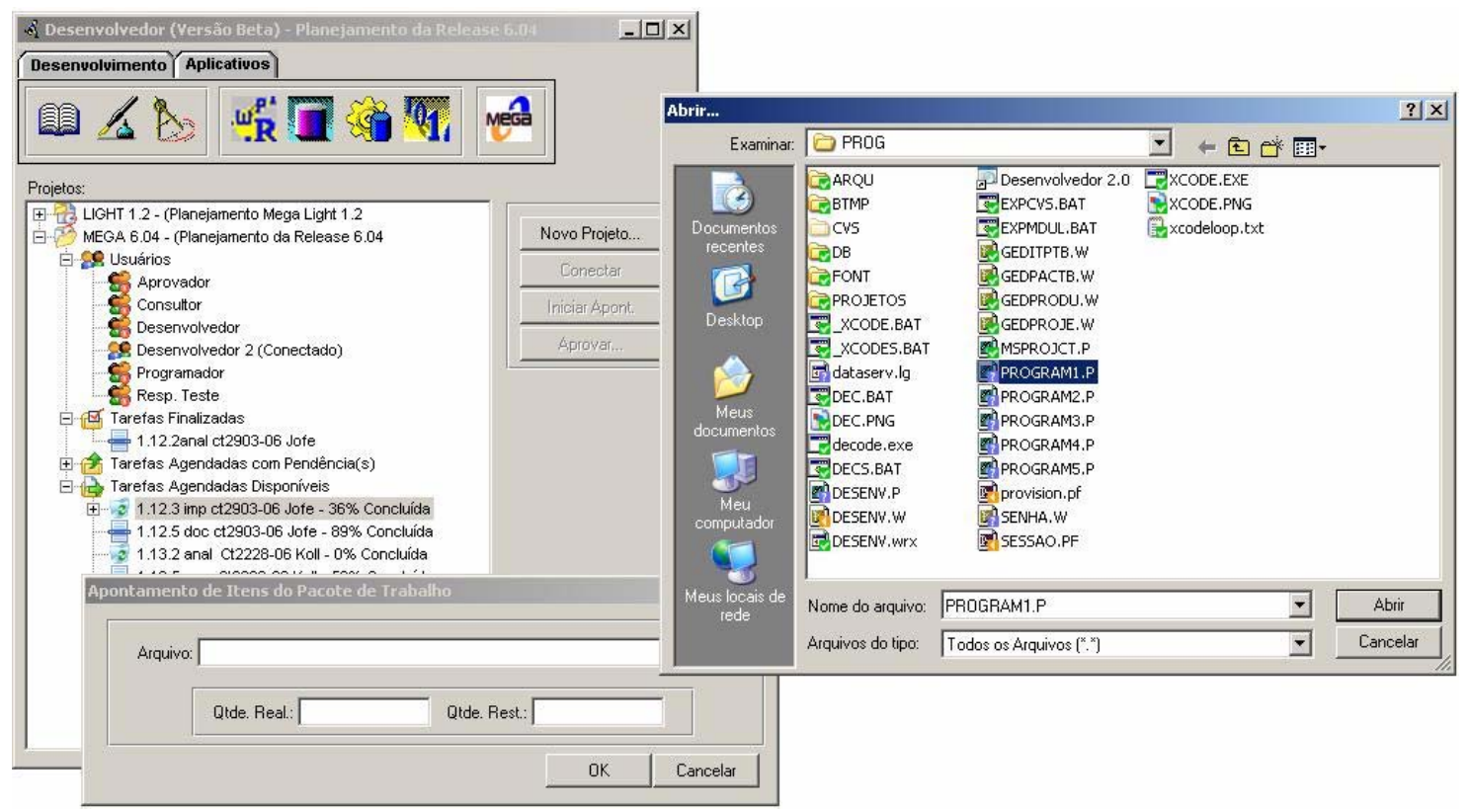

Figura 48: Adição de um item a um pacote de trabalho 
- Controle de acesso: neste momento, a interface utiliza comandos internos do CVS para incluir o arquivo na configuração e liberá-lo para alteração; caso o usuário tivesse selecionado um arquivo anteriormente (o arquivo já estava em alteração pelo usuário), a interface apenas requisita a liberação de acesso de gravação. Com a liberação pelo CVS, internamente, a interface abre uma seção de alteração para o item e só será interrompido quando o usuário explicitamente encerrar a seção de trabalho. Esta seção é criada sempre que o usuário cria ou seleciona um item da configuração; com o encerramento da seção, o acesso é imediatamente bloqueado. O item também só pode ser alterado se estiver em um status que permita alteração. No caso da criação do item, a interface seleciona os possíveis status de origem na hierarquia (status que não possui um status anterior) e só permite a seleção de um status que não bloqueie a alteração; já para um item existente em status de bloqueio é necessário que o usuário altere o status para um status que permita alterações. Neste exemplo, em ambos os casos o item deve estar em situação ED;

- Medição do Trabalho: concomitantemente à seção de trabalho, a associação do item ao pacote de trabalho e produto-projeto é gravada na base de dados, o que dá início a medição interna do tempo de alteração do item e que continua enquanto a seção não for encerrada. Nesta versão do software, a entrada dos apontamentos de horas de trabalho realizadas ainda é manual; a próxima versão trará o apontamento automático. Para cada item, o usuário informa a quantidade de trabalho realizada sobre o item e a quantidade estimada restante para o mesmo. Dessa forma, pode-se estimar o quanto do trabalho total já está finalizado, ao mesmo tempo em que se atualiza a previsão de término. A figura 49 ilustra um exemplo de apontamento; 


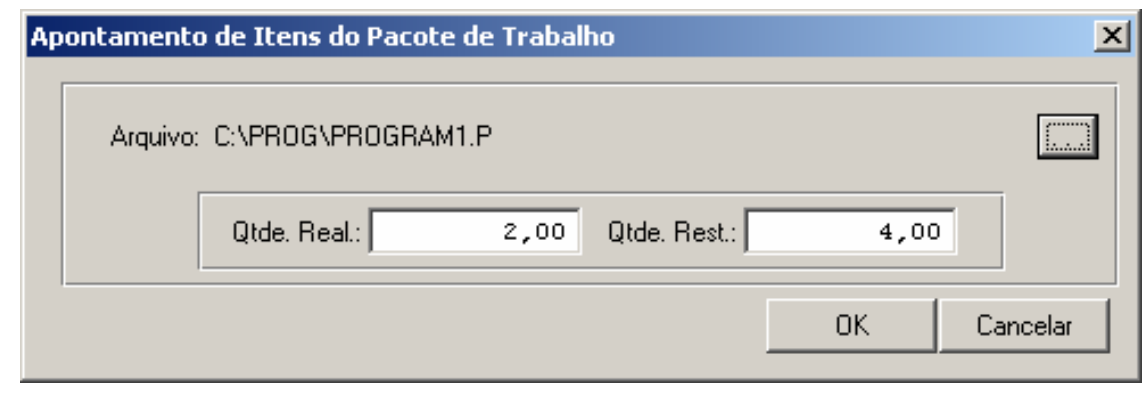

Figura 49: Apontamento de horas na interface

- Acompanhamento - Item da Configuração: Durante o processo de alteração, o usuário Desenvolvedor 2 pode encerrar a sessão diversas vezes, dependendo da quantidade de trabalho a ser realizado. A cada encerramento, a interface grava um registro log interno com as datas e horas de início e término da sessão e a quantidade de trabalho realizado; em seguida, requisita que o usuário informa a quantidade de trabalho que ele estime restar para a finalização do trabalho. Esta informação também é gravada no registro log e é vital no sentido de acompanhamento do projeto;

- Acompanhamento - Pacote de Trabalho: Através do trabalho realizado e o trabalho restante, a interface totaliza diretamente 0 trabalho realizado dos itens e calcula a quantidade restante para todo o pacote; para pacotes sem associação de itens, a interface requisita diretamente 0 trabalho realizado quanto 0 trabalho restante;

- Finalização - Item da Configuração: para iniciar a finalização do item da configuração, o usuário deve informar a quantidade de trabalho restante como zero. Neste momento, a interface requisita que o item seja aprovado através da troca de status. Inicialmente, é verificado se o item, de acordo com o pacote a que ele está associado, necessita passar pelo processo de aprovação de situação. Se não necessitar, a interface permite que o usuário altere a situação do item para o status de aprovação, caso esta troca esteja configurada, sem nenhuma verificação adicional. Se não estiver configurada, o item só será finalizado no momento 
que algum usuário, com permissão para a troca configurada, efetue a mudança de situação para o item. No caso, o usuário Desenvolvedor 2 deve, além de zerar o trabalho restante, trocar o status do item relativo ao documento de análise para a situação AP. Se o processo de aprovação fosse necessário, apesar de o item estar na situação AP, ainda seria necessário uma validação pela lista de assinaturas para aprovação definitiva, caso haja uma lista cadastrada. Para isso, após a troca, são gerados pacotes de trabalho fantasmas (sem apontamento) para os usuários associados ao status de aprovação pela lista de assinaturas (Aprovador, Consultor). Estes pacotes, ao invés de quantidade de trabalho restante, requisitam a validação de campos de aprovação ou verificação. Após a validação da lista, os pacotes fantasmas são excluídos e o item fica aprovado e sem pendências. Com a aprovação final (quantidade realizada igual a zero e item com status de aprovação sem pendências da lista de assinaturas), a data de término do trabalho é gravada no item da configuração e é requisitada a gravação do item alterado no repositório central do CVS;

- Finalização - Pacote de Trabalho: para pacotes sem itens associados, são considerados finalizados os pacotes com trabalho restante igual a zero; para pacotes com itens, a finalização é derivada da verificação se todos os itens que o compõem estão finalizados. Com a finalização é gravado o campo data de término do pacote derivado da maior data de finalização dos itens ou da data que a quantidade restante foi zerada, de acordo com o tipo do pacote;

- Exportação de Dados: os dados de cada pacote são exportados de diretamente para as respectivas tabelas da base do Microsoft Project com base na documentação interna fornecida pela Microsoft. São exportados os campos referentes aos pacotes de trabalho, datas inicial e final, trabalho realizado e também é incluído o campo quantidade de trabalho restante (Remaining 
Work). Os dados são gerados a parir dos registros de log para os itens e pacotes gravados na base de dados. 


\section{Considerações Finais}

Este trabalho compreende uma descrição detalhada da especificação e modelagem de uma solução para o acompanhamento de projetos de software a partir das alterações realizadas diretamente sobre os componentes da configuração. A solução proposta é um software que atua como uma interface entre sistemas gerenciadores de projetos e sistemas de gerenciamento da configuração através do relacionamento das atividades da WBS do projeto e os itens da configuração do produto. Dessa forma, o escopo do trabalho procurou restringir as áreas de gerenciamento de projetos e da configuração ao controle e acompanhamento das alterações no produto.

A viabilidade da especificação e modelagem proposta para a interface foi avaliada através da montagem de um exemplo de aplicação em um ambiente real, do qual o pesquisador participa diretamente e que está de acordo com o método de pesquisa adotado. A seção 6.1 trata das conclusões e contribuições deste trabalho, enquanto a seção 6.2 descreve problemas e limitações encontrados. Finalmente, na seção 6.3, são apresentadas as sugestões para trabalhos futuros.

\subsection{Conclusões e Contribuições}

A principal contribuição e também conclusão deste trabalho foi demonstrar a viabilidade de acompanhamento do projeto, diretamente a partir das alterações nos itens da configuração. Como visto na revisão bibliográfica realizada seção 2 e na justificativa principal deste trabalho, os sistemas de gerenciamento de projeto (dos sistemas mais simples aos de gerenciamento de ciclo de vida do produto - PLM) de acordo com a revisão, não possuem integração completa entre fluxo de trabalho, projeto e a configuração do produto. Há sistemas PLM, por exemplo, o RUP, que possuem o relacionamento entre os resultados produzidos (itens da configuração) e as atividades do projeto, mas sem o apontamento automático proposto na interface. O mérito da interface está exatamente no fato de modelar esta integração entre fluxo de trabalho, projeto e configuração, de forma que as alterações sobre os itens só são permitidas por liberação da interface que por sua vez, internamente, mantém ativo o controle de tempo de utilização do item. 
No momento de encerrar o acesso ao item, a interface possui o mecanismo de requisitar o apontamento manual do trabalho restante, o qual propicia o cálculo da participação proporcional de cada item dentro do seu respectivo pacote de trabalho no projeto. Permite, portanto, atualizar o esforço total ainda a ser gasto na atividade mantendo-se atualizadas as previsões de horas a serem gastas no projeto e a identificação de atrasos. A totalização dos itens, para cada pacote, é então enviada ao sistema gerenciador do projeto, o que propicia um acompanhamento mais aproximado da realidade que o paradigma comumente empregado de utilizar o lançamento manual das horas trabalhadas sem a correção.

Derivada desta análise há outra contribuição importante: através da interface proposta, é possível desenvolver soluções mais acessíveis para o apontamento do trabalho relacionando a configuração do produto e o gerenciamento do projeto. Se comparadas, verifica-se que às soluções integradas são voltadas para as grandes corporações. Dependendo do ambiente da organização, é possível construir a solução a partir de softwares de código aberto e softwares livres, onde não há custo de aquisição (como no caso do TortoiseCVS, descrito no exemplo da seção 5). Como se trata de uma interface ela poderá ser customizada no futuro, permitindo a conexão com diferentes pacotes, tanto de gestão de projetos como CVS. Em tese, poderá ser empregada em ambientes multi-plataforma como é o caso dos projetos cooperados de desenvolvimento de produtos, onde não necessariamente as mesmas empresas utilizam sistemas de informação padronizados.

Através do controle de situações e lista de assinaturas proposto, torna-se possível implementar a finalização de uma alteração, a partir da reunião de um grupo de pessoas responsáveis por auditorias de verificação e aprovação do trabalho realizado o que possibilita a integração dos itens da configuração ao conceito de phase gates, que correspondem a reuniões de aprovação da linha de base do projeto para uma mudança de fase.

Entre as contribuições adicionais pode-se citar:

- Levantamento de Requisitos: com a revisão bibliográfica e a construção dos casos de uso, obteve-se uma lista de requisitos consistentes e que podem ser utilizados para a proposição de outras soluções com abordagens diferentes deste trabalho; 
- Detalhamento da WBS: o tratamento a WBS, descrito na seção 4 resume os critérios definidos em PMI (2001), PMBOK (2004) e ICM (2003), no sentido de descrever as melhores práticas para que o desmembramento seja mais facilmente gerenciável com relação ao controle de alterações na configuração do produto;

- Fluxo de Trabalho: com o controle de situações na configuração, torna-se possível a implementação de um fluxo simples de trabalho para organizações que não dispõem de sistemas de workflow, ou possuem, mas não de forma integrada ao projeto;

- Controle de Acesso: através da interface, apenas usuários alocados no projeto podem acessar os itens da configuração aumentando a capacidade de controle direto sobre os custos planejados sobre os recursos do tipo mão-de-obra;

- Projetos Cooperados: através de um mecanismo eficiente de apontamento ligado às atividades do projeto e à configuração do produto, viabiliza-se uma forma direta de acompanhamento de projetos à distância, com menor dependência dos gerentes e participantes de cada subprojeto, ajudando a preencher da lacuna existente nos sistemas de desenvolvimento colaborativo descrita em RODRIGUEZ \& AL-ASHAAB (2005);

- Valor Agregado: apurações mais efetivas do trabalho realizado refletem diretamente em dois elementos básicos do cálculo do valor agregado no projeto (VARGAS, 2006): o BCWP (Budget Cost of Work Performed - Valor Agregado), valor que indica a parcela do orçamento que deveria ser gasta de acordo com trabalho realizado até o momento; e o ACWP (Actual Cost of Work Performed - Valor Gasto) que corresponde ao custo real do trabalho realizado até a data de referência ou data atual do projeto, a partir dos dados financeiros. Também influencia o cálculo da variação do tempo previsto em relação ao tempo realizado, a TV (Time Variance). 
Outra consideração final deste trabalho é a carência de literatura envolvendo explicitamente o gerenciamento da configuração do projeto. Como visto em PSPCM (2006), o PMI só em 2006, está fazendo uma compilação específica sobre o tema. Outra carência de literatura, que aparece também entre as justificativas deste trabalho, está na área de apontamento de projetos relacionado ao fluxo de trabalho e a gerência da configuração, o que levou o autor a abordar o tema sob o prisma da abordagem dos principais sistemas comerciais na gerência de portfólios.

\subsection{Problemas e Limitações da Pesquisa}

O principal problema encontrado foi a grande variedade de sistemas de acadêmicos aos comerciais e com diferentes abordagens, o que dificultou no estabelecimento de uma visão geral sobre apontamento do trabalho em projetos.

O trabalho desenvolvido não pode ser generalizado, pois não teve todas as suas condições de falha refutadas em termos de especificação e modelagem. O exemplo de aplicação foi limitado, pois, apesar de obter-se um protótipo funcional adaptado à necessidade da empresa, não envolveu uma situação real de uso. A integração foi testada através de um exemplo de projeto finalizado e realizado no passado. De qualquer forma, trata-se de um caso real, comum a pequenas empresas, com um sistema simples de gerenciamento de projetos desvinculado da configuração. Outras limitações incluem:

- Flexibilidade dos sistemas de gerenciamento da configuração para possibilitar abertura às implementações propostas não suportadas;

- Sistemas de fluxo de trabalho podem não suportar a implementação do mecanismo de controle de situação proposto, mais precisamente com relação à lista de assinaturas;

- Existência de projetos com mecanismo diferente de apontamento;

- Controle de níveis de acesso aos itens da configuração do sistema de gerenciamento da configuração não foi considerado;

- Foram desconsiderados mecanismos de segurança para os dados de apontamento não serem corrompidos; 
- Falta de tratamento para pacotes de trabalho associados a mais de um usuário;

- Consideraram-se apenas as dependências do tipo término-início (FS Finsih-Start), por serem o uso mais comum em projetos. O processamento de outros tipos de dependências aumentaria o grau de complexidade de verificação de acesso aos pacotes de trabalho.

\subsection{Sugestões para Trabalhos Futuros}

Em se tratando de áreas tão amplas quanto o gerenciamento de projetos, configuração de produtos e fluxo de trabalho, muitas possibilidades de trabalhos futuros podem ser sugeridas:

- Implementação da interface: com base na especificação e modelagem propostas, implementar uma solução computacional em ambiente de desenvolvimento de software;

- Apontamento de projetos cooperados: construir um sistema que consolida estas informações e possibilita o acompanhamento do projeto global para resolver o problema da dependência dos membros de cada projeto individual na atualização dos dados para o projeto global;

- Análise do valor agregado em projetos cooperados: derivado do item anterior, esta sugestão corresponde a um mecanismo para consolidar as informações de custo, orçamento e financeira de cada subprojeto em uma visão comum, a partir do apontamento consolidado;

- Edição dos itens da configuração: aprimorar funcionamento do fluxo de trabalho incorporando conceitos de GED (Gerenciamento Eletrônico de Documentos) para fazer o controle da edição direta dos itens da configuração a partir da interface;

- Repositório: incorporar base de dados da interface ao repositório da configuração para centralização dos dados da configuração do produto; 
- Integração de direitos e níveis de acesso: mecanismo de Integração das restrições de acesso aos itens da configuração propostas na interface às regras de direitos e perfis de acesso do sistema de gerenciamento da configuração, para bloquear a associação de itens não autorizados a pacotes de trabalho. Vincular também o controle de mudança de situação aos níveis de acesso;

- Mecanismo de segurança para a gravação dos apontamentos: a gravação dos dados de apontamento proposta foi um mecanismo de geração de arquivos seqüências de log para os apontamentos de cada usuário, o que pode gerar informações corrompidas;

- Integração dos recursos, pacotes de trabalho e apontamento do trabalho: criação de padronização de interfaces de comunicação com sistemas de gerenciamento de projetos para automatizar os processos de carga de informação conforme, por exemplo, descrito em CHENG et al. (2003) através da utilização da linguagem PSL;

- Interface para WBS e configuração: de forma similar à realizada neste trabalho para o ambiente de configuração, criar interface para relacionar os itens da configuração aos pacotes de trabalho, diretamente no sistema gerenciador de projetos (suportado em sistemas PLM). 


\section{BIBLIOGRAFIA}

ABBAGNANO, N. (1970). Dicionário de filosofia. São Paulo: Mestre Jou, 1970.

ALSHAWI M., INGIRIGE B. (2003). Web-enabled project management: an emerging paradigm in construction. Automation in Construction, No.12, p. 349364, 2003.

ALLEN, G, JARMAN, R. (1999). Collaborative R\&D: Manufacturing's New Tool, Ed. Wiley, New York, N.Y., 1999.

AMARAL, D. C. (2001). Arquitetura para gerenciamento de conhecimentos explícitos sobre o processo desenvolvimento de produto. São Carlos, 190p. Tese (Doutorado) - Escola de Engenharia de São Carlos, Universidade de São Paulo, 2001.

BADIRU, A.B. (1996). Project management in manufacturing and high technology operations. Editora John Wiley \& Sons Inc., 2a. edição., NY, 1996.

BRYMAN, A. (1989). Research methods and organization studies. London, Routledgep. 170-188, 1989.

CASCIO, W.F., SHURYGAILO S. (2001). E-leadership and virtual teams. Organizational Dynamics. Vol.31, No. 4, p.362-376, 2003.

CASSELL C., SYMON G. (1994). Qualitative methods in organizational research: a practical guide. London. Ed. Sage, 253 páginas, 1994. 
CHENG J., LAW K. H., KUMAR N. (2003). Online Collaboration of Project Management Applications. Environmental Engineering Department, Stanford University, Stanford, CA, 2003.

CHO, S. H. (2001). An integrated method for managing complex engineering projects using the design structure matrix (DSM) and advanced simulation. M.S. thesis. Massachusetts Institute of Technology, USA, 2001.

CIMDATA (2004). All about PLM. Disponível em http://www.cimdata.com/PLM/plm.html. Acesso em 23/01/2005.

CLAUSING, D. (1994). Total Quality Development. New York: ASME, 1994.

CMBOK (2006). Configuration Management Body of Knowledge. Disponível em http://www.cmcrossroads.com/cgi-in/cmwiki/bin/view/CM/CMBoKCompleteText. Acesso em 22/02/2006.

DANE, F. C. (1990). Research methods. Belmont, CA; Brooks/Cole, 1990.

EVARISTO R., FENEMA. P. (1999). A typology of project management: emergence and evolution of new forms. International Journal of Project Management Vol. 17, No. 5, pp. 275-281, 1999.

GASCOIGNE, B. (1995). PDM: The essential technology for concurrent engineering. World Class Manufacture. v. 2, n. 1, p. 38-42, 1995.

GIL, A. C. (1999). Métodos e técnicas de Pesquisa Social. São Paulo: Atlas, 1999. 
GUMMENSON (2000). Qualitative methods in management research. 2nd. Ed., Sage, Thousand Oaks, CA, USA, 2000.

HAMERI, A. PUITTINEN, R. (2003). WWW-enabled knowledge management for distributed engineering projects. Computers in Industry n. 50, p. 165-177. Disponível em www.sciencedirect.com. Acesso em 22/01/2005.

ICM (2003). Project Management Relative to CMII. Institute of Configuration Management, 2003. Disponível em www.icmhq.com. Acesso em 10/07/2006.

KAPLAN, B., DUCHON, D. (1988). Combining qualitative and quantitative methods in information systems research: a case study. MIS

Quarterly, v. 12, No. 4, p. 571-586, 1988.

KULAK D., GUINEY E. (2004). Use Cases: Requirements in Context. Ed. Addison-Wesley Personal Education Inc., Boston, MA, USA, 2004.

KOVÁCS G.L., PAGANELLI P. (2003). A planning and management infrastructure for large, complex, distributed projects-beyond ERP and SCM. Computers in Industry, No. 51, p. 165-183, 2003.

LEE Y., KUMARA S. R. T. (2003). Advances in e-manufacturing: foundations of market-based collaborative planning and control of distributed multiple product development projects. Journal of Materials Processing Technology, No. 139, p. 178-186, 2003.

LI W. D., Fuh J. Y. H., Wong Y. S. (2004). An Internet-enabled integrated system for co-design and concurrent engineering. Computers in Industry n. 55 p.87-103. Disponível em www.sciencedirect.com. Acesso em 22/01/2005. 
GARTNER (2005). Magic Quadrant for IT Project and Portfolio

Management. Gartner RAS Core Research Note G00129208, 2005.

LYON, D. (2000). Pratical CM - Best Configuration Management Pratices. Ed. Butterworth-Heinemann, 2000.

MARTINS, G.A. (1995). Epistemologia da pesquisa em Administração. São Paulo: Universidade de São Paulo - Faculdade de Economia, Administração e Contabilidade. Tese de livre-docência, 1995.

MIL-HDBK-61 (2005). Military Handbook - Configuration Management Guidance. Department of Defense, USA. Disponível em http://www.faa.gov/cm/cmdocs/3Standards/Hdbk61/hdbk61.htm, 2005.

MUSSER, J. (2002). Principles of Software Project Management. Disponível em http://www.columbia.edu/ im2217/Q7503 2post.ppt. Acesso em 22/07/2006.

NUNES, R. J. E. (2003). Gerenciamento de Projetos em Ambientes Distribuídos. Seminário de Gestão de Projetos, SUCESU, SP, 2003.

OKUBO T., MATSUTSUKA T., HARA H. (2000). System for Distributed Project Management over the Internet: PI-CEE, 2000.

OMOKAWA, R. (1999). Utilização de sistemas PDM em ambientes de engenharia simultânea: O caso de uma implantação em uma montadora de veículos pesados. Dissertação (Mestrado) - Escola de Engenharia de São Carlos, Universidade de São Paulo, São Carlos, 1999. 
ORION (2006). Sistema MEGAERP-Full. Orion-ASP Soluções em Informática Ltda., São Paulo, 2006. Disponível em http://www.orionasp.com.br. Acesso em 22/07/2006.

OSI (Open Source Initiation). The Open Source Definition, versão 1.9. Disponível no site: http://www.opensource.org/docs/definition.php. Acessado em maio de 2004.

PÁDUA, E. M. M. (1996). Metodologia de Pesquisa: abordagem teórico-prática. Editora Papirus, São Paulo, 1996.

PATTON, M. Q. (1980). Qualitative evaluation methods. Beverly Hills, CA: Sage, 381 páginas, 1980.

PETRIE C., GOLDMANN S., RAQUET A. (1999). Agent based project management. Lecture notes in AI - 1600. Berlin: Springer; 1999.

PMBOK (2004). Um Guia de Conhecimentos em Gerenciamento de Projetos. Project Management Institute, Four Campus Boulevard, Newton Square, Pennsylvania, USA, 2004.

PMI (2001). Pratice Standard for WBS. Project Management Institute, Four Campus Boulevard, Newton Square, Pennsylvania, USA, 2001.

PSPCM (2006). Pratice Standard on Project Configuration Management - Final Exposure Draft. Project Management Institute, 2006.

PRASAD, B. (1996). Concurrent Engineering Fundamentals. New Jersey, USA, Ed. Prentice Hall, Cap.4, 1996. 
PROBASCO, L (2000). The Ten Essentials off RUP: The Essence off an Effective Development Process. Rational Software White paper, Rational Software Corporation, 2000.

PUGH, S. (1996). Creating Innovative Products Using Total Design. Massachussetts, USA, Ed. Addison-Wesley, 1996. RANDOM (1980).The Random House College Dictionary (1980),

RODRIGUEZ K., AL-ASHAAB A. (2005). Knowledge web-based system architecture for collaborative product development, Computers in Industry, No. 56, p. 125-140, 2005.

RORIZ, J.H.; JUCÁ Jr, A.;AMARAL, D.C. (2004) Critérios para análise de softwares de gerenciamento de projetos. In12o. SIICUSP, São Paulo, 25 a 26/11/2004.

ROZENFELD, H.; AMARAL, D. C.; TOLEDO, J. C.; CARVALHO, J. (2000). O processo de desenvolvimento de produtos e processos na fábrica do futuro. A Fábrica do Futuro. São Paulo: Banas, 2000.

ROZENFELD, H.; AMARAL, D. C.; TOLEDO, J. C.; FORCELLINI, F.; SILVA, S. L.; ALLIPRANDINI, D. H.; SCALKE, R. K. (2006). Gestão de desenvolvimento de produtos. São Paulo, Ed. Saraiva, 2006.

RUPP T. M., STEINER C. P. (2003). Supporting Distributed Engineering in the Aerospace Industry by Web-based Collaborative Applications. MTU Aero Engines GmbH, Dachawer Strasse, München, Germany, 2003. 
SAMARAS T. T., CZERWINSKI F. L. (1971). Fundamentals of Configuration Management. Ed. Wiley-Interscience, USA, 1971.

SILVA, A. A. (2001). Planejamento e Controle de Múltiplos Empreendimentos em Edificações. Dissertação (Mestrado) - Universidade Federal de Santa Catarina, 2001.

TERGAARD, K. J., SUMMERS, J. D. (2003). A taxonomic classification of collaborative design. International Conference on Engineering Design, No. 14, Stockholm Anais, Stockholm, 2003

THOBEN K., WEBER F. (1997). Information e Comunication Structures for Product Development in the Concurrent Enterprise: Requeriments and Concepts. University of Bremen and Bremen Institute of Industrial Technology and Applied Work Science at the University of Bremen (BIBA), Bremen, Germany, 1997.

TORTOISE (2006). Using Tortoise CVS for Revision Control. Disponível em http://helpdesk.biomath.ucla.edu/howtos/tortoise cvs. Acesso em 25/07/2006.

TORTOISECVS (2006). TortoiseCVS: Development. Disponível em http://www.tortoisecvs.org. Acesso em 03/09/2006.

VARGAS, R. (2006). Gerenciamento de Projetos Utilizando a Análise do Valor Agregado: Como Revolucionar o Controle e Avaliação de desempenho em Projetos. Ed. Brasport, Rio de Janeiro, 2006.

VAVASSORI F. B., SOUZA E. W., FIAMONCINI J.C., GAUTHIER F. A. O. (2000). Uma Ferramenta para Gerenciamento Distribuído de Projetos. 
Universidade Vale do Itajaí - UNIVALE, Universidade de Santa Catarina UFSC, 2000.

VERZUH, E. (2000). MBA Compacto, Gestão de Projetos. Editora Campus, 3a. Edição, 2000.

WIKIPÉDIA (2006). CVS. Disponível em http://pt.wikipedia.org/wiki/CVS. Acesso em 25/07/2006. 
Casos de Uso: Integração Pacote de Trabalho - Item da Configuração

Este grupo de casos uso envolve os fluxos de eventos relacionados à associação entre os pacotes de trabalho do projeto e os itens da configuração.

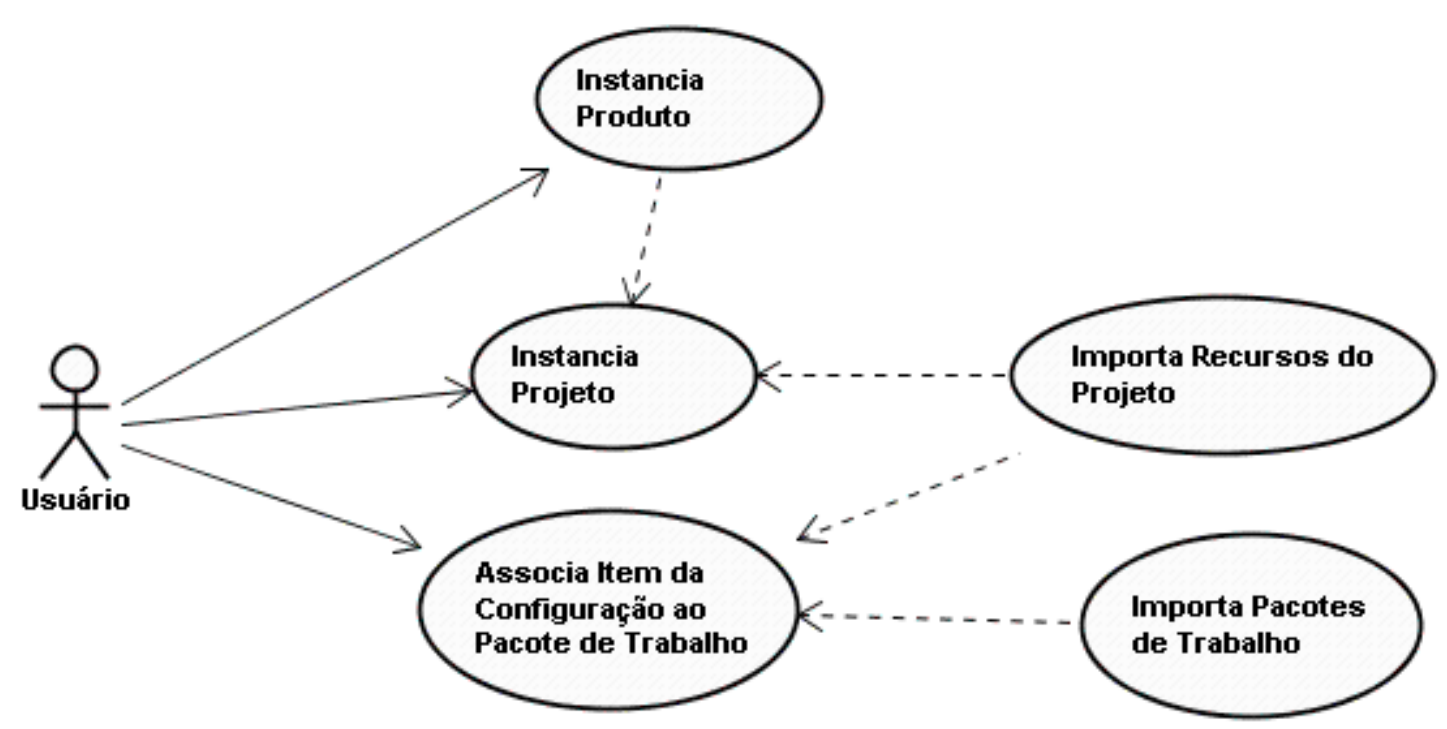

Casos de Uso: Integração Pacote de Trabalho-Item da Configuração

\section{Caso de Uso: Instância de Produto}

Descrição: Seleção de produto para alteração.

Atores: Usuário.

Atores Secundários: Nenhum

\section{Fluxo de Eventos:}

\section{Fluxo Básico:}

- Usuário fornece a chave de acesso.

- A interface verifica se a chave é válida e apresenta os produtos já cadastrados.

- Usuário seleciona o produto que fica instanciado como produto atual de alteração.

Fluxos Secundários: Nenhum.

Fluxos de Exceção: 
- Fornecimento de chave inválida: O gerente pode conectar novamente ou sair da interface.

Pré-Condições: Produto cadastrado.

Pós-Condições: Produto instanciado na interface para alteração.

\section{Caso de Uso: Instância de Projeto}

Descrição: Seleção de projeto para alteração.

Atores: Usuário.

Atores Secundários:

Fluxo de Eventos:

Fluxo Básico:

- A interface lista os projetos cadastrados para o produto selecionado para alteração.

- O Usuário seleciona um projeto que fica instanciado como projeto cujos pacotes de trabalho terão apontamento de alterações.

Fluxos Secundários: Nenhum.

Fluxos de Exceção: Nenhum.

Pré-Condições: Produto e projeto cadastrados.

Pós-Condições: Projeto instanciado na interface para alteração.

3. Caso de Uso: Ass. Item da Configuração - Pacote de Trabalho

Descrição: Relacionamento de itens da configuração a pacotes de trabalho do projeto.

Atores: Usuário.

Atores Secundários: Nenhum.

Fluxo de Eventos:

Fluxo Básico:

- A interface lista os pacotes de trabalho existentes relacionados ao usuário.

- O usuário seleciona um pacote para alteração.

- A interface verifica as dependências do pacote. Para maiores detalhes verificar fluxos secundários.

- A interface lista todos os itens existentes na configuração. 
- O usuário pode selecionar diretamente um item existente ou criar um novo item. Para maiores detalhes, verificar fluxos secundários.

- A interface exibe tela para gravação da porcentagem de trabalho no item com relação ao pacote inteiro.

- A associação é gravada e os dados disponibilizados.

\section{Fluxos Secundários:}

- Criação do item na configuração:

- É aberto um cadastro para entrada dos campos: nome, descrição, arquivo físico na configuração e status.

- A interface verifica se o item já está cadastrado.

- Após o término da entrada os dados são gravados e disponibilizados.

- Início da medição de alterações.:

Fluxos de Exceção:

- Item já existe: caso o item para criação já exista, o cadastro não é confirmado, mas permite associação ao item existente, caso ele passe pela análise das dependências.

- Item em alteração: caso o item esteja em alteração a associação não é confirmada.

- Dependências não resolvidas: se houverem pacotes antecessores ainda não finalizados, a operação não é confirmada.

Pré-Condições: Produto, projeto, pacote de trabalho, recurso e dependências cadastrados.

Pós-Condições: Item da configuração associado ao pacote de trabalho. 


\section{Casos de Uso: Controle de Situações}

Este grupo de casos uso envolve os fluxos de eventos relacionados às mudanças de situação dos itens.

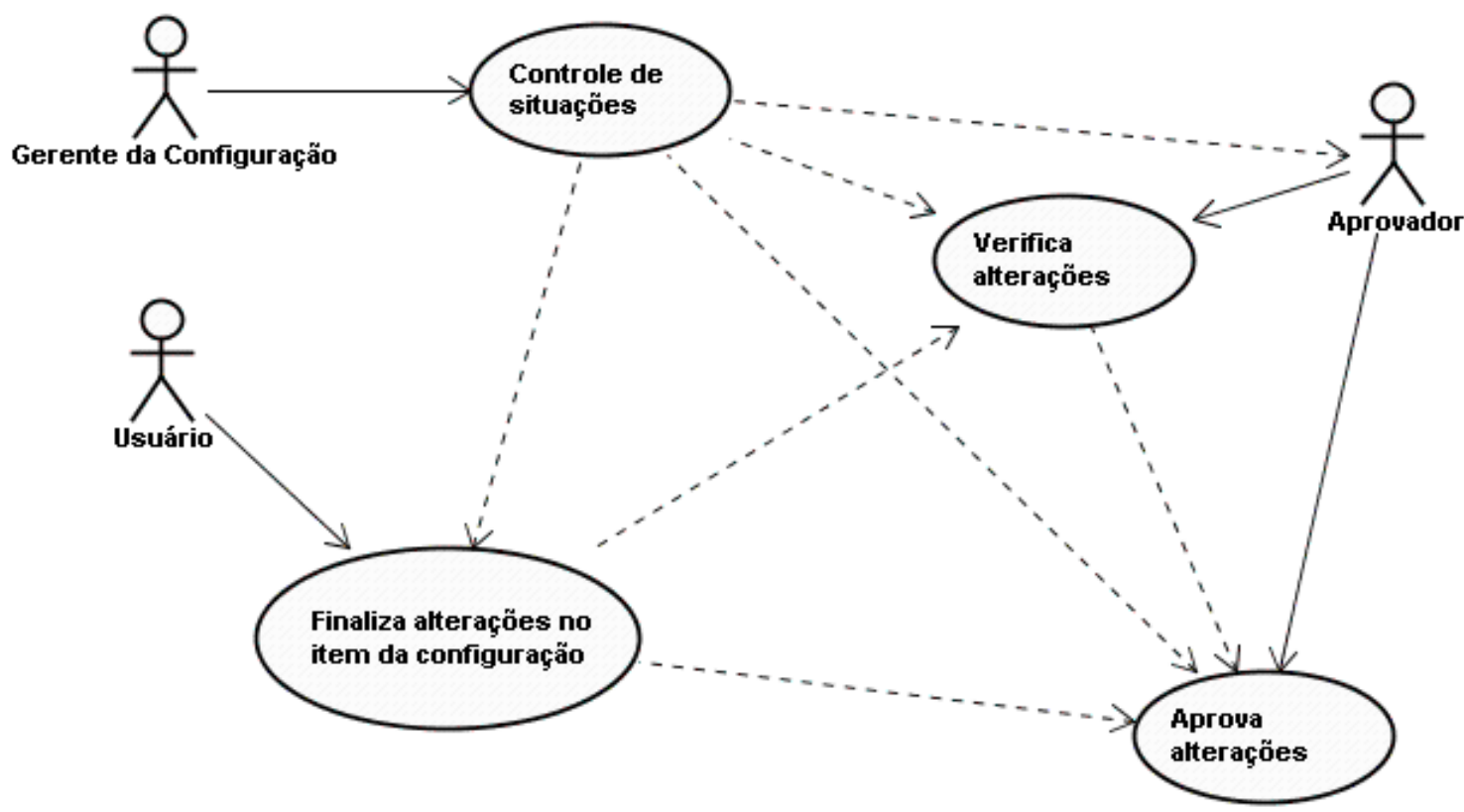

Casos de Uso: Controle de Situações

\section{Caso de Uso: Controle de Situações}

Descrição: Associação de trocas possíveis de situação para um usuário.

Atores: Gerente da Configuração.

Atores Secundários: Nenhum.

\section{Fluxo de Eventos:}

\section{Fluxo Básico:}

- A interface lista os usuários existentes.

- Após a seleção do usuário, são exibidas as trocas possíveis para o mesmo.

- A interface permite criar e excluir status, criar e excluir troca e criar uma lista de usuários de aprovação associada a um status. Para maiores detalhes, verificar fluxos secundários.

- Gerente associa troca de situação ao usuário. 
- Criação de situação:

- Interface exibe tela para incluir campos status, descrição, bloqueio e aprovação.

- Interface verifica se a situação já está cadastrada.

- Após entrada os dados são confirmados e disponibilizados.

- Exclusão de situação:

- A interface exibe uma tela com as situações existentes.

- O gerente seleciona e confirma uma situação para exclusão.

- A interface verifica se a situação selecionada já está sendo utilizada por alguma troca ou item da configuração.

- A exclusão da situação é confirmada e os dados atualizados.

- Criação de troca:

- Interface exibe tela para incluir campos status anterior e status posterior.

- Interface verifica se a troca já está cadastrada.

- Após entrada os dados são confirmados e disponibilizados.

- Exclusão de troca:

- A interface exibe uma tela com as trocas existentes.

- O gerente seleciona e confirma uma troca para exclusão.

- A interface verifica se a troca selecionada já está sendo utilizada por algum usuário.

- A exclusão da troca é confirmada e os dados atualizados.

- Inserção de usuário na lista de usuários para uma situação:

- Interface exibe tela para seleção de situações existentes.

- Gerente seleciona situação.

- Interface exibe tela para incluir campo aprovação (valor positivo para aprovação e negativo para consulta).

- Interface verifica se o usuário já existe na lista de aprovação daquela situação.

- Cadastro do usuário na lista é confirmado e os dados da lista liberados. 
- Exclusão de usuário da lista de usuários para uma situação:

- Interface exibe tela para seleção de situações existentes.

- Gerente seleciona situação.

- A interface exibe tela com os usuários associados e verifica se alguma aprovação já foi realizada com o usuário na lista.

- A exclusão do usuário da lista é confirmada e os dados atualizados.

Fluxos de Exceção:

- Situação já existe: cadastro da situação não é confirmado.

- Situação já utilizada: exclusão da situação não é confirmada.

- Troca já existe: cadastro da troca não é confirmado.

- Troca utilizada: exclusão da troca não é confirmada.

- Usuário já cadastrado na lista: cadastro do usuário na lista não é confirmado.

- Usuário já possui aprovação com a lista: exclusão do usuário da lista não é confirmada.

Pré-Condições: Usuário cadastrado.

Pós-Condições: Situação, mudanças de situação e lista de usuários de aprovação cadastrados.

\section{Caso de Uso: Verificação de Alterações}

Descrição: Usuário da lista de aprovação confirma verificação de uma alteração de item da configuração.

Atores: Aprovador.

Atores Secundários:

Fluxo de Eventos:

Fluxo Básico:

- A interface exibe a lista de itens da configuração para verificação pelo aprovador.

- Aprovador seleciona item da lista.

- Aprovador afetiva verificação do item. 
Fluxos Secundários: Nenhum.

Fluxos de Exceção:

- Item já verificado: neste caso a operação é abortada.

Pré-Condições: Projeto, produto e pacote selecionados e item da configuração em estado de verificação.

Pós-Condições: Item verificado.

\section{Caso de Uso: Aprovação de Alterações}

Descrição: Aprovação de alterações sobre o item para gravar o total de trabalho realizado e data de término.

Atores: Aprovador

Atores Secundários: Usuário

Fluxo de Eventos:

Fluxo Básico:

- É exibida uma tela para o aprovador com os itens da configuração.

- Interface verifica se o item está finalizado e não aprovado.

- É gravada a data de término para o item.

- Trabalho realizado e trabalho restante são atualizados no respectivo pacote.

Fluxos Secundários:

- Lista de usuários de aprovação:

- Caso haja uma lista associada à situação de aprovação são enviadas requisições de aprovação/verificação.

- Após as requisições processadas, a data de término e as quantidades são gravadas no item com posterior recálculo no pacote.

- Item reprovado:

- Na mesma tela com a lista de itens pendentes para a aprovação, o Aprovador pode ter a opção de reprovar o item. 
- Neste caso, é exibida uma tela para atualizar a quantidade de trabalho restante para o item para que ele retorne para o estado de alteração não finalizada.

Fluxos de Exceção:

- Item não finalizado: operação não é confirmada.

- Item já aprovado: operação não é confirmada.

Pré-Condições: Projeto, produto e pacote selecionados e item alterado com quantidade de trabalho restante igual a zero.

Pós-Condições: Item aprovado.

\section{Caso de Uso: Finalização de Alterações}

Descrição: Informação ao sistema do término de alterações em um item da configuração ou pacote de trabalho.

Atores: Usuário.

Atores Secundários: Nenhum.

Fluxo de Eventos:

Fluxo Básico:

- Usuário seleciona um item associado a um pacote de trabalho.

- Ao término do acesso ao item é exibida tela para informa quantidade de trabalho restante.

- Com a quantidade restante igual a zero, o item fica disponível para aprovação.

Fluxos Secundários:

- Finalização de pacote de trabalho:

- Usuário seleciona pacote de trabalho.

- Ao término do acesso ao pacote é exibida tela para informa quantidade de trabalho restante.

- Com a quantidade restante igual a zero o pacote é finalizado e a data de término é gravada.

Fluxos de Exceção: Nenhum.

Pré-Condições: Projeto, produto e pacote selecionados e item alterado.

Pós-Condições: Item finalizado. 


\section{Casos de Uso: Apontamento}

Este grupo de casos uso envolve os fluxos de eventos relacionados ao apontamento do trabalho realizado.

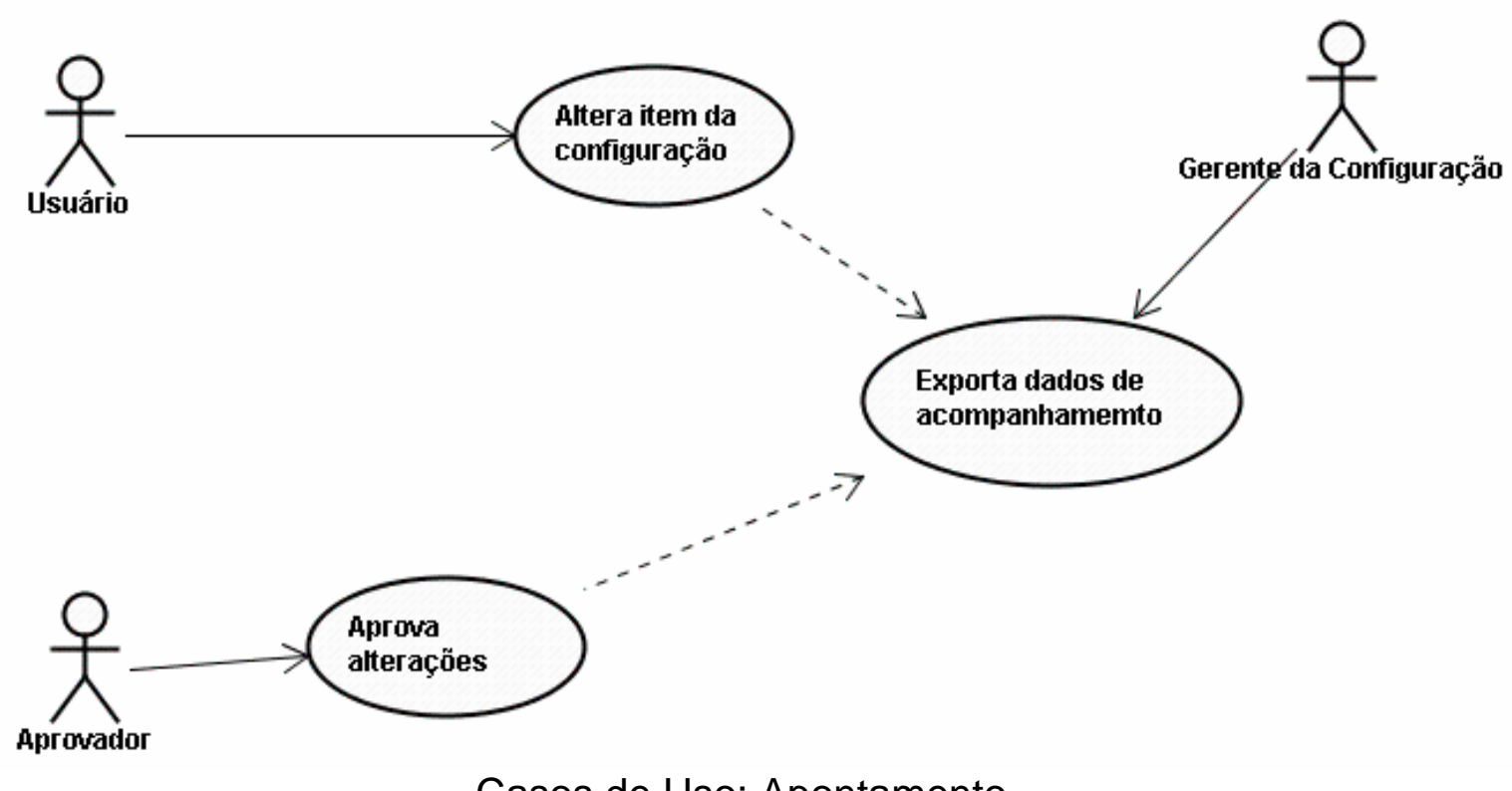

Casos de Uso: Apontamento

\section{Caso de Uso: Alteração de Item da Configuração}

Descrição: Processo de iniciar e finalizar a medição do trabalho realizado sobre o item da configuração.

Atores: Usuário.

Atores Secundários: Nenhum.

\section{Fluxo de Eventos:}

\section{Fluxo Básico:}

- Interface exibe lista de pacotes de trabalho e itens associados ao usuário.

- Usuário seleciona item e requisita sessão de alteração.

- A interface inicia medição de trabalho.

- Usuário inicia alterações no item da configuração.

- Usuário finaliza alterações e requisita término da sessão de alteração.

- Usuário finaliza sessão de alteração. 
- Interface grava quantidade realizada.

- Interface exibe tela para preenchimento da quantidade restante.

- Interface calcula a quantidade realizada e restante para o pacote de trabalho considerando a porcentagem do pacote.

Fluxos Secundários: Nenhum.

Fluxos de Exceção:

- Item bloqueado: operação abortada.

- Item aprovado: operação abortada.

- Item em uso: operação abortada.

Pré-Condições: Projeto, produto e pacote selecionados e item associado ao pacote e liberado para alteração ou sendo alterado pelo próprio usuário.

Pós-Condições: Item alterado e apontamento de trabalho gravado.

\section{Caso de Uso: Exportação de Dados}

Descrição: Gravação das datas de início e término e quantidade realizada e restante para cada pacote de trabalho (campos de apontamento).

Atores: Gerente da Configuração.

Atores Secundários: Nenhum.

\section{Fluxo de Eventos:}

\section{Fluxo Básico:}

- A interface exibe uma tela para seleção do arquivo destino de exportação.

- Usuário seleciona o arquivo e confirma gravação.

- A interface lê todos os pacotes de trabalho para o projeto e grava no arquivo o produto, projeto, pacote e os campos de apontamento no arquivo selecionado.

Fluxos Secundários:

- Nenhum.

Fluxos de Exceção:

- Arquivo já existe: corresponde a um outro apontamento. Operação abortada.

Pré-Condições: Produto e projeto selecionados. 
Pós-Condições: Arquivo exportado. 


\section{APÊNDICE B - MODELAGEM FUNCIONAL DA INTERFACE}

\section{Controle de Situações}

Esta seção trata das funcionalidades modeladas para o cadastro e configuração de situações, mudanças de situação e controle de aprovação dos itens da configuração. $\mathrm{Na}$ interface a situação de um item será chamada de status, que é um termo mais difundido na comunidade científica.

Diagrama de fluxo de dados para o Controle de Situações

\section{Funcionalidades:}

1. Listar status:

a. Criar tela para listar as informações de status (tabela status).

b. Incluir opção de seleção de um ou mais status.

\section{Cadastrar status:}

a. Na tela de listagem de status incluir opções de inclusão, alteração e exclusão.

b. As opções de exclusão e alteração requerem um status selecionado.

c. A alteração não deve ser permitida no campo status, pois este é a chave primária da tabela.

d. A exclusão só pode ser realizada se o status não tiver sido utilizado por nenhum item da configuração (tabela item_configuracao), nem na hierarquia de status (tabelas hierarquia_status e hierarquia_status_usuario) e na lista de assinaturas (tabela lista_assinaturas).

e. A inserção abre uma tela com os detalhes gravados para o status. Deve verificar se o status já não foi cadastrado.

\section{Cadastrar hierarquia de status:}

a. Na tela de listagem dos status existentes, incluir opção para acesso a hierarquia de status.

b. Criar tela listando os status destinos para o status origem selecionado (tabela hierarquia_satus). 
c. Permitir inclusão e exclusão de pares de status. Não permitir se o par estiver associado a algum usuário (tabela hierarquia_status_usuario).

\section{Associar usuários à hierarquia de status:}

a. Na tela de listagem de status destino, incluir opção para associação de usuários.

b. Criar tela listando os usuários cadastrados na tabela usuario.

c. Não permitir associação se ela já existir.

\section{Trocar status:}

a. Verificar se há trocas cadastradas para o usuário (tabela hierarquia_status_usuario); caso não haja troca de status cadastrada para o usuário, exibir mensagem de erro e interromper o processo.

b. Criar tela de seleção de status destino associados ao usuário a partir de um status de origem (status do item da configuração).

c. Verificar se status selecionado é de aprovação (campo flag_aprovacao na tabela status).

d. Caso não seja status de aprovação procede à mudança de status.

e. Em caso positivo, verificar se o item está com a quantidade realizada igual a zero (terminou as alterações); se não estiver, exibir aviso e interromper operação.

f. Verificar se o pacote de trabalho associado ao item está configurado para permitir o processo de aprovação.

g. Caso não esteja configurado, a operação corresponde a simples mudança de status. O usuário que possua a troca configurada pode executá-la em 2 ocasiões: no item corrente que esteja alterando, ou diretamente na tela de listagem dos itens da configuração - ver seção 4.3.3.2, item 5.c). No caso da listagem de itens, como uma aprovação irá finalizar as alterações no item, pode haver duas possibilidades: o usuário realiza a troca e finaliza a medição de trabalho no item, ou o pode reprovar o item (ver item 6) fazendo com que o usuário original volte a realizar alterações sobre o mesmo.

h. No caso do processo de aprovação estar configurado, o status destino ser de aprovação e também existir uma lista de assinaturas 
associada ao status (ver item 7), após a troca, o status de aprovação ficará pendente até o processamento de aprovação da lista. Para encaminhar o processamento da lista, são gerados pacotes de trabalho fantasmas (sem apontamento) para cada um dos usuários associados da lista de assinaturas. Estes pacotes, ao invés de quantidade de trabalho restante, requisitam a validação de campos de aprovação ou verificação, de acordo com o usuário da lista. Quando o respectivo usuário acessa a interface e lista seus pacotes de trabalho, são exibidos os pacotes fantasmas com situação de pendência de assinatura. Estes pacotes possuem uma associação "fantasma" com o item da configuração aprovado originalmente, mas neste caso, ao invés do apontamento de horas, a interface requisita a validação da assinatura como uma aprovação ou verificação (ver item 8) de acordo com a configuração da lista. Após a validação do usuário, a interface registra a conclusão desta pendência gravando o campo flag_operacao_concluida na tabela lista_assinatura_itens que relaciona a validação da lista ao item da configuração aprovado. Após a validação da lista, os pacotes fantasmas são excluídos e o item fica aprovado e sem pendências. Da mesma forma que no item anterior, qualquer usuário da lista de assinaturas habilitado para aprovação pode reprovar o item.

\section{Reprovar item:}

a. Na tela de lista de itens da configuração, verificar se o usuário possui uma troca de status de aprovação configurada (status destino configurado como aprovação e status origem igual ao do item selecionado).

b. Caso o trabalho no pacote esteja realizado (quantidade restante igual a zero), criar a opção Reprovar.

c. Selecionando esta opção deve ser aberta uma tela requisitando novamente a quantidade restante de trabalho para o item e desta forma ele volta a ser acessado pelo usuário que estava fazendo as alterações.

\section{Cadastrar lista de assinaturas para status:}


a. Na tela de listagem de status incluir a opção para lista de assinaturas.

b. Criar tela para associar usuários da configuração a um status cadastrado que necessariamente deve ter o campo flag_aprovação habilitado na tabela status. Esta associação deve ser gravada na tabela lista_assinaturas que, através da habilitação ou não do campo flag_aprovacao, indica se a validação da lista para o usuário deve ser uma aprovação ou verificação respectivamente. Todos os usuários com flag_aprovacao habilitado (aprovação) devem validar a lista. já no caso dos usuários da lista com o campo flag_aprovacao desabilitado, só é necessária a validação de apenas um deles. Após cada validação, utilizando esta regra, a interface deve processar se a pendência da lista de assinaturas está satisfeita e, neste caso, para todos os usuários da lista, na tabela lista_assinatura_itens deve ser habilitado o campo flag_operacao_concluida.

8. Verificar liberação da lista de assinaturas para o status:

a. Listar a tabela relacionada lista_assinatura_itens e verificar se há algum registro com o campo flag_operacao_concluida desabilitado. Em caso positivo, a lista está pendente de aprovação, caso contrário, o status de aprovação está liberado para o item relacionado.

9. Verificar bloqueio de status: para um status selecionado retornar valor do campo flag_bloqueio na tabela status.

10. Verificar aprovação de status: para um status selecionado retornar valor do campo flag_aprovacao na tabela status. 


\section{Apontamento}

São descritas nesta seção, as funcionalidades modeladas para o gerenciamento do apontamento do trabalho realizado durante a alteração na configuração do produto.

\section{Funcionalidades:}

1. Iniciar medição de apontamento:

2. Gravar dados de apontamento no pacote de trabalho:

3. Gravar dados do apontamento no item da configuração.

4. Cadastrar quantidade de trabalho restante para pacote de trabalho e item da configuração.

5. Calcular quantidade restante para pacote de trabalho.

6. Finalizar apontamento.

7. Verificar existência de apontamento para o produto:

8. Verificar existência de apontamento para o projeto:

9. Verificar se pacote já está finalizado: 